\author{
Universidade de São Paulo \\ Instituto de Física
}

\title{
Caracterização de pinturas da artista Anita Malfatti por meio de técnicas não destrutivas
}

\author{
Pedro Herzilio Ottoni Viviani de Campos
}

Orientadora: Profa. Dra. Márcia de Almeida Rizzutto

Tese de doutorado apresentada ao Instituto de Física para a obtenção do título de Doutor em Ciências 


\author{
Universidade de São Paulo \\ Instituto de Física
}

\title{
Caracterização de pinturas da artista Anita Malfatti por meio de técnicas não destrutivas
}

\author{
Pedro Herzilio Ottoni Viviani de Campos
}

Orientadora: Profa. Dra. Márcia de Almeida Rizzutto

Tese de doutorado apresentada ao Instituto de Física para a obtenção do título de Doutor em Ciências

Banca Examinadora:

Profa. Dra. Márcia de Almeida Rizzutto (Instituto de Física, Universidade de São Paulo) Prof. Dr. Carlos Roberto Appoloni (Universidade Estadual de Londrina)

Prof. Dr. Augusto Camara Neiva (Escola Politécnica, Universidade de São Paulo)

Prof. Dr. Nilberto Heder Medina (Instituto de Física, Universidade de São Paulo)

Prof. Dr. José Fernando Diniz Chubaci (Instituto de Física, Universidade de São Paulo) 


\section{FICHA CATALOGRÁFICA \\ Preparada pelo Serviço de Biblioteca e Informação do Instituto de Física da Universidade de São Paulo}

Campos, Pedro Herzilio Ottoni Viviani de

Caracterização de pinturas da artista Anita Malfatti por meio de técnicas não destrutivas. São Paulo, 2015.

Tese (Doutorado) - Universidade de São Paulo. Instituto de Física. Departamento de Física Nuclear.

Orientadora: Profa ${ }^{\mathrm{a}}$. Dra . Márcia de Almeida Rizzutto

Área de Concentração: Física Aplicada ao Estudo do Patrimônio Artístico, Histórico e Cultural

Unitermos: 1. Fluorescência; 2. EDXRF; 3. Imageamento; 4. Raios X; 5. Arqueometria; 6. Malfatti, Anita, 1889-1964. 
A todos aqueles que vieram antes de mim e a todos aqueles que cruzaram meu caminho, permitindo a realização deste trabalho 


\section{AGRADECIMENTOS}

Inicialmente gostaria de agradecer minha família, que me deu todo o suporte e estímulo possível e imaginável em todos esses anos, principalmente minha querida mãe Maluh Barciote, meu pai Herzilio Campos, minha irmãzinha Bruna Morena e meu irmãozinho André Perpignan.

Os anos que pude estar no Instituto de Física da Universidade de São Paulo, desde a minha iniciação científica, passando pelo mestrado e doutorado, foram muito gratificantes, divertidos, de grande aprendizagem e desenvolvimento pessoal, muito graças a minha orientadora Márcia Rizzutto, do qual serei eternamente grato.

Este trabalho não seria possível se não fosse a pronta disposição da Pinacoteca do Estado de São Paulo, pelas queridas Valéria Mendonça e Tatiana Russo, que desde o inicio se colocaram extremamente apoiadoras da iniciativa do estudo do seu acervo.

A presente pesquisa teve uma amplitude ainda maior devido à parceria com o Instituto de Estudos Brasileiros da Universidade de São Paulo, pela cumplicidade da Lúcia Thomé e da Bianca Dettino.

Agradeço também o Instituto de Física da Universidade de São Paulo por me acolher como aluno e pesquisador e fornecer todo o suporte e infraestrutura necessários.

Aos professores Manfredo Tabacniks e Nemitala Added, por suas excelentes críticas e contribuições científicas.

Aos professores Augusto Neiva e Carlos Appoloni pela parceria em diversos projetos.

Agradeço todos os alunos e técnicos do Grupo de Física Aplicada com Aceleradores e do Laboratório de Materiais e Feixes lônicos do Instituto de Física da Universidade de São Paulo; Tiago Fiorini, Marquinhos Rodrigues, Alisson Rodolfo, Marcos Moro, Fernando Aguirre, Cleber Rodrigues e Renan Assis.

Ao Centre de Recherche et de Restauration des Musées de France que me recebeu muito bem e me proporcionou uma excelente vivência e aprendizado durante meu doutorado sanduíche, especialmente ao Thomas 
Calligaro. Merci!

Agradeço a parceria da querida Elizabeth Kajiya, em nossos diversos trabalhos e descobertas juntos e por seu olhar de restauradora sobre minha pesquisa.

Agradeço a Jéssica Curado, Eva Kaiser Mori e Anna de Matos pelas agradáveis tardes e por não medir esforços para contribuir para meus estudos.

A querida Bárbara Campos, pela parceria e pelo gigantesco apoio, inclusive nas intermináveis revisões da tese.

Todos não chegamos mais longe se não tivermos por perto bons amigos e eu tive a sorte de ter muitos durante a vida. Muito obrigado a todos.

Gostaria de agradecer ao Movimento Escoteiro por grande parte da minha formação por contribuir para os valores que possuo.

Agradeço aos órgãos de fomento FAPESP, CNPq e CAPES pelos recursos para equipamentos, projetos e bolsas de pesquisa.

Muito obrigado a todos! 


\section{RESUMO}

Anita Catarina Malfatti foi uma das mais importantes artistas plásticas brasileiras, suas primeiras obras são consideradas por muitos como um marco que dá início ao movimento modernista no Brasil. Muitos trabalhos já foram realizados a respeito da biografia e estudos estilísticos desta grande artista, mas pouca ou nenhuma informação se tem sobre os materiais por ela utilizados, bem como do processo criativo desta. No caso particular de pinturas a óleo, os estudos que empregam técnicas não destrutivas de análise por imageamento, medições de cores e caracterização elementar e composicional (chamadas aqui de "artmetria") podem revelar características das obras e criativas do artista. Estas técnicas de análise ainda são pouco utilizadas nos estudos dos artistas brasileiros e muito trabalho ainda tem-se para fazer. Neste trabalho, foram estudadas algumas obras mais importantes da artista durante 0 período de 1915-1916 quando esta estudou nos Estados Unidos e uma de 1923 para comparação. As obras analisadas foram: "O Japonês" (1915/1916), "A Estudante Russa" (1915), "Retrato de Mário de Andrade" (1923), e "O Homem Amarelo" (1915/1916), pertencentes ao acervo do Instituto de Estudos Brasileiros da Universidade de São Paulo (IEB-USP) e a obra "Tropical" (1917) pertencente ao acervo da Pinacoteca do Estado de São Paulo. Particularmente as duas últimas obras citadas possuem figuras subjacentes, e nenhum estudo sobre estas características havia sido anteriormente realizado.

Os estudos aqui apresentados utilizaram as técnicas não destrutivas: Imageamento (radiografia, fotografia com luz rasante, fluorescência ultravioleta e reflectografia no infravermelho) que forneceram importantes informações a respeito do estado de conservação dos quadros analisados e o processo criativo da artista que inclui o aprimoramento de visualização de possíveis figuras subjacentes; Colorimetria, para a determinação e registro técnico das cores que compõem a obra; Fluorescência de Raios $X$ por Dispersão de Energia (EDXRF), que permitiu obter informações a respeito dos materiais e pigmentos utilizados, enriquecendo e aumentando as informações existentes a respeito das obras da artista Anita Malfatti. 
Deste modo, neste trabalho foi obtido um conjunto significativo de informações, até então desconhecidos, sobre as características e materiais utilizados por Anita Malfatti nestas obras que envolvem o período de 1915 a 1917 e de uma obra de 1923 para comparação. Estas informações permitem a construção de um banco de dados com informações relevantes para historiadores da arte, curadores, conservadores e restauradores para assim melhor conhecer a artista e suas obras. 


\begin{abstract}
Anita Catarina Malfatti was one of the most important Brazilian artists, her early works are considered by several art historians as a milestone that begins the modernist movement in Brazil. Many studies have been conducted about the biography and artistic style of this great artist, but little or no information exists about the materials, the production techniques used and the creative process performed by her. In the particular case of easels oil paintings, studies employing non-destructive techniques of analysis such as imaging, colorimetry and elemental and compositional characterization (named here as "artmetry") can reveal characteristics of the works and the artist's creative process. These techniques of analysis are still rarely applied in the studies of Brazilian artists and a lot of work still has to be done. In this study, we analyzed some of the most important artworks by the artist performed during 1915-1916 period when she was studding in the United States and one of 1923 for comparison. The artworks analyzed were: "O Japonês" - "The Japanese" (1915/1916), "A Estudante Russa" - "The Russian Student" (1915), "Retrato de Mário de Andrade" - "Portrait of Mário de Andrade" (1923) and "O Homem Amarelo" - "The Yellow Man" (1915/1916), all of them belonging to the collection of the Instituto de Estudos Brasileiros of the São Paulo University (IEB-USP) and the painting "Tropical" (1917) belonging to the Pinacoteca do Estado de São Paulo collection. Particularly the last two artworks have underpainting figures, and no study about these characteristics have been previously performed.
\end{abstract}

The studies presented here used non-destructive techniques: Imaging such as radiography, photography with tangential light, ultraviolet fluorescence and infrared reflectography that provide important information about the conservation status as well as the artist's creative process, including the improvement of visualization of the underpainting figures; Colorimetric measurements were also performed for the determination and technical registration of the colors used up in all these analyzed artworks; The elemental analysis by Energy Dispersive X-ray Fluorescence (EDXRF), which provided information about the chemical elements presents and pigments, enriching and 
adding new information about the works performed by the artist Anita Malfatti.

Thus, in this study it was obtained a significant set of unknown information about the characteristics and materials used by the artist in these works involving the period from 1915 to 1917 and was also studied an artwork of 1923 for comparison. These information allow the creation of a database with the relevant information data for art historians, curators, conservationists and restorers in order to better understand the artist and her artworks. 


\section{SUMÁRIO}

Resumo IV

Abstract $\quad$ VI

Índice de Figuras $\quad x$

Índice de Tabelas XVII

Capítulo 1 - Introdução 1

1.1. Estudos de pigmentos em telas de artistas brasileiros 3

1.2. A Proposta 4

1.3. A Artista 6

1.3.1. Estudos das Obras da Anita Malfatti 7

1.4. Contribuição deste trabalho na área interdisciplinar 8

Capítulo 2 - Fundamentação Teórica 9

2.1. Raios X 9

2.2. Modelo Atômico 10

2.3. Interação de raios $X$ com a matéria 13

2.3.1. Efeito Foto Elétrico 14

2.3.2. Efeito Compton 16

2.3.3. Espalhamento Coerente 17

2.4. Técnicas de Análise 18

2.4.1. Fluorescência de Raio X 18

2.4.1.1. Fluorescência de Raio X por dispersão de energia 20

2.4.1.2. Formulação do método de Fluorescência de Raio 21

2.4.1.3. Equipamento 28

2.4.1.3.1. Detectores de Si-PIN e SDD 28

2.4.1.3.1. Tudo de Raio X 31

2.5. Imageamento 32

2.5.1. Teoria de Cor 32

2.5.2. Modelo de CorCIELAB $\quad 40$

2.5.3. Interação da Luz com a Matéria 42

2.6. Análise Estatística Multivariada $\quad 45$

2.6.1. Análise de Componentes Principais $\quad 46$

Capítulo 3 - Materiais e Métodos $\quad 51$

3.1. Materiais 51

3.1.1. Pigmentos $\quad 51$

3.1.2. Tela 51

3.1.3. Tinta $\quad 52$

3.1.4. As Obras $\quad 52$

3.1.3.1 "Tropical" 53

3.1.3.2 "O Homem Amarelo" $\quad 56$

3.1.3.3 "A Estudante Russa" $\quad 58$

3.1.3.4 "O Japonês" 60

3.1.3.4 "Retrato de Mário de Andrade" 62

3.2. Imageamento 63

3.2.1. Luz Visível $\quad 63$

3.2.2. Luz Rasante $\quad 65$

3.2.3. Luz Ultravioleta 66

3.2.4. Reflectografia de Infravermelho 67 
3.2.4. Radiografia Digitalizada $\quad 69$

3.3. Colorimetria $\quad 70$

3.4. Fluorescência de Raio X Por Dispersão de Energia (EDXRF) 71

3.5. Testes Estatísticos $\quad 72$

3.5.1. Analise de Componentes Principais (PCA) 73

Capítulo 4 - Resultados e Discussões $\quad 75$

4.1. "O Japonês"

4.2. "A Estudante Russa" 101

4.3. "Retrato de Mário de Andrade" 116

4.4. "Tropical" 128

4.5. "O Homem Amarelo" 149

Capítulo 5 - Conclusões 174

Referências $\quad 177$

$\begin{array}{ll}\text { Anexo A } & 185\end{array}$ 


\section{Índice de Figuras}

Figura 2.1 - Diagrama energético e as transições de raio $\mathrm{X}$ mais importantes com os respectivos números máximos de elétrons em cada camada, e os números quânticos $n, l$ e $j$ para cada camada e subcamada (CESAREO, 2000)

Figura 2.2 - A ionização por efeito fotoelétrico pode ser seguida tanto por uma emissão de um raio $X$ característico, quanto pela emissão de um elétron Auger (JENKINS; GOULD; GEDCKE, 1981)

Figura 2.3 - Efeito Compton observado de espalhamento de um feixe de raios $X$, proveniente de um tubo de raio $X$ de Mo, sobre um alvo de carbono, e o espectro observado para diferentes ângulos de detecção do raio $X$ espalhado (NAVE, 2009)

Figura 2.4 - No espalhamento elástico, quando a onda de raio $X$ colide com o átomo, os elétrons desse átomo espalham o raio $X$. A onda espalhada elasticamente é imediatamente reemitida em todas as direções e pode ser imaginada como uma frente de onda esférica (JANSSENS, 2004)

Figura 2.5 - Os diferentes modos de interação entre fótons e a matéria para um alvo de chumbo, em função da energia do fóton. Cada processo possui um domínio energético particular. Na faixa das baixas energias (0-100 keV), o efeito foto elétrico é dominante. No regime intermediário (100-1000 keV), o espalhamento Compton é predominante. Na região das altas energias (acima de $1 \mathrm{MeV}$ ), a produção de pares tem a principal contribuição (CALLIGARO; DRAN; SALOMON, 2004)

Figura 2.6 - Probabilidade relativa de emissão de fluorescência de raio X (linha tracejada) e Auger (linha contínua) (HUBIN; TERRYN, 2004)

Figura 2.7 - Representação esquemática da geometria de excitação para feixe monoenergético em fluorescência de raios X (NASCIMENTO FILHO, 1999)

Figura 2.8 - Dependência do coeficiente de absorção de massa em função da energia, para os elementos cálcio, cobre e urânio (NASCIMENTO FILHO, 1999)

Figura 2.9 - Valores da razão de salto (jump ratio) em função do número atômico (NASCIMENTO FILHO, 1999)

Figura 2.10 - Representação esquemática das dependências entre as variáveis na equação fundamental de fluorescência de raios $X$ para feixe monoenergético (NASCIMENTO FILHO, 1999)

Figura 2.11 - Esboço ilustrando o funcionamento de um fotodiodo convencional (modificado de AMPTEK, 2013)

Figura 2.12 - Esboço ilustrando o funcionamento do detector de SDD (modificado de AMPTEK, 2013)

Figura 2.13 - Curvas de eficiência intrínseca de um detector de Si-PIN (AMPTEK, 2013)

Figura 2.14 - Curvas de eficiência intrínseca de um detector de SDD (AMPTEK, 2013)

Figura 2.15 - Distribuição da resolução dos detectores SDD e Si-PIN (site do fabricante AMPTEK, 2013)

Figura 2.16 - Espectro de raio $X$ do tubo Mini-X com ânodo de prata da Amptek com $40 \mathrm{kV}$ de voltagem (AMPTEK, 2014)

Figura 2.17 - Esquema ilustrativo da luz incidindo sobre outro meio e refratada Figura 2.18 - Acima temos o rascunho do "experimentum crucis" de Newton (LONGAIR, 1995); abaixo temos uma representação esquemática do experimento

Figura 2.19- Caixa de luz de Maxwell, Newton (LONGAIR, 1995) 
Figura 2.20 - Capacidade receptiva das células da retina humana (GRANDIS, 1986)

Figura 2.21 - Espectro eletromagnético entre 370 e 750 nm - (TRUSSEL, ELI e VRHEL, 2005)

Figura 2.22 - Representação esquemática da mistura de cores e da mistura de pigmentos

Figura 2.23 - llustração de um feixe de luz penetrando nas camadas de pigmentos e aa possiblidades de absorção, espalhamento e reflexão da luz neste material (WRIGHT, 1958)

Figura 2.24 - Curva espectral para cada temperatura de um corpo negro com base na lei de Planck (GRANDIS, 1986)

Figura 2.25 - Representação do espaço de cor para um tipo de dispositivo gerador de luz (WHITEHEAD, 2015)

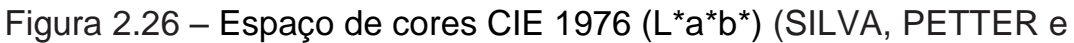
SCHNEIDER, 2007)

Figura 2.27 - A radiação da luz interagindo com a camada de pintura e o fundo (WEINER, 1998)

Figura 3.1 - A obra "Tropical" de Anita Malfatti (1917, óleo sobre tela, 77x102 $\mathrm{cm})$ do acervo da Pinacoteca do Estado de São Paulo. Foto: P.H.O.V. Campos e E. Kajiya

Figura 3.2 - A obra "O Homem Amarelo" de Anita Malfatti (1915/1916, óleo sobre tela, $61 \times 51 \mathrm{~cm}$ ) do acervo do IEB-USP. Foto: P.H.O.V. Campos e E. Kajiya

Figura 3.3 - A obra "A Estudante Russa" de Anita Malfatti (1915, óleo sobre tela, $76 \times 61 \mathrm{~cm}$ ) do acervo do IEB-USP. Foto: P.H.O.V. Campos e E. Kajiya

Figura 3.4 - A obra "O Japonês" de Anita Malfatti (1915/1916, óleo sobre tela, $76 \times 61 \mathrm{~cm})$ do acervo do IEB-USP. Foto: P.H.O.V. Campos e E. Kajiya

Figura 3.5 - A obra "O Retrato de Mário de Andrade" de Anita Malfatti (1923, óleo sobre tela, $44 \times 638 \mathrm{~cm}$ ) do acervo do IEB-USP (BATISTA e LIMA,1998)

Figura 3.6 - Esquema ilustrativo do arranjo exeperimental utilizado nas fotografias com luz visível

Figura 3.7 - Esquema ilustrativo do arranjo experimental de fotografia com luz rasante

Figura 3.8 - Esquema ilustrativo do arranjo experimetal utilizadno no processo de fotografia de fluorescência com luz ultratravioleta

Figura 3.9 - Esquema ilustrativo do processo e arranjo de reflectogradia por infravermelho

Figura 3.10 - Câmera Osiris de reflectografia por infravermelho produzida pela Opus Instruments (OPUS, 2014)

Figura 3.11 - Esquema ilustrativo do processo e arranjo de radiografia digital

Figura 3.12 - Espectrofotômetro portátil com geometria esférica e alinhamento horizontal modelo CM-2500d (KONICA-MINOLTA, 2014)

Figura 3.13 - Espectro típico obtido com espectrofotômetro CM-2500d, KonicaMinolta. Ponto P25, marrom avermelhado, medido na obra "A Estudante Russa"

Figura 3.14 - Espectro típico de um tubo de raios X de Prata (Ag) (AMPTEK, 2014)

Figura 3.15 - Foto dos equipamentos utilizados. Amplificador e fonte PX5; Detector SDD XR-100CR; Tubo de raio X Mini-X (AMPTEK, 2014)

Figura 3.16 - Exemplo de Círculo de correlação utilizado na análise de componentes principais. Este gráfico de exemplo corresponde à análise feita 
por XRF nos fragmentos apresentados neste estudo (CURADO, 2012)

Figura 4.1 - Arranjo fotográfico para as análises de imageamento, sendo realizado na obra "Tropical" da artista Anita Malfatti, pertencente ao acervo da

Pinacoteca do Estado de São Paulo. Foto: E. Kajiya

Figura 4.2 - Fotografia do equipamento de EDXRF do Instituto de Física realizando medidas in situ nas diferentes obras: A) "Tropical" (1917) do acervo da Pinacoteca do Estado de São Paulo. B) "O Homem Amarelo" (1915/1916) do acervo do IEB-USP, C) O Retrato de Mario de Andrade (1923) do acervo do IEB-USP. D) "A Estudante Russa" (1916) do acervo do IEB-USP E) "O Japonês" (1915/1916) do acervo do IEB-USP

Figura 4.3 - Espectro EDXRF típico para um pigmento (vermelho alaranjado) da obra "O Retrato de Mario de Andrade" de Anita Malfatti (1923) do acervo do IEB-USP

Figura 4.4 - Imagem de reflectografia no infravermelho da obra "O Japonês" (1915/1916) do acervo do IEB-USP

Figura 4.5 - Imagem de fluorescência com luz ultravioleta da obra "O Japonês" (1915/1916) do acervo do IEB-USP

Figura 4.6 - Imagem com luz rasante de um detalhe da obra "O Japonês" (1915/1916) do acervo do IEB-USP

Figura 4.7 - Imagem da assinatura da obra "O Japonês" (1915/1916) do acervo do IEB-USP

Figura 4.8 - Fotografia com os pontos de EDXRF medidos na obra "O Japonês" de Anita Malfatti (1915/1916, óleo sobre tela, 61x51cm) do acervo do IEB-USP

Figura 4.9 - Gráfico de barras das áreas do pico do $\mathrm{Pb}$ identificado nos espectros de EDXRF para os diferentes pontos medidos na obra "O Japonês" de Anita Malfatti (1915/1916), acervo IEB-USP

Figura 4.10 - Gráfico de barras das áreas do pico do Ca identificado nos espectros de EDXRF para os diferentes pontos medidos na obra "O Japonês" de Anita Malfatti (1915/1916) do acervo do IEB-USP

Figura 4.11 - Gráfico de barras das áreas do pico de Zn identificado nos espectros de EDXRF para os diferentes pontos medidos na obra "O Japonês" de Anita Malfatti (1915/1916) do acervo do IEB-USP

Figura 4.12 - Gráfico de barras das áreas do pico de Ba identificado nos espectros de EDXRF para os diferentes pontos medidos na obra "O Japonês" de Anita Malfatti (1915/1916) do acervo do IEB-USP

Figura 4.13 - Gráfico de barras das áreas do pico de Fe identificado nos espectros de EDXRF para os diferentes pontos medidos na obra "O Japonês" de Anita Malfatti (1915/1916) do acervo do IEB-USP

Figura 4.14 - Gráfico de barras das áreas do pico do Cr identificado nos espectros de EDXRF para os diferentes pontos medidos na obra "O Japonês" de Anita Malfatti (1915/1916) do acervo do IEB-USP

Figura 4.15 - Gráfico de barras das áreas do pico de Sr identificado nos espectros de EDXRF para os diferentes pontos medidos na obra "O Japonês" de Anita Malfatti ((1915/1916) do acervo do IEB-USP

Figura 4.16 - Gráfico de barras das áreas do pico de Cd identificado nos espectros de EDXRF para os diferentes pontos medidos na obra "O Japonês" de Anita Malfatti (1915/1916) do acervo do IEB-USP

Figura 4.17 - Gráfico de barras das áreas do pico de $\mathrm{Hg}$ identificado nos espectros de EDXRF para os diferentes pontos medidos na obra "O Japonês" de Anita Malfatti (1915/1916) do acervo do IEB-USP

Figura 4.18 - Gráfico de barras das áreas do pico do $\mathrm{K}$ identificado nos espectros de EDXRF para evidenciar a correlação entre este elementos os diferentes pontos medidos na obra "O Japonês" de Anita Malfatti (1915/1916) do acervo do IEB-USP

Figura 4.19 - Gráfico da correlação por PCA entre os elementos presentes nos espectros de EDXRF pontos medidos na obra "O Japonês" de Anita Malfatti do acervo do IEB-USP 
Figura 4.20 - Imagem de reflectografia por infravermelho da obra "A Estudante Russa" (1915) do acervo do IEB-USP

Figura 4.21 - Imagem de fluorescência de ultravioleta da obra "A Estudante Russa" (1915) do acervo do IEB-USP

Figura 4.22 - Imagem com iluminação rasante de uma região da obra "A Estudante Russa" (1915) do acervo do IEB-USP

Figura 4.23 - Imagem da assinatura da obra "A Estudante Russa" (1915) do acervo do IEB-USP

Figura 4.24 - Fotografia com os pontos de EDXRF medidos na obra "A estudante Russa" de Anita Malfatti (1915, óleo sobre tela, 76x61cm) do acervo do IEB-USP

Figura 4.25 - Gráfico de barras das áreas do pico do $\mathrm{Pb}$ identificado nos espectros de EDXRF para os diferentes pontos medidos na obra "A Estudante Russa" de Anita Malfatti (1915) do acervo do IEB-USP

Figura 4.26 - Gráfico de barras das áreas do pico do Ca identificado nos espectros de EDXRF para os diferentes pontos medidos na obra "A Estudante Russa" de Anita Malfatti (1915) do acervo do IEB-USP

Figura 4.27 - Gráfico de barras das áreas do pico do Fe identificado nos espectros de EDXRF para os diferentes pontos medidos na obra "A Estudante Russa" de Anita Malfatti (1915) do acervo do IEB-USP

Figura 4.28 - Gráfico de barras das áreas do pico do $\mathrm{Hg}$ identificado nos espectros de EDXRF para os diferentes pontos medidos na obra "A Estudante Russa" de Anita Malfatti (1915) do acervo do IEB-USP

Figura 4.29 - Gráfico de barras das áreas do pico do Cd identificado nos espectros de EDXRF para os diferentes pontos medidos na obra "A Estudante Russa" de Anita Malfatti (1915) do acervo do IEB-USP

Figura 4.30 - Gráfico de barras das áreas do pico do $\mathrm{Pb}$ identificado nos espectros de EDXRF para os diferentes pontos medidos na obra "A Estudante Russa" de Anita Malfatti (1915) do acervo do IEB-USP

Figura 4.31 - Gráfico de barras das áreas do pico do Zn identificado nos espectros de EDXRF para os diferentes pontos medidos na obra "A Estudante Russa" de Anita Malfatti (1915) do acervo do IEB-USP

Figura 4.32 - Gráfico de barras das áreas dos picos do Ba identificados nos espectros de EDXRF para os diferentes pontos medidos na obra "A Estudante Russa" de Anita Malfatti (1915) do acervo do IEB-USP

Figura 4.33 - Gráfico de barras das áreas dos picos do Sr identificados nos espectros de EDXRF para os diferentes pontos medidos na obra "A Estudante Russa" de Anita Malfatti (1915) do acervo do IEB-USP

Figura 4.34 - Gráfico da correlação por PCA entre os elementos presentes nos espectros de EDXRF pontos medidos na obra "A Estudante Russa" de Anita Malfatti do acervo do IEB-USP

Figura 4.35 - Fotografia com os pontos de EDXRF medidos na obra "Retrato de Mário de Andrade" de Anita Malfatti (1923) do acervo do IEB-USP

Figura 4.36 - Gráfico de barras das áreas dos picos do $\mathrm{Ca}$ identificados nos espectros de EDXRF para os diferentes pontos medidos na obra "Retrato de Mário de Andrade" de Anita Malfatti (1923) do acervo do IEB-USP

Figura 4.37 - Gráfico de barras das áreas dos picos do Ba identificados nos espectros de EDXRF para os diferentes pontos medidos na obra "Retrato de Mário de Andrade" de Anita Malfatti (1923) do acervo do IEB-USP Figura 4.38- Gráfico de barras das áreas dos picos do Sr identificados nos espectros de EDXRF para os diferentes pontos medidos na obra "Retrato de Mário de Andrade" de Anita Malfatti (1923) do acervo do IEB-USP Figura 4.39 - Gráfico de barras das áreas dos picos do $\mathrm{Pb}$ identificados nos espectros de EDXRF para os diferentes pontos medidos na obra "Retrato de Mário de Andrade" de Anita Malfatti (1923) do acervo do IEB-USP

Figura 4.40 - Gráfico de barras das áreas dos picos do Fe identificados nos espectros de EDXRF para os diferentes pontos medidos na obra "Retrato de 
Figura 4.41 - Gráfico de barras das áreas dos picos do Co identificados nos espectros de EDXRF para os diferentes pontos medidos na obra "Retrato de Mário de Andrade" de Anita Malfatti (1923) do acervo do IEB-USP

Figura 4.42 - Gráfico de barras das áreas dos picos do $\mathrm{Cr}$ identificados nos espectros de EDXRF para os diferentes pontos medidos na obra "Retrato de Mário de Andrade" de Anita Malfatti (1923) do acervo do IEB-USP

Figura 4.43 - Gráfico de barras das áreas dos picos do Cd identificados nos espectros de EDXRF para os diferentes pontos medidos na obra "Retrato de Mário de Andrade" de Anita Malfatti (1923) do acervo do IEB-USP

Figura 4.44 - Gráfico de barras das áreas dos picos do Zn identificados nos espectros de EDXRF para os diferentes pontos medidos na obra "Retrato de Mário de Andrade" de Anita Malfatti (1923) do acervo do IEB-USP

Figura 4.45 - Gráfico de barras das áreas dos picos do Hg identificados nos espectros de EDXRF para os diferentes pontos medidos na obra "Retrato de Mário de Andrade" de Anita Malfatti (1923) do acervo do IEB-USP Figura 4.46 - Gráfico da correlação por PCA entre os elementos presentes nos espectros de EDXRF pontos medidos na obra "Retrato de Mário de Andrade" de Anita Malfatti do acervo do IEB-USP

Figura 4.47 - Imagem de fotografia visível da obra "Tropical" de Anita Malfatti (1917, óleo sobre tela, 77x102cm) do acervo da Pinacoteca do Estado de São Paulo. Foto P.H.O. V. Campos e E. Kajiya.

Figura 4.48 - Fotografia de Reflectografia de infravermelho da obra "Tropical" de Anita Malfatti do acervo da Pinacoteca do Estado de São Paulo. Foto:

P.H.O.V. Campos e E. Kajiya

Figura 4.49 - Destaques de figuras subjacentes observadas na fotografia de reflectografia de infravermelho da obra "Tropical" de Anita Malfatti do acervo da Pinacoteca do Estado de São Paulo. Foto: P.H.O.V. Campos e E. Kajiya. Figura 4.50 - Fotografia com luz rasante da obra "Tropical" de Anita Malfatti (1917, óleo sobre tela, 77x102cm) do acervo da Pinacoteca do Estado de São Paulo. Foto: P.H.O.V. Campos e E. Kajiya.

Figura 4.51 - Fotografia por luz visível da fluorescência ultravioleta da obra "Tropical" de Anita Malfatti (1917, óleo sobre tela, 77×102cm) do acervo da Pinacoteca do Estado de São Paulo. As regiões circuladas representam áreas com intervenções de restauro recentes. Foto: P.H.O.V. Campos e E. Kajiya Figura 4.52 - Recortes das fotografias realizadas com as técnicas da região do rosto de uma figura subjacente da obra "Tropical" de Anita Malfatti (1917): A) luz visível; B) reflectografia de infravermelho; C) fotografia por fluorescência UV; D) fotografia com luz rasante. Fotos: P.H.O.V. Campos e E. Kajiya Figura 4.53 - Recortes das fotografias da região do rosto da figura principal da obra "Tropical" de Anita Malfatti (1917) realizadas com as técnicas de imageamento: A) fluorescência $U$; B) reflectografia de infravermelho; C) fotografia com luz rasante; D) fotografia com luz visível. P.H.O.V. Campos e E. Kajiya

Figura 4.54 - Imagem da assinatura da artista Anita Malfatti da obra "Tropical" (1917) do acervo do IEB-USP

Figura 4.55 - Fotografia com os pontos de EDXRF medidos na obra "Tropical" de Anita Malfatti (1917, óleo sobre tela, 77×102cm) do acervo da Pinacoteca do Estado de São Paulo

Figura 4.56 - Gráfico de barras das áreas do pico do Fe identificado nos espectros de EDXRF para os diferentes pontos medidos na obra "Tropical" de Anita Malfatti (1917) do acervo da Pinacoteca do Estado de São Paulo Figura 4.57 - Gráfico de barras das áreas do pico do Ca identificado nos espectros de EDXRF para os diferentes pontos medidos na obra "Tropical" de Anita Malfatti (1917) do acervo da Pinacoteca do Estado de São Paulo Figura 4.58 - Gráfico de barras das áreas do pico do Ba identificado nos espectros de EDXRF para os diferentes pontos medidos na obra "Tropical" de Anita Malfatti (1917) do acervo da Pinacoteca do Estado de São Paulo 
Figura 4.59 - Gráfico de barras das áreas do pico do Sr identificado nos espectros de EDXRF para os diferentes pontos medidos na obra "Tropical" de Anita Malfatti (1917) do acervo da Pinacoteca do Estado de São Paulo Figura 4.60 - Gráfico de barras das áreas do pico do $\mathrm{Pb}$ identificado nos espectros de EDXRF para os diferentes pontos medidos na obra "Tropical" de Anita Malfatti (1917) do acervo da Pinacoteca do Estado de São Paulo Figura 4.61 - Gráfico de barras das áreas do pico do Zn identificado nos espectros de EDXRF para os diferentes pontos medidos na obra "Tropical" de Anita Malfatti (1917) do acervo da Pinacoteca do Estado de São Paulo Figura 4.62 - Gráfico de barras das áreas do pico do Cr identificado nos espectros de EDXRF para os diferentes pontos medidos na obra "Tropical" de Anita Malfatti (1917) do acervo da Pinacoteca do Estado de São Paulo Figura 4.63 - Gráfico de barras das áreas do pico do Co identificado nos espectros de EDXRF para os diferentes pontos medidos na obra "Tropical" de Anita Malfatti (1917) do acervo da Pinacoteca do Estado de São Paulo Figura 4.64 - Gráfico de barras das áreas do pico do As identificado nos espectros de EDXRF para os diferentes pontos medidos na obra "Tropical" de Anita Malfatti (1917) do acervo da Pinacoteca do Estado de São Paulo Figura 4.65 - Gráfico de barras das áreas do pico do Cd identificado nos espectros de EDXRF para os diferentes pontos medidos na obra "Tropical" de Anita Malfatti (1917) do acervo da Pinacoteca do Estado de São Paulo Figura 4.66 - Gráfico de barras das áreas do pico do Cu identificado nos espectros de EDXRF para os diferentes pontos medidos na obra "Tropical" de Anita Malfatti (1917) do acervo da Pinacoteca do Estado de São Paulo.

Figura 4.67 - Gráfico da correlação por PCA entre os elementos presentes nos espectros de EDXRF pontos medidos na obra "Tropical" de Anita Malfatti do acervo da Pinacoteca do Estado de São Paulo

Figura 4.68 - Fotografia com luz visível da obra "O Homem Amarelo" de Anita Malfatti $(1915 / 1916$, óleo sobre tela, $61 \times 51 \mathrm{~cm})$ do acervo do IEB-USP. Foto: P.H.O.V. Campos e E. Kajiya

Figura 4.69 - Fotografia de reflectografia de infravermelho da obra "O Homem Amarelo" de Anita Malfatti (1915/1916, óleo sobre tela, 61x51cm) do acervo do IEB-USP. Foto P.H.O.V. Campos e E. Kajiya

Figura 4.70 - Imagens da região da assinatura com fotografia com luz visível (esquerda) e reflectografia IR (direita) da obra "O Homem Amarelo" de Anita Malfatti do acervo do IEB-USP. Foto: P.H.O.V. Campos e E. Kajiya

Figura 4.71 - Imagem de Radiografia digital da obra "O Homem Amarelo" de Anita Malfatti (1915/1916, óleo sobre tela, $61 \times 51 \mathrm{~cm})$ do acervo do IEB-USP

Figura 4.72 - Imagem visível e de Radiografia digital da parte superior esquerda da obra "O Homem Amarelo" de Anita Malfatti (1915/1916, óleo sobre tela, $61 \times 51 \mathrm{~cm})$ do acervo do IEB-USP

Figura 4.73 - Imagem girada de $90^{\circ}$ da Radiografia digital da obra "O Homem Amarelo" de Anita Malfatti $(1915 / 1916$, óleo sobre tela, $61 \times 51 \mathrm{~cm})$ do acervo do IEB-USP

Figura 4.74 - Imagens obtidas com fotografia com luz rasante da obra "O Homem Amarelo" de Anita Malfatti do acervo do IEB-USP, lado esquerdo evidencia a camada espessa de tinta, Lado direito evidencia detalhes e pontos de deformação do suporte. Foto: P.H.O.V. Campos e E. Kajiya

Figura 4.75 - Fotografia por fluorescência UV da obra "O Homem Amarelo" de Anita Malfatti (1915/1916, óleo sobre tela, $61 \times 51 \mathrm{~cm})$ do acervo do IEB-USP. Foto: P.H.O.V. Campos e E. Kajiya

Figura 4.76 - Recortes das fotografias feitas da região do rosto da obra "O Homem Amarelo" de Anita Malfatti do acervo do IEB-USP com as técnicas de: A) fotografia de luz rasante; B) visível; C) reflectografia de infravermelho; D) fluorescência UV Foto: P.H.O.V. Campos e E. Kajiya

Figura 4.77 - Fotografia com os pontos de EDXRF medidos na obra "O Homem Amarelo" de Anita Malfatti (1915/1916, óleo sobre tela, 61×51cm) do acervo da Pinacoteca do Estado de São Paulo 
Figura 4.78 - Gráfico de barras das áreas do pico do $\mathrm{Pb}$ identificado nos espectros de EDXRF para os diferentes pontos medidos na obra "O Homem Amarelo" de Anita Malfatti (1915/1916) do acervo da Pinacoteca do Estado de São Paulo

Figura 4.79 - Gráfico de barras das áreas do pico do Ca identificado nos espectros de EDXRF para os diferentes pontos medidos na obra "O Homem Amarelo" de Anita Malfatti (1915/1916) do acervo da Pinacoteca do Estado de São Paulo

Figura 4.80 - Gráfico de barras das áreas do pico do Ba identificado nos espectros de EDXRF para os diferentes pontos medidos na obra "O Homem Amarelo" de Anita Malfatti (1915/1916) do acervo da Pinacoteca do Estado de São Paulo

Figura 4.81 - Gráfico de barras das áreas do pico do Zn identificado nos espectros de EDXRF para os diferentes pontos medidos na obra "O Homem Amarelo" de Anita Malfatti (1915/1916) do acervo da Pinacoteca do Estado de São Paulo

Figura 4.82 - Gráfico de barras das áreas do pico do Cr identificado nos espectros de EDXRF para os diferentes pontos medidos na obra "O Homem Amarelo" de Anita Malfatti (1915/1916) do acervo da Pinacoteca do Estado de São Paulo

Figura 4.83 - Gráfico de barras das áreas do pico do Sr identificado nos espectros de EDXRF para os diferentes pontos medidos na obra "O Homem Amarelo" de Anita Malfatti (1915/1916) do acervo da Pinacoteca do Estado de São Paulo

Figura 4.84 - Gráfico de barras das áreas do pico do Fe identificado nos espectros de EDXRF para os diferentes pontos medidos na obra "O Homem Amarelo" de Anita Malfatti (1915/1916) do acervo da Pinacoteca do Estado de São Paulo

Figura 4.85 - Gráfico de barras das áreas do pico do Cd identificado nos espectros de EDXRF para os diferentes pontos medidos na obra "O Homem Amarelo" de Anita Malfatti (1915/1916) do acervo da Pinacoteca do Estado de São Paulo

Figura 4.86 - Gráfico de barras das áreas do pico do Hg identificado nos espectros de EDXRF para os diferentes pontos medidos na obra "O Homem Amarelo" de Anita Malfatti (1915/1916) do acervo da Pinacoteca do Estado de São Paulo

Figura 4.87 - Gráfico de barras das áreas do pico do As identificado nos espectros de EDXRF para os diferentes pontos medidos na obra "O Homem Amarelo" de Anita Malfatti (1915/1916) do acervo da Pinacoteca do Estado de São Paulo

Figura 4.88 - Gráfico da correlação por PCA entre os elementos presentes nos espectros de EDXRF pontos medidos na obra "Tropical" de Anita Malfatti do acervo da Pinacoteca do Estado de São Paulo Figura 4.89: Esquema de distribuição temporal do uso dos pigmentos utilizados pela artista Anita Malfatti para obras aqui estudadas, na ordem de cima para baixo: Bases de preparação; pigmentos brancos; pigmentos amarelos

Figura 4.90: Esquema de distribuição temporal do uso dos pigmentos utilizados pela artista Anita Malfatti para obras aqui estudadas, na ordem de cima para baixo: pigmento verde; pigmentos azuis; pigmento violeta; pigmento marrom; pigmentos pretos 


\section{Índice de Tabelas}

Tabela 2.1 - Percepção humana para diferentes valores de $\Delta \mathrm{E}^{*}$ ab empregada pela indústria de tintas (Norma DIN 6174, 1979)

Tabela 4.1 - Medidas de colorimetria com o espectrômetro modelo CM-2500d da marca Konica-Minolt na cartela ColorChecker da X-Rite Photo

Tabela 4.2 - Relação das cores obidas por colorimetria (em coordenadas $L^{*} a^{*} b^{*}$ ) e fotografia digital (em coordenadas RGB) por nos pontos analisados por EDXRF na obra "O Japonês" de Anita Malfatti (1915/1916) do acervo do IEB-USP

Tabela 4.3 - Matriz de correlação dos elementos presentes nos pontos analisados por EDXRF na obra "O Japonês" de Anita Malfatti (1915/1916) do acervo do IEB-USP

Tabela 4.4: Possíveis pigmentos utilizados por Anita Malfatti na obra "O Japonês" de Anita Malfatti (1915/1916) do acervo do IEB-USP (JANSSENS, 2004; STUART, 2008; VASCONCELOS et al., 1992; MAYER, 2006; LFNATEC, 2009)

Tabela 4.5 - Relação das cores obtidas por colorimetria (em coordenadas $L^{*} a^{*} b^{*}$ ) e fotografia digital (em coordenadas RGB) nos pontos analisados por EDXRF na obra "A Estudante Russa" de Anita Malfatti (1915/1916) do acervo do IEB-USP

Tabela 4.6 - Matriz de correlação dos elementos presentes nos pontos analisados por EDXRF na obra "A Estudante russa" de Anita Malfatti (1915) do acervo do IEB-USP

Tabela 4.7: Possíveis pigmentos utilizados por Anita Malfatti na obra "A Estudante Russa" de Anita Malfatti (1915) do acervo do IEB-USP (JANSSENS, 2004; STUART, 2008; VASCONCELOS et al., 1992; MAYER, 2006; LFNATEC, 2009)

Tabela 4.8 - Matriz de correlação dos elementos presentes nos pontos analisados por EDXRF na obra "Retrato de Mário de Andrade" de Anita Malfatti (1923) do acervo do IEB-USP

Tabela 4.9: Possíveis pigmentos utilizados por Anita Malfatti na obra "Retrato de Mario de Andrade" de Anita Malfatti (1923) do acervo do IEB-USP (JANSSENS, 2004; STUART, 2008; VASCONCELOS et al., 1992; MAYER, 2006; LFNATEC, 2009)

Tabela 4.10 - Relação das médias de cores por fotografia digital (em coordenadas RGB) nos pontos analisados por EDXRF na obra "Tropical" de Anita Malfatti (1917) do acervo da Pinacoteca do Estado de São Paulo Tabela 4.11 - Matriz de correlação dos elementos presentes nos pontos analisados por EDXRF na obra "Tropical" de Anita Malfatti (1917) do acervo da Pinacoteca do Estado de são Paulo

Tabela 4.12 - Possíveis pigmentos utilizados por Anita Malfatti na obra "Tropical" de Anita Malfatti (1917) do acervo da Pinacoteca do Estado de São Paulo (JANSSENS, 2004; STUART, 2008; VASCONCELOS et al., 1992; MAYER, 2006; LFNATEC, 2009)

Tabela 4.13 - Relação das cores obtidas por colorimetria (em coordenadas $L^{*} a^{*} b^{*}$ ) e fotografia digital (em coordenadas RGB) nos pontos analisados por EDXRF na obra "O Homem Amarelo" (1915/1916) do acervo do IEB-USP

Tabela 4.14 - Matriz de correlação dos elementos presentes nos pontos analisados por EDXRF na obra "O Homem Amarelo" de Anita Malfatti (1917) do acervo da Pinacoteca do Estado de são Paulo

Tabela 4.15 - Possíveis pigmentos utilizados por Anita Malfatti na obra "O Homem Amarelo" de Anita Malfatti (1915/1916, óleo sobre tela, $61 \times 51 \mathrm{~cm}$ ) do acervo do IEB-USP (JANSSENS, 2004; STUART, 2008; VASCONCELOS et al., 1992; MAYER, 2006; LFNATEC, 2009)

Tabela 4.16 - Lista de pigmentos que podem estar presentes nas obras analisadas a partir dos elementos químicos encontrados nas analises por EDXRF, sendo as obras identificadas como "O Japonês" (J), "A Estudante 
Russa" (ER), "Retrato do Mário de Andrade" (RMA), "O Homem Amarelo" (HA) e "Tropical" (T). (JANSSENS, 2004; STUART, 2008; VASCONCELOS et al., 1992; MAYER, 2006; LFNATEC, 2009). 


\section{INTRODUÇÃO}

Aplicações sistemáticas de métodos técnico-científicos para estudos em bens patrimoniais tem origem na Europa e sua primeira manifestação ocorre por volta do século XVIII. No início do século XIX o químico Jean-Antoine Chaptal publica estudos sobre os pigmentos de Pompéia, e ao mesmo, Humphry Davy, estuda pigmentos de sítios arqueológicos romanos. $\mathrm{Na}$ segunda metade do século XIX, Giovani Morelli criou um método de autenticação de pinturas denominado análise estilística de composições secundárias. O primeiro laboratório em um museu, com o objetivo de trabalhar em bens culturais, foi instituído em 1888 por Friedrich Rathgen, que inicia pesquisas científicas no Laboratório Químico do Museu Royal de Berlin, propondo contribuir para o entendimento do processo de deterioração dos objetos da coleção. Com o decorrer do tempo, cada vez mais os grandes museus europeus decidem criar seus próprios laboratórios de pesquisa e vários laboratórios de universidades passaram também a direcionar pesquisas sobre objetos artísticos. Além disso, foram criadas muitas redes nacionais e internacionais com o objetivo de melhor usar os conhecimentos existentes nas várias estruturas, para melhorar o potencial humano e técnico e para compartilhar os conhecimentos (LUKICHEVA, 1987).

Ao contrário das pesquisas realizadas internacionalmente, esta área de pesquisas científicas é relativamente recente no Brasil. $O$ inicio se dá em alguns grupos de pesquisas vinculados às universidades na década de 90, como o Laboratório de Física Nuclear Aplicada do Instituto de Física da Universidade Estadual de Londrina que iniciou 1992 as possibilidades da tomografia na arqueometria, assim como com a técnica fluorescência de raios $X$ por dispersão em energia (EDXRF) (APPOLONI; PARREIRA, 2007). Desde 1996 a pesquisadora Dra. Rosa Scorzelli do Centro Brasileiro de Pesquisas Físicas (CBPF) tem trabalhando com caracterização e datação de cerâmicas arqueológicas com ênfase nas cerâmicas da bacia Amazônica e com caracterização de obsidianas principalmente no estudo da difusão destas nas culturas andinas pré-hispânicas (SCORZELLI et al., 1999; SCORZELLI 2001), e desde 2005 tem realizado trabalhos de análises de objetos preciosos do 
Patrimônio Cultural em parceria com os pesquisadores do Museu do Louvre (Paris) (SCORZELLI; GUERRA; VIEIRA, 2005).

E em torno do ano de 2000 vários grupos e laboratórios no Brasil iniciaram as atividades nesta interface entre ciência e patrimônio cultural, como o Laboratório de Ciências da Conservação (LACICOR), da Escola de Belas Artes da Universidade Federal de Minas Gerais (UFMG), que possuem trabalhados de estudos de obras artísticas (ROSADO; SOUZA; FRONER, 2007; ROSADO, 2011). Em São Paulo o Laboratório de Espectroscopia Molecular LEM do Instituto de Química da Universidade de São Paulo, inicia em 2000 os trabalhos em espectroscopia Raman para estudo de bens culturais (FARIA; EDWARDS, 2001; FARIA; AFONSO; EDWARDS, 2003; EDWARDS et al., 2003; FARIA et al., 2004). O Grupo de Física Aplicada com Aceleradores (GFAA) do departamento de Física Nuclear do Instituto de Física da Universidade de São Paulo, que em 2002 inicia suas medidas em objetos arqueológicos (SAETTONE et al., 2003) e em 2003 monta o primeiro arranjo de feixe externo no Laboratório de Análises de Materiais por Feixes lônicos (LAMFI) (RIZZUTTO et al., 2005; RIZZUTTO et al., 2006; RIZZUTTO et al., 2007). Em 2003, no Rio de Janeiro, temos também os inícios dos trabalhos do Laboratório de instrumentação Nuclear (LIN) da COPPE, Universidade Federal do Rio de Janeiro, através do desenvolvimento de um sistema portátil de Fluorescência de Raios X (XRF) (CALZA; ANJOS; LOPES, 2004; CALZA et al. 2005; CALZA et al., 2007a; CALZA, 2007b). Ainda na Universidade de São Paulo, o Laboratório de Eletroquímica e Corrosão de Materiais da Escola Politécnica começa em 2005, com a montagem de um espectrômetro de Fluorescência de Raios X semi portátil no estudo eletroquímico de pátinas artificiais (HERNÁNDEZ et al., 2006; NEIVA, et al. 2006; NEIVA; DRON; LIMA, 2007; NEIVA; DRON, 2008). Durante o IX Encontro Nacional de Aplicações Nucleares (ENAN-INAC) os vários representantes dos grupos de pesquisa que trabalham com este tema criaram uma Rede de laboratórios com aplicações em Patrimônio Cultural no Brasil - LAPAC (LAPAC, 2015). Acoplado ao instrumental e métodos analíticos observa-se uma crescente consolidação na área estudos dos objetos do patrimônio cultural no Brasil. 
Em 2012 foi criado o Núcleo de Pesquisa de Física Aplicada ao Estudo do Patrimônio Artístico e Histórico (FAEPAH), que se propões a realizar parcerias e projetos entre diversos Institutos e Museus em prol do estudo do grande acervo artístico histórico e cultural da Universidade de São Paulo, a partir da utilização de técnicas analíticas não destrutivas (FAEPAH, 2015). Alguns destes estudos são apresentados no trabalho de Rizzutto (RIZZUTTO, 2014).

\subsection{Estudos de pigmentos em telas de artistas brasileiros}

Dentre os muitos estudos realizados em bens culturais por estes diversos grupos e laboratórios de pesquisa citados, alguns dos projetos foram dedicados à pesquisa de obras de pintores nacionais. Dentre eles, estão os estudos de Calza (CALZA, 2007b) e colaboradores (CALZA; PEDREIRA; LOPES, 2009), após desenvolver um sistema de EDXRF portátil, realiza medidas em treze telas de pintores nacionais, produzidas entre 1860 e 1895, entre elas, a célebre pintura "Primeira Missa no Brasil" (1860) de Vitor Meireles, e de obras de outros artistas, como Almeida Junior e Rodolfo Amoedo, produzindo um repertório de materiais utilizados. Calza e colaboradores (CALZA et al., 2010) também realizam medidas com o EDXRF portátil e radiografia digital em outra importante obra brasileira "Gioventù" (1898), do pintor Eliseu Visconti. A obra "Moema" (1866), também do artista Vitor Meireles, foi igualmente analisada por EDXRF portátil, além das técnicas de fluorescência de raios X por reflexão total (TXRF) e espectroscopia Raman, nos estudos de Appoloni e Lopes (APPOLONI; LOPES, 2013).

Campos e colaboradores (CAMPOS et al., 2013) também realizaram trabalhos de caracterização elementar dos pigmentos com análises de EDXRF e ampliaram os estudos utilizando as técnicas de imageamento (fluorescência de luz ultravioleta, reflectografia de infravermelho, fotografia com luz rasante) de duas obras do pintor Oscar Pereira da Silva: "Hora da Música (1901) e "Autorretrato" (1936). Já Oliveira e colaboradores (OLIVEIRA et al., 2013) faz diversas análises por radiografia de obras de artistas brasileiros. Kajiya e colaboradores (KAJIYA et al., 2013) também utilizam análises de pigmentos por EDXRF e técnicas de imageamento (fluorescência de luz ultravioleta, 
reflectografia de infravermelho, fotografia com luz rasante) para estudar algumas obras do pintor modernista Di Cavalcanti, a fim de compará-las com um quadro que estava em discussão de sua originalidade. E em um amplo estudo sobre pigmentos artísticos, Freitas (FREITAS, 2014) faz o uso de diversas técnicas analíticas para estudar várias amostras de pigmentos, gerando assim um conjunto de dados para estes materiais.

No entanto, no Brasil ainda percebe-se uma grande carência de trabalhos nesta área e há, portanto, um cenário de grandes oportunidades para estudos posteriores e complementares.

\subsection{A Proposta}

Em termos de estudos de bens culturais, arqueologia e obras de arte, diversas pesquisas vêm sendo realizadas no Instituto de Física da Universidade de São Paulo (IFUSP) por meio do Grupo de Física Aplicada com Aceleradores (GFAA), a partir de diversas parcerias com museus, instituições e grupos de pesquisa desde 2003 (SAETTONE et al., 2003). Dentre estas parcerias, sugiram projetos de pesquisa voltados ao estudo do acervo de duas importantes instituições: a Pinacoteca do Estado de São Paulo e o Instituto de Estudos Brasileiros da Universidade de São Paulo, que possuem uns dos mais importantes e representativos acervos de documentos e arte do patrimônio nacional. Estas pesquisas foram baseadas na importância dos estudos dos artistas brasileiras em termos de arteometria, e dentre as diversas obras presentes nos acervos, os quadros da importante artista brasileira Anita Malfatti recebem destaque, por possuírem questões em comum.

Desta forma, surge a proposta deste trabalho, a partir da associação de técnicas de análise por imagem, colorimetria e atômicas não destrutivas, caracterizar pinturas a óleo de autoria da artista brasileira Anita Malfatti (18891964), produzidas entre 1915 e 1923, pertencentes ao acervo da Pinacoteca do Estado de São Paulo e do Instituto de Estudos Brasileiro da Universidade de São Paulo (IEB-USP). 
O objetivo deste trabalho foi caracterizar os materiais utilizados pela pintora Anita Malfatti em cinco de suas pinturas a óleo, executadas no período em que seus quadros tiveram a maior repercussão, devido ao contexto de grande transformação artística no Brasil. Teve-se como objetivo estudar e determinar a paleta de cores e pigmentos utilizada pela artista. As análises ainda contribuem para a determinação do perfil estilístico da Anita, à medida que as técnicas utilizadas possibilitam a observação do processo criativo dos artistas. O conjunto de todas estas informações contribuirá para o processo inicial de constituição de um banco de dados dos materiais utilizados pela artista, com informações que servirão de subsídio para historiadores e curadores, na ampliação do conhecimento em História da Arte e nas técnicas de pintura desta importante artista brasileira, assim como para subsidiar os profissionais das áreas de conservação e restauro, na definição das técnicas e condições de preservação e restauração deste patrimônio material.

No caso particular de pinturas de cavaletes, este tipo de estudo de caracterização das obras por imageamento, técnicas atômicas e colorimetria podem revelar características dos pintores e da própria obra, anteriormente desconhecidas, pelo fato de terem sido utilizadas anteriormente apenas análises visuais, baseadas no conhecimento estilístico de especialistas, por serem estudos mais antigos e/ou por estas técnicas ainda não estarem ao alcance destas instituições. Através de imagens de fotografias visíveis de fluorescência de ultravioleta, reflectografia de infravermelho e luz rasante, radiografia, colorimetria e caracterização elementar dos pigmentos utilizados pelos artistas é possível construir um banco de dados com informações sobre pigmentos e técnicas de pinturas utilizadas pelos pintores, e é possível um aprofundamento das pesquisas sobre as técnicas e os materiais utilizados, contribuindo para o número maior de informações da constituição de cada obra, assim como na alimentação de uma base de referência para comparação com demais obras do mesmo artista, em caso de processos de autenticidade. 


\subsection{A Artista}

Anita Catarina Malfatti (São Paulo, SP, Brasil, 1889-1964) é uma das mais importantes artistas plásticas brasileiras, suas primeiras obras são consideradas por muitos como as pioneiras no modernismo brasileiro. Anita iniciou seus estudos na Alemanha, entre 1910 a 1914, onde frequentou a Academia Imperial de Belas Artes de Berlim. Neste período ainda, estudou com Fritz Burger, Bischoff-Culm e Lovis Corith, e sob suas orientações inclinou-se na arte moderna, focando, desde o princípio, o estudo da cor. Com o início da Primeira Guerra Mundial, retorna ao Brasil e realiza sua primeira exposição individual em 1914. Em 1915 parte para os Estados Unidos, permanecendo em Nova lorque até 1916, onde estudou na Art Student League e na Independent School of Art, de Homer Boss, que possui forte influência nas suas obras.

A partir destes estudos, Anita se afasta da pintura realista e adere definitivamente à arte moderna, desenvolvendo desenhos, pinturas e gravuras de tendência expressionista, (BATISTA; LIMA, 1998). Neste período, pinta algumas das suas obras mais famosas e emblemáticas: "O Homem Amarelo", "A Estudante Russa", "O Japonês" (Coleção Mário de Andrade, Instituto de Estudos Brasileiros da USP); "A Boba" (Col. Museu de Arte Contemporânea da USP); "A Mulher de Cabelos Verdes" (Col. Ernesto Wolf); "Uma Estudante" (Col. Museu de Arte de São Paulo Assis Chateaubriand).

Retorna ao Brasil em 1916, e organiza em São Paulo sua segunda exposição individual em 1917-1918, consagrada como o marco inicial do movimento modernista. Suas obras impactaram o público paulistano, que ainda estava acostumado às artes academistas. Monteiro Lobato, crítico de arte na época, publicou uma violenta crítica em sua coluna. Muitos futuros modernistas passaram pela exposição. A partir desta exposição, Anita foi a agente aglutinadora inicial do grupo modernista brasileiro, que começou a se organizar somente após a polêmica exposição (DE ANDRADE, 1944). Oswald de Andrade publicou um artigo defendendo a artista, enquanto Mario de Andrade dedicou um poema parnasiano à obra "O Homem Amarelo".

Anita participa da Semana de Arte Moderna de 1922 com a maior 
representação individual do evento. No mesmo ano, Anita produz a obra Tropical (Pinacoteca do Estado de São Paulo), já com o tema e influência do modernismo brasileiro. Em 1923 parte para Paris, permanecendo até 1928, expondo em salões e exposições individuais. Retorna a São Paulo e passa a ensinar desenho e a participar de diversas exposições e retrospectivas em homenagem ao seu trabalho, com o tempo sua pintura se torna mais intimista e ingênua (BATISTA; LIMA, 1998; BATISTA, 2006).

Este estudo buscou, com base na sua vasta carreira e número de obras, analisar quatro obras um mesmo período e uma de um período diferente, comparando o resultado com o material utilizado por artistas antecessores e contemporâneos, para determinar os materiais utilizados, e concluir se houve uma mudança no decorrer de sua carreira e se os artistas modernistas também exerceram influência quanto à utilização de novas matérias primas na arte nacional. Informações estas de extrema importância tanto para historiadores da arte e curadores, como para conservadores e restauradores.

\subsubsection{Estudos das Obras da Anita Malfatti}

Por ser uma artista uma pioneira e uma referência importante no movimento artístico nacional, o modernismo, Anita Malfatti tem muitos trabalhos publicados voltados aos estudos de suas obras, catalogação dos seus trabalhos e biografias. Por ser um dos agentes transformadores de um pensamento e estilo artístico, algumas publicações se dedicam a discutir o contexto histórico e as repercussões e das obras e exposições da artista, que em seu tempo gerou inúmeros debates públicos (CAMARGOS, 2003; ALMEIDA, 1976), incluindo os famosos artigos do escritor e crítico de arte Monteiro Lobato (LOBATO, 1922), além dos trabalhos relacionados às mudanças estéticas e estilísticas que Anita também protagonizou neste período de transformação, assim como os rumos que a artista tomou em suas produções (CHIARELLI, 1995; PINTO, 2007; CHIARELLI, 2008; CHIARELLI, 2010) e trabalhos reunindo e catalogando suas obras e relatando sua biografia e o contexto artístico que Malfatti estava inserida (ANDRADE, 1989; BATISTA, 2006; CAMARGO, 2009; MALFATTI, 2009), incluindo trabalhos que também discutem a comercialização e falsificação de obras da artista (GREGGIO, 
2007). Mas em todas as biografias pesquisadas, nada se propõe a estudar os materiais utilizados pela artista.

\subsection{Contribuição deste trabalho na área interdisciplinar}

Espera-se que este trabalho contribua para a área de patrimônio cultural auxiliando os historiadores, conservadores, entre outros pesquisadores e interessados, para um melhor conhecimento da artista e sua obra. As técnicas físico-químicas de análise permitem a caracterização da paleta da artista em diferentes obras, a identificação do seu processo criativo, as possíveis alterações ocorridas com o tempo e o estado atual de conservação. Como já foi ressaltado, o estudo sistemático de um artista e suas obras permite construir um conjunto de informações que associadas podem auxiliar nos processos de conservação preventiva, restauro e em alguns casos até identificar falsificações. 


\section{FUNDAMENTAÇÃO TEÓRICA}

Quando se trata de bens históricos e culturais, a conservação e preservação são os critérios mais importantes. Ao realizarmos estudos nesta área do conhecimento, como todas as demais, as metodologias de pesquisa escolhidas dependem do tipo de matéria a ser estudado e das perguntas que se querem responder. Mas nesta área de pesquisa dá-se prioridade às técnicas analíticas não destrutivas e não invasivas.

No caso das pinturas de cavalete, muitos questionamentos podem ser respondidos utilizando técnicas arqueométricas. Dentre as várias técnicas disponíveis, foram aqui escolhidas técnicas de imageamento (fotografia com luz visível, fotografia visível por fluorescência UV, fotografia com luz rasante, reflectografia de infravermelho e radiografia) e, por se tratarem de técnicas não destrutivas, portáteis, e por possuírem a potencialidade de responder grande parte dos questionamentos aqui levantados.

Com exceção da radiografia, todas as demais técnicas de caracterizações, que serão aqui apresentadas, por serem portáteis, possuem uma grande vantagem, pois podem ser realizadas in situ. Neste caso facilitando o procedimento de análise, já que o translado destes objetos de arte aos laboratórios de análises é uma das maiores dificuldades nesta área de pesquisa.

\subsection{Raios $X$}

Os raios $X$ são radiações eletromagnéticas que são também conhecidos como radiação Röntgen, em homenagem a Wilhelm Conrad Röntgen, o primeiro a descrevê-los, (RÖNTGEN, 1895; BERTIN, 1975; BUTCHER; PONTING; CHANDLER, 1997).

Os raios $X$ são produzidos principalmente pela interação de fótons ou partículas carregadas (elétrons ou partículas carregadas mais pesadas) com a matéria. Suas produções estão relacionadas à perda de energia destas partículas (espectro de raios $X$ contínuo) e radiação característica que é produzida nas transições dos elétrons nos orbitais energéticos dos átomos. 


\subsection{Modelo Atômico}

No modelo atômico, o átomo possui uma distribuição de elétrons em torno do núcleo, confinados em níveis específicos.

O número atômico principal $n=1,2,3, \ldots$ define a camada principal. $\mathrm{O}$ número quântico $l=1,2,3, \ldots(n-1)$ é dado como o momento angular do elétron. $O$ número quântico $j=l \pm 1 / 2$ descreve o vetor da soma de $l$ e $s$, sendo o último, o número quântico de spin intrínseco que vale $\pm 1 / 2$ (spin para cima ou spin para baixo).

O número máximo de elétrons em qualquer subcamada é dado por $2 j+1$. O número máximo de elétrons em qualquer camada é dado por $2 n^{2}$.

A camada eletrônica mais fortemente ligada é a que possui o número quântico principal $n=1$, e é denominada como camada $K$. Esta camada pode ter no máximo 2 elétrons (spin para cima e spin para baixo).

A próxima camada eletrônica mais fortemente ligada é a $n=2$, ou camada $L$, com o número máximo de 8 elétrons, que é composta por três subcamadas: $L_{I} \quad(n=2, l=0, j=1 / 2)$, com 0 máximo de 2 elétrons; $L_{I I}$ $(n=2, l=1, j=1 / 2)$, com o máximo de 2 elétrons; e $L_{I I I}(n=2, l=1, j=3 / 2)$, com o máximo de 4 elétrons.

Na camada seguinte temos $n=3$, ou camada $M$, com o máximo de 18 elétrons, com as subcamadas $M_{I}$ (2 elétrons), $M_{I I}$ (2 elétrons), $M_{I I}$ (4 elétrons), $M_{I V}$ (4 elétrons) e $M_{V}$ (6 elétrons). E assim sucessivamente para as próximas camadas como $n=4$, ou camada $N$, a camada $n=5$, ou camada $O$, conforme exemplificado na figura 2.1.

Os raios $X$ são produzidos devido às transições de elétrons de uma camada para outra. Quando há uma vacância em uma camada de maior energia de ligação, ou de menor número quântico principal, esta pode ser ocupada por um elétron de uma camada de maior nível energético. Como consequência dessa mudança de níveis, um fóton, com energia igual à 
diferença dos níveis eletrônicos, pode ser emitido pelo átomo. As transições eletrônicas mais importantes para o estudo em questão, que correspondem às séries $K, L$ e $M$ de raios $\mathrm{X}$, são mostradas na figura 2.1.

Todas as séries de transições $K\left(K_{\alpha 1}, K_{\alpha 2}, K_{\beta 1}, \ldots\right)$ correspondem aos preenchimentos de vacâncias na camada $K$, o mesmo se aplica às demais séries. Mas estas transições só são permitidas para $\Delta l \neq 0$ e $\Delta j=0, \pm 1$.

Uma vez que uma vacância na camada $K$ é criada, ou em qualquer outra camada, o átomo está em estado de excitação. A transição atômica não pode ocorrer, a menos que camadas superiores estejam ocupadas. Por isso, 0 $\mathrm{H}$ e o $\mathrm{He}$ não possuem raios $\mathrm{X}$, pois suas camadas $L$ não estão ocupadas. Logo, para todos os elementos que possuam número atômico igual ou maior a $Z=3$ (Li) um $K_{\alpha}$ pode ser observado. Sendo $K_{\alpha}$ transições das camadas $L$ para a camada $K$. Os $K_{\beta}$ correspondem a transições eletrônicas das camadas $M\left(K_{\beta 1}, K_{\beta 3}, K_{\beta 5}\right)$ ou $N\left(K_{\beta 2}, K_{\beta 4}\right)$ para a camada $K$, nenhum raio $\mathrm{X} K_{\beta}$ será emitido antes que $Z$ seja igual ou maior que $11(\mathrm{Na})$. 


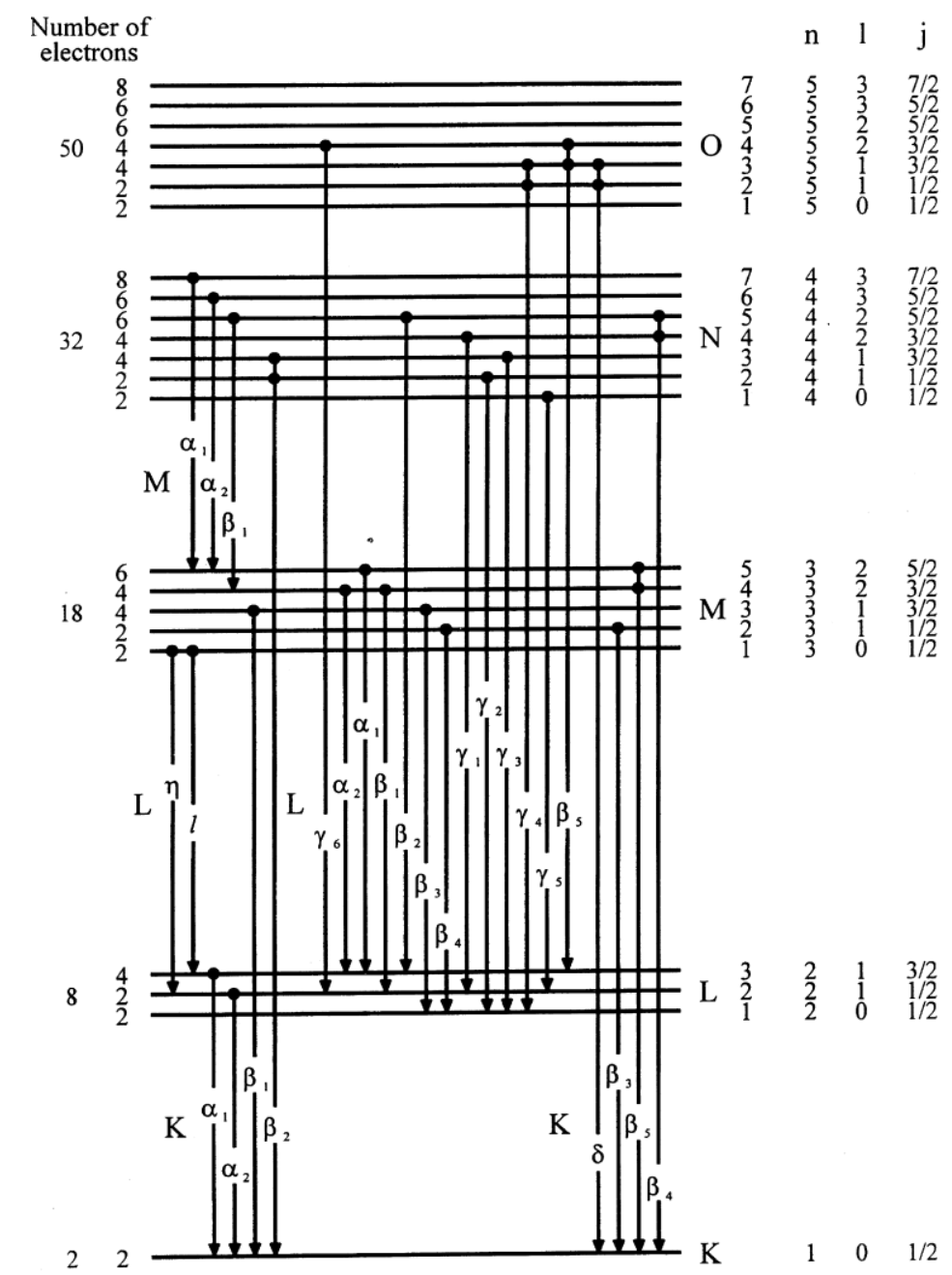

Figura 2.1 - Diagrama energético e as transições de raio $X$ mais importantes com os respectivos números máximos de elétrons em cada camada, e os números quânticos $n$, l e j para cada camada e subcamada (CESAREO, 2000)

A série $L$ de raios $X$ corresponde ao preenchimento de uma vacância de uma subcamada $L$, no qual raios X $L_{\alpha 1}$ e $L_{\alpha 2}$ correspondem à transição de um elétron de uma subcamada $M_{V}$ e $M_{I V}$, respectivamente, para a subcamada $L_{I I I}$, ao passo que as linhas $L_{\beta 1}$ e $L_{\beta 2}$ correspondem à transição da subcamada $M_{I V}$ e $N_{V}$ para uma vacância em $L_{I I}$ e $L_{I I}$, respectivamente.

$\mathrm{Na}$ prática, as linhas das séries $K$ e $L$ são as mais utilizadas para auxiliar na caracterização do átomo, por ser a maior mudança de energia que o elétron pode se submeter. Por esta razão, os valores energéticos e as razões de intensidades dos raios $X K$ e $L$ são parâmetros mais utilizados tanto em análises qualitativas quanto quantitativas. Apenas em aplicações especiais os 
raios X $M$ são utilizados. Os valores energéticos das linhas $K$ e $L$ tabelados para vários elementos podem ser vistos no anexo $A$.

Cada elemento possui um conjunto de camadas eletrônicas orbitais características, isso se deve ao seu número atômico e às interações dos elétrons entre si, que cria uma eletrosfera única, na qual as distâncias energéticas entre as camadas são específicas para cada átomo. Deste modo, a radiação eletromagnética consequente do decaimento entre tais camadas é característica de um átomo.

O valor da energia do raio $X$ característico emitido está relacionado com o número atômico, $Z_{a}$, do material pela lei de Moseley:

(Eq. 1)

$$
E_{i}=C_{i}(Z-s)^{2},
$$

onde $C$ é uma constante diferente para cada série espectral e $s$ é uma constante de blindagem, próxima de 1. Logo, os valores energéticos das linhas $K_{\alpha}$ podem ser calculados por:

$$
E_{K \alpha}=10,212(Z-1)^{2} \mathrm{eV}
$$

Os valores experimentais se ajustam bem aos valores teóricos para números atômicos baixos ou médios. Se usarmos os valores $Z=10,20,30,40$ e 50 , pela equação 2 teremos os valores 0,$83 ; 3,69 ; 8,6 ; 15,5 ; 24,5 \mathrm{keV}$, enquanto os valores experimentais vistos no anexo A são 0,$83 ; 3,69 ; 8,6 ; 15,7$; 25,2 keV. Mostrando deste modo o bom acordo na determinação das energias para $Z$ baixos.

\subsection{Interação de raios $X$ com a matéria}

Neste trabalho, as técnicas analíticas utilizam raios $X$ característicos que pertencem à faixa de energia entre 0,5 e $50 \mathrm{keV}$. Com esta energia, há três modos primários de interação de raios $X$ com a matéria: o efeito fotoelétrico, 0 espalhamento Compton e o espalhamento coerente (JENKINS; GOULD; GEDCKE, 1981). 
O efeito fotoelétrico é a interação mais frequente na faixa de energia de raio $X$, sendo cerca de $80 \%$ das interações para elemento com $Z$ maiores que 40. Nesta mesma faixa de energia, o efeito incoerente (efeito Compton) é cerca de 5 a 10\% das interações (CESAREO, 2000), onde sua contribuição se torna mais importante em raios $X$ de altas energias e para elementos de baixo $Z$.

\subsubsection{Efeito Fotoelétrico}

No efeito fotoelétrico, um fóton interage com um elétron das camadas eletrônicas mais internas do átomo. O fóton é absorvido e o elétron é ejetado de sua órbita. $O$ elétron toma como energia cinética toda a energia proveniente do fóton incidente, menos a energia de ligação entre átomo e elétron. Dessa maneira, foi criada uma vacância onde anteriormente estava o elétron.

Pela conservação de energia temos:

$$
E_{e}=E_{0}-\phi_{i}
$$

onde $E_{0}$ é a energia do fóton incidente, $E_{e}$ é a energia cinética do elétron ejetado, e $\phi_{i}$ é a energia de ligação do elétron da camada $i$ do átomo.

Uma expressão semi empírica para a energia de ligação em $K$, para elementos com número atômicos não muito baixos, é dada por:

$$
\phi_{K}=13,6 Z_{i}^{2} \mathrm{eV},
$$

onde: $Z_{i}=Z-2.5$ (para $\left.Z=10-18\right) ; Z_{i}=Z-3$ (para $\left.Z=19-70\right)$; e $Z_{i}=Z-1.5$ (para $Z=71-95$ ).

Após a nova vacância ser criada, há possibilidade de ocorrer dois processos:

- Um elétron de uma órbita superior (na camada $L$, por exemplo) ocupa a vacância criada (no orbital $K$ ), havendo, conjuntamente, 
a emissão de um fóton com energia igual à energia da diferença entre os dois orbitais $\left(\phi_{K}-\phi_{L}\right)$.

- O elétron de uma camada superior ocupa um orbital mais baixo. Um elétron é ejetado como uma consequência do retorno da ionização atômica para seu estado fundamental. Este elétron liberando tem energia cinética de $\phi_{K}-\phi_{L}-\phi_{M}$, é chamado de elétron Auger.

Após o elétron ser ejetado, a radiação em fótons emitida pode ter energia na faixa do raio $X$, dependendo da diferença energética entre os orbitais da interação. Esta interação de radiação e a emissões características são apresentadas esquematicamente na figura 2.2 .
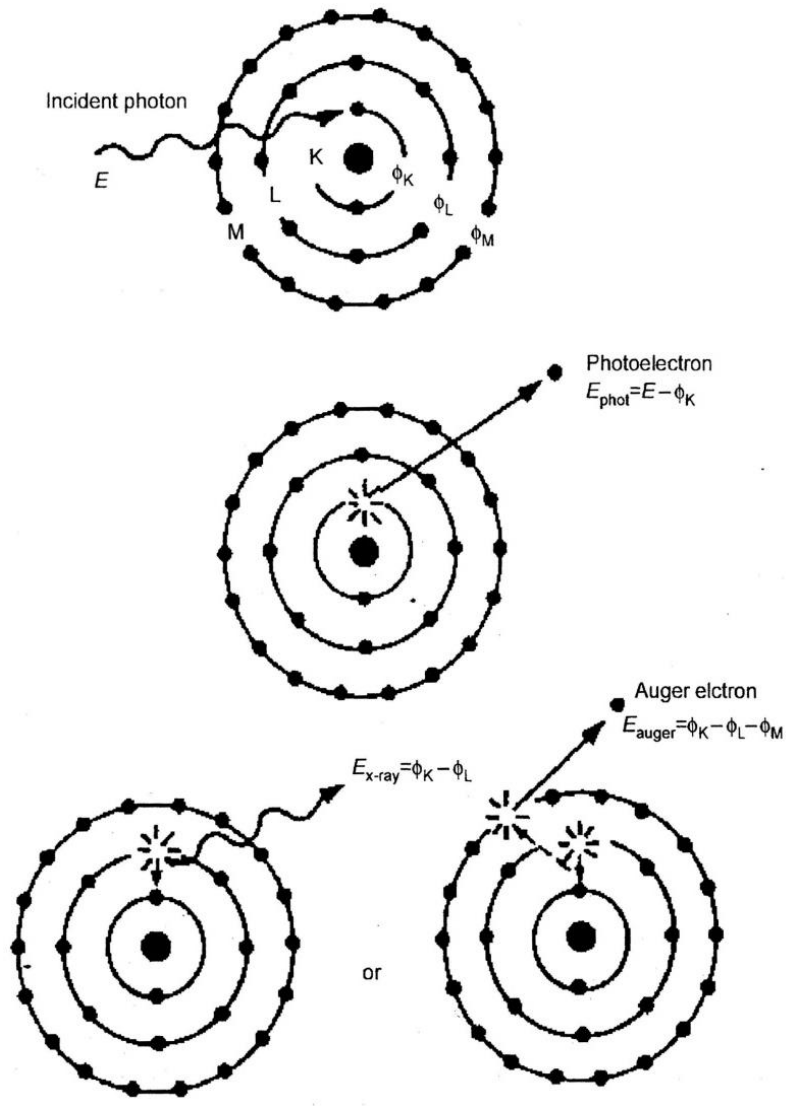

Figura 2.2 - A ionização por efeito fotoelétrico pode ser seguida tanto por uma emissão de um raio X característico, quanto pela emissão de um elétron Auger (JENKINS; GOULD; GEDCKE, 1981) 


\subsubsection{Efeito Compton}

Tem-se um espalhamento Compton (COMPTON, 1923) (também chamado de espalhamento incoerente) quando um fóton colide com um elétron e perde parte de sua energia e sofre uma deflexão da sua trajetória original. Neste efeito, uma condição importante é a interação ocorrer com um elétron fracamente ligado ao átomo.

No espalhamento Compton, um fóton com energia $E_{0}$ colide com um elétron, após a colisão, teremos o elétron com energia $E_{e}$ e um fóton com energia $E_{c}$, que forma um ângulo $\theta$ com a direção do fóton incidente. Pela conservação de energia e momento, para um elétron livre ou uma interação com energia suficiente para retirar o elétron do seu orbital, temos:

(Eq. 5)

$$
E_{c}=\frac{E_{0}}{1+\alpha(1-\cos \theta)},
$$

onde $\alpha=E_{0}(\mathrm{keV}) / 511(\mathrm{keV})$, no qual $511 \mathrm{keV}$ é a massa de repouso do elétron. A figura 3.3 mostra uma representação do espalhamento Compton para diferentes ângulos $\theta$. 


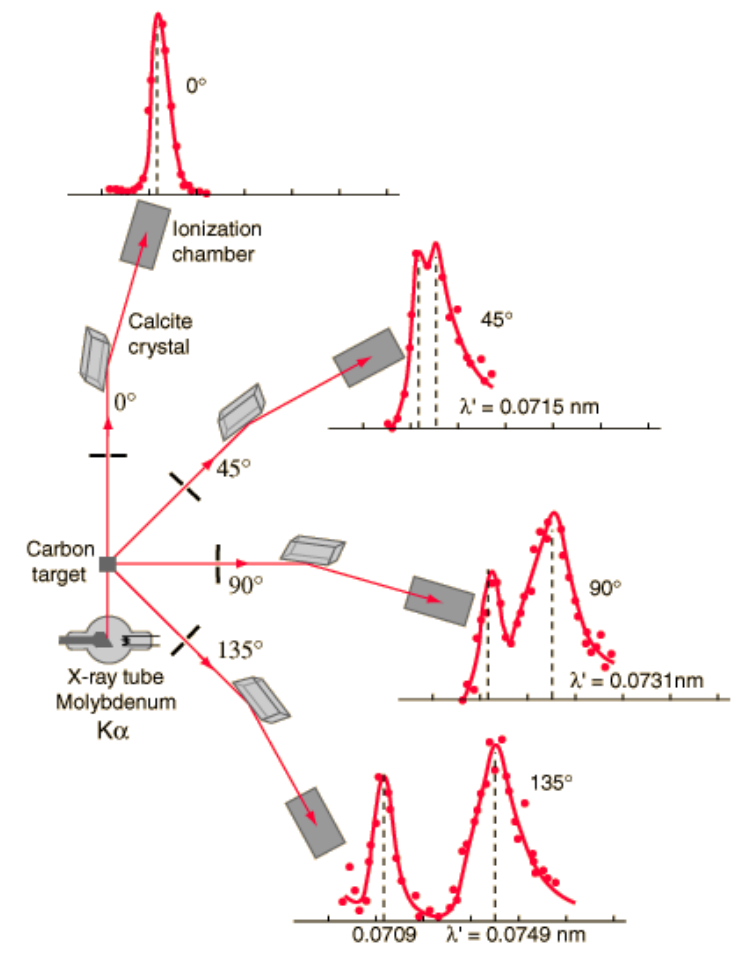

Figura 2.3 - Efeito Compton observado de espalhamento de um feixe de raios $X$, proveniente de um tubo de raio $X$ de Mo, sobre um alvo de carbono, e o espectro observado para diferentes ângulos de detecção do raio $X$ espalhado (NAVE, 2009)

\subsubsection{Espalhamento Coerente}

O espalhamento coerente (também chamado de Rayleigh ou elástico) acontece quando fótons são espalhados por elétrons ligados aos átomos $\mathrm{e}$ onde o átomo não se torna ionizado e nem excitado. Este processo ocorre principalmente em baixas energias e para materiais com $Z$ altos.

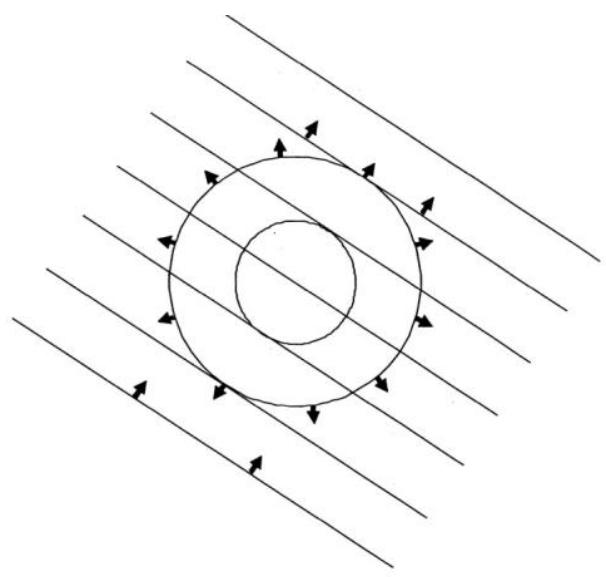

Figura 2.4 - No espalhamento elástico, quando a onda de raio $X$ colide com o átomo, os elétrons desse átomo espalham o raio $X$. A onda espalhada elasticamente é imediatamente reemitida em todas as direções e pode ser imaginada como uma frente de onda esférica (JANSSENS, 2004) 


\subsection{Técnicas de Análise}

Como mencionado anteriormente, os raios $X$ são gerados pelo bombardeamento do alvo por meio de fótons ou partículas carregadas (elétrons, ou íons), e cada elemento emite raios $X$ com energia específica que o caracteriza. As linhas de emissão atômica do espectro de raios $X$ característico são muito mais simples do que as linhas no ultravioleta (UV) e no visível. Não mais do que 600 linhas de raios $X$ são relevantes para a espectrometria de raio $\mathrm{X}$, suficientes para a caracterização de quase todos os elementos, enquanto só o Fe possui 6000 linhas de emissão no UV (MOENS; BOHLEN; VANDENABEELE, 2000).

De modo geral, nenhuma diferenciação pode ser feita por raios $X$ para isótopos de um mesmo elemento. $A$ energia do raio $X$ emitido nos permite identificar o elemento presente na amostra, enquanto que a intensidade do sinal individual nos possibilita, por proporcionalidade, determinar a concentração desse elemento.

\subsubsection{Fluorescência de Raio $X$}

O processo de absorção de um fóton pela matéria para a posterior emissão de um elétron Auger ou um fóton característico é denominado de fluorescência de raio X ( $X$-Ray Fluorescence, XRF).

No presente trabalho, o nosso interesse são as linhas características dos elementos. Mas a intensidade de emissão de tais fótons característicos depende de alguns fatores como:

- Probabilidade de um fóton ionizar o átomo em uma camada mais interna.

- Probabilidade da vacância criada em tal camada ser ocupada por um elétron de uma camada superior

- Probabilidade do fóton não emergir do átomo e um elétron ser emitido pelo efeito Auger 
A primeira condição está relacionada com a absorção do fóton pela matéria, caracterizada pelo coeficiente de absorção de massa $\mu$, que é a soma da contribuição do efeito fotoelétrico e do espalhamento Compton, como pode ser visto na figura 2.5 .

Para a faixa de energia de 0 a $100 \mathrm{keV}$, o coeficiente de absorção do efeito fotoelétrico é predominante no coeficiente de absorção total. Na figura 2.5, as descontinuidades na linha de absorção pelo efeito fotoelétrico são chamadas linhas de bordas de absorção, sendo as energias associadas às energias para que se consiga superar a energia de ligação do elétron ao átomo e promover a ionização da camada ocupada por tal elétron.

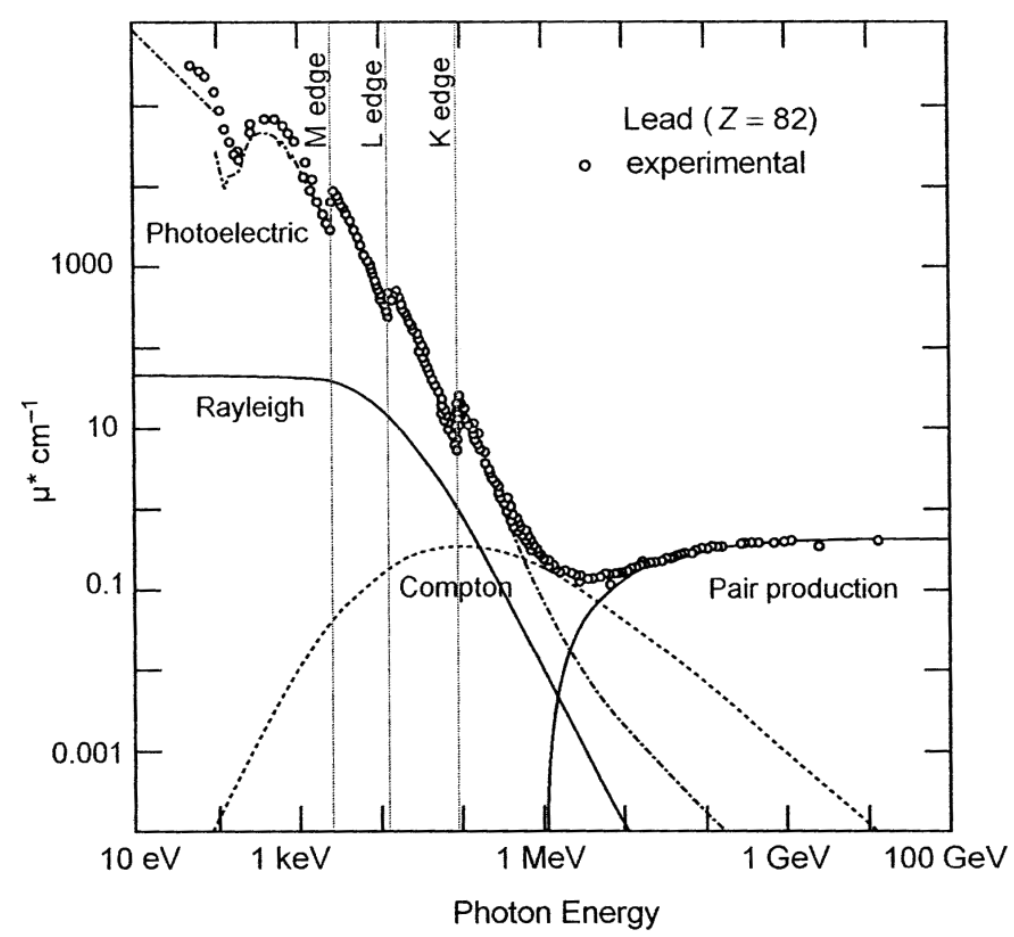

Figura 2.5 - Os diferentes modos de interação entre fótons e a matéria para um alvo de chumbo, em função da energia do fóton. Cada processo possui um domínio energético particular. Na faixa das baixas energias $(0-100 \mathrm{keV})$, o efeito foto elétrico é dominante. No regime intermediário (100-1000 keV), o espalhamento Compton é predominante. Na região das altas energias (acima de 1,022 MeV), a produção de pares tem a principal contribuição (CALLIGARO; DRAN; SALOMON, 2004)

A segunda condição, que é a probabilidade de transição, é governada pelas regras de seleção da mecânica quântica. 
A terceira e última condição é a probabilidade de não ocorrer o efeito Auger, e essa probabilidade está relacionada ao rendimento de florescência $\omega_{i}$, que é a razão entre o número de raios $X$ característicos emitidos e 0 número total de vacâncias nas camadas mais internas, no qual a vacância ocorre, sendo $i$ a camada em questão.

Para elementos leves, onde $Z<20$, a produção de elétrons Auger é predominante, sendo $\omega_{K}<0,2$, mas para elementos médios e pesados há 0 predomínio da produção de raios $\mathrm{X}$ característico, no qual $0,2<\omega_{K}<1$. Veja a figura 2.6, onde temos a dependência de $\omega_{K}, \omega_{L 3}, \omega_{M 5}$ em relação a $Z$.

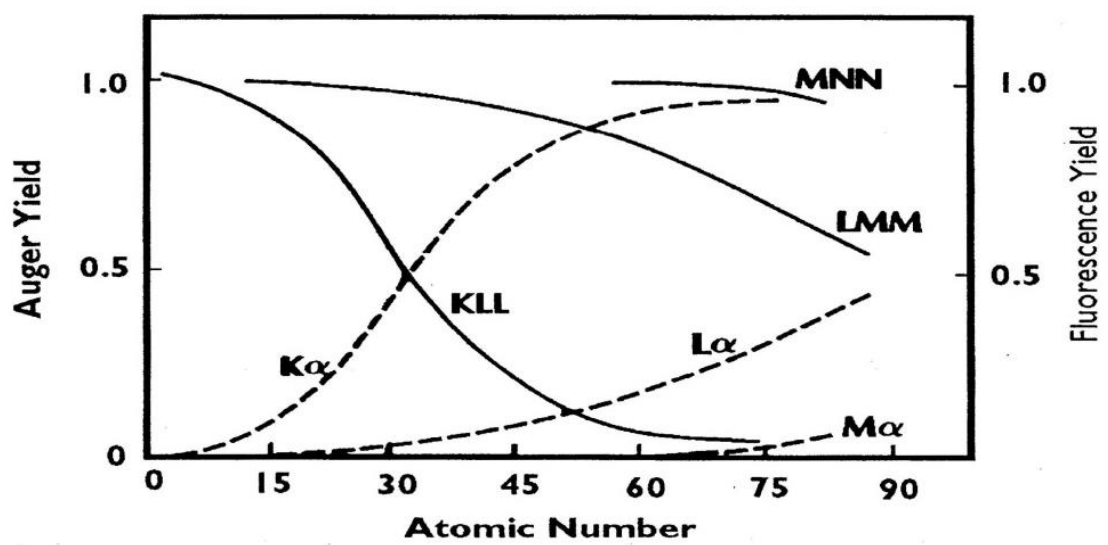

Figura 2.6 - Probabilidade relativa de emissão de fluorescência de raio $X$ (linha tracejada) $e$ Auger (linha contínua) (HUBIN; TERRYN, 2004)

A espectroscopia de fluorescência de raios $X$ baseia-se na emissão de raios $X$ característicos dos elementos presentes na amostra, a partir da excitação por meio de um feixe de raios $X$. Existem distintas técnicas de fluorescência de raios $X$, a aqui utilizada foi a fluorescência por dispersão de energia (Energy Dispersive X-Ray Fluorescence, EDXRF).

\subsubsection{Fluorescência de Raio X por dispersão de energia (EDXRF)}

O desenvolvimento de materiais semicondutores trouxe novas características à espectrometria de raios $\mathrm{X}$, pois através da resolução de energia dos detectores de $\mathrm{Si}$, que é suficientemente alta, pode-se realizar uma espectrometria de raios $\mathrm{X}$ sem uma dispersão prévia em um cristal refletor de Bragg. Assim, foi desenvolvida uma técnica de espectrometria de fluorescência 
de raios $X$ por dispersão de energia (Energy-Dispersive $X$-ray Fluorescence Spectrometry, EDXRF). Esta é uma técnica analítica não destrutiva, multielementar e simultânea, que permite a determinação de teores totais de elementos químicos, através da detecção das linhas de raios $X$ característicos $K$ e $L$ dos elementos que estão presentes em uma dada amostra. A técnica EDXRF pode atingir limites de detecção da ordem de 1 a 20 ppm para amostras sólidas (sem tratamento químico) e da ordem de 1 a 20 ppb para amostras líquidas (com tratamento de pré-concentração) (NASCIMENTO FILHO, 1999).

\subsubsection{Formulação do método de Fluorescência de Raio $X$ por dispersão de energia (EDXRF)}

A formulação para o método EDXRF foi retirada do trabalho de Nascimento Filho (1999).

Para uma excitação monoenergética, admitindo uma amostra homogênea com espessura uniforme $D$ e desprezando os efeitos de reforço (enhancement), a intensidade da linha $K_{\alpha}$ de um elemento de interesse produzida numa camada $d x$ a uma profundidade $x$, como pode ser visto na figura 2.7, é produto de três probabilidades:

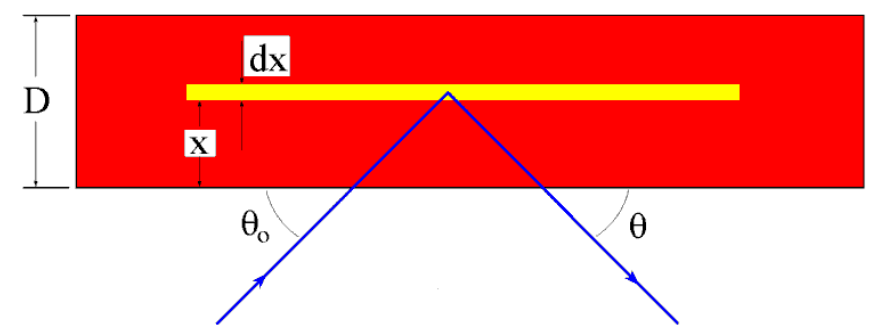

Figura 2.7 - Representação esquemática da geometria de excitação para feixe monoenergético em fluorescência de raios X (NASCIMENTO FILHO, 1999)

A probabilidade $P_{1}$ da radiação de excitação atingir a camada $d x$ a uma profundidade $x$ :

(Eq. 6)

$$
P_{1}=e^{-\mu_{0} \rho_{0} x / \operatorname{sen} \theta_{0}},
$$


onde $\mu_{0}$ é coeficiente de absorção de massa da matriz na energia dos fótons incidentes, $\rho_{0}$ é a densidade da matriz e $\theta_{0}$ é o ângulo de incidência (entre a direção do feixe incidente e a superfície da amostra).

O valor de $\mu_{0}$ pode ser calculado como a somatória dos produtos dos coeficientes de absorção de massa pela fração em massa de todos os elementos presentes na amostra. A figura 2.8 ilustra a dependência deste coeficiente em função da energia da radiação para os elementos $\mathrm{Ca}, \mathrm{Cu}$ e $\mathrm{U}$, onde pode ser notada as bordas de absorção da camada $\mathrm{K}$ para os dois primeiros elementos, e as bordas K, L (com 3 sub-níveis) e M (com 5 subníveis) para o U.

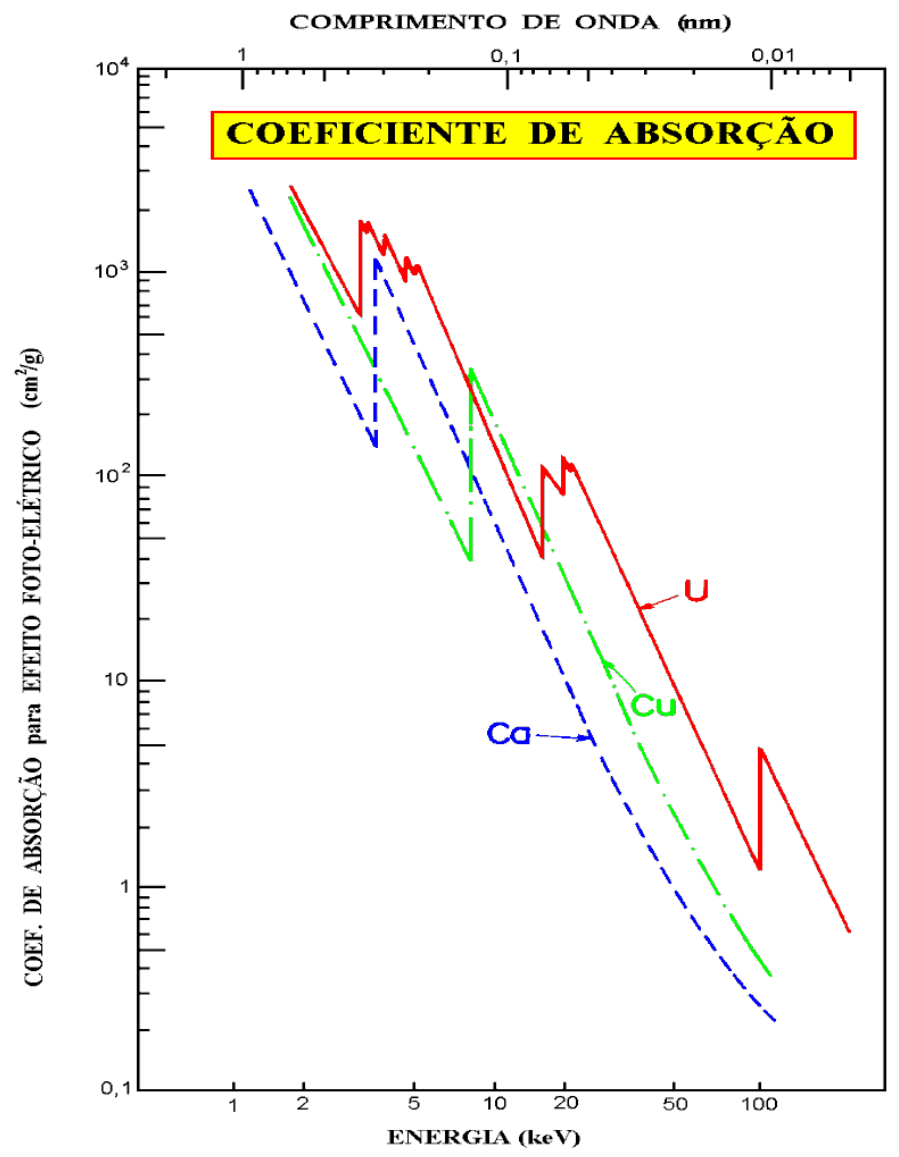

Figura 2.8 - Dependência do coeficiente de absorção de massa em função da energia, para os elementos cálcio, cobre e urânio (NASCIMENTO FILHO, 1999)

A probabilidade $P_{2}$ da radiação de excitação produzir uma vacância nos átomos de um elemento de interesse contidos na espessura $d x$, com consequente produção de raios $X$ característicos, é dada por: 
(Eq. 7)

$$
P_{2}=\tau . w \cdot\left(1-\frac{1}{j}\right) \cdot f \cdot \rho \cdot d x
$$

onde $\tau$ é o coeficiente de absorção de massa para o efeito foto-elétrico do elemento de interesse na energia de excitação, $w$ é o rendimento de fluorescência da camada $\mathrm{K}, j$ é a razão de salto (jump ratio) da camada $\mathrm{K}$ para L, $f$ é fração de fótons $\mathrm{K}$ emitidos como raios $\mathrm{X} K_{\alpha}$, característicos, e $\rho$ é a "densidade", ou concentração do elemento de interesse em base de volume na espessura $d x$.

O coeficiente de absorção para o efeito foto-elétrico exatamente na energia da borda de absorção (figura 2.8) tem dois valores: um superior, que indica a probabilidade de se retirar elétrons de todas as camadas $K, L, M$, etc., e um inferior, que indica a probabilidade de se retirar elétrons de todas as camadas, com exceção da camada K (ou seja, camadas L, M, etc.).

Desse modo, a razão entre os valores superior e inferior, denominada de razão de salto ou jump ratio (figura 2.9) indica a probabilidade de se retirar elétrons de todas as camadas em relação à probabilidade das camadas $L, M$, etc. Por outro lado, o termo $(1-1 / j)$ representa a probabilidade de se ionizar a camada $\mathrm{K}$ em relação a todas as camadas $\mathrm{K}, \mathrm{L}, \mathrm{M}$, etc., e assim o termo $\tau .(1-1 / j)$ representa o número de ionizações ocorridas na camada K.

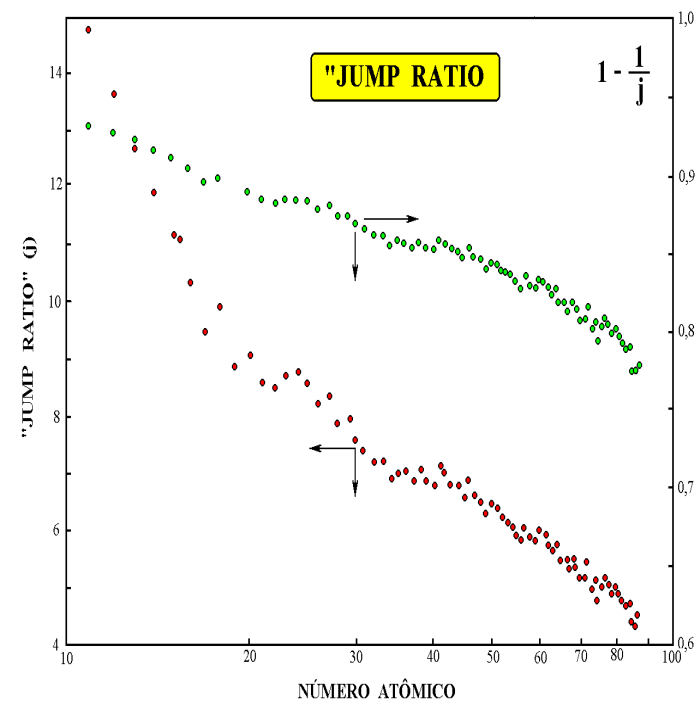

Figura 2.9 - Valores da razão de salto (jump ratio) em função do número atômico (NASCIMENTO FILHO, 1999) 
Os parâmetros fundamentais $\tau, w, j$ e $f$ para um dado elemento dependem unicamente da energia de excitação e podem ser agrupados em um único termo $K$, denominado de constante dos parâmetros fundamentais, e assim a equação 7 pode ser reescrita como:

(Eq. 8)

$$
P_{2}=K \cdot \rho \cdot d x,
$$

onde:

(Eq. 9)

$$
K=\tau \cdot w \cdot\left(1-\frac{1}{j}\right) \cdot f
$$

A probabilidade $P_{3}$ do raio $\mathrm{X} K_{\alpha}$ característico produzido na camada $d x$ não ser absorvido na espessura $x$ e atingir o detector, produzindo um pulso eletrônico (ou uma contagem), é dada por:

$$
P_{3}=\varepsilon \cdot e^{-\mu \cdot \rho_{0} \cdot x / \operatorname{sen} \theta},
$$

onde, $\varepsilon$ é a eficiência do detector na energia dos fótons característicos, $\mu$ é o coeficiente de absorção de massa da matriz, e $\theta$ é o ângulo de emergência.

A eficiência $\varepsilon$ do detector pode ser calculada teoricamente a partir das dimensões dos componentes do detector (camadas ativa e morta de $\mathrm{Si}$, camada de ouro, janela de $\mathrm{Be}$, etc.) especificados pelo fabricante, distância entre a amostra e detector, e condições de excitação (sob vácuo, ar ou gás hélio).

Assim, a intensidade fluorescente $d I$ (ou a taxa de contagem) produzida pelo elemento de interesse contido na espessura $d x$ pode então ser escrita como:

$$
d I=G \cdot e^{-\mu_{0} \cdot \rho_{0} \cdot x / \operatorname{sen} \theta_{0}} \cdot \tau \cdot w \cdot\left(1-\frac{1}{j}\right) \cdot f \cdot \rho \cdot d x \cdot \varepsilon \cdot e^{-\mu \cdot \rho_{0} \cdot x / \operatorname{sen} \theta},
$$


onde a variável $G$, denominada de fator de geometria, é uma constante de proporcionalidade e depende da geometria do sistema de excitação-detecção, da corrente do tubo ou da atividade da fonte, etc., mas não do próprio elemento de interesse.

Esta última equação pode ser reescrita como:

$$
d I=G \cdot e^{-\left(\mu_{0} / \operatorname{sen} \theta_{0}+\mu / \operatorname{sen} \theta\right) \rho_{0} \cdot x} \cdot \tau \cdot w \cdot\left(1-\frac{1}{j}\right) \cdot f \cdot \rho \cdot \varepsilon \cdot d x
$$

Definindo-se o coeficiente de absorção de massa total $\chi$ como:

$$
\chi=\frac{\mu_{0}}{\operatorname{sen} \theta_{0}}+\frac{\mu}{\operatorname{sen} \theta}
$$

e utilizando-se a equação 9, pode-se rescrever a equação 12 na forma:

$$
d I=G \cdot \varepsilon \cdot K \cdot e^{-\chi \cdot \rho_{0} \cdot x} \cdot \rho \cdot d x
$$

Integrando a equação 14 ao longo da espessura total da amostra, $D$, obtem-se a intensidade fluorescente $I$ para um dado elemento de interesse:

$$
I=G \cdot \varepsilon \cdot K \cdot \rho \cdot \frac{1-e^{-\chi \cdot \rho_{0} \cdot D}}{\chi \cdot \rho_{0}}
$$

A razão $\rho / \rho_{0}$ representa a "densidade" do elemento de interesse em relação à densidade da matriz e, portanto, é a própria concentração $C$ do elemento de interesse na amostra, ou seja, a concentração fracional do elemento em base de massa. Sendo assim:

$$
I=G \cdot \varepsilon \cdot K \cdot C \cdot \frac{1-e^{-\chi \cdot \rho_{0} \cdot D}}{\chi}
$$

Tomando-se:

(Eq. 17)

$$
S=G . \varepsilon . K,
$$


onde $S$ representa a sensibilidade do espectrômetro de raios $\mathrm{X}$ para $\mathrm{o}$ elemento de interesse. Desta forma a equação 16 pode ser escrita como:

(Eq. 18)

$$
I=S . C . \frac{1-e^{-\chi . \rho_{0} . D}}{\chi}
$$

Em alguns casos, ao invés de se referir à concentração $C$ do elemento em base de massa, prefere-se referir à densidade superficial $c$ do elemento na amostra, ou seja:

(Eq. 19)

$$
c=\frac{C}{\rho_{0} . D}
$$

e portanto a equação 18 pode ser reescrita na forma:

(Eq. 20)

$$
I=S . c . \frac{1-e^{-\chi \cdot \rho_{0} . D}}{\chi \cdot \rho_{0} \cdot D}
$$

A razão apresentada na equação 20 é denominada de fator de absorção A para o elemento de interesse:

(Eq. 21)

$$
A=\frac{1-e^{-\chi \cdot \rho_{0} \cdot D}}{\chi \cdot \rho_{0} \cdot D},
$$

e desse modo a equação 20 pode ser reescrita na forma:

$$
I=S . c . A
$$

Uma representação esquemática da dependência entre estas variáveis é mostrada na figura 2.10. Como mencionado no início deste item, foi apresentado um modelo para os raios $X$ característicos da camada $K$, especificamente para a linha $K_{\alpha}$. De maneira análoga, as mesmas equações podem ser obtidas para as linhas $L_{\alpha}$, onde logicamente, os parâmetros fundamentais terão outros valores. 


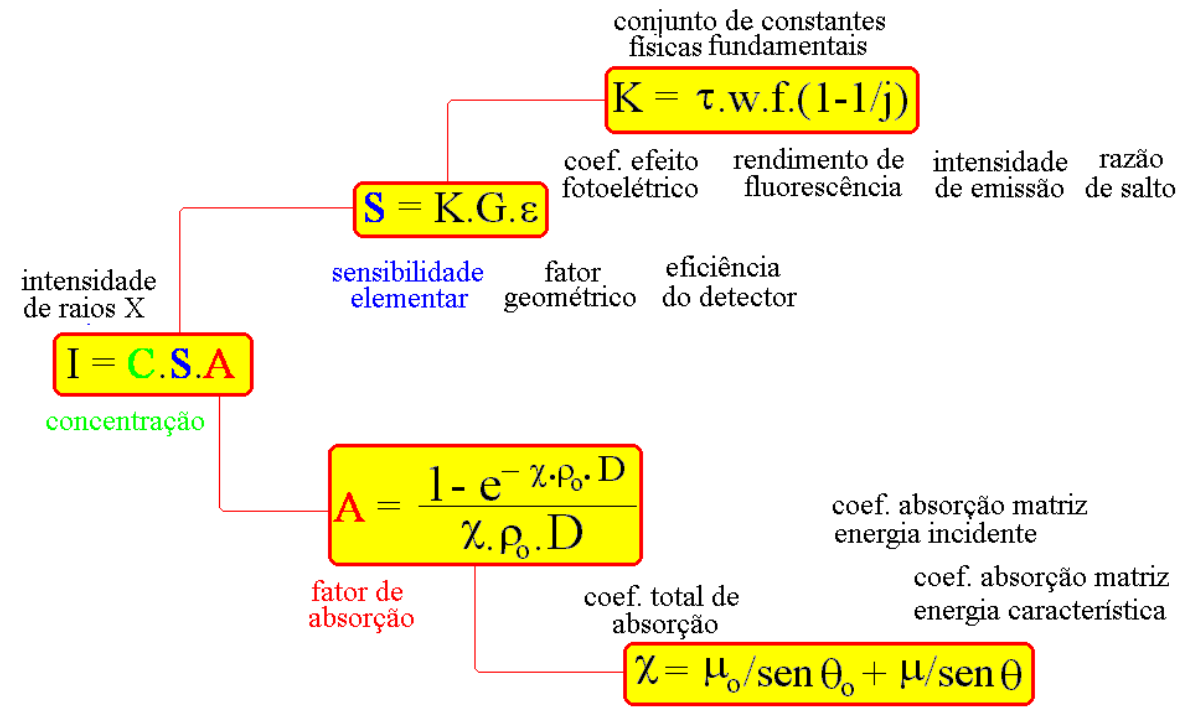

Figura 2.10 - Representação esquemática das dependências entre as variáveis na equação fundamental de fluorescência de raios X para feixe monoenergético (NASCIMENTO FILHO, 1999)

Deve ser ressaltado que para amostras consideradas finas, o termo $\chi \cdot \rho_{0} . D$ tende a zero, e o termo $e^{-\chi \cdot \rho_{0} \cdot D}$ tende a ${ }_{1-\chi \cdot \rho_{0} D}$. Logo, nestas condições, o fator de absorção tem valor unitário:

(Eq. 23)

$$
\text { Amostra fina } \rightarrow \quad \mathrm{A}=1
$$

No extremo oposto, ou seja, para amostras consideradas espessas, o termo $\chi \cdot \rho_{0} . D$ tende a infinito, e o termo $\circ e^{-\chi \cdot \rho_{0} \cdot D}$ tende a zero. Nestas condições, o fator de absorção assume o valor:

$$
\text { Amostra espessa } \rightarrow \quad A=\frac{1}{\chi \cdot \rho_{0} \cdot D}
$$

O levantamento da curva de sensibilidade elementar pode ser feito utilizando-se padrões de espessuras finas. Neste caso, pode-se calcular o fator de absorção A para estes padrões, pela equação 21, e com base na medida da taxa de contagem $I$ pode-se estimar a sensibilidade elementar $S$ pela equação 18 ou 20.

Por outro lado, a sensibilidade elementar $S$ é relacionada aos parâmetros fundamentais $K$ e à eficiência de detecção $\varepsilon$ através de uma 
constante elementar independente, chamada de fator de geometria $G$, como mostra a equação 17 , que pode ser reescrita na forma:

(Eq. 25)

$$
G=\frac{S}{\varepsilon \cdot K}
$$

Este fator de geometria deve permanecer constante para todas as energias, e desse modo, pode-se obter um fator de geometria médio, a ser utilizado posteriormente nas análises quantitativas.

\subsubsection{Equipamento}

\subsection{Detectores de Si-PIN e SDD}

Para observarmos os raios $\mathrm{X}$ característicos produzidos por uma amostra, precisamos ser capazes de detectá-los. Para isso se faz uso de um detector de raios $X$. Os detectores utilizados nesse estudo foram semicondutores de silício dopados do tipo Si-PIN e SDD (Silicon Drift Diode). Os detectores de semicondutores dopados, como o de $\mathrm{Si}(\mathrm{Li})$, utilizam refrigeração por criogenia. Com o desenvolvimento da refrigeração eletrônica por efeito Peltier, foi possível a redução das dimensões dos detectores utilizados na detecção de fótons na faixa energética dos raios $X$, tornando-os portáteis. Um exemplo dessa aplicação é o detector de diodos Si-PIN portáteis, que utiliza os mesmos conceitos de detecção de radiação que os detectores de $\mathrm{Si}(\mathrm{Li})$ (PANTAZIS et al., 1994).

Um fotodiodo convencional de Si-PIN é esboçado na figura 2.11 (AMPTEK, 2014). Há dois contatos planos, o ânodo e o cátodo, com um campo elétrico uniforme entre eles. Um fóton interage em algum local, ionizando os átomos de silício e produzindo pares elétron-buraco. O campo elétrico leva as cargas para seus respectivos contatos, causando um pulso transiente de corrente $I(t)$ neste diodo. O cátodo é conectado a um pré-amplificador, um amplificador e a um processador de pulso eletrônico que mede o pulso e sua amplitude. 


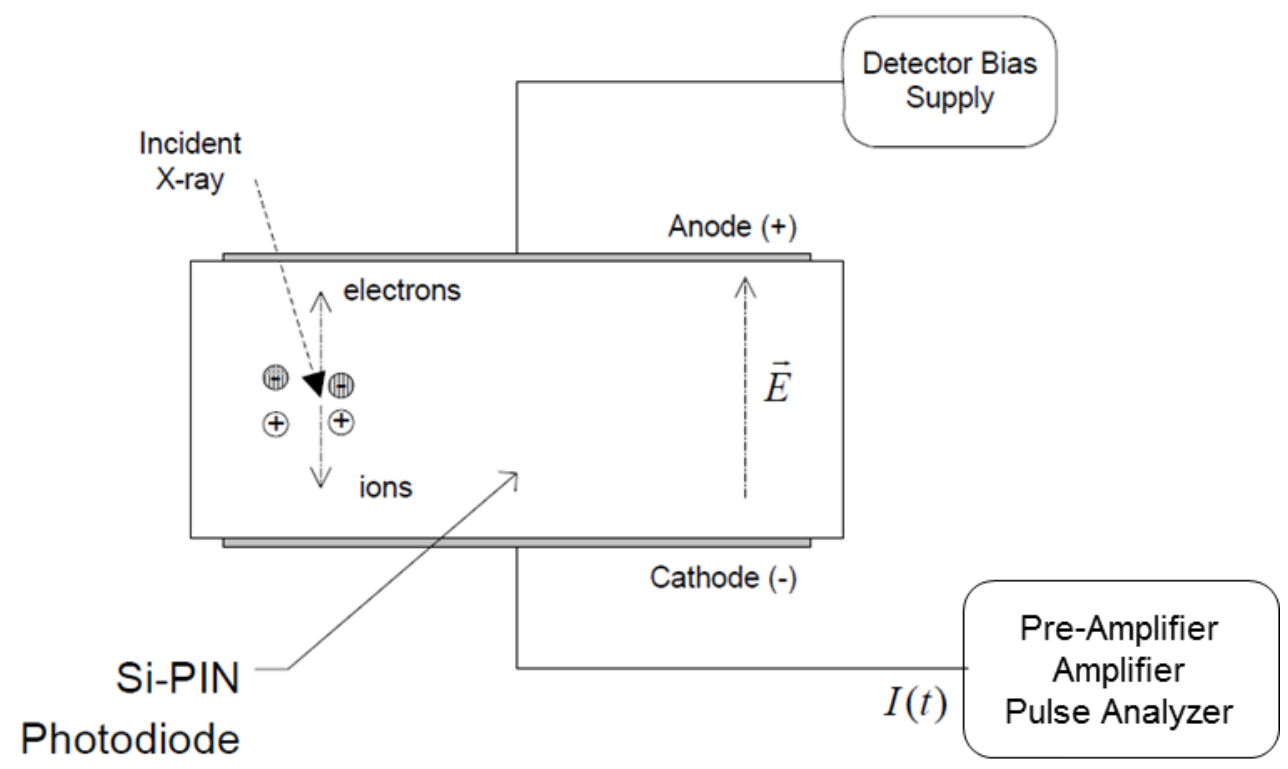

Figura 2.11 - Esboço ilustrando o funcionamento de um fotodiodo convencional (modificado de AMPTEK, 2014)

Outro detector do tipo fotodiodo recentemente desenvolvido para melhorar o desempenho de detecção é o SDD, esboçado na figura 2.12. Este detector utiliza um cátodo plano e um ânodo pequeno cercado por uma série de eletrodos. O detector SDD possui simetria cilíndrica, de modo que o ânodo é um pequeno círculo e os eletrodos são concêntricos anelares. Estes eletrodos são polarizados criando um campo elétrico que guia os elétrons através do detector até o ânodo. O resto do sistema eletrônico de processamento de sinal é praticamente idêntico ao utilizado no detector de Si-PIN. 


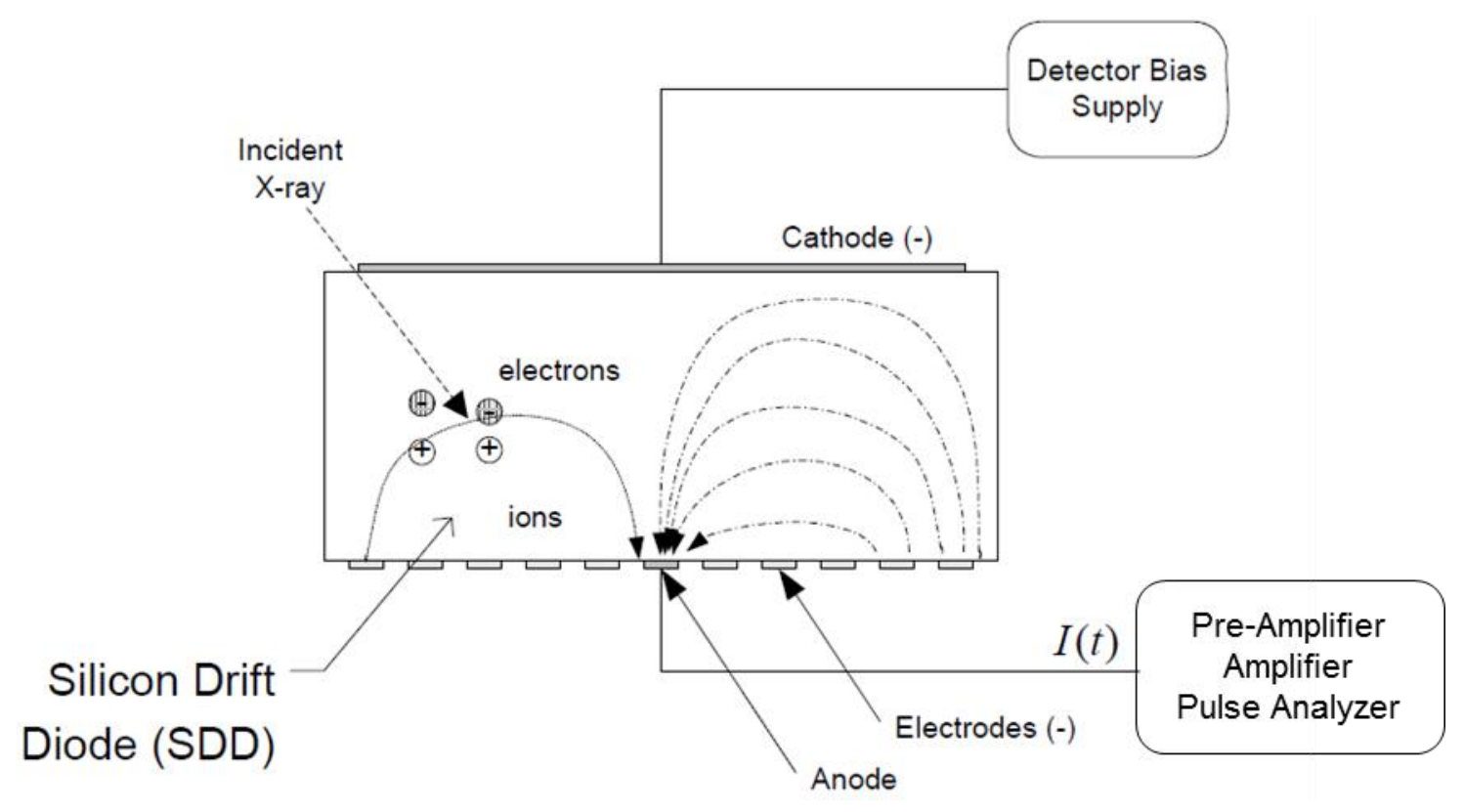

Figura 2.12 - Esboço ilustrando o funcionamento do detector de SDD (modificado de AMPTEK, 2014)

As diversas espessuras da janela de Be e do cristal determinam a curva de eficiência de detecção, conforme mostrado nas figuras 2.13 e 2.14 (AMPTEK, 2014).

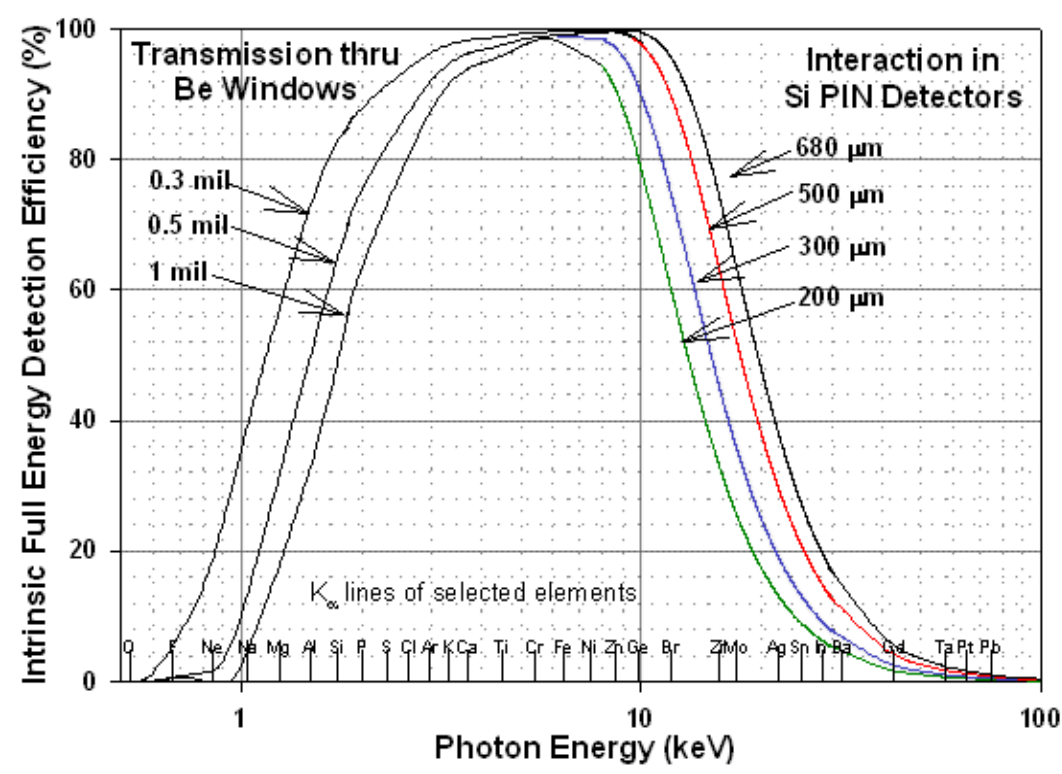

Figura 2.13 - Curvas de eficiência intrínseca de um detector de Si-PIN (AMPTEK, 2014) 


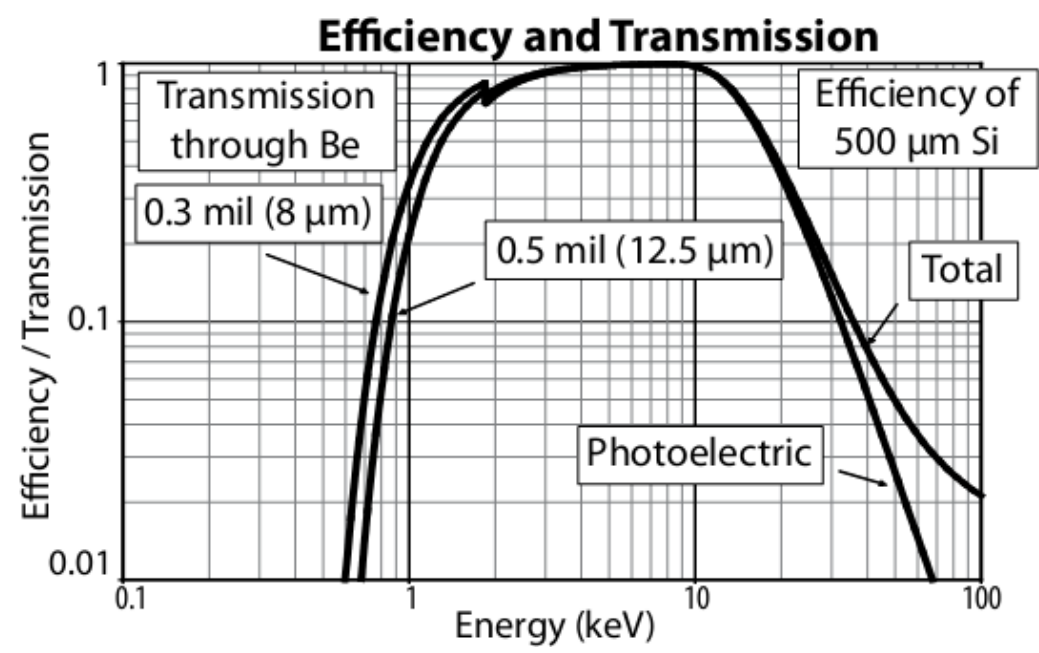

Figura 2.14 - Curvas de eficiência intrínseca de um detector de SDD (AMPTEK, 2014)

O SDD possui uma melhor resolução de energia do que um Si-PIN para detectores com a mesma área, como pode ser visto na figura 2.15. O SDD tem resolução de energia muito melhor quando se utiliza tempos curtos de formação de pulso, o que é bastante útil em altas taxas de contagem. O Si-PIN possui modelos com uma área ativa maior e profundidade de depleção mais espessa, assim, possui modelos com maior eficiência de detecção.

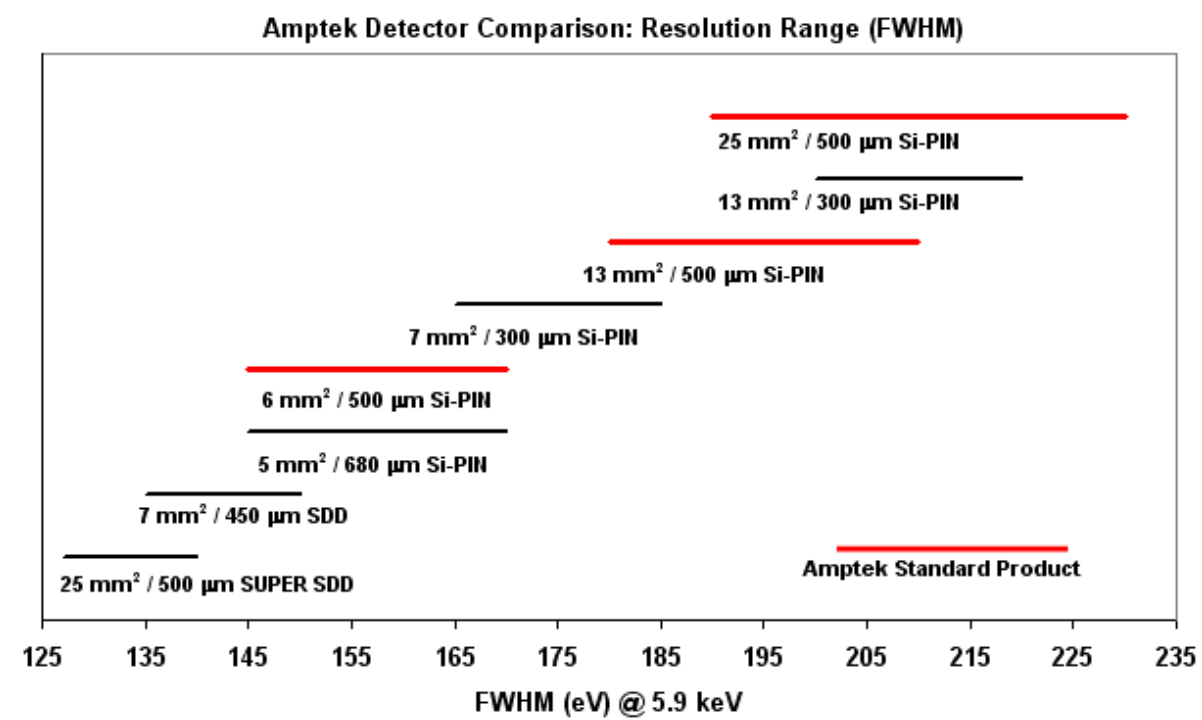

Figura 2.15 - Distribuição da resolução dos detectores SDD e Si-PIN (site do fabricante AMPTEK, 2014)

\subsection{Tubo de Raio $X$}

Algumas das técnicas utilizadas neste estudo se valem da excitação por raios $X$ do material a ser analisado, necessitando assim de uma fonte de raios $X$ capaz de gerar a radiação necessária. Como fonte, o tubo de raios $X$, tem 
como princípio a produção de elétrons livres, gerados a partir de um filamento aquecido (que servirá também como cátodo). Estes elétrons são acelerados, por uma diferença de potencial, em direção a um alvo (ânodo). Quando o feixe de elétrons proveniente do cátodo é desacelerado no alvo, raios $X$ de energia contínua (radiação de Bremsstrahlung) são emitidos. A máxima energia (em $\mathrm{keV}$ ) será correspondente à voltagem do tubo $(\mathrm{kV})$. Além disso, há a produção de raios $X$ característicos vindos do material que compõem o ânodo, devido à ionização dos átomos das camadas mais internas. A figura 2.16 mostra 0 espectro gerado pelo tubo de ânodo de Ag utilizado neste estudo para as análises de EDXRF, onde podem ser observadas as linhas características 22,2 keV (linha K $\alpha$ ) e 24,9 keV (linha K $\beta$ ) e o fundo de breemstralung presente.

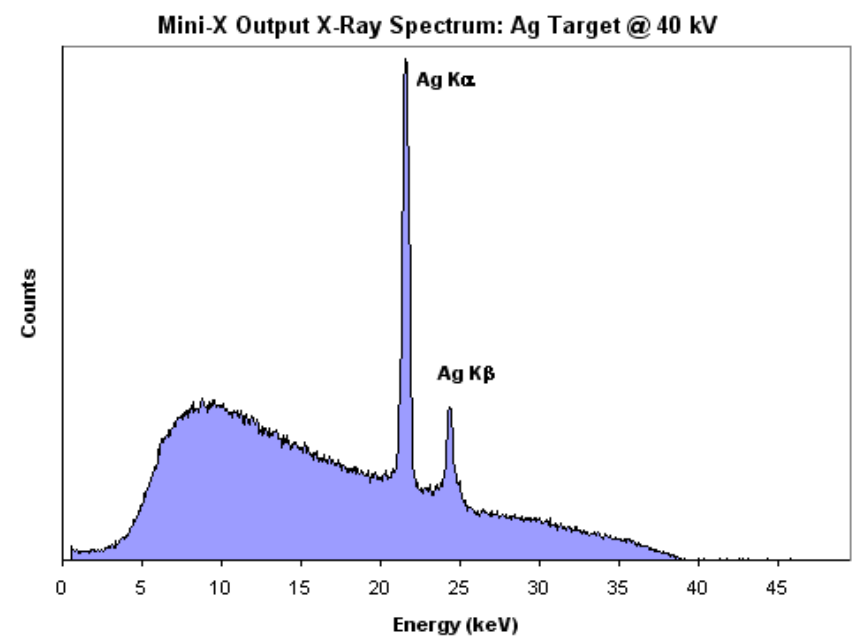

Figura 2.16 - Espectro de raio $X$ do tubo Mini-X com ânodo de prata da Amptek com $40 \mathrm{kV}$ de voltagem (AMPTEK, 2014)

\subsection{Imageamento}

\subsubsection{Teoria da Cor}

Há séculos a luz tem intrigado os seres humanos e sido objeto de estudos intensivos pela ciência e pesquisadores de várias áreas. Embora os fenômenos óticos que existem na natureza não tenham ligação com as observações humanas, os estudos realizados e consequentemente, as técnicas utilizadas na detecção e produção artificial de luz estão intimamente ligados à fisiopsicologia humana. 
Um dos primeiros estudos na ótica foi realizado por Willebrord van Snel van Royen, que em 1621 descobriu a lei da refração, descrita no grande tratado de Christiaan Huygens, "Treatise on Light", de 1690, onde uma simples relação trigonométrica descreve a relação entre um raio de luz que incide sobre outro meio e é refratado (LONGAIR, 1995), figura 2.17.

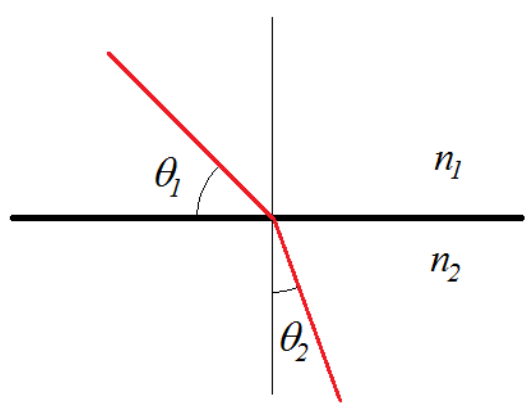

Figura 2.17- Esquema ilustrativo da luz incidindo sobre outro meio e refratada

(Eq. 26)

$$
n_{1} \sin \theta_{1}=n_{2} \sin \theta_{2}
$$

Onde n1 e n2 são constantes, chamadas de índice de refração do meio

Em 1665-1666, em sua reclusão, durante a Grande Praga, Isaac Newton desenvolve a teoria das cores em óptica, além do teorema binomial, o cálculo diferencial e integral, a unificação da mecânica celestial e a teoria da gravitação universal. Em seus experimentos em ótica, Newton utiliza um prisma ótico para decompor a luz do Sol, denominado por Newton como "experimentum crucis", figura 2.18. 

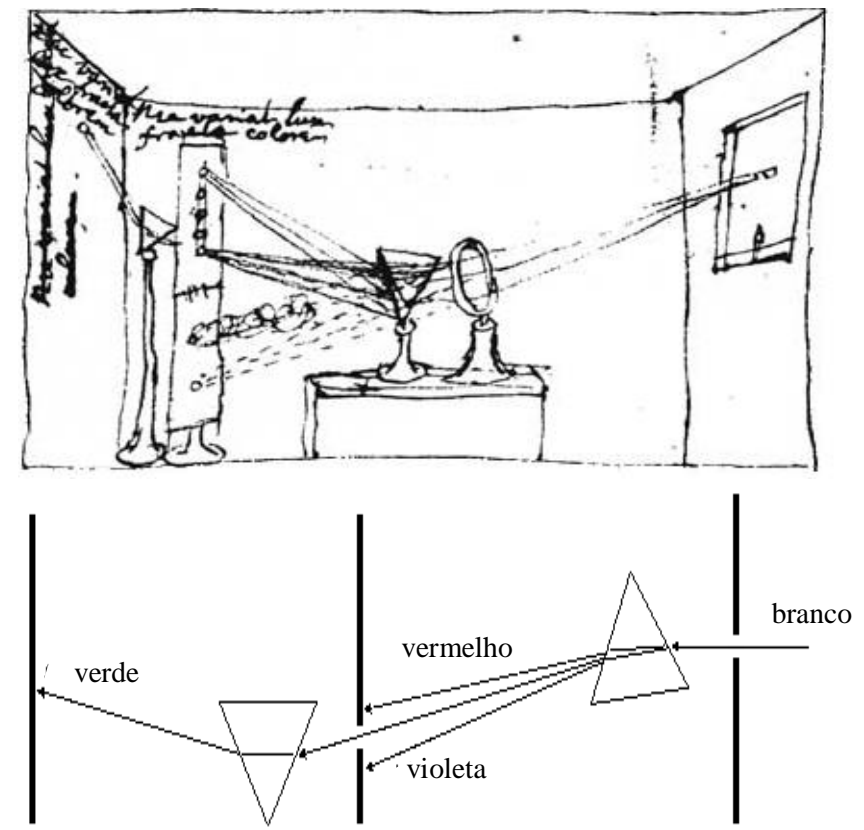

Figura 2.18 - Acima temos o rascunho do "experimentum crucis" de Newton (LONGAIR, 1995); abaixo temos uma representação esquemática do experimento

Neste experimento, foi demostrado que a luz branca do Sol pode ser decomposta nas sete cores do arco-íris, após passar em por um prisma. Neste experimento, dentre as cores decompostas, Newton seleciona uma única cor e a faz passar por um segundo prisma. Mas ao contrário do primeiro prisma, esta luz selecionada não foi decomposta. Isto fez Newton acreditar que a cor branca é composta pelas sete cores do arco-íris, assim, a luz branca seria uma união de todas as cores do espectro.

Mas foi Christiaan Huygens, em seu "Treatise on Light", de 1690, que propôs que a luz viajava na forma de onda, da sua fonte até o observador, no qual cada ponto de uma frente de onda poderia ser considerado uma nova fonte de novas ondas, com a mesma frequência da original, o que permitiu uma explanação dos fenômenos de reflexão e refração da luz.

Em 1802, Thomas Young postulou a existência de três tipos de fotorreceptores no olho (agora conhecidas como células cone), cada uma das quais era sensível a uma determinada faixa de luz visível (YOUNG, 1802). Em 1850, Hermann von Helmholtz desenvolveu a teoria que os três tipos de cones fotorreceptores poderiam ser classificados como: preferência curta (azul), preferência média (verde) e preferência longa (vermelho), de acordo com a 
resposta aos comprimentos de onda de luz que atingem a retina (CAHAN, 1993).

Inspirados nestas teorias, em 1855, James Clerk Maxwell, realizou um experimento buscando comprová-la, que foi chamada de "caixa de luz de Maxwell”, figura 2.19. Nesta caixa Maxwell compara uma luz branca natural do Sol com a luz branca composta pela soma de três diferentes cores (vermelha, verde e azul), que entram pelo ponto $B$, onde a abertura pode ser regulada $e$ escolhida a quantidade de luz de entrada de cada cor. Desta forma, foi possível desenvolver uma teoria quantitativa da visão por três cores, possibilitando determinar a quantidade necessária de cada uma das três cores na composição de cada cor.
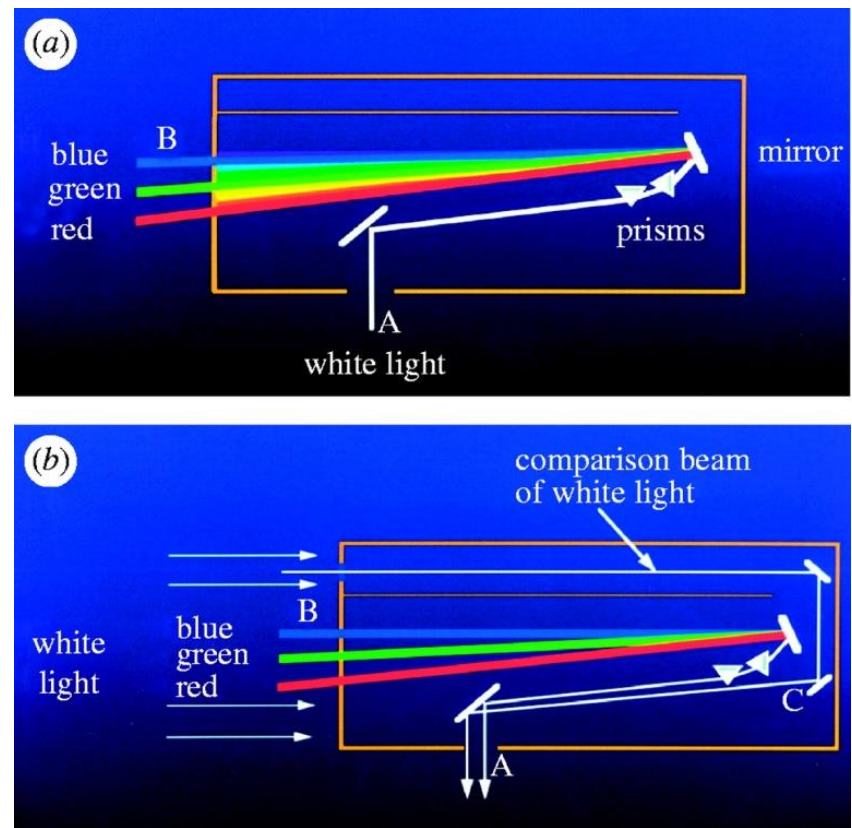

Figura 2.19- Caixa de luz de Maxwell, Newton (LONGAIR, 1995)

Os seres humanos tem sua percepção de cor baseada na combinação dos estímulos gerados em cada uma dos três tipos fotorreceptores celulares (células cones). A sensibilidade de cada cone somada à capacidade de interpretação cerebral do estimulo gerado nos dá uma divisão da sensibilidade humanas a luz para três regiões, como podem ser vistas na figura 2.20. A soma da capacidade receptivas destes três tipos de células permite que os seres humanos reconhecerem tipicamente a faixa do espectro eletromagnético entre 370 e 750 nm (SÈVRE, 1996), figura 2.21. 

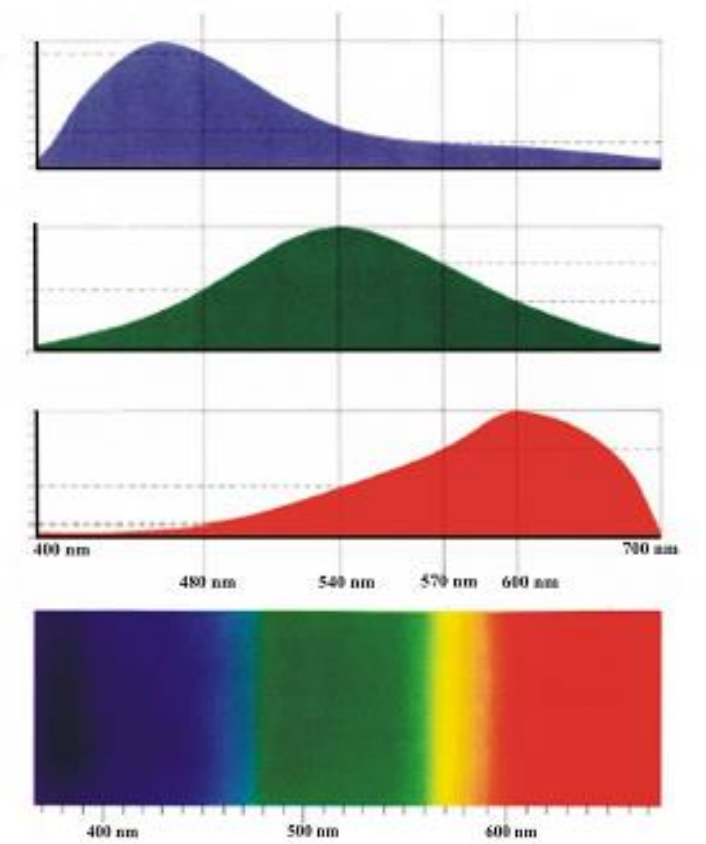

Figura 2.20 - Capacidade receptiva das células da retina humana (GRANDIS, 1986)

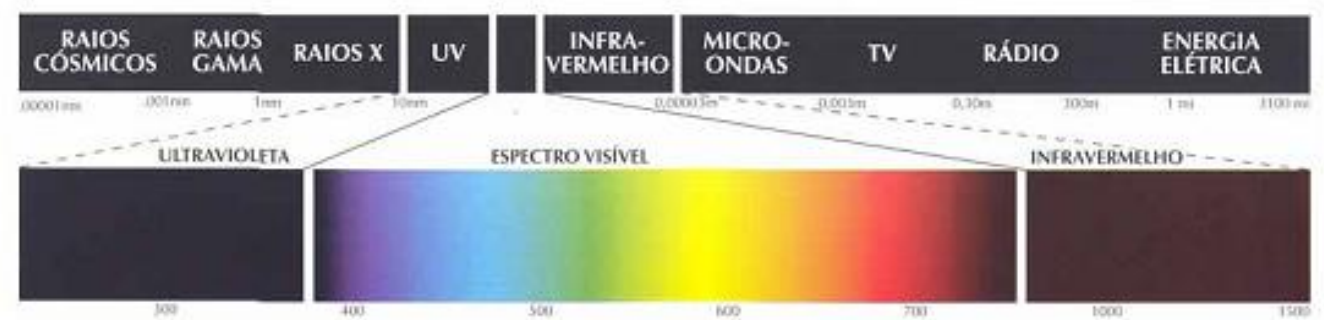

Figura 2.21 - Espectro eletromagnético entre 370 e 750 nm - (TRUSSEL, ELI e VRHEL, 2005)

As cores que os seres humanos são capazes de reconhecer podem ser geradas pela combinação das três cores primárias: vermelho $(\mathrm{R}$, red), verde (G, green) e Azul (B, blue), a chamada tricromaticidade. A Comissão Internacional de lluminação (CIE, Commission Internationale de l'Éclairage), padronizou que os comprimentos de onda das cores primárias são: 435,8 nm (azul), 546,1 nm (verde) e $700 \mathrm{~nm}$ (vermelho) (HUNT, 2004). Da soma de duas destas cores primárias, obtemos as cores secundárias. A soma das três cores primárias, ou a soma de uma cor secundária com a cor primaria oposta dará a luz branca. Em se tratando de pigmentos, as cores primárias são o ciano (C), o magenta (M) e o amarelo ( $\mathrm{Y}$, yellow), ou cores primárias subtrativas (CMY). Suas cores secundárias são verde, vermelho e azul. O modelo CMY é a base do processo de impressão em quatro cores (contando com a cor preta como pigmento, "key", CMYK). A soma dos três pigmentos de cores primárias dará o preto, como podem ser vistos na figura 2.22. 
Mistura de Pigmentos

(Primária subtrativas)

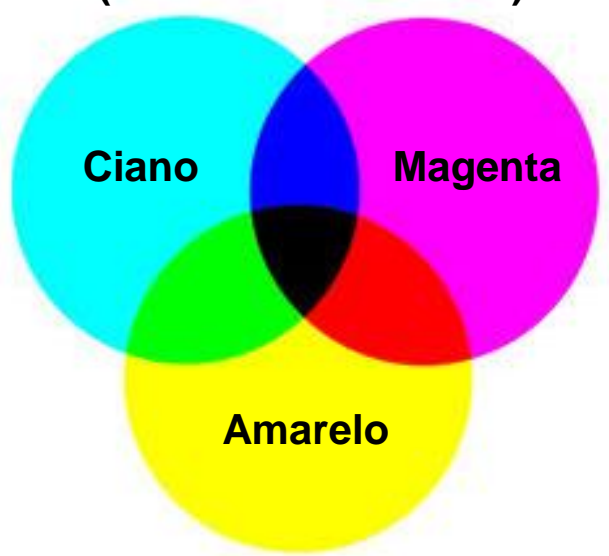

Mistura de Cores

(Primária aditivas)

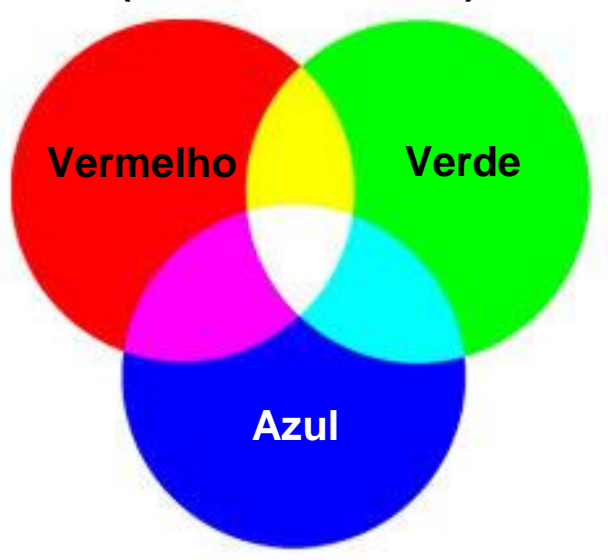

Figura 2.22 - Representação esquemática da mistura de cores e da mistura de pigmentos

As cores dos pigmentos são governadas pela absorção diferenciada dos comprimentos de ondas. Quando se incide uma luz branca sobre o material, a absorção acontece tanto na superfície das partículas quanto dentro delas, ou ambas, dependendo da opacidade da partícula. As múltiplas reflexões e espalhamentos dentro do material causam sucessivas absorções de uma parte ou outra do espectro incidente, assim, a luz emergente colorida. A profundidade da cor da superfície depende de quanto a luz incidente penetrou no material, e isso será definido pelas dimensões, estrutura e índice de refração das estruturas que compõem o material (WRIGHT, 1958), uma ilustração do feixe de luz penetrando nas camadas de pigmentos pode ser observada na figura 2.23 .

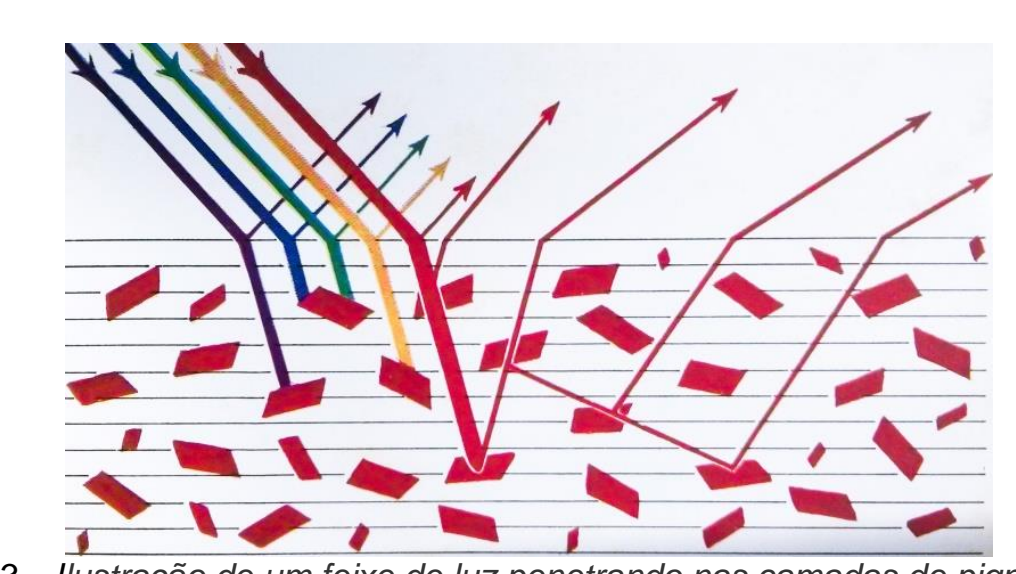

Figura 2.23 - Ilustração de um feixe de luz penetrando nas camadas de pigmentos e as possiblidades de absorção, espalhamento e reflexão da luz neste material (WRIGHT, 1958) 
Outra grande contribuição de Maxwell na história da ciência está presente em seu artigo de 1865, onde estrutura matematicamente a representação e a teoria dos campos eletromagnéticos (MAXWELL, 1865), em consequência à sua formulação, pôde-se demonstrar que a luz se constituía de ondas eletromagnéticas, e foi possível inclusive deduzir sua velocidade no vácuo.

Em 1900, com base em seus estudos experimentais da radiação de corpo negro, Max Planck sugere que a única solução para resolver o problema que ficou conhecido como a catástrofe do ultravioleta, seria propor a quantização da luz, indo de encontro à toda a bibliografia sobre termodinâmica (PLANCK, 1900). Este estudo foi de fundamental importância para o desenvolvimento da física moderna e para o estudo e compreensão das fontes luminosas. Desta forma temos que (SÈVRE, 1996):

- Em qualquer temperatura, com exceção do zero absoluto, todo corpo emite uma radiação eletromagnética de espectro contínuo.

- Para uma dada temperatura e um dado comprimento de onda, a radiação não pode ultrapassar um valor máximo: radiação térmica ideal, ou radiação de Planck.

- Para um dado corpo, a luminescência energética da superfície só dependerá do comprimento de onda e da temperatura.

A lei de Planck é dada pela equação:

$$
L_{\varepsilon, \lambda}(\lambda, T)=\frac{c_{1}}{\pi} \lambda^{-5}\left[\exp \left(\frac{c_{2}}{\lambda \tau}\right)-1\right]^{-1}
$$

onde $L e, \lambda$ é a luminescência energética espectral, $\lambda$ o comprimento de onda de radiação, $\mathrm{T}$ a temperatura termodinâmica, $\mathrm{c} 1$ a primeira constante radiativa $\left(\mathrm{c}_{1} / \pi=1,191044 \cdot 10^{-16} \mathrm{~W} \cdot \mathrm{m}^{2} \cdot \mathrm{sr}^{-1}\right)$ e $\mathrm{c}_{2}$ a segunda constante radioativa (c1/ $\pi=1,438769.10^{-2} \mathrm{mK}$ ). Usando a lei de Planck, pode ser traçada a curva espectral para cada temperatura de um corpo negro, figura 2.24. Estes valores em Kelvin são associados ao termo "temperatura de cor", designado para caracterizar uma fonte de luz a partir do seu espectro luminescente. 


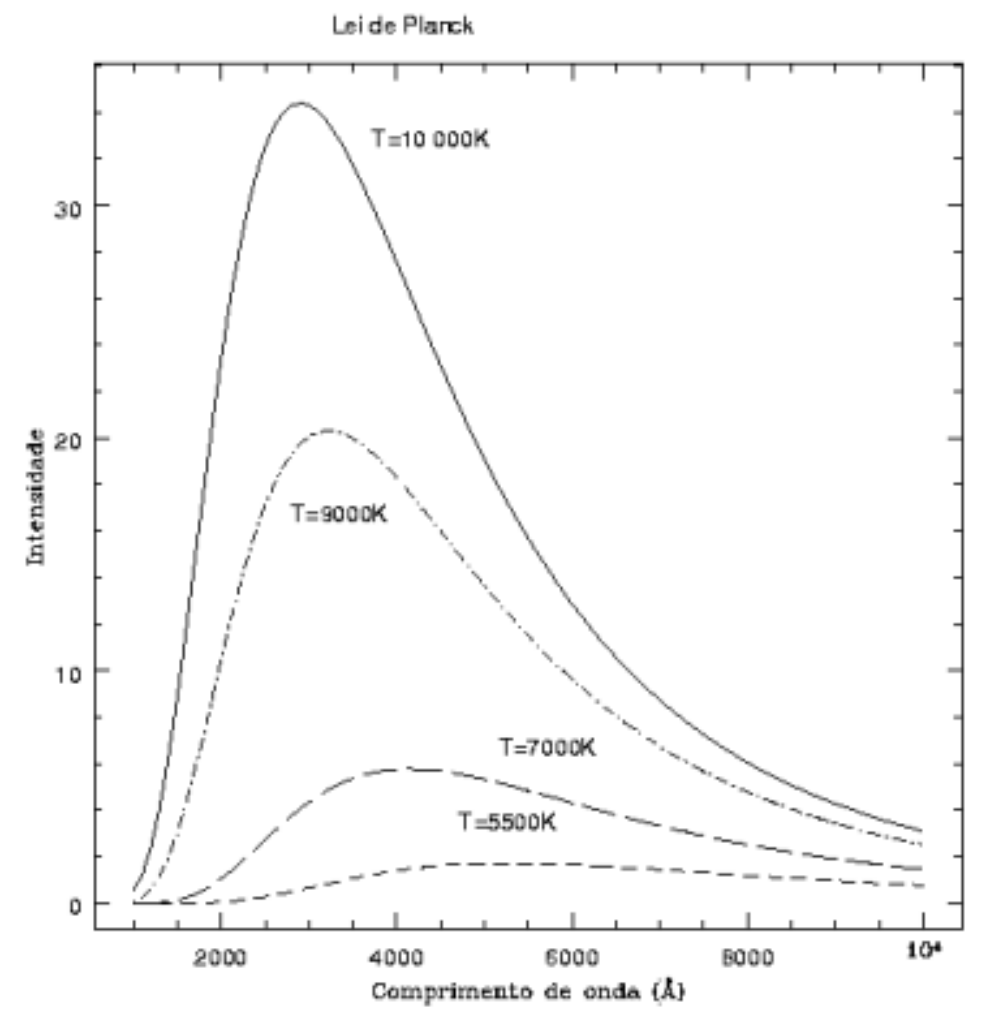

Figura 2.24 - Curva espectral para cada temperatura de um corpo negro com base na lei de Planck (GRANDIS, 1986)

A CIE (Commission Internationale de l'Éclairage) estabelece definições dos iluminantes padrões e as especificações para o observador padrão. Os lluminantes padrões são fontes de luz com curvas espectrais determinadas. $O$ Iluminante $D$ é o mais utilizado no gerenciamento de cores, sendo o D50 correspondente à temperatura de cor de $5000 \mathrm{~K}$ e o D65 a $6500 \mathrm{~K}$ (LEÃO, ARAÚJO e SOUZA, 2005).

Mas, em termos da tricromaticidade, para a composição das cores, temos o que se chama de espaço de cores (gamut), que é uma representação geométrica, tridimensional das possíveis combinações variadas das cores primárias. O RGB é um modelo de mistura, ou método de descrição de cores, usado em monitores coloridos e outros meios luminosos, que se valem da superposição de cores. Consiste na reprodução de cor, utilizando as três coresluz primárias (vermelha, verde e azul), em porcentagens variadas. Na figura 2.25 podemos observar a representação do espaço de cor para um destes dispositivos geradores de luz (LEITE, 2006). 


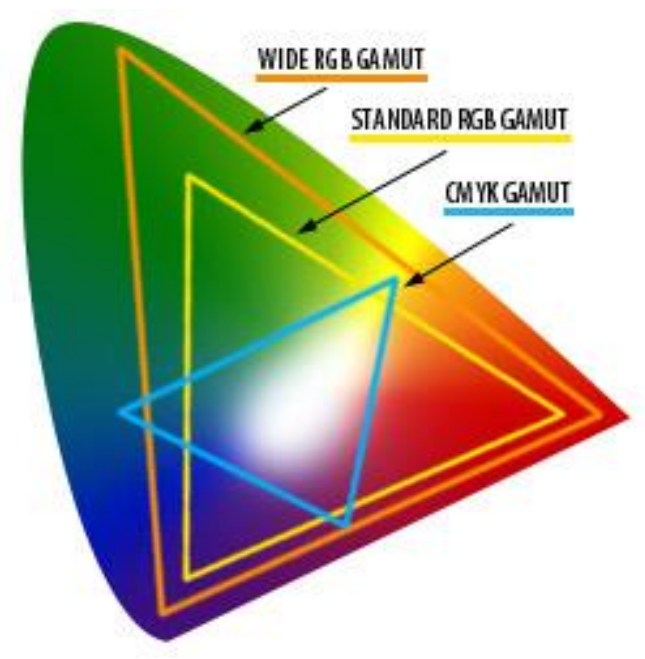

Figura 2.25 - Representação do espaço de cor para um tipo de dispositivo gerador de luz (WHITEHEAD, 2015)

\subsubsection{Modelo de Cor CIELAB}

Em 1976, o CIE apresentou e recomendou dois novos espaços (conhecido como CIELAB e CIELUV) cujas coordenadas são funções nãolineares de $X, Y$ e $Z$. A recomendação foi apresentada em uma tentativa de unificar a então muito diversificada prática em espaços de cores uniformes e diferentes fórmulas de cores associadas. Os valores numéricos que representam, aproximadamente, a magnitude das diferenças de cor podem ser descritos pelas simples distâncias euclidianas nos espaços ou por fórmulas mais sofisticadas que melhoram a correlação com o tamanho das diferenças percebidas. (CIE, 2015).

As três coordenadas do CIELAB representam a luminosidade da cor $\left(L^{*}=0\right.$ rendimentos preto $e L^{*}=100$ indica branca difusa; branco especular poderá ser mais elevado), a sua posição entre o vermelho/magenta e verde ( $\mathrm{a}^{*}$, valores negativos indicam o verde enquanto os valores positivos indicam 0 magenta) e a sua posição entre o amarelo e o azul ( $b^{*}$, os valores negativos indicam o azul e valores positivos indicam o amarelo).

O modelo de cor CIELAB permite a especificação de percepções de cores em termos de um espaço tridimensional. A componente axial $L$ é 
conhecida como luminosidade e se estende de 0 (preto) a 100 (branco). As outras duas coordenadas $a^{*}$ que se estende de -100 (azul) ao 100 (amarelo) e $b^{*}$ de -100 (verde) a 100 (vermelho), conforme a figura 2.26. O espaço de cores CIE $1976\left(\mathrm{~L}^{*} \mathrm{a}^{*} \mathrm{~b}^{*}\right)$ proporciona uma representação tridimensional para a percepção do estímulo de cores. Conforme aumenta a distância entre os dois pontos no espaço é razoável assumir que a diferença de cor percebida entre os estímulos representa aumentos correspondentes. Uma medida da diferença na cor entre dois estímulos é, portanto, proporcional à distância euclidiana entre os dois pontos no espaço tridimensional. O modelo CIELab é percebido mais linearmente que outros espaços de cores. Ele é também um espaço de cor absoluto, isto é, define exatamente as cores, ao contrário, por exemplo, do RGB ou do CMYK que dependem do recebimento de luz ou tinta, respectivamente.

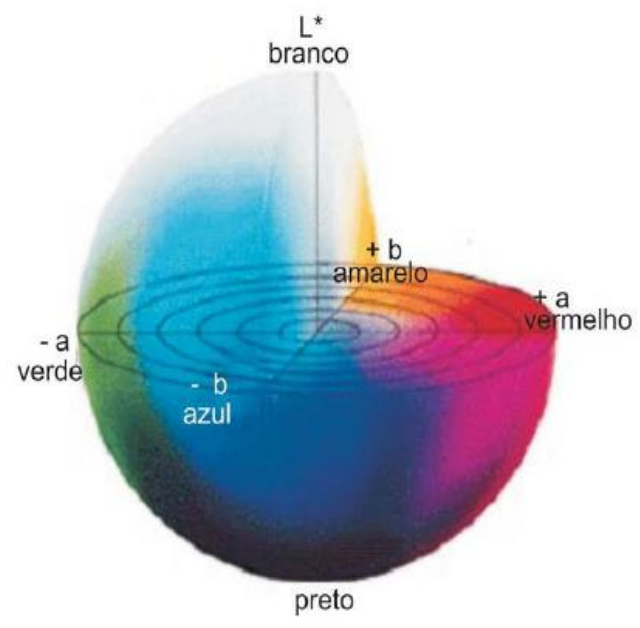

Figura 2.26 - Espaço de cores CIE 1976 (L*a*b*) (SILVA, PETTER e SCHNEIDER, 2007)

Diferenças de $\operatorname{cor}\left(\Delta \mathrm{E}^{*} \mathrm{ab}\right)$, que são importantes para avaliar relações visuais e numéricas (CIE, 1995), podem ser calculadas pela distância entre dois pontos no espaço tridimensional definido pelos parâmetros $a^{*}, b^{*}$ e $L^{*}$. Matematicamente, o parâmetro colorimétrico $\Delta \mathrm{E}$ é descrito pela equação 28 :

$$
\Delta E_{a b}^{*}=\sqrt{\left(\Delta L^{*}\right)^{2}+\left(\Delta a^{*}\right)^{2}+\left(\Delta b^{*}\right)^{2}}
$$


A tabela 2.1 mostra a classificação usada pela indústria de tintas em relação aos valores de $\Delta \mathrm{E}^{*}$ ab para a percepção do olho humano (DIN 6174, 1979).

Tabela 2.1 - Percepção humana para diferentes valores de $\Delta E^{*}$ ab empregada pela indústria de tintas (Norma DIN 6174, 1979)

\begin{tabular}{c|c}
\hline Diferenças $\left(\Delta \mathbf{E}^{*}{ }_{\mathrm{ab}}\right)$ & Classificação \\
\hline $0,0-0,2$ & Imperceptível \\
\hline $0,2-0,5$ & Muito pequena \\
\hline $0,5-1,5$ & Pequena \\
\hline $1,5-3,0$ & Distinguivel \\
\hline $3,0-6,0$ & Facilmente distinguivel \\
\hline Maior que 6 & Muito grande \\
\hline
\end{tabular}

\subsubsection{Interação da Luz com a Matéria}

Quando a luz incide na superfície de uma pintura é parcialmente absorvida e parcialmente espalhada. A parcela de luz que não é absorvida e nem espalhada pela superfície, penetra nas camadas de tinta (REAL, 1985), como pode ser observado na figura 2.27. A teoria ótica de Kubelka-Munk é necessária para compreender a interação da radiação, na faixa de energia do visível, ultravioleta e infravermelho, com os materiais que compõem as obras de arte, como vernizes, tintas, ligantes, etc. (WEINER, 1998). Na figura 2.27 temos a visualização esquemática do processo de interação da luz com a camada de pintura e com o suporte. O entendimento deste processo de interação é importante para descrever principalmente o processo desta nas diferentes faixas do espectro eletromagnético, particularmente no infravermelho, que apesar de ter baixa energia comparada com os raios $X$ auxilia na descoberta de desenhos ou inscrições existentes embaixo da camada pictórica. 


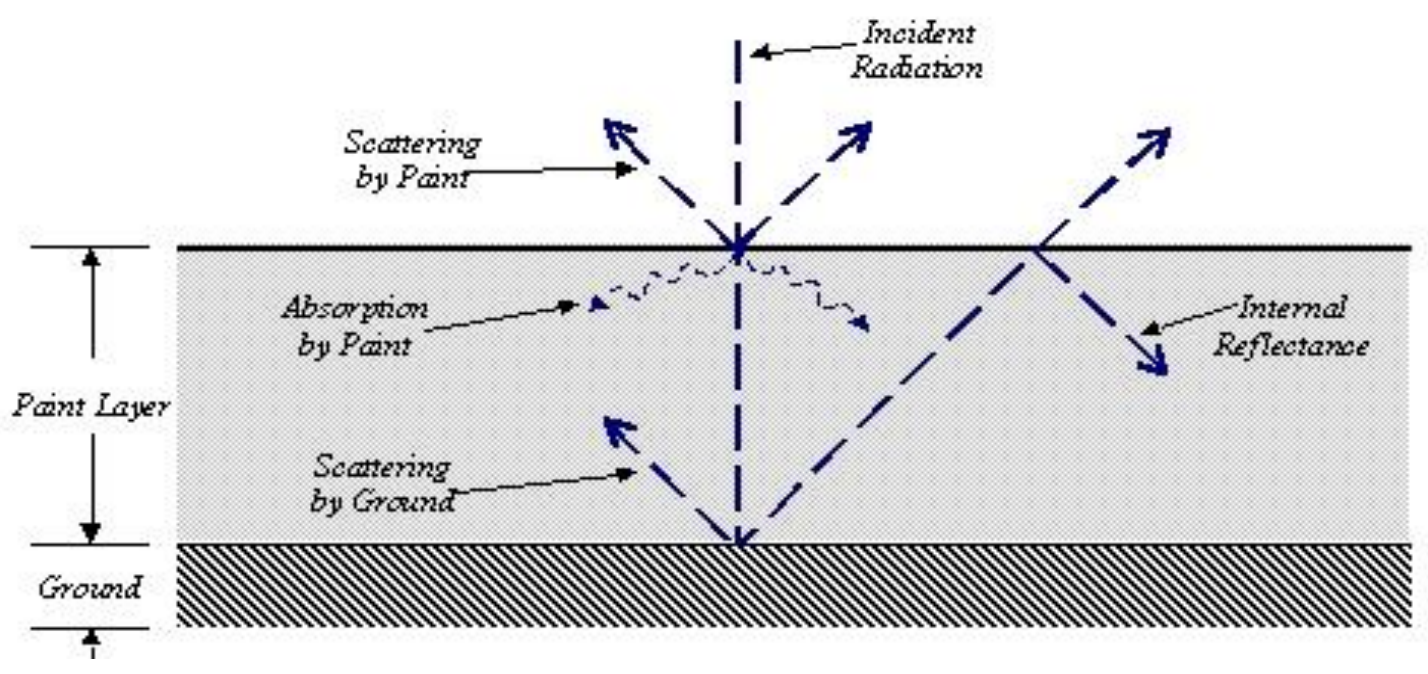

Figura 2.27 - A radiação da luz interagindo com a camada de pintura e o fundo (WEINER, 1998)

Usando o trabalho de Kubelka, a reflectância de uma camada de pintura uniforme $(R)$, de certa espessura $(X)$, pode ser encontrado utilizando a seguinte equação:

$$
R=\frac{1-R_{G} \cdot[a-b \cdot \operatorname{coth}(b \cdot S \cdot X)]}{a-R_{G}+b \cdot \operatorname{coth}(b \cdot S \cdot X)}
$$

onde a e b são definidos por:

$$
a=\frac{S+K}{S} \quad b=\sqrt{a^{2}-1}
$$

onde $R G$ é a reflectância de fundo, $S$ é o coeficiente de espalhamento da camada de tinta e K é o coeficiente de absorção (REAL, 1985).

Existem algumas limitações na teoria de Kubelka-Munk, uma vez que a teoria assume que a lei de decaimento exponencial é verdadeira, a refletância especular a partir do lado superior do limite de película não é considerada. Isto por sua vez significa que a teoria seria aplicável apenas se os pigmentos estiverem contidos num meio com o mesmo índice de refração do meio circundante (ASPEREN DE BOER, 1970). No entanto, uma vez que só é necessário encontrar uma aproximação da relação da espessura da camada de tinta para o comprimento de onda da radiação, a lei de Beer-Lambert não é relevante neste caso (BARNES, 1994). 
A lei de decaimento exponencial mostra a relação entre a transmissão de luz através de uma substância e a concentração desta substância, assim como também entre a transmissão e a longitude do corpo que a luz atravessa.

$$
A=\alpha l c
$$

$$
\begin{gathered}
\frac{I_{1}}{I_{0}}=e^{-\alpha l e} ; \alpha=\frac{4 \pi k}{\lambda} \\
A=-\log \frac{I_{1}}{I_{0}}
\end{gathered}
$$

onde A é a absorbância (ou absorvância), $I_{0}$ é a intensidade da luz incidente, $I_{1}$ é a intensidade da luz uma vez tendo atravessado o meio, lé a distância que a luz atravessa pelo corpo, $c$ é a concentração de sustância absorvente no meio, $\alpha$ é a absortividade molar da substância, $\lambda$ é o comprimento de onda do feixe de luz, $k$ é o coeficiente de extinção.

A lei da relação entre concentração e absorção de luz é a base do uso de espectroscopia para determinar a concentração de substâncias em química analítica. Por ela, podemos deduzir que a sensibilidade à interação com o meio é menor quanto maior for o comprimento de onda da luz incidente na substância, tendo o infravermelho uma penetração maior do que o ultravioleta,

Outra hipótese da teoria de Kubelka-Munk, é que existe uniformidade dos coeficientes de dispersão e absorção por toda a camada de tinta, o que raramente ocorre nas pinturas. O coeficiente de absorção e o coeficiente de dispersão estão ambos relacionados com a razão pigmento/médium, ou a concentração do pigmento em volume. Uma dificuldade observada é que geralmente, os pigmentos, quando moídos a mão, não apresentam uniformidade em tamanho. Entretanto, várias influências, tais como os índices de refração do meio e a necessidade de uniformidade do tamanho da partícula, podem ser desconsideradas uma vez que a relação entre a espessura e comprimento de onda deve ser aproximada (BARNES, 1994). Outra limitação 
da teoria de Kubelka-Munk é que os seus parâmetros são dependentes do comprimento de onda (ASPEREN DE BOER, 1970).

Em se tratando da reflectografia de infravermelho, o êxito na observação do desenho subjacente é afetado pelo poder de espalhamento na camada de tinta e a espessura desta mesma camada. À medida que aumenta o comprimento de onda da radiação, o espalhamento pelas partículas é diminuído. Portanto, para uma radiação, quanto maior seu comprimento de onda, maior é a sua capacidade de passar através das camadas de tinta e ser refletida ou absorvida pelo desenho subjacente. Por isso, a radiação infravermelha é capaz de passar através da camada de tinta enquanto a radiação visível e ultravioleta é refletida por ela (WEINER, 1998).

\subsection{Análise estatística multivariada}

A estatística multivariada consiste em um conjunto de métodos estatísticos que permite a análise simultânea de medidas múltiplas para cada indivíduo ou objeto em análise, ou seja, qualquer método que permita a análise simultânea de duas ou mais variáveis pode ser considerado como multivariado.

Existem vários métodos de análise multivariada com finalidades bem diversas entre si e podem ser classificados em dois grupos. O primeiro grupo constitui em técnicas exploratórias de simplificação da estrutura de variabilidade dos dados, tais como as técnicas de análise de componentes principais e análise de agrupamento entre outras. O segundo constitui em técnicas de inferência estatística tais como testes de hipóteses e análises de variância (MINGOTI, 2007; VICINI, 2005).

De maneira geral, os métodos multivariados têm o objetivo de simplificar e facilitar a interpretação dos casos estudados por meio do cálculo de índices ou gráficos que sintetizem as informações gerais.

Historicamente, essas técnicas foram inicialmente aplicadas em áreas das ciências humanas, porém sua utilização foi expandida às diversas áreas do conhecimento. Atualmente, os diversos métodos de análise multivariados são realizados com o auxílio computacional baseados em fundamentos teóricos. 


\subsubsection{Análise de Componentes Principais}

A análise de componentes principais, também chamada de PCA (Principal Component Analysis), é um método de análise estatística multivariada e tem como objetivo determinar em um conjunto de variáveis a existência de subconjuntos coerentes relativamente independentes uns dos outros. De maneira resumida, é uma técnica de classificação que determina as relações existentes entre os diversos casos a serem estudados e suas variáveis (VARELLA, 2008).

Essa técnica utiliza um inter-relacionamento entre as variáveis de modo que estas possam ser escritas em termos de um grupo de menores elementos denominados fatores. Os fatores explicam a variância das variáveis através das correlações entre as variáveis utilizadas em determinado estudo.

Para realizar uma análise de componentes principais necessitamos dos dados de ' $p$ ' variáveis para ' $n$ ' indivíduos de uma população ' $\pi$ '. Utilizando estas informações, calculamos uma matriz de covariância.

Suponhamos um conjunto de amostras de tamanho ' $n$ ' com ' $p$ ' variáveis. Agrupando as informações de todas as amostras podemos gerar uma matriz ' $\mathrm{n} \times \mathrm{p}$ ' dada por:

$$
X=\left[\begin{array}{ccccc}
x_{11} & x_{12} & x_{13} & \cdots & x_{1 p} \\
x_{21} & x_{22} & x_{23} & \cdots & x_{2 p} \\
x_{31} & x_{32} & x_{33} & \cdots & x_{3 p} \\
\vdots & \vdots & \vdots & \ddots & \vdots \\
x_{n 1} & x & x_{n 3} & \cdots & x_{n p}
\end{array}\right]
$$

A estrutura de interdependência entre as variáveis da matriz de dados é representada pela matriz de covariância ' $S$ ' ou pela matriz de correlação ' $R$ '. A matriz de covariâncias amostrais ' $S$ ' de ordem ' $\mathrm{p}$ x p' é definida por:

(Eq. 33)

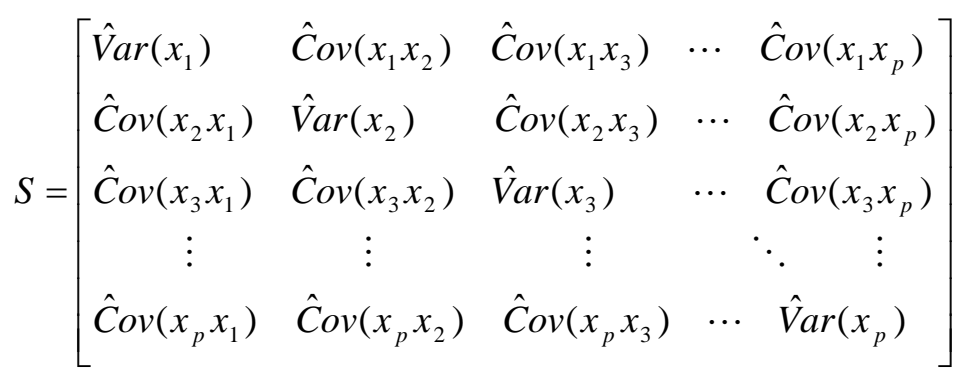


Normalmente as características são observadas em unidades de medidas diferentes entre si, e neste caso, segundo (VARELLA, 2008), é conveniente padronizar as variáveis $X_{j}(i=1,2,3,5 \ldots, p)$. A padronização pode ser feita com média zero e variância 1, ou com variância 1 e média qualquer (equação 35 e 36, respectivamente):

$$
z_{i j}=\frac{x_{i j}-\bar{x}_{j}}{s\left(x_{j}\right)}, \quad i=1,2, \cdots, n \quad e \quad j=1,2, \cdots, p
$$

$$
z_{i j}=\frac{x_{i j}}{s\left(x_{j}\right)}, \quad i=1,2, \cdots, n \quad e \quad j=1,2, \cdots, p
$$

onde, $\bar{X}_{j}$ e $\mathrm{S}\left(\mathrm{x}_{\mathrm{j}}\right)$ são, respectivamente, a estimativa da média e o desvio padrão da característica j:

$$
\overline{x_{j}}=\frac{\sum_{i=1}^{n} x_{i j}}{n}
$$

$\mathrm{e}$

$$
s\left(x_{j}\right)=\sqrt{\hat{\operatorname{Var}}\left(x_{j}\right)}, j=1,2, \ldots, p
$$

$$
\sqrt{\hat{\operatorname{Var}}\left(x_{j}\right)}=\frac{\sum_{i=1}^{n}\left(x_{i j}-\overline{x_{j}}\right)^{2}}{n-1} \quad \text { ou } \quad \sqrt{\hat{\operatorname{Var}}\left(x_{j}\right)}=\frac{\sum_{i=1}^{n} x_{i j}^{2}-\frac{\left(\sum_{i=1}^{n} x_{i j}\right)^{2}}{n}}{n-1}
$$

Após a padronização obtemos uma nova matriz de dados Z:

(Eq. 39)

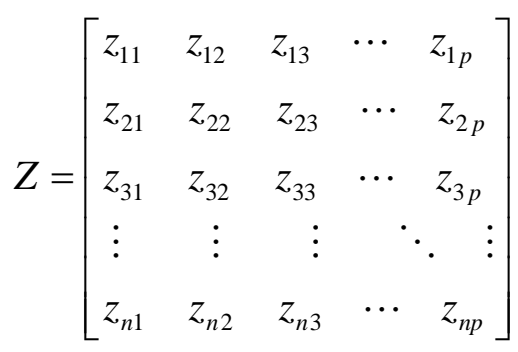


A matriz ' $Z$ ' das variáveis padronizadas ' $z_{j}$ ' é igual à matriz de correlação da matriz de dados ' $X$ '. Para determinar os componentes principais normalmente parte-se da matriz de correlação ' $R$ '. O resultado encontrado para a análise a partir da matriz ' $S$ ' pode ser diferente do resultado encontrado a partir da matriz 'R'. A recomendação é que a padronização só dever ser feita quando as unidades de medidas das características observadas não forem as mesmas.

Os componentes principais são determinados resolvendo-se a equação característica da matriz ' $S$ ' ou ' $R$ ', isto é:

$$
\operatorname{det}[R-\lambda I]=0
$$

$$
R=\left[\begin{array}{ccccc}
1 & r\left(x_{1} x_{2}\right) & r\left(x_{1} x_{3}\right) & \cdots & r\left(x_{1} x_{p}\right) \\
r\left(x_{2} x_{1}\right) & 1 & r\left(x_{2} x_{3}\right) & \cdots & r\left(x_{2} x_{p}\right) \\
r\left(x_{3} x_{1}\right) & r\left(x_{3} x_{2}\right) & 1 & \cdots & r\left(x_{3} x_{p}\right) \\
\vdots & \vdots & \vdots & \ddots & \vdots \\
r\left(x_{p} x_{1}\right) & r\left(x_{p} x_{2}\right) & r\left(x_{p} x_{3}\right) & \cdots & 1
\end{array}\right]
$$

Se a matriz $R$ não apresentar nenhuma coluna que seja combinação linear de outra, a equação 40 terá ' $p$ ' raízes chamadas de autovalores. Sejam $\lambda_{1}, \lambda_{2}, \lambda_{3}, \ldots$, $\lambda_{\mathrm{p}}$ as raízes da equação característica da matriz $\mathrm{R}$ ou $\mathrm{S}$, então:

$$
\lambda_{1}>\lambda_{2}>\lambda_{3} \cdots, \lambda_{p} .
$$

Para cada autovalor $\lambda_{i}$ existe um autovetor:

$$
\tilde{a}_{i}=\left[\begin{array}{c}
a_{i 1} \\
a_{i 2} \\
\cdot \\
a_{i p}
\end{array}\right]
$$

Os autovetores $\tilde{a}_{i}$ são normalizados, isto é, a soma dos quadrados dos coeficientes é igual a 1, e ainda são ortogonais entre si. Sendo $\tilde{a}_{i} 0$ autovetor 
correspondente ao autovalor $\lambda_{\mathrm{i}}$, então o i-ésimo componente principal é dado por:

$$
Y_{i}=a_{i 1} X_{1}+a_{i 2} X_{2}+\ldots+a_{i p} X_{p}
$$

Os componentes principais apresentam as seguintes propriedades:

1) A variância do componente principal $Y_{i}$ é igual ao valor do autovalor $\lambda_{i}$.

$$
\hat{\operatorname{Var}}\left(Y_{i}\right)=\lambda_{i}
$$

2) O primeiro componente é o que apresenta maior variância e assim por diante:

$$
\hat{\operatorname{Var}}\left(Y_{1}\right)>\hat{\operatorname{Var}}\left(Y_{2}\right)>\ldots>\hat{\operatorname{Var}}\left(Y_{p}\right)
$$

3) O total de variância das variáveis originais é igual ao somatório dos autovalores que é igual ao total de variância dos componentes principais:

$$
\sum \hat{\operatorname{Var}}\left(X_{i}\right)=\sum \lambda_{i}=\sum \hat{\operatorname{Var}}\left(Y_{i}\right)
$$

4) Os componentes principais não são correlacionados entre si:

$$
\widehat{\operatorname{Cov}}\left(Y_{i}, Y_{j}\right)=0
$$

A contribuição $C_{i}$ de cada componente principal $Y_{i}$ é expressa em porcentagem. É calculada dividindo-se a variância de $Y_{i}$ pela variância total. Representa a proporção de variância total explicada pelo componente principal $Y_{\mathrm{i}}$.

(Eq. 49)

$$
C_{i}=\frac{\hat{\operatorname{Var}}\left(Y_{1}\right)}{\sum_{i=1}^{p} \hat{\operatorname{Var}}\left(Y_{1}\right)} \cdot 100=\frac{\lambda_{i}}{\sum_{i=1}^{p} \lambda_{i}} \cdot 100
$$

O grau de influência que cada variável $X_{j}$ tem sobre o componente $Y_{i}$ é dado pela correlação:

$$
\operatorname{Corr}\left(X_{j}, Y_{1}\right)=a_{1 j} \cdot \frac{\sqrt{\widehat{\operatorname{Var}}\left(Y_{1}\right)}}{\sqrt{\widehat{\operatorname{Var}}\left(X_{j}\right)}}=\sqrt{\lambda_{1}} \cdot \frac{a_{1 j}}{\sqrt{\widehat{\operatorname{Var}}\left(X_{j}\right)}}
$$


A fim de comparar a influência de $X_{1}, X_{2}, \ldots, X_{p}$ sobre $Y_{1}$ analisa-se 0 peso de cada variável sobre o componente $Y_{1}$. O peso de cada variável sobre um determinado componente é dado por:

(Eq. 51)

$$
w_{1}=\frac{a_{11}}{\sqrt{\operatorname{Var}\left(X_{1}\right)}}, w_{2}=\frac{a_{12}}{\sqrt{\operatorname{Var}\left(X_{2}\right)}}, \ldots w_{p}=\frac{a_{1 p}}{\sqrt{\operatorname{Var}\left(X_{p}\right)}}
$$

Sendo $\mathrm{w}_{1}$ o peso de $\mathrm{X}_{1}$. 


\section{MATERIAIS E MÉTODOS}

\subsection{Materiais}

\subsubsection{Pigmento}

Pigmento é uma substância colorida e finamente dividida, que passa seu efeito de cor a outro material, quer quando bem misturado a ele, quer quando aplicado sobre sua superfície. Quando um pigmento é misturado ou moído em um veículo líquido para formar uma tinta, ele não se dissolve, mas permanece disperso ou suspenso no líquido. Substâncias coloridas que se dissolvem em líquidos e que concebem a outros materiais seus efeitos de cor, manchando-os ou sendo por eles absorvidas, são classificados como tinturas ou corantes. Os vários métodos de pintura (óleo, aquarela, têmpera, pastel, entre outros) diferem-se quanto ao material com o qual a cor é aplicada e aderida ao fundo. Os pigmentos utilizados são os mesmos, em todos os métodos, exceto o fato de que um pigmento apropriado para um propósito nem sempre atende às exigências de outro (MAYER, 2006).

\subsubsection{Tela}

A palavra "tela" não se refere apenas a algum material especifico no campo dos têxteis, mas é aplicada a inúmeros materiais de fibra relativamente áspera e de trama fechada. Na pintura, o termo geralmente implica um tecido revestido, pronto para ser usado. A palavra também é empregada para uma pintura a óleo acabada. O material sobre o qual uma pintura a óleo é executada é dividido em duas partes: a imprimação, ou fundo, e o suporte que é a fundação ou apoio. Os três tipos de fundo são: o fundo a óleo, os de gesso e os fundos de emulsão. Os principais suportes são: placas finas de metal, painéis de madeira e tecidos têxteis ou sintéticos esticados em chassi ou colados em painéis de madeira (MAYER, 2006). 


\subsubsection{Tinta}

Consiste em partículas de pigmentos finamente divididas e dispersadas por igual em um médium ou veículo líquido: possui propriedade de secar e formar uma película contínua, aderente, quando aplicada a uma superfície com fins decorativos ou de proteção. As superfícies em geral podem ser coloridas ou decoradas pela aplicação direta do pigmento; na pintura à pastel a função protetora pode ser fornecida por um fixativo, cuja aplicação é posterior à aplicação da cor, e, na pintura afresco o próprio fundo fornece a propriedade adesiva e aglutinante. Entretanto a tinta, no significado mais comumente aceito do termo, em geral significa um material que combina essas funções, como a típica tinta óleo ou a têmpera. (MAYER, 2006).

\subsubsection{As obras}

Inicialmente foram escolhidas duas telas de pintura a óleo da artista Anita Malfatti para serem estudadas: "O Homem Amarelo" e "Tropical", dado o seu grande valor histórico e cultural que representam para o patrimônio artístico brasileiro. Estas obras também possuem alta importância histórica e artística, frente ao grande acervo disponível da artista, pois em estudos prévios e em discussões com os profissionais restauradores e conservadores, responsáveis pelas obras, surgiam questionamentos a respeito de possíveis figuras subjacentes presentes nas telas que eram percebidas a olho nu (BATISTA, 2006; GREGGIO, 2013). Posteriormente, foram adicionadas às análises mais três obras da artista: "O Japonês", "A Estudante Russa" e "O Retrato de Mário de Andrade", a fim de se realizar comparações entre elas e obter referências dos materiais e da paleta utilizada pela artista nos períodos de produção das obras. Esta obras foram incluídas principalmente por aparentemente não apresentam desenhos e camadas pictóricas sobrepostas, já que estas sobreposições podem tornar mais complexos os estudos de caracterização dos materiais, pigmentos, técnicas utilizadas e outras características da obra.

A obra "Tropical" pertence ao acervo da Pinacoteca do Estado de São Paulo. As obras "O Homem Amarelo", "O Japonês", "A Estudante Russa" e 
"Retrato de Mário de Andrade" pertencem ao Instituto de Estudos Brasileiros da Universidade de São Paulo da Universidade de São Paulo (IEB-USP).

\subsubsection{1. "Tropical"}

Pintada após a volta de Anita dos EUA, em 1917, é considerada uma obra produzida em um momento de transição, divisor de dois momentos na vida da artista (figura 3.1). Uma das primeiras críticas recebidas por ocasião da exposição de 1917, na qual "Tropical" foi exposta com o nome de "Negra Baiana", foi do jornalista Nestor Pestana: "A Senhorita Malfatti aceitou as franquias desta pseudoescola para fazer sua "Negra Baiana", que é para nós, pobres mortais, um caso teratológico em anatomia. Mas ao lado dela, pôs uns abacaxis tão bem desenhados e tão acabadinhos que faria delícias aos botânicos" (PESTANA, 1918).

De acordo com Greggio (GREGGIO, 2013), esta obra também é uma evidência de que não foi a crítica de Monteiro Lobato, fato tão destacado na história da arte brasileira, que determinou a mudança de rumo na pintura de Anita, pois "Tropical" foi pintado entre sua volta dos EUA e a exposição de 1917, antes da crítica de Lobato. Conforme Chiarelli Anita não foi a única a resgatar valores abandonados inicialmente pelas vanguardas em favor do experimentalismo. A artista procedia a uma mudança em sua linguagem pictórica, afastando-se das concepções de vanguarda que adotara até então para, aderindo ao clima de retorno à ordem internacional, aproximar-se das discussões sobre o nacionalismo na arte (CHIARELLI, 2008). "Resultado de um fenômeno mais comum do que ainda hoje se imagina no Brasil, a partir da eclosão da I Guerra Mundial vários artistas da vanguarda internacional passaram por um processo de recuperação dos valores de arte anteriores às experimentações estéticas dos primeiros anos do século XX" (CHIARELLI, 1999).

Na obra "Tropical", Anita esboçou e desenvolveu a figura de uma mulata que segura uma cesta de frutas tropicais, e colocou como fundo uma vegetação de caráter nacional, trazendo consigo muitas características da sua fase norte americana. Esta obra ultrapassa a pregação nacionalista, pois a 
pintora tratou o tema de maneira nova, inovando-o também tecnicamente, sendo a primeira vez que o tema nacional é encontrado dentro da arte moderna no Brasil (BATISTA, 2006). Nesta obra, há um reaproveitamento de uma tela que "pode-se perceber sob a pintura, um nu provavelmente da fase norte americana." (BATISTA, 2006). Isso é tudo o que foi dito e perceptível a respeito das figuras subjacentes. No entanto, nenhum estudo foi realizado anteriormente sobre tal figura em questão. Questões sobre as próprias figuras, seus traços estilísticos, os temas desenvolvidos e suas autorias nunca foram discutidas anteriormente. 


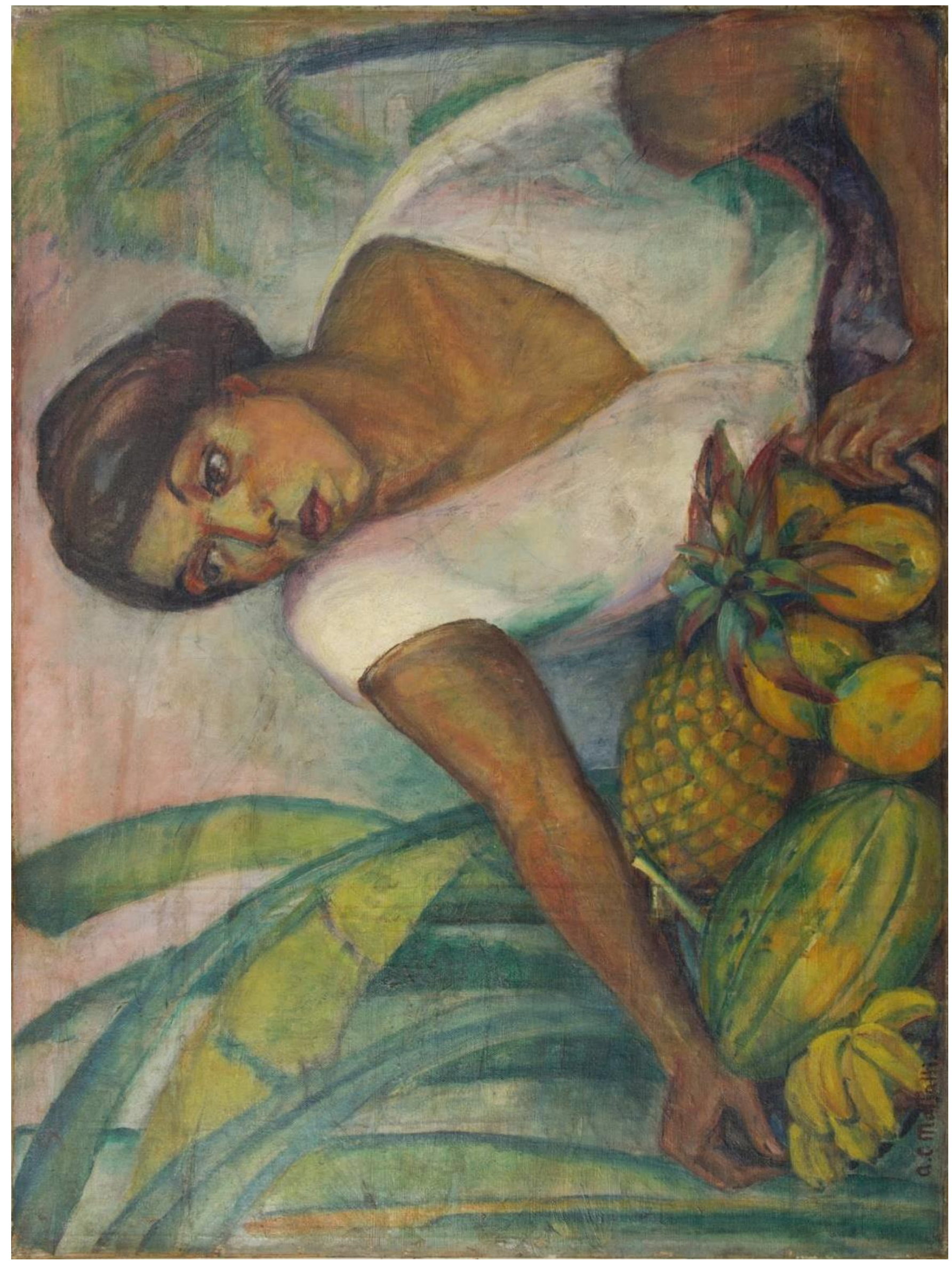

Figura 3.1 - A obra "Tropical" de Anita Malfatti (1917, óleo sobre tela, $77 \times 102 \mathrm{~cm}$ ) do acervo da Pinacoteca do Estado de São Paulo. Foto: P.H.O.V. Campos e E. Kajiya

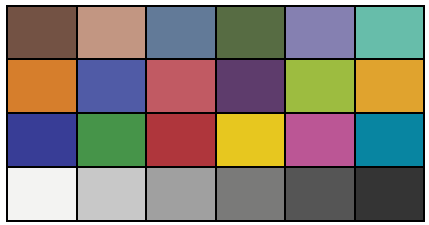




\subsubsection{2. "O Homem Amarelo"}

A obra "O Homem Amarelo" (figura 3.2) foi produzida por Malfatti quando estava realizando seus estudos nos Estados Unidos, em Nova lorque (19141916), influenciada pela arte moderna europeia, com base nas interpretações norte-americanas de artistas como Van Gogh, Gauguin, Cézanne, Matisse, Picasso, e movimentos como fauvismo, cubismo, sincronismos, que foram algumas das tendências que a pintora, junto à grande maioria dos artistas modernos nos Estados Unidos na época, absorveu em suas lições.

"O modelo do O Homem Amarelo foi um pobre imigrante italiano, contaria a pintora: "Era um que entrou para posar. Tinha uma expressão tão desesperada". Anita retratou-o incialmente a pastel, produzindo uma primeira tela e, a seguir, pintou uma a óleo (a obra em questão), aproveitando uma tela já iniciada, cujos vestígios continuam a transparecer sob os vermelhos." (BATISTA, 2006). De acordo com Batista (2006), esta tela "foi provavelmente a obra que mais ouviu blagues e ataques", pois o anedotário sobre ela é grande. Em 1917/18 foi também a que mais impressionou a Mário de Andrade, que lhe dedicou um soneto parnasiano e depois, na Semana de 1922 a adquiriu". Utilizando um fundo de tons de laranja e amarelos, a figura retratada de pele amarela e olhos vermelhos porta um paletó marrom desgastado de forma despojada, e possui traços marcantes, retratado por Anita com características cubistas e expressionistas, com pinceladas displicentes. O retratado está de lado, com o corpo contorcido e ultrapassando os limites da tela, de forma não convencional, como na maioria das obras da artista desta época (GREGGIO, 2013). 


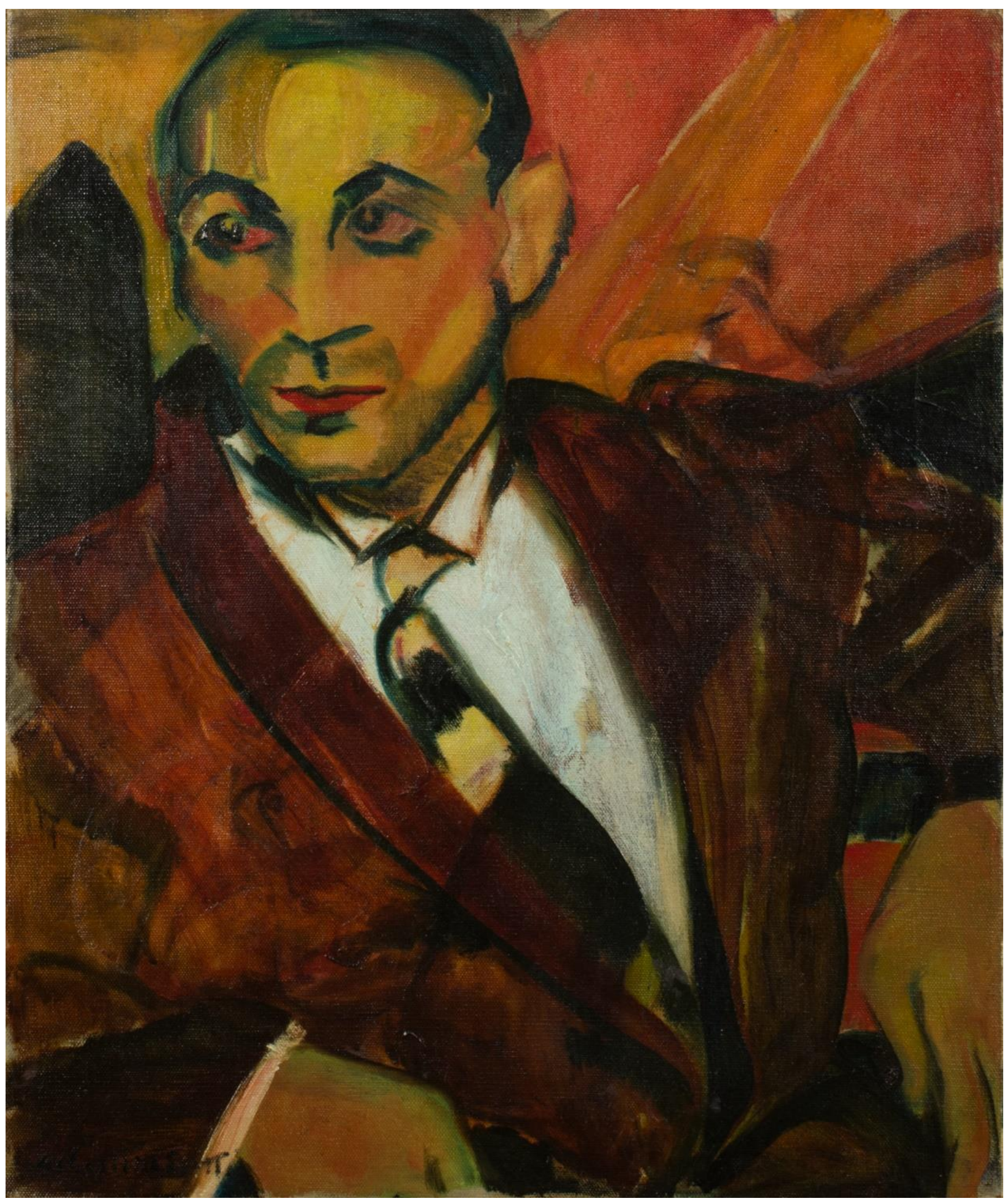

Figura 3.2 - A obra "O Homem Amarelo" de Anita Malfatti (1915/1916, óleo sobre tela, $61 \times 51 \mathrm{~cm})$ do acervo do IEB-USP. Foto: P.H.O.V. Campos e E. Kajiya

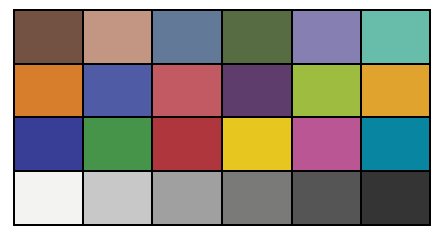




\subsubsection{3. "A Estudante Russa"}

Esta obra de 1915 (76 x $61 \mathrm{~cm}$, óleo sobre tela), do acervo do Instituto de Estudos Brasileiros da Universidade de São Paulo (figura 3.3), foi pintada pela artista nos Estados Unidos, ainda na primeira escola que frequentou a Arts Students League of New York, antes da sua convivência com Homer Boss. Esta obra é considerada uma transição entre as influências anteriores da escola alemã e as produções posteriores, pintadas na Independent School de Boss, pois ainda não apresenta as grandes deformações que iriam caracterizar os últimos retratos feitos nos EUA (GREGGIO, 2013). Esta tela estava presente na sua segunda exposição individual em 1917 e na Semana de 22.

Mário de Andrade que a comprou em 1935 a considerava a melhor tela da Anita, e muitos acreditam ser um autorretrato. "A nobre artista coube fazer não um retrato indiferente de mulher desconhecida, mas uma comovida expressão de raça, a violência cantiga dessa pátria - tumulto, orgulho e dor, erro e crença, beleza e crime que é a Rússia; é sem dúvida uma grande criadora" (ANDRADE, 1921). Neste retrato uma mulher está sentada em uma cadeira vermelha, aparentemente escolar, com o seu braço direito pousado sobre o braço da cadeira. $O$ fundo foi pintado em uma azul profundo e tons de ocre e marrom. A personagem de pele bem amarela, veste uma roupa que varia em tons de cinza, ocre e verde. O seu corpo está levemente retorcido, com o ombro esquerdo mais alto do que o direito, mostrando uma representação modernista, de não seguir as normas da academia de retratar as pessoas. A camada pictórica nesta tela é fina, a ponto de vermos em algumas regiões do quadro o que seria o tecido e sua trama. 


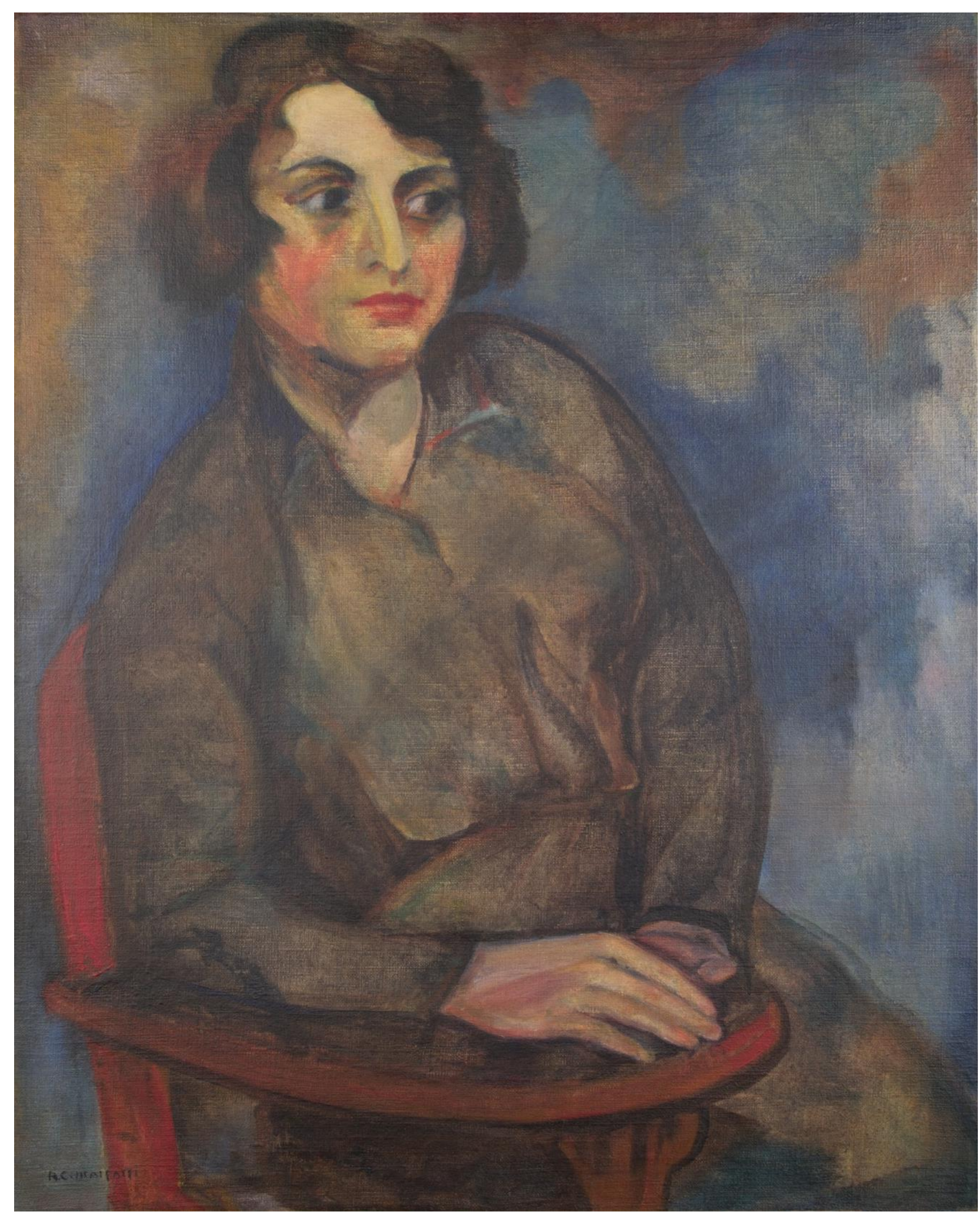

Figura 3.3 - A obra "A Estudante Russa" de Anita Malfatti (1915, óleo sobre tela, $76 \times 61 \mathrm{~cm})$ do acervo do IEB-USP. Foto: P.H.O.V. Campos e E. Kajiya

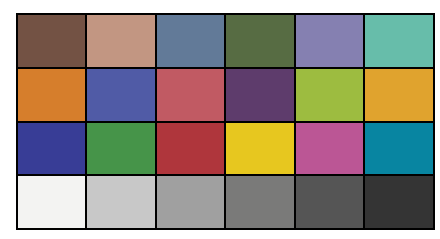




\subsubsection{4. "O Japonês"}

A obra "O Japonês" representada na figura 3.4 é datada entre 1915 e 1916 (61 x $51 \mathrm{~cm}$, óleo sobre tela), pertencente ao acervo do Instituto de Estudos Brasileiros da Universidade de São Paulo. Esta provavelmente representa o retrato do pintor Yasuo Kuniyoshi (1893-1953), que também estudou na Arts Students League e na Independent School of Art, de Nova York. Comprado por Mário de Andrade em 1920, era um dos seus preferidos. (GREGGIO, 2013). A tela estava presente na Semana de 22 e na VI Bienal Internacional de São Paulo, quando Anita foi homenageada com uma sala especial.

Nesta obra, a artista utilizou uma fina camada de tinta, onde é possível ver a tela e sua trama em algumas regiões. O quadro é pintado em tons de amarelos e vermelhos que se confundem e são discretamente contornados por sinuosos e vigorosos traços marrons e azulados. A roupa despojadamente delineada em curvas se contrapõe a um fundo chapado e anguloso. A figura quase não cabe no espaço da tela e a cabeça e as mãos estão cortadas, como em muitos desenhos da artista na época, a exemplo do "O Homem Amarelo" (GREGGIO, 2013).

"Há grande liberdade de desenho e de composição da tela, mas na cabeça do retrato, Anita ainda não recorre a deformações e assimetrias mais violentas. O tratamento do rosto trás reminiscências das obras alemãs." (BATISTA, 2006). 


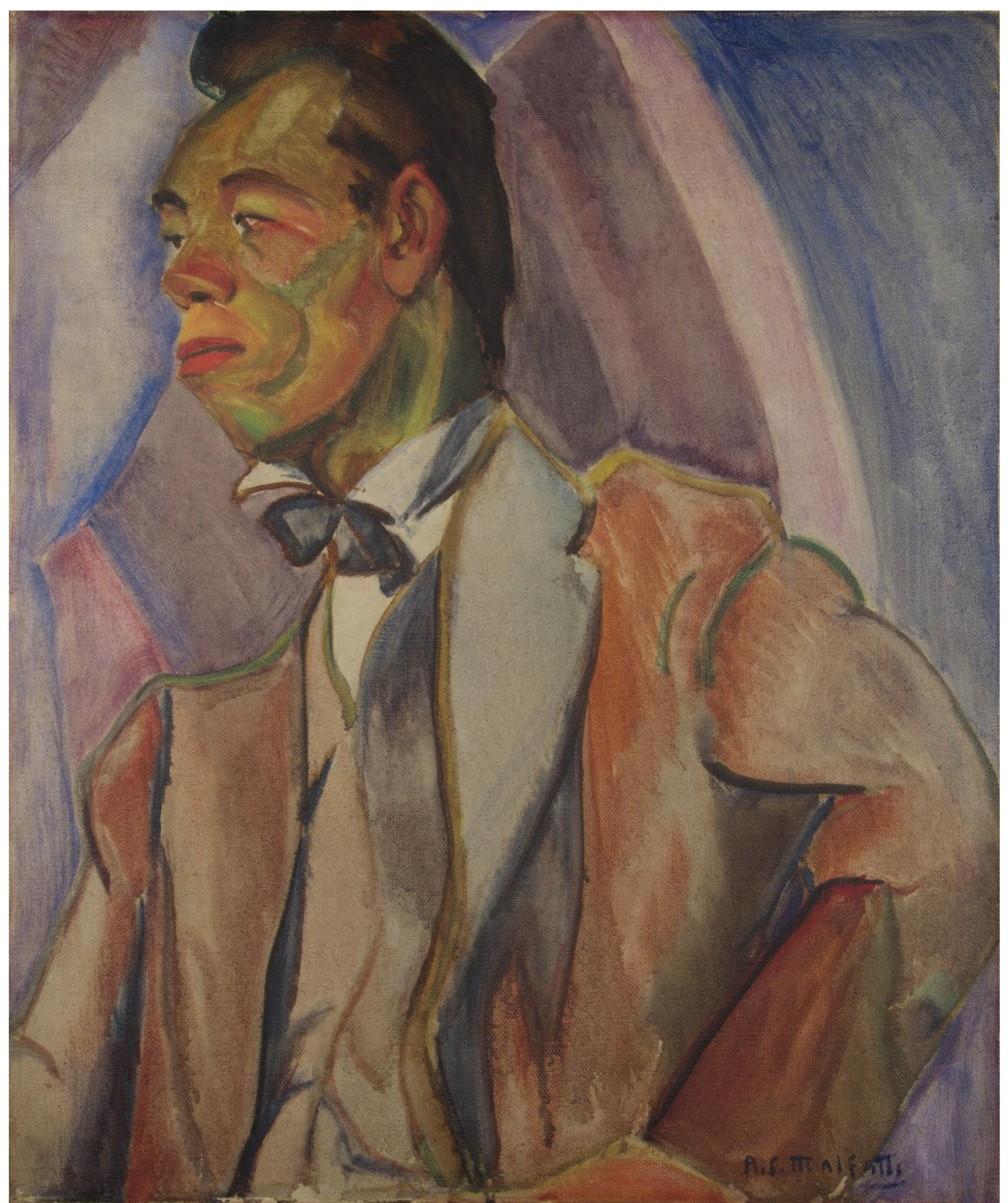

Figura 3.4 - A obra "O Japonês" de Anita Malfatti (1915/1916, óleo sobre tela, 61×51cm) do acervo do IEB-USP. Foto: P.H.O.V. Campos e E. Kajiya

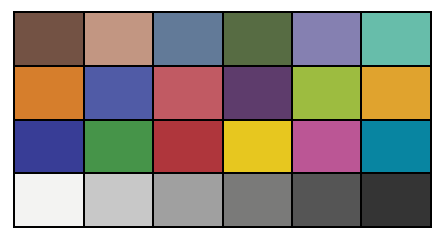




\subsubsection{5. "Retrato de Mário de Andrade"}

Entre os anos de 1921 e 1922, Anita Malfatti produz sua primeira tela dedicada ao amigo Mário de Andrade. A composição carrega as características expressionistas das obras da fase norte-americana da artista, a mais apreciada pelo poeta. Anita pintou três retratos do amigo, e o aqui apresentado é o terceiro deles, pintado em 1923 em óleo sobre tela, (figura 3.5), antes que a artista embarcasse para Paris em uma viagem de estudos conseguida pelo amigo junto ao mecenas Freitas Valle (TAMENY, 2010). A obra possui um fundo de traçados retos verdes e cinza, com o poeta retratado com uma fisionomia com poucas deformações, com uma gravata amarela, em seu costumeiro terno preto.

Figura 3.5 - A obra "O Retrato de Mário de Andrade" de Anita Malfatti (1923, óleo sobre tela, $44 \times 38 \mathrm{~cm})$ do acervo do IEB-USP (BATISTA; LIMA, 1998) 


\subsection{Imageamento}

As análises e diagnósticos por imagens aplicadas em obras de arte têm desempenhado um papel importante na avaliação do estado de conservação das pinturas e no exame de autenticidade, detectando desenhos subjacentes e alterações do próprio artista (BALLAS et al., 2003; CABRAL 2013).

Neste estudo, as análises por meio de imagem utilizaram as técnicas de fotografia com luz visível, fluorescência visível da radiação ultravioleta, reflectografia de infravermelho, luz visível rasante ou tangencial e radiografia digitalizada.

Todas as imagens obtidas foram editadas e ajustadas, quando necessário, no programa Adobe Photoshop Lightroom CC, versão 2015.1.

\subsubsection{Luz Visível}

A radiação visível está na região de 400 a 780 nm de comprimento de onda e a fotografia com esta luz, figura 3.6, seja colorida e/ou preto e branco, é utilizada como um registro do estado que se encontra a obra, assim como a paleta de cores do artista, evitando, dessa maneira, uma série de manuseios do objeto para as análises, preservando a integridade da obra. Além disso, com os processamentos digitais em fotografias de alta resolução, e o uso de lentes objetivas macros, é possível registrar pequenos detalhes presentes que muitas vezes são imperceptíveis a olho nu. Este registro fotográfico também é importante como uma referência para comparação com outras técnicas realizadas e auxilia no registro de possíveis processos de degradação que possam ter ocorrido.

O equipamento fotográfico utilizado foi uma câmera fotográfica digital da marca Nikon modelo D90, com uma lente objetiva 18-105 mm, f/3.5-5.6, e uma câmera fotográfica digital modelo Canon EOS 5D Mark III, com uma lente objetiva de 24-105 mm, f/2.2-4. Como fontes iluminantes, foram utilizados duas lâmpadas halógenas de $1000 \mathrm{~W}$ posicionadas a aproximadamente $45^{\circ}$ da obra para evitar reflexos e conferir maior uniformidade de distribuição da luz incidida. Para evitar brilho, reflexo e sombras, e para facilitar no processo de edição das 
imagens, utilizou-se um fundo negro atrás das obras. A figura 3.6 exemplifica o esquema ilustrativo do arranjo experimental utilizado para as medidas de imageamento com luz visível.

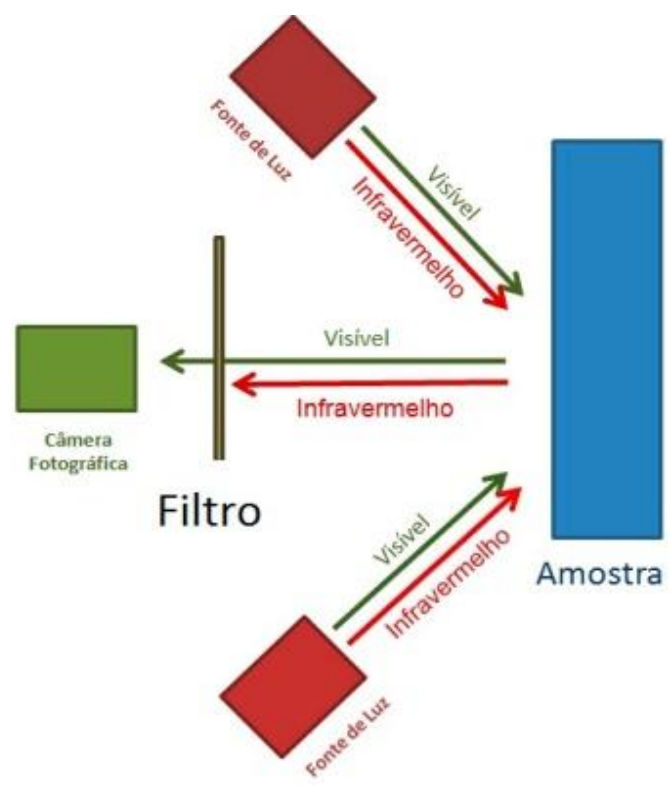

Figura 3.6 - Esquema ilustrativo do arranjo exeperimental utilizado nas fotografias com luz visível

Nas imagens com luz visível, foi utilizada a cartela de cor ColorChecker, da empresa X-Rite Photo para padronização das cores. A cartela ColorChecker é um quadro com um conjunto de 24 amostras de cores naturais, espectrais, primárias e cinzas, produzidas em uma ampla gama de tonalidades. Muitos desses quadrados representam as cores de objetos naturais. Visto que exemplificam as cores dos seus correspondentes no mundo real e refletem a luz da mesma forma em todas as regiões do espectro visível, os quadrados matizarão as cores dos objetos naturais que representam sob qualquer iluminação e com qualquer processo de reprodução de cores. O ColorChecker pode também ser utilizado para criar um balanço de branco da câmera digital para garantir um branco neutro, preciso e uniforme para diversas condições de iluminação. Posteriormente, no programa Adobe Photoshop Lightroom, foi utilizado o módulo de extensão para o programa: ColorChecker Passport, de modo a corrigir a temperatura de cor utilizada na seção de fotos e os desvios das cores característicos da câmera utilizada, com base na cartela de cores. 


\subsubsection{Luz Rasante}

A técnica com luz rasante (figura 3.7), pelo efeito de luz e sombra, pode realçar as irregularidades da superfície, deformações do suporte, relevos, suas rugosidades, volumes, craquelamentos na camada pictórica levantada ou enterrada, fissuras, fungos, entre outras. Nesta técnica a iluminação rasante é posicionada tangencialmente à superfície do quadro ou variando a posição da fonte luminosa e é feito um registro fotográfico do fenômeno obtido. No caso de pinturas de cavalete, a imagem pode auxiliar na identificação das técnicas artísticas usadas pelos artistas, pois suas pinceladas podem ficar mais evidenciadas com o procedimento de iluminar as obras com luzes tangenciais à superfícies das obras.

Nesta técnica foi utilizada uma câmera fotográfica digital Nikon modelo D90, com uma lente objetiva $18-105 \mathrm{~mm}, \mathrm{f} / 3.5-5.6$, e uma câmera fotográfica digital Canon EOS 5D Mark III, com uma lente objetiva de 24-105 mm, f/2.2-4., e o objeto foi iluminado por um conjunto linear de luz LED branco, manufaturado pelo grupo de pesquisa, posicionada rasante ao quadro. A figura 3.7 apresenta o esquema ilustrativo do arranjo experimental para as medidas por imageamento por luz tangencial ou rasante

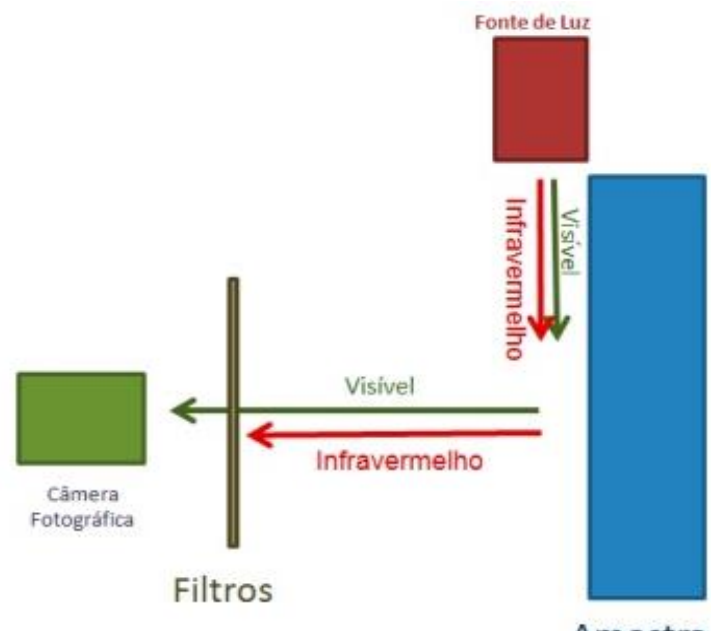

Amostra

Figura 3.7 - Esquema ilustrativo do arranjo experimental de fotografia com luz rasante 


\subsubsection{Luz ultravioleta}

A imagem por fluorescência com luz UV é uma técnica utilizada para a investigação da superfície de obras de arte (figura 3.8). Este tipo de análise contribui em estudos de diversos materiais, como os ligantes das tintas e vernizes sobre uma pintura, pois pode emitir colorações diferenciadas para cada material. Pode-se também diferenciar as regiões onde existem intervenções de restauro, devido à diferença de fluorescência dos materiais, e em alguns casos, ela pode ainda ser utilizada para identificar pigmentos dada a fluorescência diferente dos pigmentos.

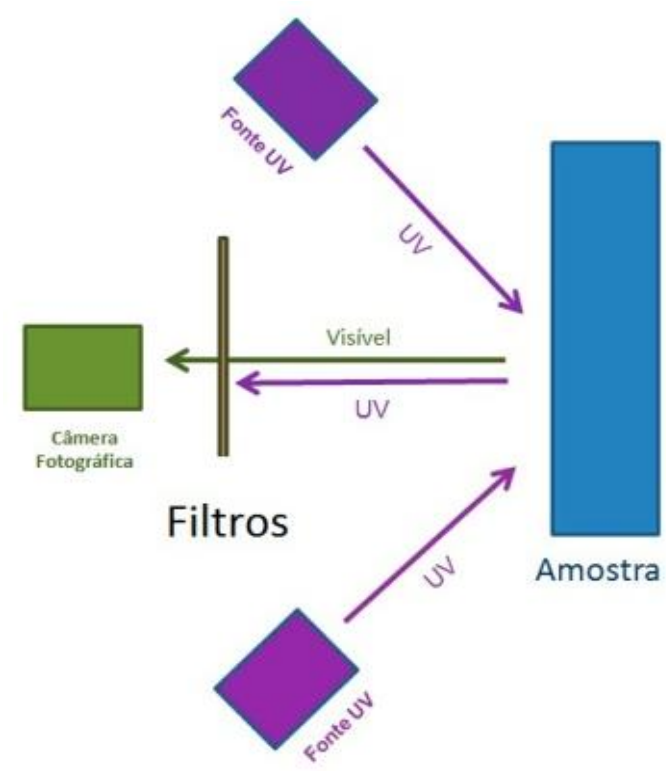

Figura 3.8 - Esquema ilustrativo do arranjo experimental utilizando no processo de fotografia de fluorescência com luz ultravioleta

O fenômeno de fluorescência consiste na absorção por um dado material de uma dada frequência de onda e a partir deste estímulo, emitir em uma frequência menor, e geralmente com intensidade menor do que a recebida. Na fotografia por fluorescência visível de ultravioleta (UV), é utilizada uma fonte de excitação na faixa energética do UV, mas a detecção fotográfica é na faixa do visível. A fluorescência UV é causada pela transição do estado quântico em um átomo ou uma molécula exposta a uma luz UV. A fluorescência de um material pode depender muito de sua natureza química. A fluorescência UV também é utilizada para verificar ou diferenciar a presença de 
materiais e a não homogeneidade, não visível de outra maneira (PINNA; GALEOTTI; MAZZEO, 2009). Além disso, esta técnica pode detectar sujidades, fungos, rasgos, fissuras na policromia e áreas retocadas, onde há difícil distinção entre estas e a pintura original.

Nas fotografias de fluorescência UV, por ser uma faixa de detecção padrão dos equipamentos comerciais, o equipamento utilizado foi uma câmera fotográfica digital Nikon modelo D90, com uma lente objetiva $18-105 \mathrm{~mm}, \mathrm{f} / 3.5$ 5.6, e uma câmera fotográfica digital modelo Canon EOS 5D Mark III, com uma lente objetiva de 24-105 mm, f/2.2-4.0. O que diferencia neste tipo de análise são as fontes luminosas. Foram utilizados quatro arranjos de lâmpadas UV com dois tipos diferentes de lâmpadas, para cada arranjo, UV fluorescente de vapor de mercúrio Phillips de $40 \mathrm{~W}$, e um conjunto de incandescente Philips HPW L 125 W T Ultraviolet, posicionadas nas laterais da obra, com distâncias equivalentes, em ângulos de $45^{\circ}$ da pintura, para maior uniformidade da distribuição da radiação.

\subsubsection{Reflectografia de Infravermelho}

A reflectografia de infravermelho (figura 3.9) é baseada na capacidade da radiação do infravermelho próximo (NIR, comprimento de onda de 780 a $3000 \mathrm{~nm}$ ) de passar através das camadas pictóricas, graças à transparência parcial de muitos pigmentos nessa faixa espectral. A radiação refletida pela base de preparação contém informações sobre as camadas da pintura. Quando feito a partir de um material absorvente, o desenho subjacente é revelado, dependendo da composição e da espessura das camadas pictóricas, e do comprimento de onda da fonte utilizada. Quando o material utilizado para realizar o desenho é à base de carbono, sua absorção do IR é maior do que dos pigmentos artísticos, e deste modo há uma diferença da reflectividade em relação ao fundo de preparação, evidenciando possíveis desenhos subjacentes, mesmo que a capa pictórica seja pouco transparente a luz visível. 


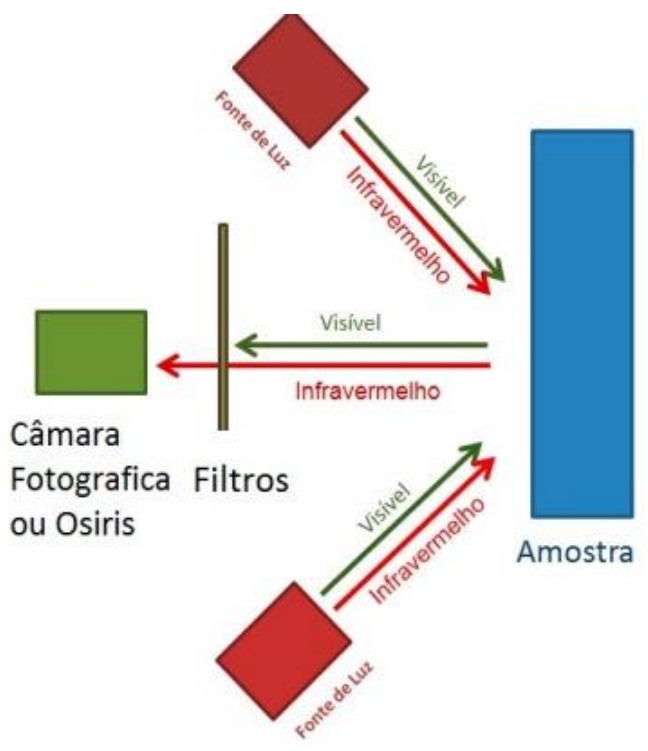

Figura 3.9 - Esquema ilustrativo do processo e arranjo de reflectogradia por infravermelho

Um dos equipamentos utilizado foi uma câmera FujiFilm FinePix S1, produzida especialmente para este tipo de análise, com uma região de trabalho entre 380 e $1000 \mathrm{~nm}$. Diferentemente das câmeras comerciais padrão, esta não possui o filtro IR, internamente, na frente do detector $C C D$, utilizado para proteção e seleção de faixa de detecção. O segundo equipamento utilizado na reflectografia IR foi a câmera Osiris (figura 3.10) produzida pela Opus Instruments, que possui uma região de trabalho entre 900 e $1700 \mathrm{~nm}$, e um conjunto de lentes objetivas de $150 \mathrm{~mm}$ e f/ 5,6-45. Este equipamento possui um detector de índio gálio arsênio (InGaAs) do tipo array.

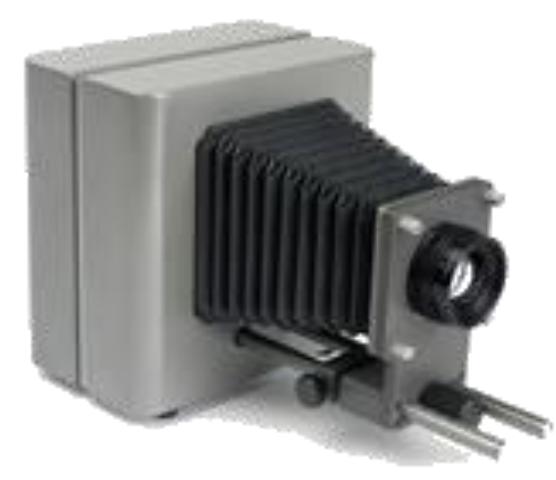

Figura 3.10 - Câmera Osiris de reflectografia por infravermelho produzida pela Opus Instruments (OPUS, 2014) 


\subsection{5. - Radiografia Digitalizada}

$\mathrm{Na}$ radiografia digital, um feixe de raios $\mathrm{X}$, com comprimento de onda de onda próximo ao intervalo de 0,0005 a $1 \mathrm{~nm}$, provém de uma fonte, e é incidido sobre um objeto, que o absorve de forma diferente de acordo com energia irradiada, densidade, espessura e composição das diferentes partes deste objeto. Os raios $X$ que atravessam o objeto são capturados atrás do objeto por um detector (um filme sensível ou um detector digital), que fornece uma imagem em duas dimensões (2D) de todas as estruturas presentes, de forma sobreposta, revelando informações tanto da superfície quanto do interior do objeto. O contraste da imagem acontece pela diferença de transmissão e absorção dos raios $X$ nas diferentes partes que compõem o objeto (figura 3.11). As medidas com radiografia foram realizadas em parceria com o Laboratório de Dosimetria do Instituto de Física da Universidade de São Paulo.

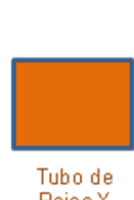

Tubo de
Raios X
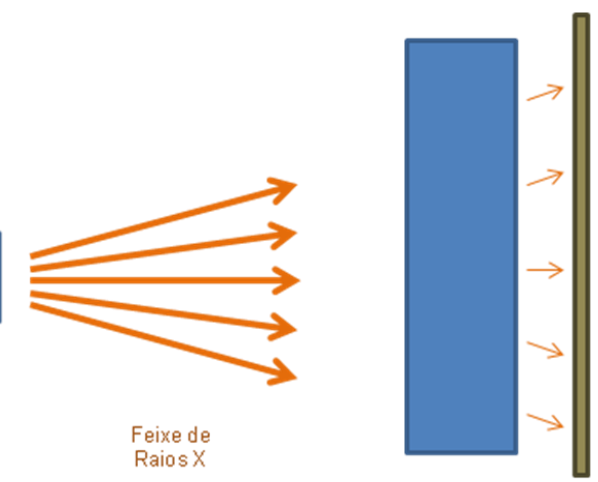

Detector
de Raio $X$

Figura 3.11 - Esquema ilustrativo do processo e arranjo de radiografia digital

O equipamento utilizado no Laboratório de Dosimetria foi um tubo de raios X Philips MG 450, com intervalo de tensão (variável) de 20 até $420 \mathrm{kV}$ e intervalo de corrente (variável) 0 a $15 \mathrm{~mA}$. As radiografias digitais foram realizadas com o sistema de $\mathrm{CR} 30-\mathrm{X}$ da Agfa Health Care. Na radiografia realizada na obra "O Homem Amarelo", utilizou-se inicialmente a tensão de 35 $\mathrm{kV}$ e $5 \mathrm{~mA}$ por $10 \mathrm{~s}$ de exposição (4 quadrantes expostos) que são os valores tipicamente utilizados para análises de pinturas de cavalete. No entanto, percebemos que com estes valores de tensão e corrente não houve grande resolução para evidenciar as imagens subjacentes. Inicialmente, testou-se uma 
exposição com $25 \mathrm{kV}, 5 \mathrm{~mA}$ e $10 \mathrm{~s}$ e finalmente chegou-se às melhores condições de imagens digitalizadas, que foi de $20 \mathrm{kV}, 5 \mathrm{~mA}$ e $10 \mathrm{~s}$

\subsection{Colorimetria}

Para a medição da cor foi utilizado um espectrofotômetro portátil com geometria esférica e alinhamento horizontal modelo CM-2500d da marca Konica-Minolta (figura 3.12), pertencente ao Instituto de Geociências da Universidade de São Paulo. Adotou-se o iluminante D65, correspondente à luz do dia, e diâmetro da área de medição de $8 \mathrm{~mm}$. Estabeleceu-se, por segurança, a realização de pelo menos três medidas em cada ponto de análise. Um espectro típico obtido por ser observado na figura 3.13. O software

utilizado para processamento dos dados foi o OnColor. A análise foi feita a partir da comparação visual dos espectros obtidos no conjunto de pontos de mesma cor e na observação do intervalo de variação dos parâmetros $L^{*}, a^{*} e$ $b^{*}$.

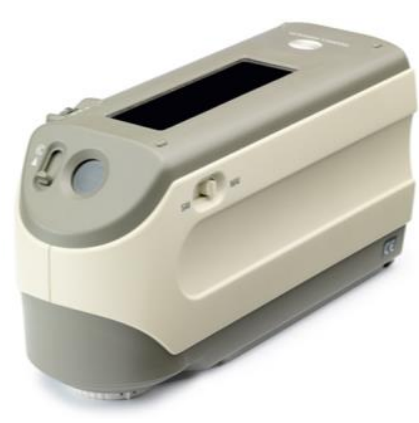

Figura 3.12 - Espectrofotômetro portátil com geometria esférica e alinhamento horizontal modelo CM-2500d (KONICA-MINOLTA, 2014) 


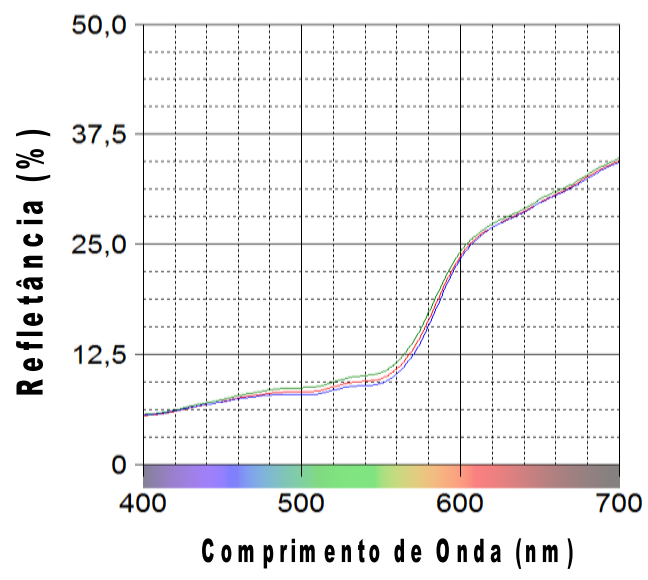

Figura 3.13 - Espectro típico obtido com espectrofotômetro CM-2500d, Konica-Minolta. Ponto P25, marrom avermelhado, medido na obra "A Estudante Russa"

\subsection{Fluorescência de Raio X por Dispersão de Energia - EDXRF}

Nas medidas de EDXRF o equipamento portátil utilizado foi um tubo Amptek Mini-X com ânodo de prata, com espessura de $0.75 \mu \mathrm{m}$, e amplitude de voltagem de 10 até $50 \mathrm{kV}$ e de corrente de 5 a $200 \mu \mathrm{A}$, com uma janela de berílio (Be) de $127 \mu \mathrm{m}$ na saída do feixe, o espectro gerado pela fonte pode ser visto na figura 3.14. O detector utilizado foi um XR-100CR de Silicon Drift Detector (SDD) da Amptex, com silício de $500 \mu \mathrm{m}$, com resolução de energia de 125 a 140 eV FWHM, com uma janela de berílio (Be) com $12.5 \mu \mathrm{m}$ de espessura (limitando a entrada de fótons de menor energia). Utilizou-se também um sistema PX5 da Amptek que um processador de pulso digital, analisador multicanal e fontes de energia de alta e baixa voltagem. Como podem ser observados na figura 3.15. O programa de aquisição utilizado foi o que acompanhou os equipamentos, fornecido pelo fabricante. 


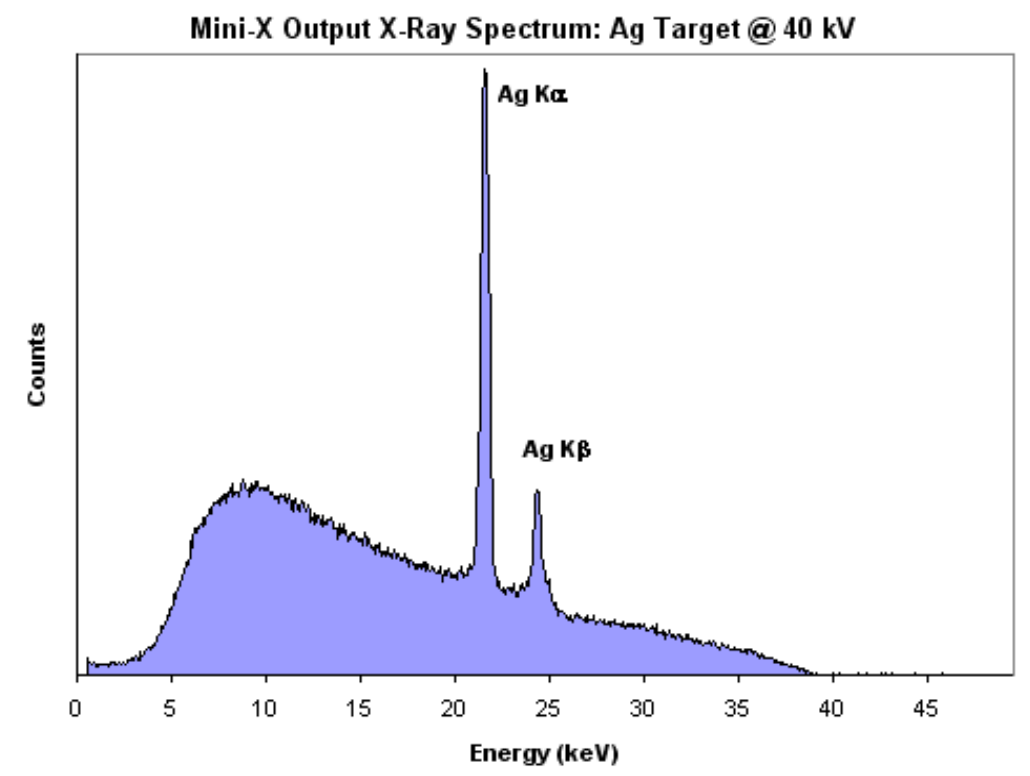

Figura 3.14 - Espectro típico de um tubo de raios X de Prata (Ag) (AMPTEK, 2014)

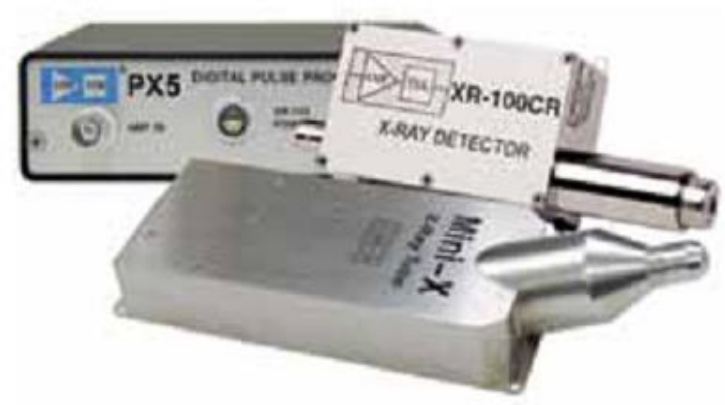

Figura 3.15 - Foto dos equipamentos utilizados. Amplificador e fonte PX5; Detector SDD XR100CR; Tubo de raio X Mini-X (AMPTEK, 2014)

\subsection{Testes Estatísticos}

A correlação é uma medida da relação entre duas ou mais variáveis. Os coeficientes de correlação podem variar de 1,00 a $-1,00$. $O$ valor de $-1,00$ representa uma perfeita correlação negativa, enquanto um valor de 1,00 representa uma perfeita correlação positiva. Um valor de 0,00 representa falta de correlação. A relação entre duas variáveis é tal que à medida que os valores de uma variável tendem a aumentar, os valores da outra variável também tendem a aumentar. Isto é representado por um coeficiente de correlação positivo. 


\subsubsection{Análise de Componentes Principais (PCA)}

As principais aplicações das técnicas de análise fatorial são: 1) para reduzir o número de variáveis e 2) para detectar a estrutura nas relações entre as variáveis, que é classificar variáveis. O exemplo descrito na ideia básica de análise fatorial como um método de redução de dados, combinando duas variáveis correlacionadas em um fator, ilustra a ideia básica da análise de componentes principais (PCA).

Para classificar e destacar as relações entre as variáveis dos casos estudados, a técnica PCA pode recorrer aos recursos gráficos. As variáveis e os casos são graficados em um espaço bidimensional gerados pelas componentes principais.

As variáveis podem ser representadas em um círculo denominado círculo de correlação cujos eixos são formados pelos fatores da componente principal. Para analisar a figura devemos levar em consideração as projeções dos pontos nos eixos. Este gráfico auxilia na classificação dos casos em diferentes conjuntos de acordo com suas coordenadas correspondentes nos eixos. A análise das proximidades ou oposições entre variáveis é feita em termos de correlações.

Como podemos observar, na figura 3.16, algumas variáveis estão sobrepostas umas às outras. Isso mostra que essas possuem a mesma representatividade no gráfico. Outro fato importante é se algumas variáveis estão bem próximas ao círculo unitário, isso mostra que estas possuem uma maior contribuição, em relação às variáveis que estão mais afastadas. 


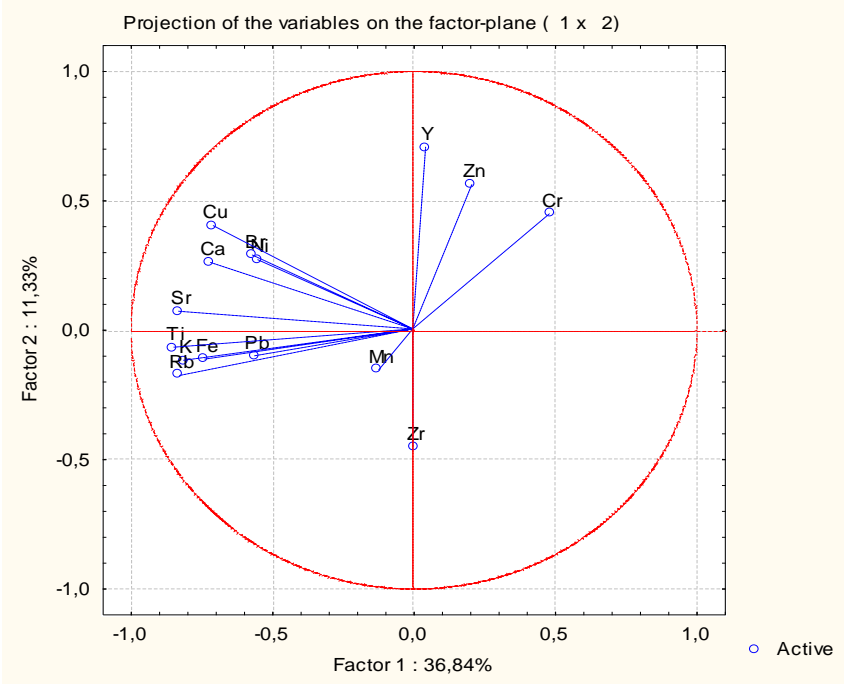

Figura 3.16. Exemplo de Círculo de correlação utilizado na análise de componentes principais. Este gráfico de exemplo corresponde à análise feita por XRF nos fragmentos apresentados neste estudo (CURADO, 2012) 


\section{RESULTADOS E DISCUSSÕES}

Com exceção da técnica de radiografia, todas as medidas de imageamentos foram realizadas in situ. Nas ocasiões das análises, foram montados nos próprios locais um estúdio fotográfico para as medidas com luz visível, ultravioleta (UV), rasante (ou tangencial) e reflectância do infravermelho. As reflectografias IR foram inicialmente realizadas com a câmera FujiFilm nas obras "Tropical" e "O Homem Amarelo", posteriormente o Instituto de Física da Universidade de São Paulo adquiriu uma câmera Osiris, e foi possível realizas imagens de reflectografia IR das obras "O Homem Amarelo", "O Japonês" e "A Estudante Russa". Um exemplo da montagem experimental para realização das técnicas de imagem é apresentado na figura 4.1, foto esta tomada na Pinacoteca do Estado de São Paulo, com a obra "Tropical". No quadro "O Homem Amarelo" foi possível ainda realizar uma radiografia computadorizada da obra.

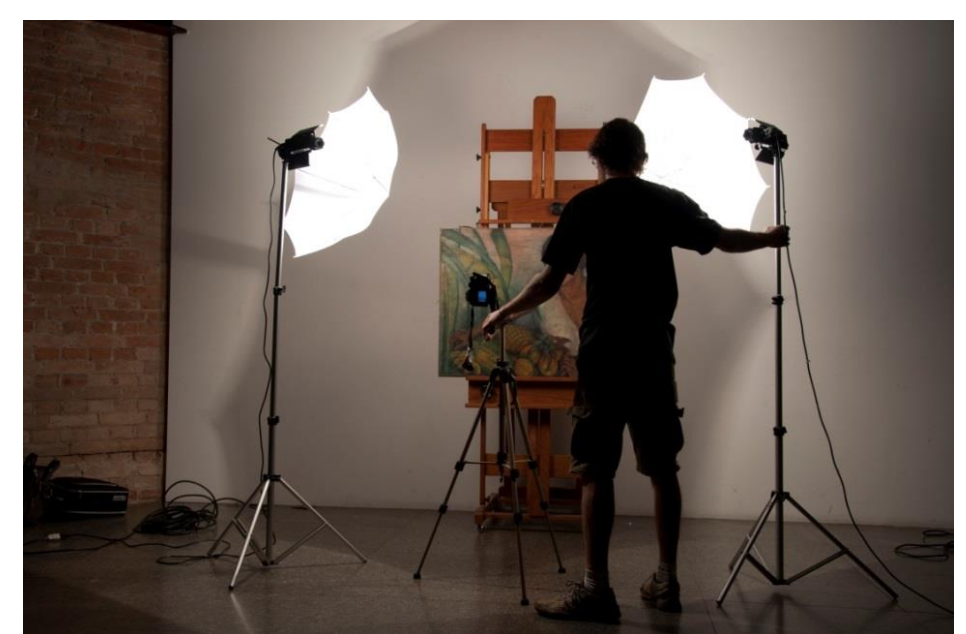

Figura 4.1 - Arranjo fotográfico para as análises de imageamento, sendo realizado na obra "Tropical" da artista Anita Malfatti, pertencente ao acervo da Pinacoteca do Estado de São Paulo. Foto: E. Kajiya

As análises com fluorescência de raios $X$ por dispersão de energia (EDXRF) foram realizadas nas cinco obras da artista Anita Malfatti, apresentadas no capítulo anterior, sendo que quatro destas obras foram analisadas por imageamento. Infelizmente na obra "O Retrato de Mário de Andrade" não foi realizado o imageamento com as diversas técnicas anteriormente apresentadas. A colorimetria esteve disponível apenas durante as medidas EDXRF das obras "O Japonês", "A Estudante Russa" e "O Homem 
Amarelo". As análises com EDXRF foram realizadas em pontos específicos das obras, a fim de estudar os pigmentos presentes nas mesmas. Os pontos escolhidos foram aqueles com a maior diversidade de tonalidades de cores representadas, assim como algumas regiões indicadas por especialistas em arte (conservadores e restauradores), que davam suporte à pesquisa e acompanhavam o trabalho de análise. Estes mesmos pontos foram escolhidos para as medidas com o espectrofotômetro, para todos aqueles que a técnica permitia, pois o fator limitante era a dimensão dos pontos escolhidos, que por vezes eram menores do que a capacidade que o espectrofotômetro permitia, correndo-se o risco de serem medidas diversas cores simultaneamente.

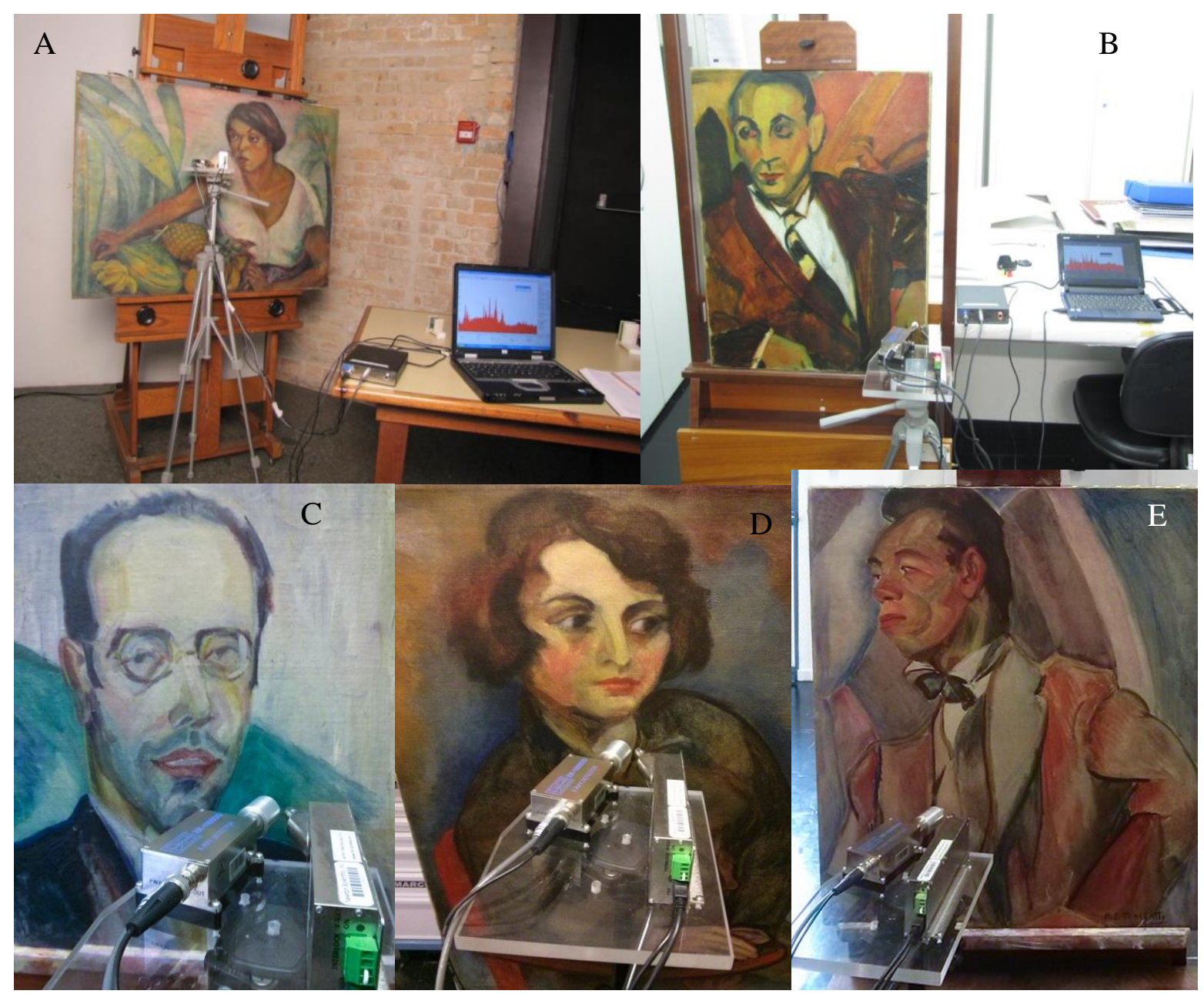

Figura 4.2 - Fotografia do equipamento de EDXRF do Instituto de Física realizando medidas in situ nas diferentes obras: A) "Tropical" (1917) do acervo da Pinacoteca do Estado de São Paulo. B) "O Homem Amarelo" (1915/1916) do acervo do IEB-USP, C) O Retrato de Mario de Andrade (1923) do acervo do IEB-USP. D) "A Estudante Russa" (1916) do acervo do IEB-USP E) "O Japonês" (1915/1916) do acervo do IEB-USP 
As imagens obtidas pelas diferentes técnicas de imageamento, tanto no visível, quanto em outras frequências, auxiliaram nas análises por EDXRF, pois possibilitaram a identificação das cores das regiões analisadas, bem como possíveis regiões de intervenções ou imagens subjacentes existentes. Em todas as obras, as análises e tomadas de dados com EDXRF foram realizadas in situ, com o sistema portátil, exemplos da utilização deste equipamento durante a análise são mostrados na figura 4.2. Os pontos analisados possuíam cerca de 1 ou $2 \mathrm{~mm}$ de diâmetro. O tempo de medida em cada ponto foi de 100 segundos, com uma voltagem de $30 \mathrm{~V}$ e corrente de $5 \mu \mathrm{A}$ no tubo de raio $\mathrm{X}$. Foi mantido o controle do tempo morto do sistema de detecção para que esse permanecesse abaixo de $10 \%$, a fim de minimizar os picos somas e a deformação dos picos no espectro obtidos nas medidas.

Após a obtenção dos espectros de raios $\mathrm{X}$ característicos de cada ponto medido pelo sistema de EDXRF portátil descrito, foi utilizado o programa WinQXAS (WinQXAS, 2002), para a obtenção das áreas dos picos dos elementos químicos observáveis presentes nos pontos analisados.

Houve dificuldade na obtenção das áreas de alguns elementos químicos que possuem baixa quantidade, pois há sobreposição de picos em algumas regiões espectrais com energias muito próximas, impossibilitando diferenciálos, alguns dos exemplos a serem citados e observados na análise estão presentes na figura 4.3, que é o espectro obtido em uma região vermelha alaranjada na obra "O Retrato de Mario de Andrade". Como exemplo, temos o caso do enxofre ( $\mathrm{S}, \mathrm{K} \alpha 1$ - 2,307 keV, $\mathrm{K} \beta 1$ - 2,464 keV) e do cloro $(\mathrm{Cl}, \mathrm{K} \alpha 1$ 2,622 keV, $K \beta 1-2,815 \mathrm{keV}$ ), que possuem seus picos de energia $\mathrm{K}$ próximos às linhas de energia $M$ do chumbo $(P b, M \alpha-2,346 \mathrm{keV}, M \beta-2,442 \mathrm{keV} ; \mathrm{M} \gamma$ $2.658 \mathrm{keV}$ ) (NATIONAL PHYSICAL LABORATORY, 2005) que é um elemento que está presente na maioria dos pontos analisados e com grande intensidade nos espectros adquiridos. Outro exemplo está na determinação do estrôncio $(\mathrm{Sr})$ que possui energia ( $K \alpha-14,165 \mathrm{keV}$ próximo às linhas $\mathrm{L}$ do chumbo $\mathrm{L} \gamma$ $14,764 \mathrm{keV}$ ) e o arsênio (As), que possui sua linha $\mathrm{K} \alpha(10,543 \mathrm{keV})$ sobreposta também às linhas $\mathrm{L} \alpha$ do $\mathrm{Pb}(10,551 \mathrm{keV})$ e se este estiver em pequena quantidade não será possível a identificação do $\mathrm{K} \beta(11,726 \mathrm{keV})$ deste 
elemento, que o diferenciaria. O potássio $(\mathrm{K})$ tem sua linha de energia $\mathrm{K} \alpha$ $(3,314 \mathrm{keV})$ próxima às linhas de energia $L$ da prata e cádmio $(\mathrm{Ag}$ : $\mathrm{L} \beta 13,151$ keV e L $\beta 2$ 3,348 keV; Cd: L $\alpha 1$ 3,134 keV e L $\beta 1$ 3,317 keV, respectivamente), e estas linhas estão presentes devido ao tubo de raios $X$ utilizado possuir um ânodo de prata e o Cd estar presente em alguns pigmentos da paleta da artista. A determinação da presença do potássio também sofre interferência devido aos picos de energia K do argônio (Ar: K $\alpha$ 2,957 keV e K $\beta$ 3,190 keV) presente na atmosfera, o que dificulta uma precisa determinação das áreas. Como pode ser vista também na figura 4.3, o pico soma do $\mathrm{Pb}$ quando presente, coincide com as linhas $\mathrm{K} \alpha$ do $\mathrm{Cd}$. Por isso, nesta análise, a presença de cádmio foi ignorada para picos nesta região energética com áreas abaixo de 200 contagens, pois este foi o valor médio das contagens dos picos soma do $\mathrm{Pb}$ para este sistema quando irradiados alvos de padrões de chumbo.

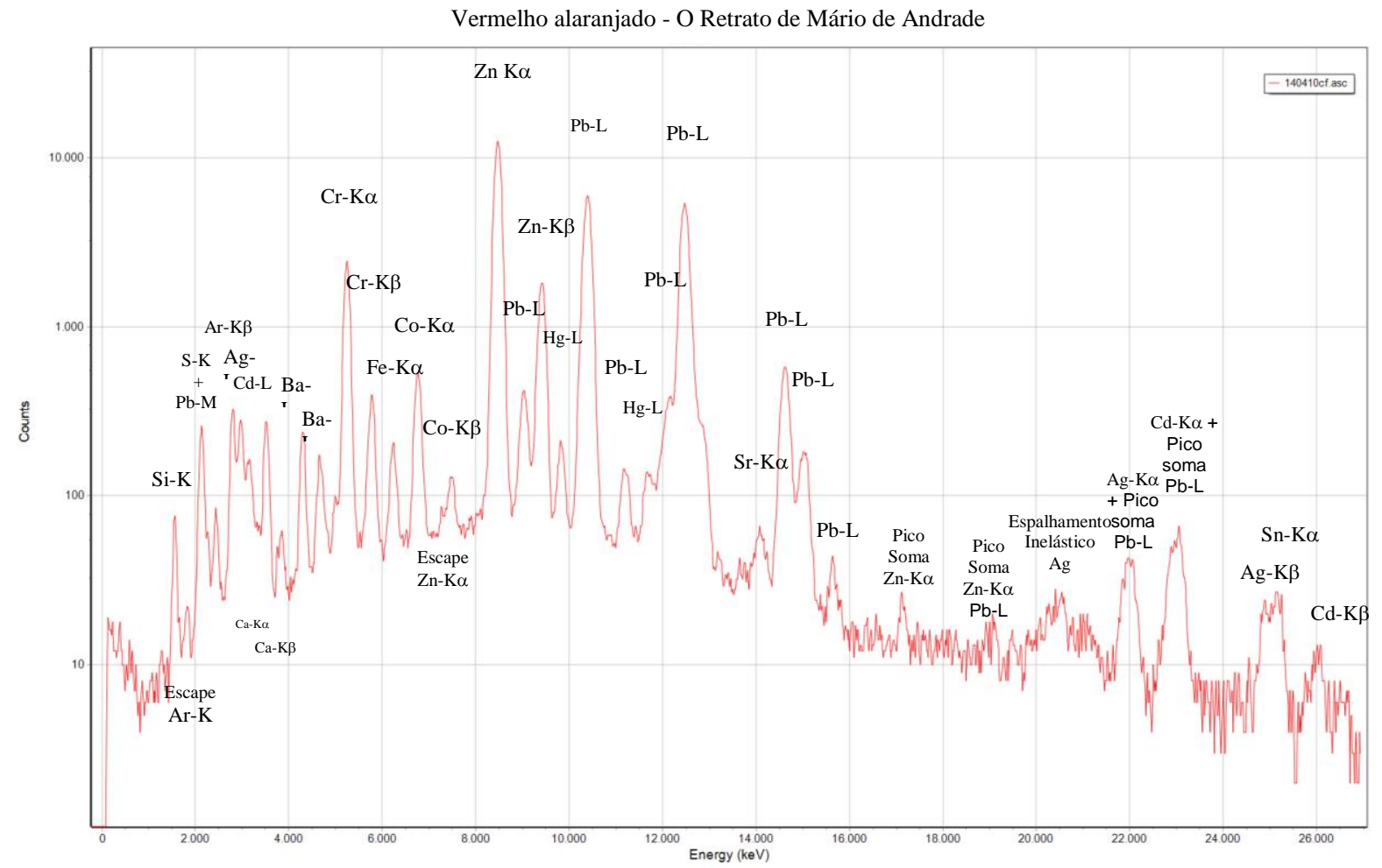

Figura 4.3 - Espectro EDXRF típico para um pigmento (vermelho alaranjado) da obra "O Retrato de Mario de Andrade" de Anita Malfatti (1923) do acervo do IEB-USP

Outro elemento que pode ser de difícil detecção, quando está em baixa concentração no pigmento analisado, é o cobalto (Co $\mathrm{K} \alpha 6,930 \mathrm{keV}, \mathrm{K} \beta 1$ $7.649 \mathrm{keV}$ ) pois coincide com a energia do pico escape (em um detector de Si) 
para a linha $\mathrm{K} \alpha$ do zinco $(\mathrm{Zn})$, em 6,897 keV, que é um elemento muito presente nos pigmentos analisados neste trabalho.

Todos estes detalhes mostram a complexidade das análises aqui apresentadas, pois diversos fatores contribuem para a presença dos elementos nos espectros dos pontos analisados, como a composição da tinta comercial, a informação da presença de elementos de diversas camadas, assim como a mistura de diferentes tintas na paleta dos artistas no momento que estes compõem a obra.

Deste modo para as análises de pinturas, a caracterização qualitativa da amostra, em geral, tem maior importância que a quantitativa, pois características intrínsecas como a não uniformidade da pincelada do artista e a presença de misturas de pigmentos ou interferências de outras camadas de tinta, fundo de preparação e suporte geram diferenças significativas na quantificação dos elementos. Ademais, em se tratando de equipamentos móveis, a geometria formada entre a obra de arte, o emissor e o detector variam de ponto para ponto, causando interferências na contagem dos fótons dos elementos, o que dificulta a análise quantitativa como um todo. Portanto, para esta aplicação a técnica foi considerada como semiquantitativa.

A partir das áreas obtidas nos diferentes espectros de energia, foram confeccionados os gráficos de barra de cada um dos elementos identificados nos pontos analisados em cada obra. Os erros estatísticos na determinação das áreas ficaram em torno de 5\%. A análise destes gráficos de barra permite a comparação da presença e da distribuição de cada um destes elementos nos pigmentos das obras analisadas. Em cada gráfico, os pontos foram agrupados simbolicamente por cores, mas que servem apenas para guiar os olhos nas análises, pois a variação de tons é muito grande para a afirmação de que aquele ponto corresponde exatamente àquela cor.

A comparação das áreas obtidas nos espectros para os diferentes elementos identificados em uma mesma obra é de difícil execução, pois se 
deve levar em conta o fator eficiência do sistema de excitação e detecção dos elementos, que pode variar muito para cada elemento.

A comparação entre as áreas de um mesmo elemento em uma mesma tela pode ser realizada com base na comparação da quantidade de raios $X$ detectados dos elementos presentes, no entanto o cálculo da concentração é de extrema complexidade, por não se tratar de materiais homogêneos, nem de camadas bem definidas destes materiais, sendo, normalmente, misturas de tintas feitas pelo próprio artista em sua paleta, durante a realização da obra. No entanto deve-se ter a cuidado ao analisar as áreas obtidas de um elemento nos diferentes pontos, pois os raios $X$ utilizados na técnica $X R F$ tem penetração suficiente para interagir com as camadas mais internas da obra (ou as diferentes pinceladas), chegando, em algumas situações, a levantar informações do chassi de madeira utilizado na estrutura da tela nos espectros obtidos. Todas as obras aqui analisadas, com exceção da paleta de madeira, foram realizadas em telas de tecido, tendo um chassi de madeira como base estrutural para a realização das pinturas.

A presença em maior ou menor quantidade de um dado elemento em cada ponto analisado tem relação direta com as espessuras das camadas que compõem a região irradiada. Um determinado pigmento, que supostamente não deveria possuir um elemento químico no espectro, pode estar presente, pois os seus raios $X$ característicos são provenientes de outras camadas. Isso se torna mais complexo à medida que uma obra possui várias camadas de pintura, como em telas reutilizadas ou com arrependimentos (pentimentos) ${ }^{1}$ artísticos.

Assim como na maioria dos pontos analisado com EDXRF, foram feitas medidas na cartela de cores ColorChecker ${ }^{\circledR}$ com o mesmo espectrofotômetro modelo CM-2500d da marca Konica-Minolt, utilizado nas obras. O resultado obtido pode ser observado na tabela 4.1. Foi utilizado o método de

\footnotetext{
${ }^{1}$ s. m. pi. do fr. repentirs, it. pentimentos, ing. repentances; aplica-se o termo a qualquer mudança, ou emenda feita pelo pintor em um quadro já colorido, ou seja nos contornos, ou em algumas de suas partes componentes; (FRANCISCO DE ASSIS,1875); Efeito de uma película opaca se tornar suficientemente transparente para que a subpintura ou desenho transpareça (MAYER, 2006).
} 
determinação de percepção de diferença de cor pelo olho humano, entre a medida obtida e a padrão ou valor nominal ( $\Delta \mathrm{E}^{*} \mathrm{ab}$ ) (DIN 6174, 1979). Os resultados mostram que o espectrômetro obteve em alguns casos, como no "red", que teve um $\Delta \mathrm{E}^{*}$ ab de 10,35 considerado uma diferença muito grande (acima de 6), enquanto que no "yellow" a diferença foi de 1,81, considerado distinguível $(1,5-3,0)$. As diferenças em média foram menores nas escala de cinza, 1,07 , considerada pequena $(0,5-1,5)$, enquanto que nas demais cores a média foi de 5,10 , considerado facilmente distinguível $(3,0-6,0)$. 
Tabela 4.1 - Medidas de colorimetria com o espectrômetro modelo CM-2500d da marca Konica-Minolt na cartela ColorChecker da X-Rite Photo

\begin{tabular}{|c|c|c|c|c|c|c|c|c|c|}
\hline Cor & Cor & $\mathrm{L}^{*}$ & $a^{*}$ & b* $^{*}$ & $\mathrm{R}^{*}$ & G* & B* & Colorimetro & ColorCheck $^{\circledast}$ \\
\hline \multirow{5}{*}{$\begin{array}{l}\text { Dark } \\
\text { Skin }\end{array}$} & \multirow{3}{*}{ Medidas } & 38,12 & 11,87 & 13,00 & \multirow{4}{*}{114,96} & \multirow{4}{*}{82,16} & \multirow{4}{*}{69,25} & & \\
\hline & & 38,17 & 11,84 & 12,94 & & & & & \\
\hline & & 37,95 & 11,85 & 12,99 & & & & & \\
\hline & Media & 38,08 & 11,85 & 12,98 & & & & & \\
\hline & $\Delta \mathrm{E}$ & \multicolumn{3}{|c|}{2,02} & & & & & \\
\hline \multirow{5}{*}{$\begin{array}{l}\text { Light } \\
\text { Skin }\end{array}$} & \multirow{3}{*}{ Medidas } & 64,76 & 14,17 & 17,45 & \multirow{4}{*}{192,42} & \multirow{4}{*}{147,15} & \multirow{4}{*}{126,65} & & \\
\hline & & 64,70 & 14,19 & 17,41 & & & & & \\
\hline & & 64,71 & 14,22 & 17,43 & & & & & \\
\hline & Media & 64,72 & 14,19 & 17,43 & & & & & \\
\hline & $\Delta \mathrm{E}$ & & 4,08 & & & & & & \\
\hline \multirow{5}{*}{ Blue Sky } & \multirow{3}{*}{ Medidas } & 51,35 & $-4,80$ & $-19,87$ & \multirow{4}{*}{89,78} & \multirow{4}{*}{126,33} & \multirow{4}{*}{155,87} & & \\
\hline & & 51,36 & $-4,81$ & $-19,89$ & & & & & \\
\hline & & 51,32 & $-4,78$ & $-19,93$ & & & & & \\
\hline & Media & 51,34 & $-4,80$ & $-19,90$ & & & & & \\
\hline & $\Delta \mathrm{E}$ & & 2,48 & & & & & & \\
\hline \multirow{5}{*}{ Foliage } & & 43,11 & $-10,57$ & 21,61 & \multirow{4}{*}{97,36} & \multirow{4}{*}{105,91} & & & \\
\hline & Medidas & 43,12 & $-10,56$ & 21,61 & & & 6551 & & \\
\hline & & 43,12 & $-10,56$ & 21,65 & & & (כ), & & \\
\hline & Media & 43,12 & $-10,56$ & 21,62 & & & & & \\
\hline & $\Delta \mathrm{E}$ & & 2,55 & & & & & & \\
\hline & & 57,49 & 6,87 & $-23,15$ & & & & & \\
\hline & Medidas & 57,46 & 6,88 & $-23,21$ & ס0 רכ2 & 12500 & 17020 & & \\
\hline Blue & & 57,49 & 6,87 & $-23,19$ & 121,90 & 130,95 & $1 / 0,<0$ & & \\
\hline & Media & 57,48 & 6,87 & $-23,18$ & & & & & \\
\hline & $\Delta \mathrm{E}$ & & 3,79 & & & & & & \\
\hline & & 71,44 & $-30,28$ & 2,58 & & & & & \\
\hline & Medidas & 71,49 & $-30,29$ & 2,60 & 10705 & 10012 & 16041 & & \\
\hline $\begin{array}{l}\text { Blulsh } \\
\text { Green }\end{array}$ & & 71,50 & $-30,31$ & 2,57 & 101,05 & 190,13 & 109,41 & & \\
\hline & Media & 71,48 & $-30,29$ & 2,58 & & & & & \\
\hline & $\Delta \mathrm{E}$ & & 4,24 & & & & & & \\
\hline & & 60,04 & 33,88 & 53,91 & & & & & \\
\hline & Medidas & 59,99 & 33,77 & 53,69 & 21000 & 110 & 5 & & \\
\hline Orange & & 60,10 & 33,98 & 54,04 & 218,00 & 118,41 & $4 /, 35$ & & \\
\hline & Media & 60,04 & 33,88 & 53,88 & & & & & \\
\hline & $\Delta \mathrm{E}$ & & 4,69 & & & & & & \\
\hline & & 43,02 & 7,17 & $-39,62$ & & & & & \\
\hline & Medidas & 43,02 & 7,20 & $-39,65$ & 111 & 101 & 16716 & & \\
\hline Purpilsn & & 43,02 & 7,20 & $-39,59$ & 01,11 & 101,31 & $10 \%, 10$ & & \\
\hline & Media & 43,02 & 7,19 & $-39,62$ & & & & & \\
\hline & $\Delta \mathrm{E}$ & & 7,72 & & & & & & \\
\hline & & 50,73 & 41,94 & 12,87 & & & & & \\
\hline & Medidas & 50,75 & 41,98 & 12,82 & 10020 & 0002 & 1000 & & \\
\hline $\begin{array}{c}\text { Modered } \\
\text { Red }\end{array}$ & & 50,75 & 41,84 & 12,87 & 190,34 & 88,83 & 100,94 & & \\
\hline & Media & 50,74 & 41,92 & 12,85 & & & & & \\
\hline & $\Delta \mathrm{E}$ & & 7,18 & & & & & & \\
\hline & & 31,71 & 19,39 & $-20,73$ & & & & & \\
\hline & Medidas & 31,62 & 19,60 & $-20,90$ & 0006 & & אר 107 & & \\
\hline Purple & & 31,59 & 19,56 & $-20,89$ & 88,86 & 64,67 & 107,26 & & \\
\hline & Media & 31,64 & 19,52 & $-20,84$ & & & & & \\
\hline & $\Delta \mathrm{E}$ & & 3,78 & & & & & & \\
\hline
\end{tabular}


Tabela 4.1 - Medidas de colorimetria com o espectrômetro modelo CM-2500d da marca Konica-Minolt na cartela ColorChecker da X-Rite Photo

\begin{tabular}{|c|c|c|c|c|c|c|c|c|c|}
\hline Cor & Cor & $\mathrm{L}^{*}$ & a* & $\mathbf{b}^{*}$ & $\mathrm{R}^{*}$ & G* & B* & Colorimetro & ColorCheck $^{\circledR}$ \\
\hline \multirow{5}{*}{$\begin{array}{l}\text { Yellow } \\
\text { Green }\end{array}$} & \multirow{3}{*}{ Medidas } & 71,36 & $-19,80$ & 57,60 & \multirow{4}{*}{170,91} & \multirow{4}{*}{182,51} & \multirow{4}{*}{61,78} & & \\
\hline & & 71,28 & $-19,86$ & 57,50 & & & & & \\
\hline & & 71,33 & $-19,80$ & 57,60 & & & & & \\
\hline & Media & 71,32 & $-19,82$ & 57,57 & & & & & \\
\hline & $\Delta \mathrm{E}$ & & 4,08 & & & & & & \\
\hline \multirow{5}{*}{$\begin{array}{l}\text { Orange } \\
\text { Yellow }\end{array}$} & \multirow{3}{*}{ Medidas } & 68,98 & 19,93 & 64,26 & \multirow{4}{*}{228,24} & \multirow{4}{*}{152,44} & \multirow{4}{*}{42,91} & & \\
\hline & & 69,00 & 20,00 & 64,41 & & & & & \\
\hline & & 68,93 & 19,96 & 64,28 & & & & & \\
\hline & Media & 68,97 & 19,96 & 64,32 & & & & & \\
\hline & $\Delta \mathrm{E}$ & & 4,66 & & & & & & \\
\hline \multirow{5}{*}{ Blue } & \multirow{3}{*}{ Medidas } & 33,18 & 10,43 & $-42,95$ & \multirow{4}{*}{29,47} & \multirow{4}{*}{76,86} & \multirow{4}{*}{146,57} & & \\
\hline & & 33,23 & 10,44 & $-42,96$ & & & & & \\
\hline & & 33,30 & 10,45 & $-43,03$ & & & & & \\
\hline & Media & 33,24 & 10,44 & $-42,98$ & & & & & \\
\hline & $\Delta \mathrm{E}$ & & 9,35 & & & & & & \\
\hline \multirow{5}{*}{ Green } & & 53,86 & $-34,23$ & 33,74 & \multirow{4}{*}{84,06} & \multirow{4}{*}{142,78} & \multirow{4}{*}{67,90} & & \\
\hline & Medidas & 53,88 & $-34,12$ & 33,63 & & & & & \\
\hline & & 53,96 & $-34,23$ & 33,67 & & & & & \\
\hline & Media & 53,90 & $-34,19$ & 33,68 & & & & & \\
\hline & $\Delta \mathrm{E}$ & & 4,94 & & & & & & \\
\hline & & 41,28 & 43,70 & 24,67 & & & & & \\
\hline & Medidas & 41,23 & 43,66 & 24,69 & 16799 & 6144 & 5932 & & \\
\hline Red & & 41,27 & 43,65 & 24,74 & כשותוט & דיד, שגט & שגנסני & & \\
\hline & Media & 41,26 & 43,67 & 24,70 & & & & & \\
\hline & $\Delta \mathrm{E}$ & & 10,35 & & & & & & \\
\hline & & 79,97 & 4,08 & 79,36 & & & & & \\
\hline & Medidas & 79,92 & 4,10 & 79,56 & 24130 & 19218 & 19.32 & & \\
\hline Yellow & & 79,93 & 4,08 & 79,57 & $24 \pm, 00$ & $10<, 10$ & 20, & & \\
\hline & Media & 79,94 & 4,09 & 79,50 & & & & & \\
\hline & $\Delta \mathrm{E}$ & & 1,82 & & & & & & \\
\hline & & 51,72 & 43,35 & $-16,12$ & & & & & \\
\hline & Medidas & 51,71 & 43,31 & $-16,11$ & 18116 & 9287 & 15171 & & \\
\hline Magenta & & 51,72 & 43,21 & $-16,04$ & 181,16 & 92,82 & $151, / 1$ & & \\
\hline & Media & 51,72 & 43,29 & $-16,09$ & & & & & \\
\hline & $\Delta \mathrm{E}$ & & 6,87 & & & & & & \\
\hline & & 53,55 & $-28,78$ & $-21,94$ & & & & & \\
\hline & Medidas & 53,55 & $-28,78$ & $-21,88$ & 0.00 & 14282 & 164.73 & & \\
\hline Cyan & & 53,59 & $-28,82$ & $-21,89$ & & $14<, 02$ & Jו, & & \\
\hline & Media & 53,56 & $-28,79$ & $-21,90$ & & & & & \\
\hline & $\Delta \mathrm{E}$ & & 7,19 & & & & & & \\
\hline & & 95,81 & $-1,06$ & 3,18 & & & & & \\
\hline & Medidas & 95,75 & $-1,04$ & 3,16 & 243,48 & 243,24 & 236,71 & & \\
\hline$\left(.05^{*}\right)$ & & 95,79 & $-1,04$ & 3,13 & & & & & \\
\hline & Media & 95,78 & $-1,05$ & 3,16 & & & & & \\
\hline & $\Delta \mathrm{E}$ & & 2,20 & & & & & & \\
\hline & & 80,57 & $-0,81$ & 0,23 & & & & & \\
\hline & Medidas & 80,36 & $-0,76$ & 0,25 & 19830 & 20011 & 19917 & & \\
\hline $8\left(.23^{*}\right)$ & & 80,52 & $-0,80$ & 0,23 & טכ, & $200,1 \pm$ & לגונכנו & & \\
\hline & Media & 80,48 & $-0,79$ & 0,24 & & & & & \\
\hline & $\Delta \mathrm{E}$ & & 0,97 & & & & & & \\
\hline
\end{tabular}


Tabela 4.1 - Medidas de colorimetria com o espectrômetro modelo CM-2500d da marca Konica-Minolt na cartela ColorChecker da X-Rite Photo

\begin{tabular}{|c|c|c|c|c|c|c|c|c|c|}
\hline Cor & Cor & $L^{*}$ & $a^{*}$ & b* & $\mathbf{R}^{*}$ & G* & B* & Colorimetro & ColorCheck $^{\circledR}$ \\
\hline \multirow{5}{*}{$\begin{array}{c}\text { Natural } \\
6.5 \\
\left(.44^{*}\right)\end{array}$} & \multirow{3}{*}{ Medidas } & 66,39 & $-0,72$ & 0,13 & \multirow{4}{*}{160,27} & \multirow{4}{*}{161,95} & \multirow{4}{*}{161,32} & & \\
\hline & & 66,43 & $-0,72$ & 0,13 & & & & & \\
\hline & & 66,54 & $-0,73$ & 0,08 & & & & & \\
\hline & Media & 66,45 & $-0,72$ & 0,11 & & & & & \\
\hline & $\Delta \mathrm{E}$ & \multicolumn{3}{|c|}{0,69} & & & & & \\
\hline \multirow{5}{*}{$\begin{array}{l}\text { Natural } \\
5\left(.70^{*}\right)\end{array}$} & \multirow{3}{*}{ Medidas } & 51,02 & $-0,11$ & $-0,30$ & \multirow{4}{*}{121,16} & \multirow{4}{*}{121,67} & \multirow{4}{*}{122,10} & & \\
\hline & & 51,11 & $-0,09$ & $-0,32$ & & & & & \\
\hline & & 51,05 & $-0,11$ & $-0,30$ & & & & & \\
\hline & Media & 51,06 & $-0,10$ & $-0,31$ & & & & & \\
\hline & $\Delta \mathrm{E}$ & \multicolumn{3}{|c|}{0,20} & & & & & \\
\hline \multirow{5}{*}{$\begin{array}{c}\text { Natural } \\
3.5 \\
\left(.1 .05^{*}\right)\end{array}$} & \multirow{3}{*}{ Medidas } & 36,76 & $-0,45$ & $-1,03$ & \multirow{4}{*}{85,16} & \multirow{4}{*}{87,02} & \multirow{4}{*}{88,34} & & \\
\hline & & 36,88 & $-0,44$ & $-1,06$ & & & & & \\
\hline & & 36,96 & $-0,46$ & $-1,01$ & & & & & \\
\hline & Media & 36,87 & $-0,45$ & $-1,03$ & & & & & \\
\hline & $\Delta \mathrm{E}$ & & 1,23 & & & & & & \\
\hline & & 21,50 & 0,07 & $-0,56$ & & & & & \\
\hline & Medidas & 21,46 & 0,01 & $-0,51$ & 5117 & 5150 & 527 & & \\
\hline Black & & 21,45 & 0,05 & $-0,54$ & ' & טכ, & 52,21 & & \\
\hline & Media & 21,47 & 0,04 & $-0,54$ & & & & & \\
\hline & $\Delta \mathrm{E}$ & & 1,11 & & & & & & \\
\hline
\end{tabular}

Nas obras em que foram realizadas fotografias com luz visível, nos pontos em que foram analisados por EDXRF também foi obtida a cor das médias dos pixels que compunham a área de análise. A média foi obtida pelo programa livre de análise de imagens ImageJ, versão 1.48V (RASBAND, 2014). As cores médias de cada ponto foram apresentadas em tabelas acompanhando as análises de cada obra, na mesma ordem dos seus respectivos pontos no gráfico de barras das medidas EDXRF.

Ainda com base nas análises de EDXRF, testes estatísticos por análise de matriz de correlações e por análise de componentes principais (PCA) foram realizados para determinar as correlações entre as presenças dos diversos elementos de cada ponto analisado nas obras. As correlações podem variar de 1,00 a $-1,00$. O valor de $-1,00$ representa uma perfeita correlação negativa, enquanto um valor de 1,00 representa uma perfeita correlação positiva. Um valor de 0,00 representa uma falta de correlação. Para realizar os testes estatísticos foi utilizado o programa STATISTICA, versão12, da Statsoft. 


\section{1 "O Japonês"}

Na obra "O Japonês", foi feito o imageamento com fotografia com luz visível, fotografia com luz rasante, fluorescência com luz UV e reflectografias IR. Na reflectografia IR obtida (figura 4.4), foi possível verificar que o quadro não possui pinturas subjacentes, ou pentimentos, assim como, ficou demonstrado que nesta obra a artista não se utiliza de um desenho prévio a grafite, ou com outro material sensível a técnica, e que os traços observados são relativos aos pigmentos que possuem carbono, que têm altas taxas de absorção de radiação infravermelha, evidenciando os traços da artista. Comparando esta imagem com a fotografia na faixa do visível (figura 3.4), é possível ver que tais pigmentos observados foram utilizados sobre os demais pigmentos, sendo assim um recurso de acabamentos e não traços iniciais para guiar o desenho.

Com a técnica de fluorescência com luz UV, notamos que esta obra possui apenas pequenos pontos de restauro de coloração violeta escuro, mostrando que por esta técnica não há evidências de regiões que exijam uma atenção especial por parte de conservadores e restauradores. Em comparação com a fotografia com luz visível, observamos que na fluorescência a maioria das regiões não difere das colorações observadas, mas na região do rosto, algumas regiões originalmente amarelas possuem fluorescência em um tom avermelhado, indicando a possibilidade dos pigmentos amarelo de cádmio, amarelo de cromo, ou amarelo de Nápoles.

$\mathrm{Na}$ técnica por luz rasante foram feitas imagens de várias regiões do quadro, mas não foi possível adquirir uma boa imagem de toda obra, isso se deve a uma diferença de nível entre o suporte e o chassi. Nota-se também, pela figura 4.6, que a borda do chassi deixa uma marca no suporte da obra. Além disso, nenhuma outra característica fica nítida, além da ondulação do suporte, mostrando que a espessura da camada pictórica é fina 


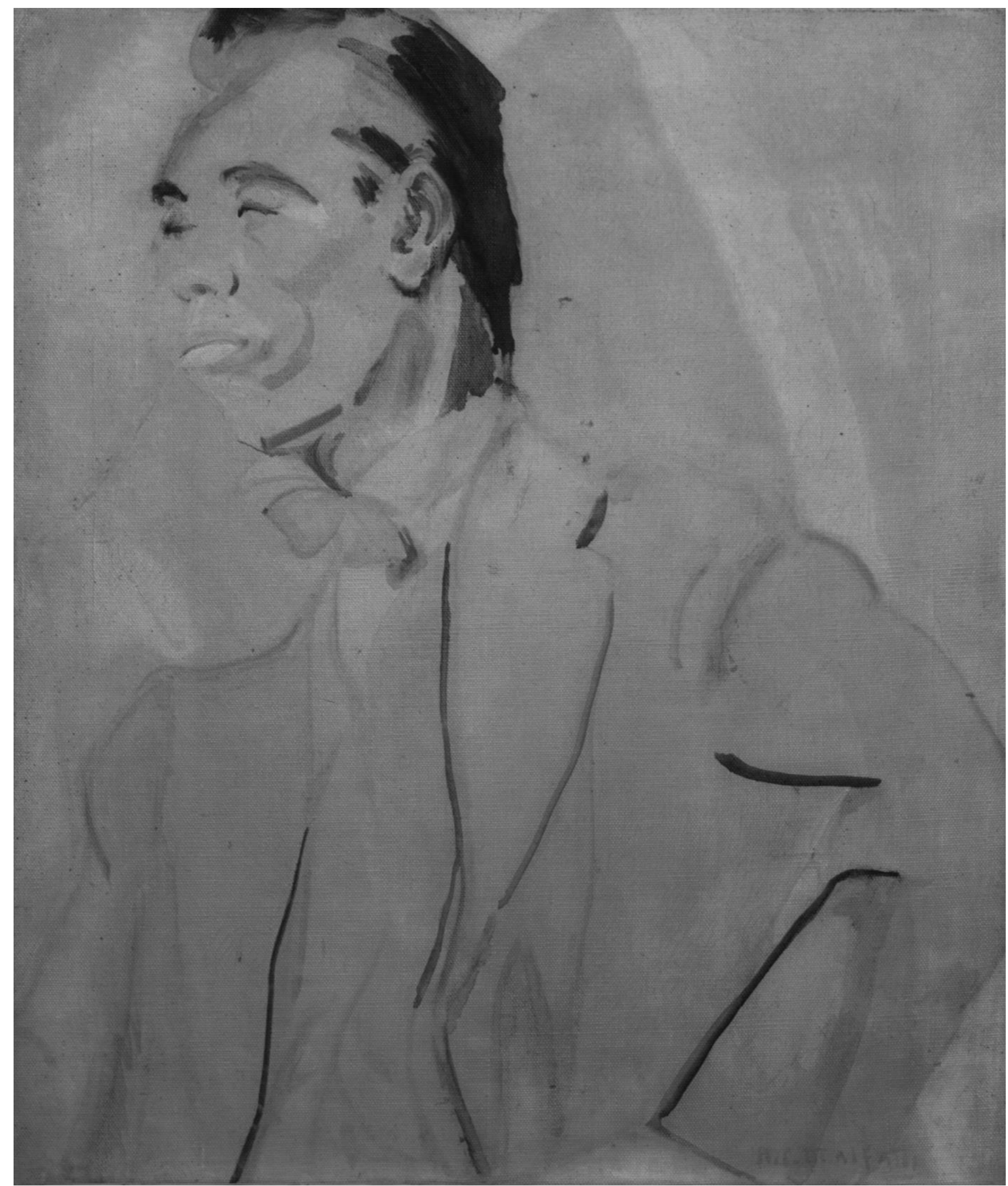

Figura 4.4 - Imagem de reflectografia no infravermelho da obra "O Japonês" (1915/1916) do acervo do IEB-USP 


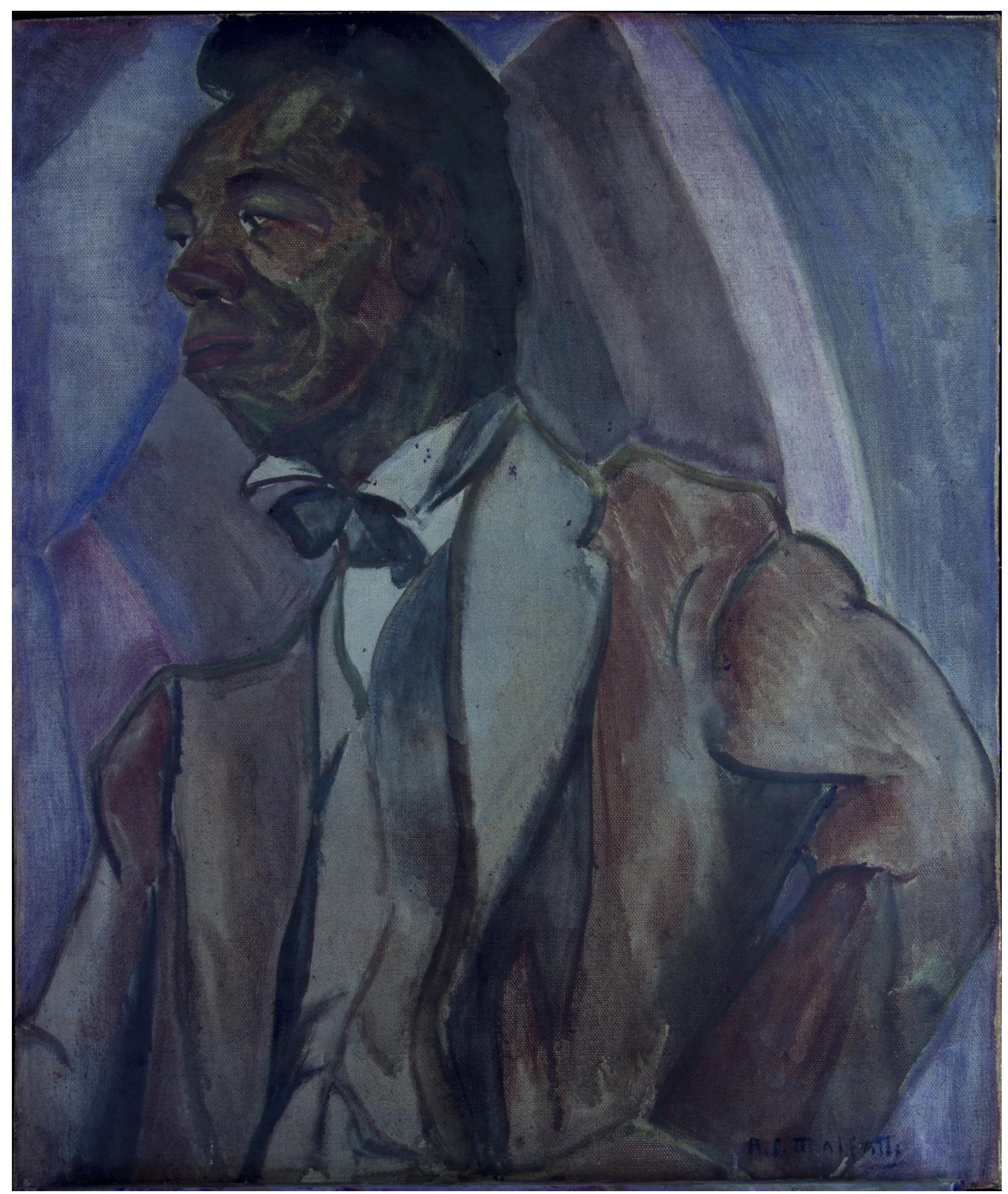

Figura 4.5 - Imagem de fluorescência com luz ultravioleta da obra "O Japonês" (1915/1916) do acervo do IEB-USP 


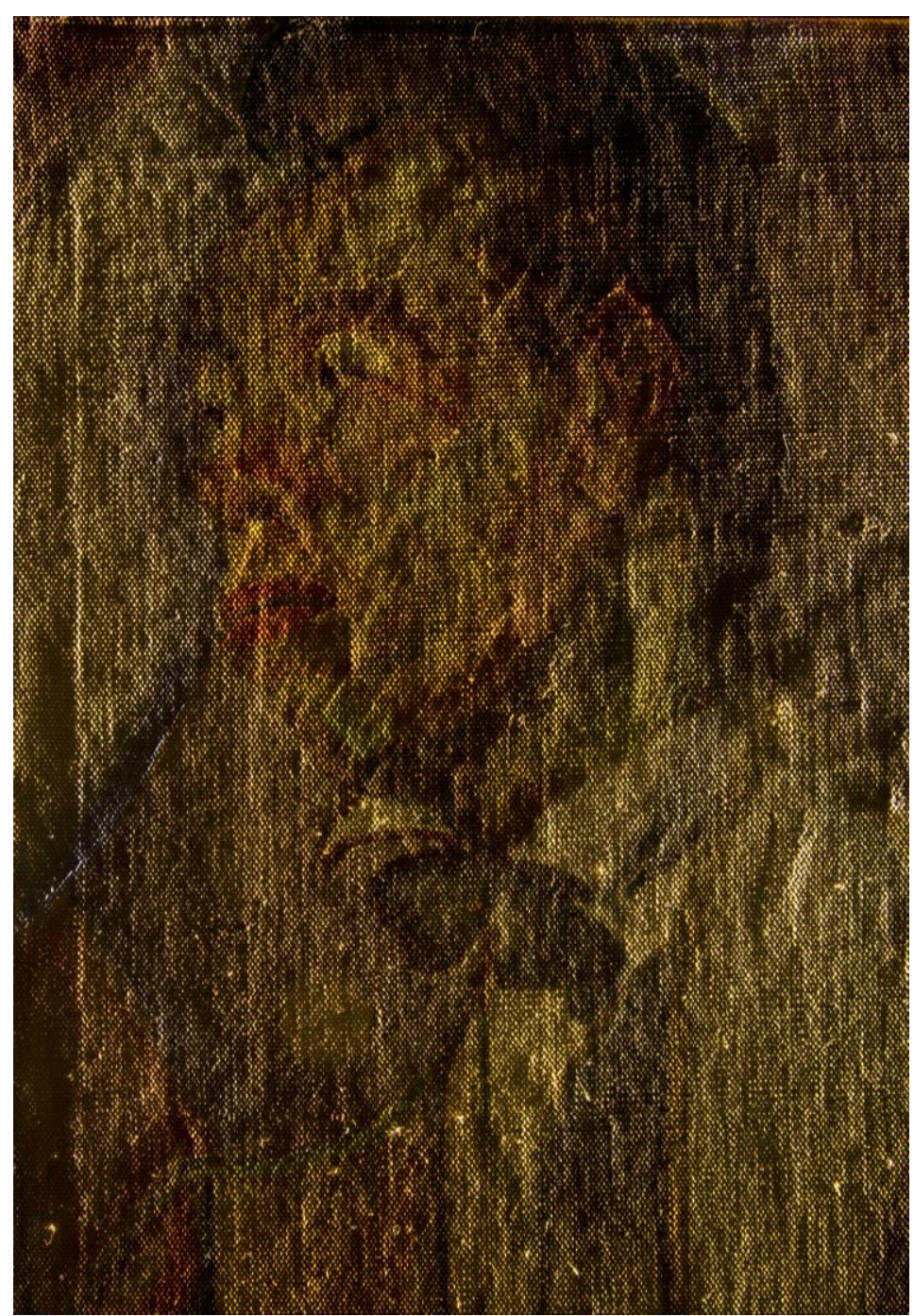

Figura 4.6 - Imagem com luz rasante de um detalhe da obra "O Japonês" (1915/1916) do acervo do IEB-USP

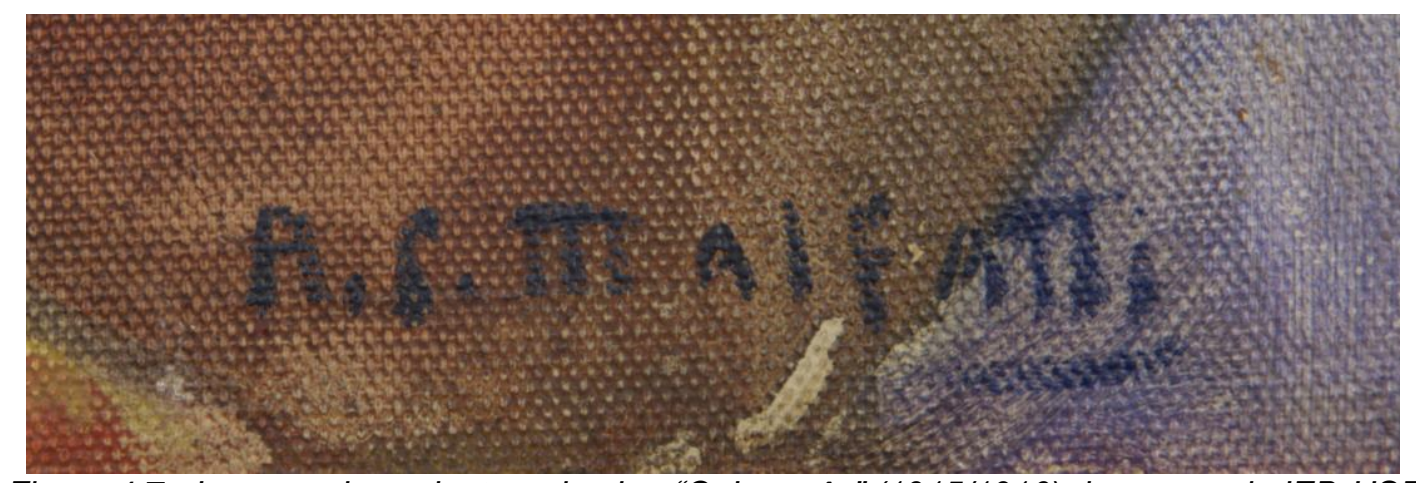

Figura 4.7 - Imagem da assinatura da obra "O Japonês" (1915/1916) do acervo do IEB-USP 
Este estudo também tomou o cuidado de registrar uma imagem em alta resolução, da assinatura da artista, a fim de gerar um banco de dados para posteriores estudos e comparações (figura 4.7).

Na obra "O Japonês", cinquenta e cinco (55) pontos foram medidos com EDXRF, que podem ser observados na figura 4.8. Na maioria desses pontos, foram feitas as medidas de cor com o espectrômetro e a determinação da média de cores pela fotografia com luz visível. Esta relação está listada na tabela 4.2 e os pontos estão na mesma ordem em que se apresentam nos gráficos de barras dos picos de cada elemento.

A análise destes diferentes pontos evidencia alta quantidade de $\mathrm{Pb}$ e 0 gráfico de barras deste elemento (figura 4.9) mostra a presença deste elemento em todos os pontos, com exceção dos pontos P54 e P55 (borda da tela onde não há camada pictórica, apenas o suporte da tela). Neste gráfico de barras os diferentes pontos foram agrupados segundo as colorações identificadas e estão evidenciadas por quadrados coloridos nas cores (preta, cinza, marrom, rosa, vermelho, azul, verde e preto). 
Tabela 4.2 - Relação das cores obidas por colorimetria (em coordenadas $L^{*} a^{*} b^{*}$ ) e fotografia digital (em coordenadas RGB) por nos pontos analisados por EDXRF na obra "O Japonês" de Anita Malfatti (1915/1916) do acervo do IEB-USP

\begin{tabular}{|c|c|c|c|c|c|c|}
\hline Ponto & P18 & P23 & P41 & P30 & P19 & P47 \\
\hline Foto (RGB) & $192,168,123$ & $181,161,122$ & $170,148,120$ & $170,146,115$ & $154,136,102$ & $172,138,109$ \\
\hline \multirow{2}{*}{$\begin{array}{c}\text { Colorimetria } \\
\left(L^{*}, a^{*}, b^{*}\right)\end{array}$} & & & & & & \\
\hline & $63,0,16$ & $60,-2,13$ & $55,-1,10$ & $55,-1,10$ & $53,-3,12$ & $56,4,10$ \\
\hline Ponto & P4 & P9 & P33 & P43 & P44 & P22 \\
\hline Foto (RGB) & $158,125,83$ & $151,119,85$ & $139,102,49$ & $135,94,40$ & $130,93,44$ & $142,111,89$ \\
\hline \multirow{2}{*}{$\begin{array}{c}\text { Colorimetria } \\
\left(L^{*}, a^{*}, b^{*}\right)\end{array}$} & & & & & & \\
\hline & $51,3,16$ & $48,2,13$ & $48,3,29$ & $42,9,22$ & $40,7,19$ & $43,3,8$ \\
\hline Ponto & P5 & P20 & P50 & P32 & P10 & P28 \\
\hline Foto (RGB) & $128,84,53$ & $162,127,49$ & $151,125,63$ & $190,123,54$ & $158,82,36$ & $181,72,43$ \\
\hline \multirow{2}{*}{$\begin{array}{c}\text { Colorimetria } \\
\left(L^{*}, a^{*}, b^{*}\right)\end{array}$} & & & & & & \\
\hline & $40,9,13$ & $48,2,30$ & - & $50,12,29$ & $40,19,20$ & $42,6,22$ \\
\hline Ponto & P29 & P36 & P35 & P6 & $\mathbf{P 2}$ & P1 \\
\hline Foto (RGB) & $155,66,48$ & $153,68,39$ & $144,64,41$ & $143,75,48$ & $105,44,34$ & $96,48,30$ \\
\hline \multirow{2}{*}{$\begin{array}{l}\text { Colorimetria } \\
\left(\mathbf{L}^{*}, \mathbf{a}^{*}, \mathbf{b}^{*}\right)\end{array}$} & & & & & & \\
\hline & $42,6,22$ & $37,24,18$ & $37,24,18$ & $38,17,14$ & $34,14,12$ & $32,14,9$ \\
\hline Ponto & P14 & P45 & P24 & P46 & P3 & P7 \\
\hline Foto (RGB) & $143,92,83$ & $121,82,68$ & $88,65,62$ & $130,100,81$ & $108,82,56$ & $72,54,38$ \\
\hline \multirow{2}{*}{$\begin{array}{c}\text { Colorimetria } \\
\left(L^{*}, a^{*}, b^{*}\right)\end{array}$} & & & & & & \\
\hline & $43,12,6$ & $24,1,0$ & $31,3,-1$ & $45,3,8$ & $41,1,11$ & $31,1,7$ \\
\hline Ponto & P39 & P40 & P16 & P31 & P48 & P21 \\
\hline \multirow{2}{*}{ Foto (RGB) } & $60,38,25$ & $68,42,26$ & $118,102,103$ & $100,96,108$ & $100,97,98$ & $96,101,118$ \\
\hline & & & & & & \\
\hline $\begin{array}{c}\text { Colorimetria } \\
\left(\mathbf{L}^{*}, \mathbf{a}^{*}, \mathbf{b}^{*}\right)\end{array}$ & $30,6,8$ & $30,6,8$ & $42,0,-2$ & $44,-2,-5$ & $43,-6,1$ & - \\
\hline Ponto & P17 & P8 & P12 & P13 & P15 & P34 \\
\hline Foto (RGB) & $49,55,61$ & $68,61,55$ & $69,58,51$ & $47,44,40$ & $114,96,69$ & $127,112,60$ \\
\hline \multirow{2}{*}{$\begin{array}{c}\text { Colorimetria } \\
\left(L^{*}, a^{*}, b^{*}\right)\end{array}$} & & & & & & \\
\hline & $28,-4,1$ & - & - & - & - & $45,3,21$ \\
\hline Ponto & P49 & P25 & P11 & P51 & P27 & P26 \\
\hline Foto (RGB) & $134,124,60$ & $117,125,60$ & $90,85,55$ & $86,88,60$ & $71,69,45$ & $59,55,38$ \\
\hline \multirow{2}{*}{$\begin{array}{c}\text { Colorimetria } \\
\left(L^{*}, a^{*}, b^{*}\right)\end{array}$} & & & & & & \\
\hline & - & $46,-8,24$ & - & - & $28,-2,4$ & $28,-2,4$ \\
\hline Ponto & P37 & P38 & P42 & & & \\
\hline Foto (RGB) & $39,36,26$ & $38,31,24$ & $56,46,35$ & & & \\
\hline \multirow{2}{*}{$\begin{array}{c}\text { Colorimetria } \\
\left(L^{*}, a^{*}, b^{*}\right)\end{array}$} & & & & & & \\
\hline & $27,1,2$ & $24,1,0$ & - & & & \\
\hline
\end{tabular}




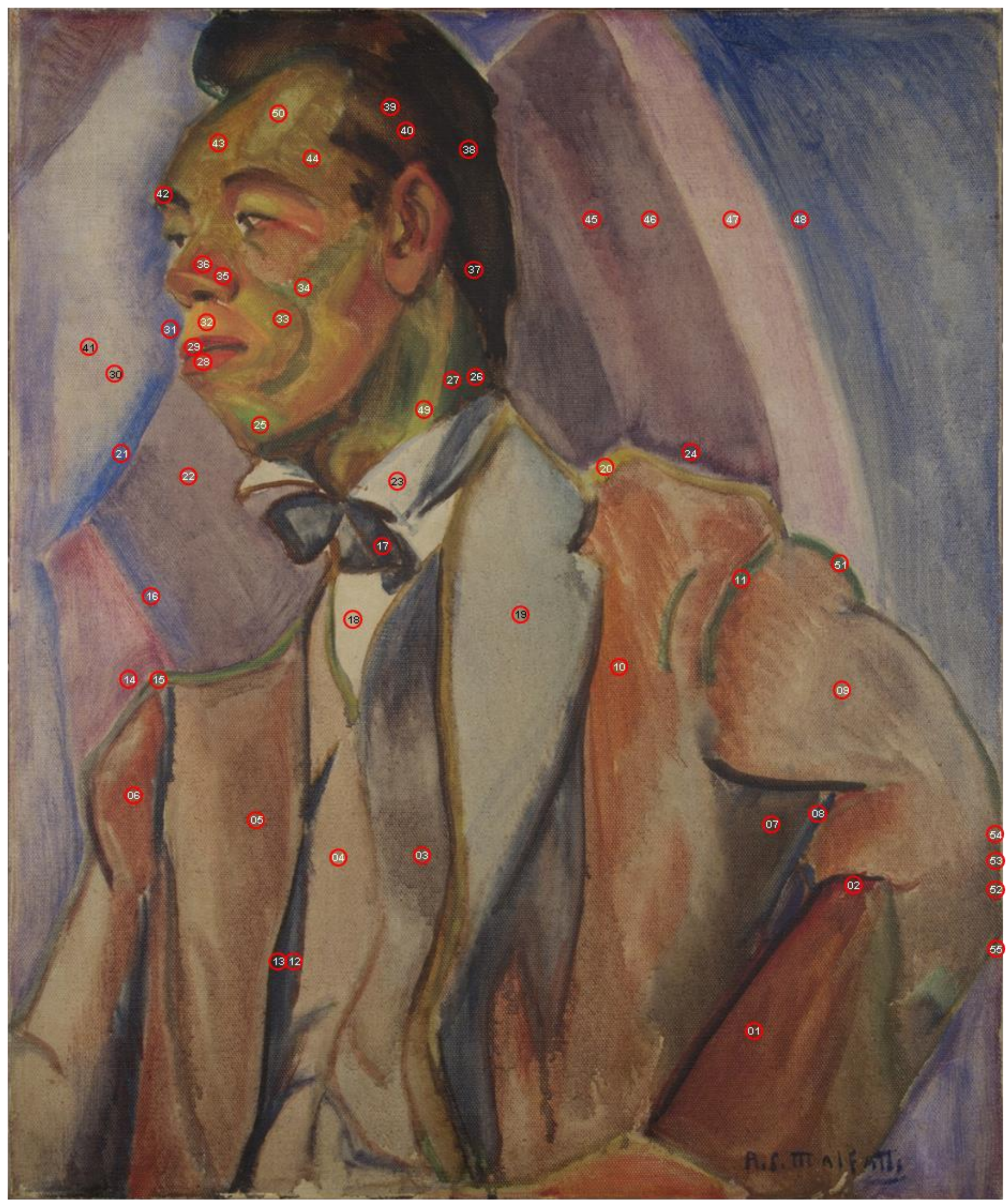

Figura 4.8 - Fotografia com os pontos de EDXRF medidos na obra "O Japonês" de Anita Malfatti (1915/1916, óleo sobre tela, $61 \times 51 \mathrm{~cm})$ do acervo do IEB-USP 


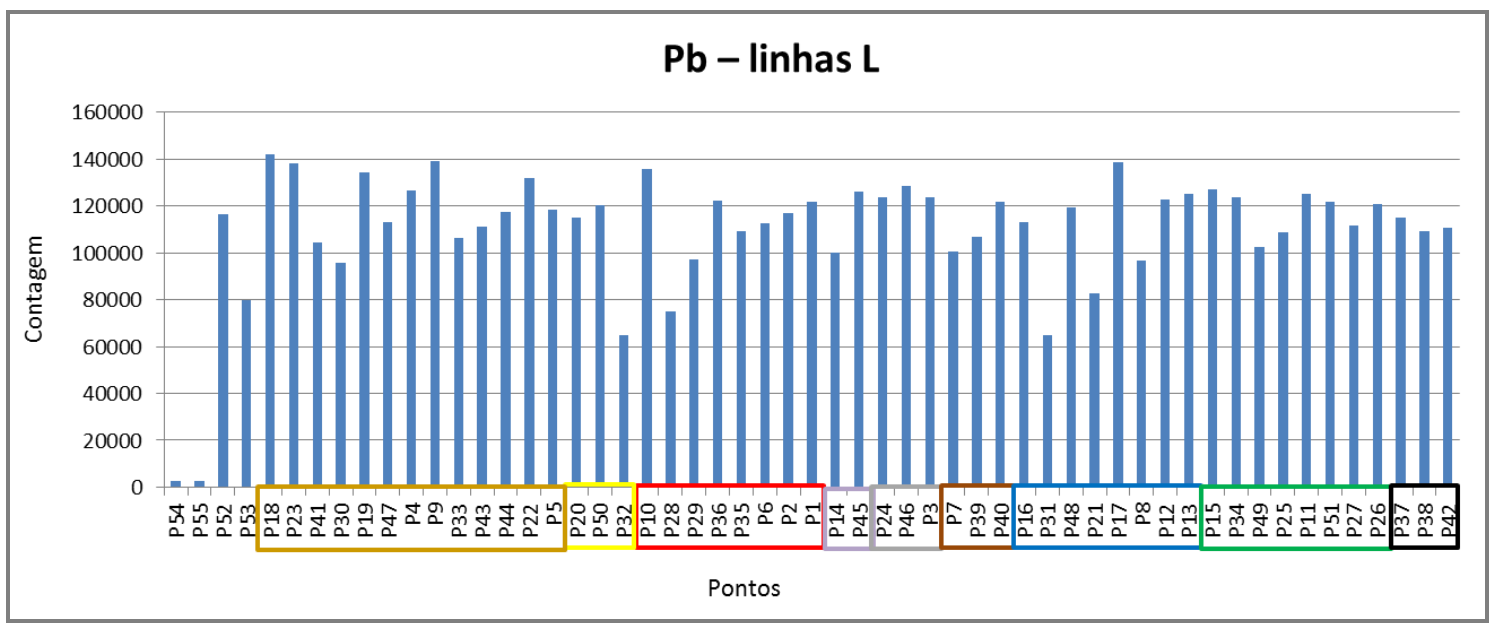

Figura 4.9 - Gráfico de barras das áreas do pico do Pb identificado nos espectros de EDXRF para os diferentes pontos medidos na obra "O Japonês" de Anita Malfatti (1915/1916) do acervo do IEB-USP

Nos pontos P52 e P53 (também na borda da tela com um material branco aplicado sobre a tela) há presença de $\mathrm{Pb}$ sugerindo a base de preparação realizada pela artista. Como pôde ser observado a presença de $\mathrm{Pb}$ é frequente em todos os pigmentos, mesmo em pigmentos como os azuis e marrons que não possuem, a princípio, o Pb em sua constituição. O elemento cálcio $(\mathrm{Ca})$, também está presente em quase todos os pontos como é mostrado na figura 4.10 .

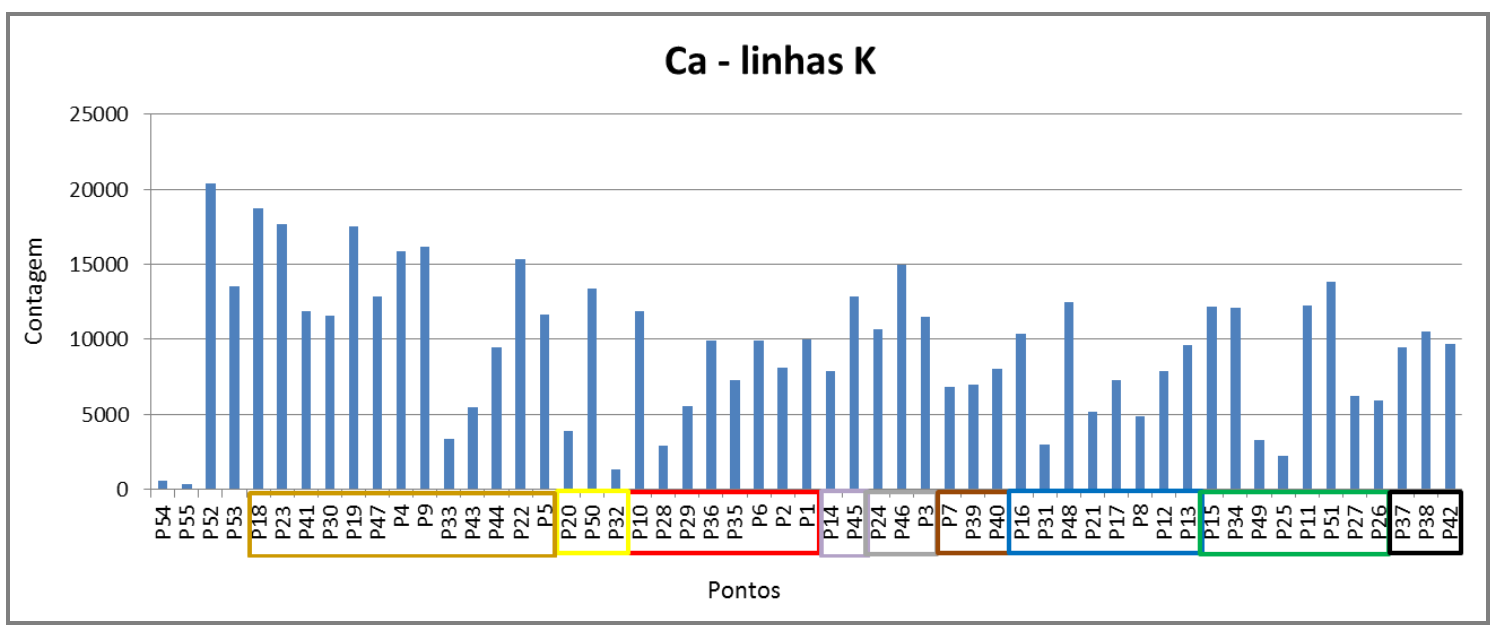

Figura 4.10 - Gráfico de barras das áreas do pico do Ca identificado nos espectros de EDXRF para os diferentes pontos medidos na obra "O Japonês" de Anita Malfatti (1915/1916) do acervo do IEB-USP 
Esta evidência da presença de Ca nos pontos P52 e P53 juntamente com $\mathrm{Pb}$ sugere que a base de preparação utilizada pela artista, ou pelo fabricante da tela, foi feita de carbonato de chumbo $\left(2 \mathrm{PbCO}_{3} \cdot \mathrm{Pb}(\mathrm{OH})_{2}\right)$ (conhecido como branco de chumbo, white lead, flack white snowflack white, branco de cremnitz, ceruse, avaiade-de-chumbo, branco-francês, branco-prata, etc.) e carbonato de cálcio $\left(\mathrm{CaCO}_{3}\right)$, que pode ser usado como carga ou adulterante em pintura a óleo e fundo de preparação para pintura a óleo e têmpera (conhecido também como whiting, gresso-cré, greda, branco-de-Paris, branco-de-Espanha). No entanto, deve-se ter em mente que estes dois compostos também podem estar presentes na composição de algumas tintas óleo comerciais (MAYER, 2006). Desta forma, há uma dificuldade na determinação de pigmentos que possuam estes mesmos elementos químicos na sua constituição, ou pigmentos em que os elementos químicos produzem raios $X$ característicos com energias próximas a estes elementos constantemente presentes.

Os pontos P18 e P23 são regiões brancas na obra, onde há a presença de $\mathrm{Ca}$ e $\mathrm{Pb}$, como mencionado anteriormente, mas onde não há presença de zinco $(\mathrm{Zn})$ e bário $(\mathrm{Ba})$, figuras 4.11 e 4.12 respectivamente, possivelmente presente no pigmento litopone $\left(\mathrm{ZnS}, \mathrm{BaSO}_{4}\right)$. Na medida em que o Ca pertence à composição da base de preparação aplicada sobre a tela, podemos afirmar que o branco usado pela artista na camada pictórica é o branco-de-chumbo $\left(2 \mathrm{PbCO}_{3} \cdot \mathrm{Pb}(\mathrm{OH})_{2}\right)$. Os elementos $\mathrm{Zn}$ e $\mathrm{Ba}$ estão presentes em maior quantidade em alguns pontos específicos como P32, P31, P21 e P14.

Observando outros elementos, podemos ver que o ferro está predominantemente presente nos tons pretos e marrons, relacionados à presença de óxido de ferro para estes tons ( $\mathrm{Fe}_{3} \mathrm{O}_{4}$ e $\mathrm{Fe}_{2} \mathrm{O}_{3}$, respectivamente) e podem ser visto no gráfico de barra da figura 4.13. Observa-se também, uma quantidade elevada nos pontos P27 e P26 que são os tons de verde mais escuro. 


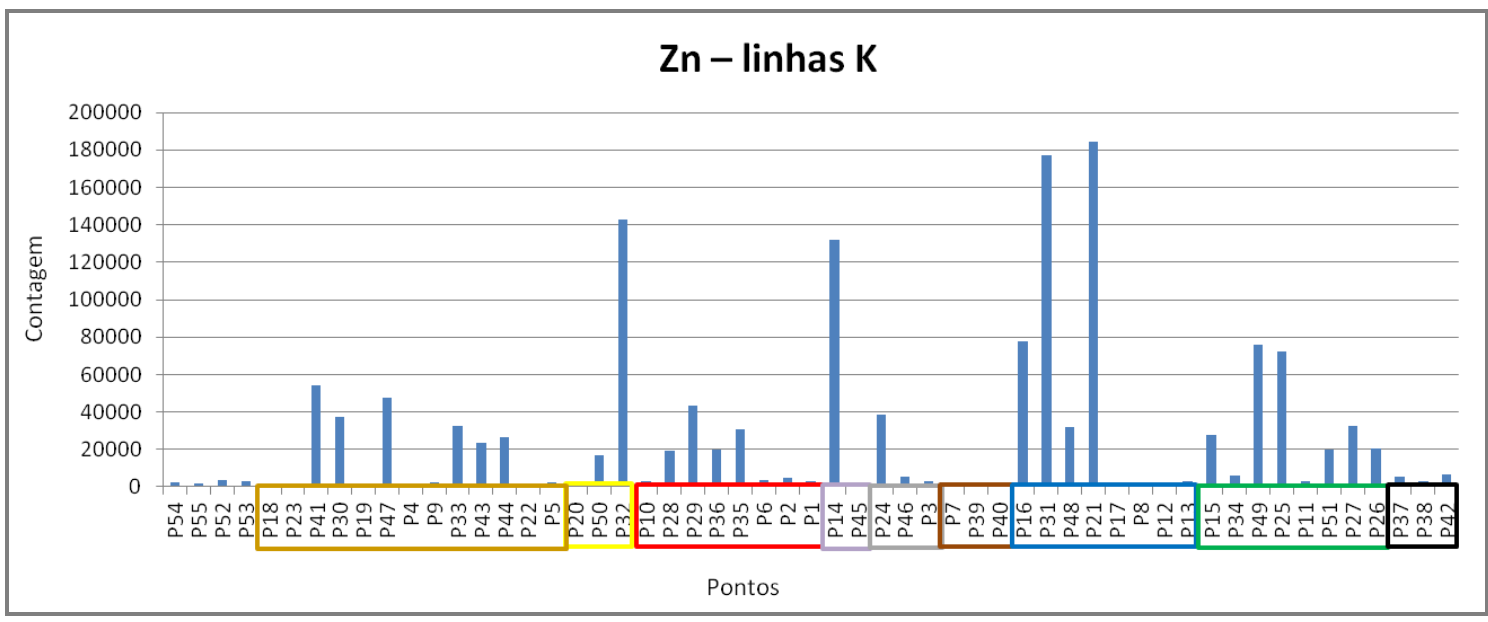

Figura 4.11 - Gráfico de barras das áreas do pico de Zn identificado nos espectros de EDXRF para os diferentes pontos medidos na obra "O Japonês" de Anita Malfatti (1915/1916) do acervo do IEB-USP

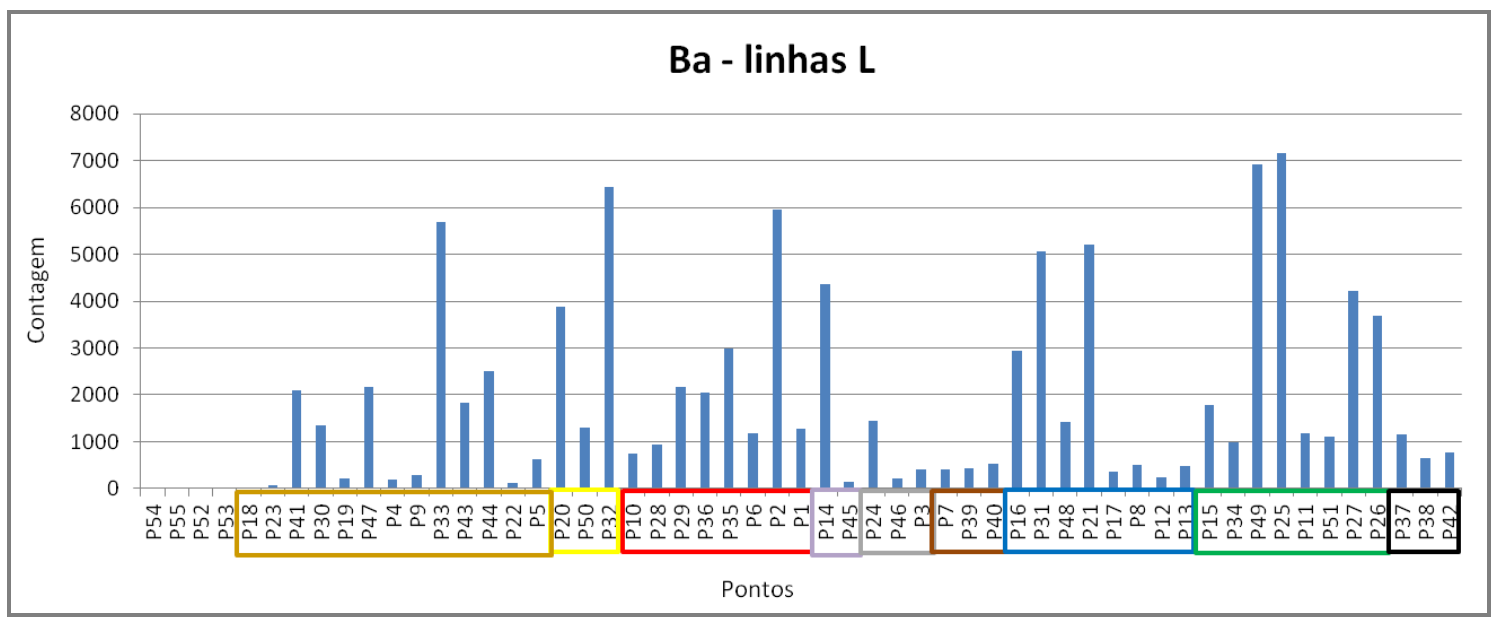

Figura 4.12 - Gráfico de barras das áreas do pico de Ba identificado nos espectros de EDXRF para os diferentes pontos medidos na obra "O Japonês" de Anita Malfatti (1915/1916) do acervo do IEB-USP

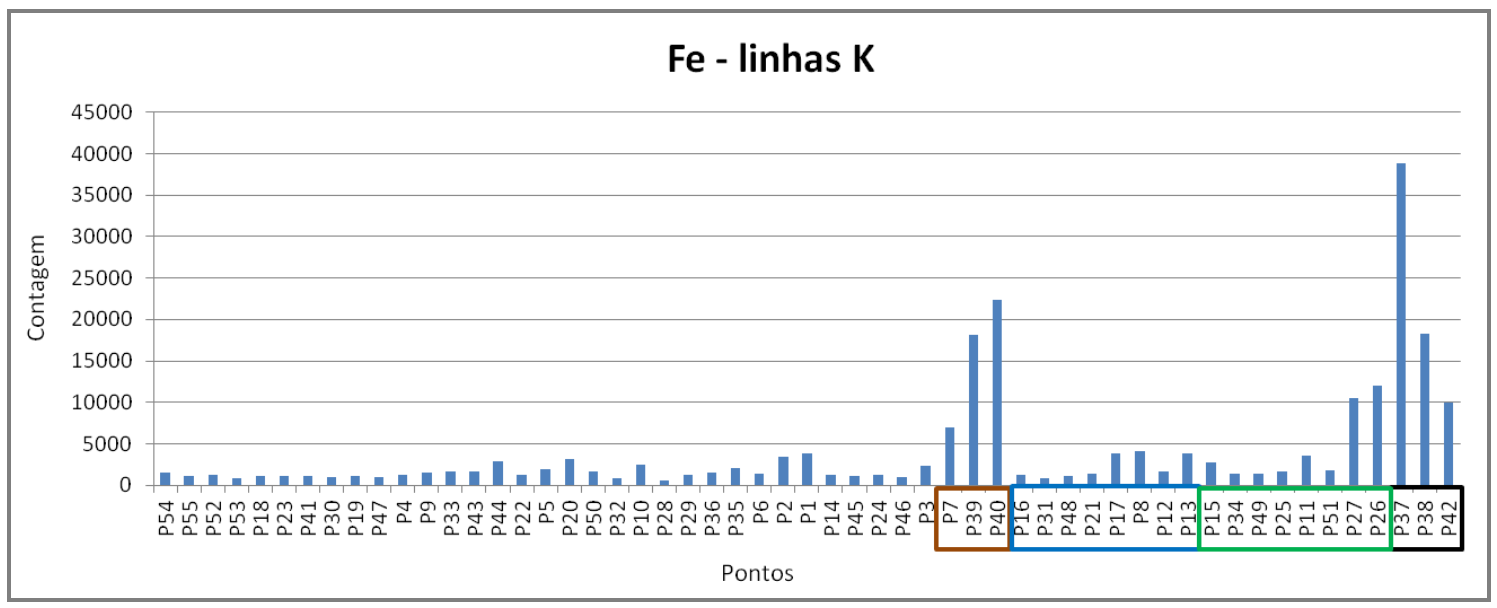

Figura 4.13 - Gráfico de barras das áreas do pico de Fe identificado nos espectros de EDXRF para os diferentes pontos medidos na obra "O Japonês" de Anita Malfatti (1915/1916) do acervo do IEB-USP 
Nos tons verdes e amarelos encontramos o elemento cromo, figura 4.14, aparece em destaque, isso nos permite afirmar que há nesta obra o uso do verde de óxido de cromo $\left(\mathrm{Cr}_{2} \mathrm{O}_{3}\right)$ e amarelo de cromo $\left(2 \mathrm{PbSO}_{4} . \mathrm{PbCrO}_{4}\right)$.

Quando olhamos para os elementos $\mathrm{Sr}$ e $\mathrm{Ba}$, figuras 4.15 e 4.12, percebe-se uma grande correlação nestes pontos. Isto é devido ao fato deles serem muito semelhantes quimicamente. Quando se faz uso da barita mineral (BaSO4), o sulfato de estrôncio (SrSO4) também está presente. A barita pode ser utilizada na composição das tintas comerciais para compor a cor, assim como o branco de zinco ( $\mathrm{ZnO}$ ). Além disso, o litopônio, que é constituído de $70 \%$ de $\mathrm{BaSO} 4$ e $30 \%$ de $\mathrm{ZnO}$, tem sido utilizado como possível elemento para compor o fundo de preparação, mas não é recomendado como pigmento para tintas óleo, apesar de às vezes ser adicionado ao branco de zinco para the conferir opacidade (MAYER, 2006).

Observando os pontos de cor amarela, vemos que há nestas regiões os elementos cromo $(\mathrm{Cr})$, bário $(\mathrm{Ba})$ e estrôncio $(\mathrm{Sr})$, além dos já mencionados $\mathrm{Ca}$ e $\mathrm{Pb}$. Isso nos dá a possibilidade da presença do amarelo-de-cromo (2PbSO $\left.4 . \mathrm{PbCrO}_{4}\right)$, amarelo-de-bário ( $\left.\mathrm{BaCrO} 4\right)$, amarelo-de-estrôncio ( $\left.\mathrm{SrCrO}_{4}\right)$, ou ainda uma mistura destes compostos, que comercialmente pode ter o nome de amarelo-limão (MAYER, 2006), que pode ser a mesma nomenclatura de um tom de amarelo esverdeado para muitas tintas óleo comerciais diferentes, dependendo do fabricante. 


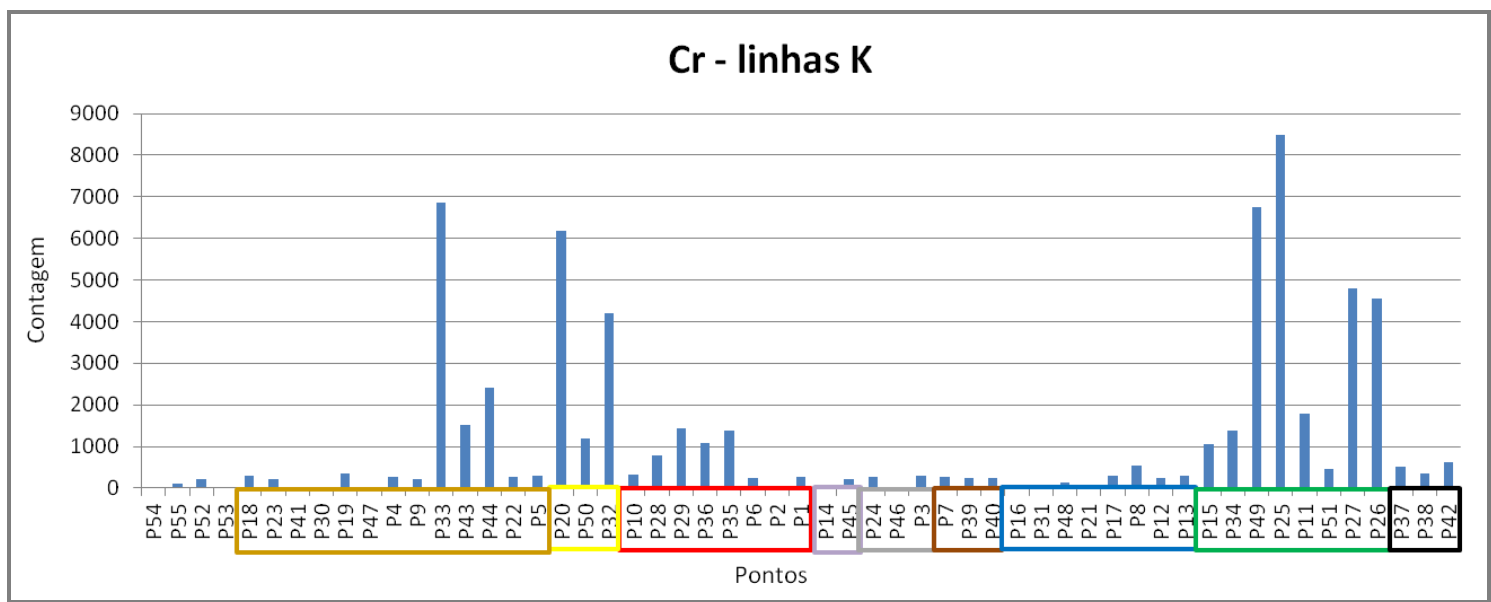

Figura 4.14 - Gráfico de barras das áreas do pico do Cr identificado nos espectros de EDXRF para os diferentes pontos medidos na obra "O Japonês" de Anita Malfatti (1915/1916) do acervo do IEB-USP

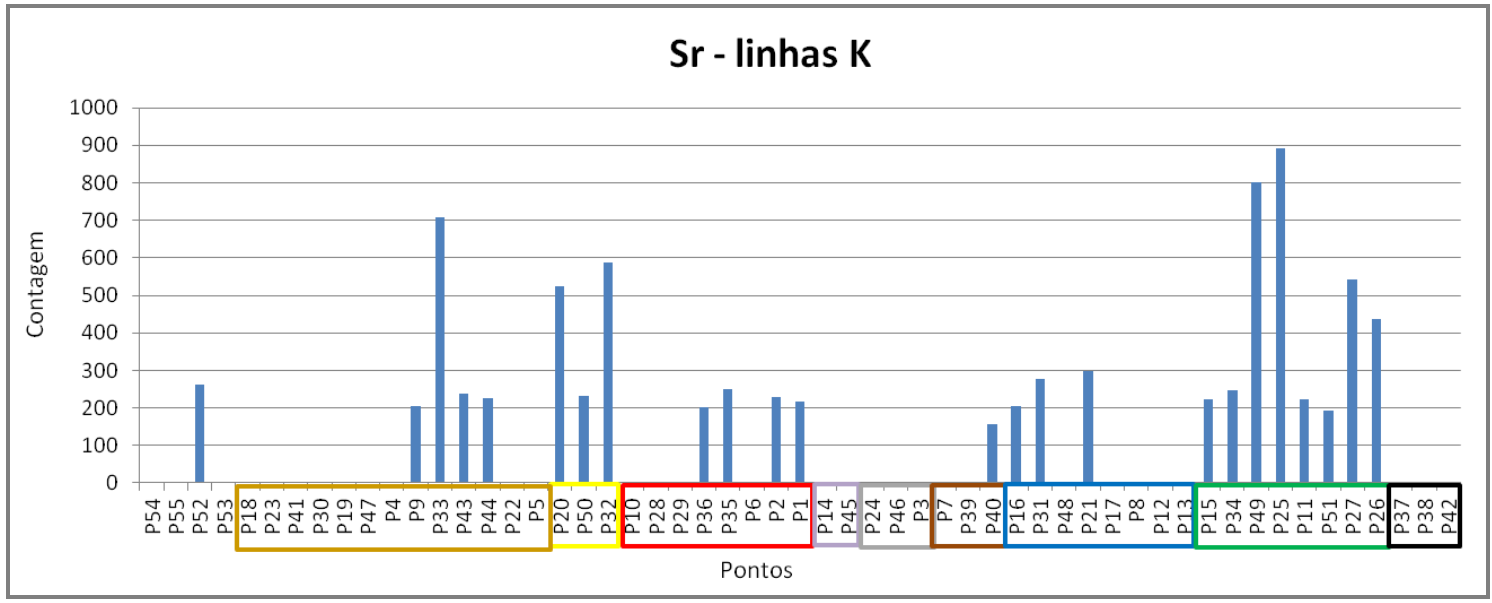

Figura 4.15 - Gráfico de barras das áreas do pico de Sr identificado nos espectros de EDXRF para os diferentes pontos medidos na obra "O Japonês" de Anita Malfatti ((1915/1916) do acervo do IEB-USP

Como dito anteriormente nos pontos verdes, a presença do elemento $\mathrm{Cr}$ indica a existência do óxido de cromo $\left(\mathrm{Cr}_{2} \mathrm{O}_{3}\right)$, que está contido em diversos pigmentos de cor verde, como verde-de-oxido-de-cromo $\left(\mathrm{Cr}_{2} \mathrm{O}_{3}\right)$ e verdeverdiano $\left(\mathrm{Cr}_{2} \mathrm{O}_{3} .2 \mathrm{H}_{2} \mathrm{O}\right.$ ou $\left.\mathrm{Cr}_{2}(\mathrm{OH})_{2}\right)$, que são indistinguíveis pela técnica $X R F$. Nota-se também, que o estrôncio (Sr) e o bário (Ba) possuem uma relação com o $\mathrm{Cr}$ nos gráficos, para os pontos verdes, e ao observarmos a imagem dos pontos em que a artista usou tinta verde, podemos afirmar que a aplicação deste verde foi feita sobre um pigmento amarelo, que contribuiu nos espectros de raio $\mathrm{X}$ com os elementos $\mathrm{Ba}$ e $\mathrm{Sr}$. 
Observando a distribuição do elemento cádmio (Cd) pela obra (figura 4.16), podemos ver que ele está presente em muitos pontos de diferentes colorações, uma vez que o Cd faz parte da composição dos pigmentos das cores vermelha, laranja e amarela. Desta forma, sua distribuição na pintura deve-se à sobreposição de camadas de diferentes tintas na pintura, ou pela mistura e contaminação das tintas na paleta da artista. Os pigmentos vermelhos e laranjas que possuem Cd também possuem selênio (Se) na sua composição, mas como este elemento não foi observado em nenhum espectro obtido, nós podemos afirmar que o $\mathrm{Cd}$ presente provêm de um pigmento amarelo. Os pigmentos amarelos com $\mathrm{Cd}$ podem também trazer consigo o sulfeto de zinco, mas observando os gráficos de barra destes elementos, não encontramos uma mínima correlação entre tais elementos (no ponto P10 não há $\mathrm{Zn}$ ), onde o $\mathrm{Cd}$ se faz muito presente. Em comparação com o $\mathrm{Ba}$, não há uma correlação clara com o $\mathrm{Cd}$, mas na obra este está presente onde há $\mathrm{Cd}$. Pelo Ba compor diversos pigmentos, não temos como afirmar se este está associado ao $\mathrm{Cd}$. Desta forma está presente um dos pigmentos amarelos com $\mathrm{Cd}$, o amarelo de cádmio (CdS), ou o amarelo de cádmio com o sulfato de bário $\left(\mathrm{CdS}+\mathrm{BaSO}_{4}\right)$, que também pode trazer $\mathrm{Sr}\left(\mathrm{SrSO}_{4}\right)$ em sua constituição (MAYER, 2006).

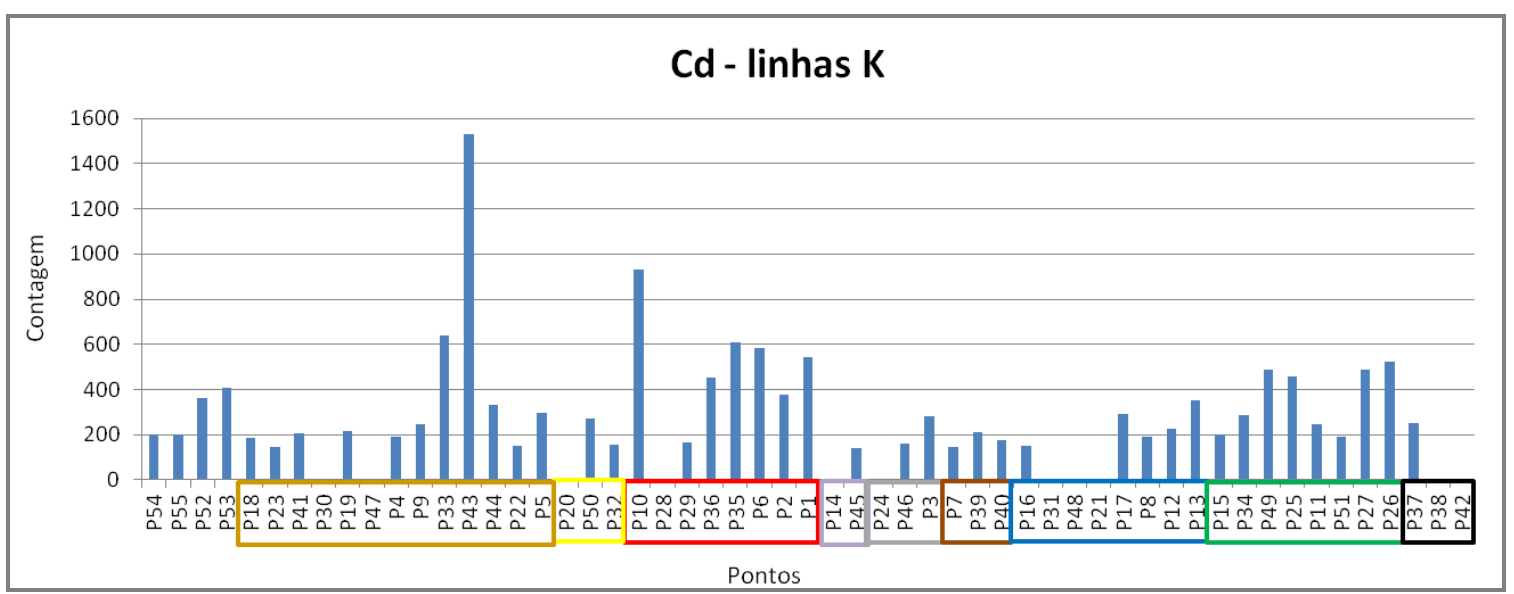

Figura 4.16 - Gráfico de barras das áreas do pico de Cd identificado nos espectros de EDXRF para os diferentes pontos medidos na obra "O Japonês" de Anita Malfatti (1915/1916) do acervo do IEB-USP

Em dois pontos vermelhos e nos pontos negros, houve o registro da presença de mercúrio $(\mathrm{Hg})$, figura 4.17 , podendo se afirmar que o vermelho 
utilizado nestes pontos pela artista é o vermelhão (HgS) e que nos pigmentos pretos também está presente uma pequena quantidade do $\mathrm{HgS}$.

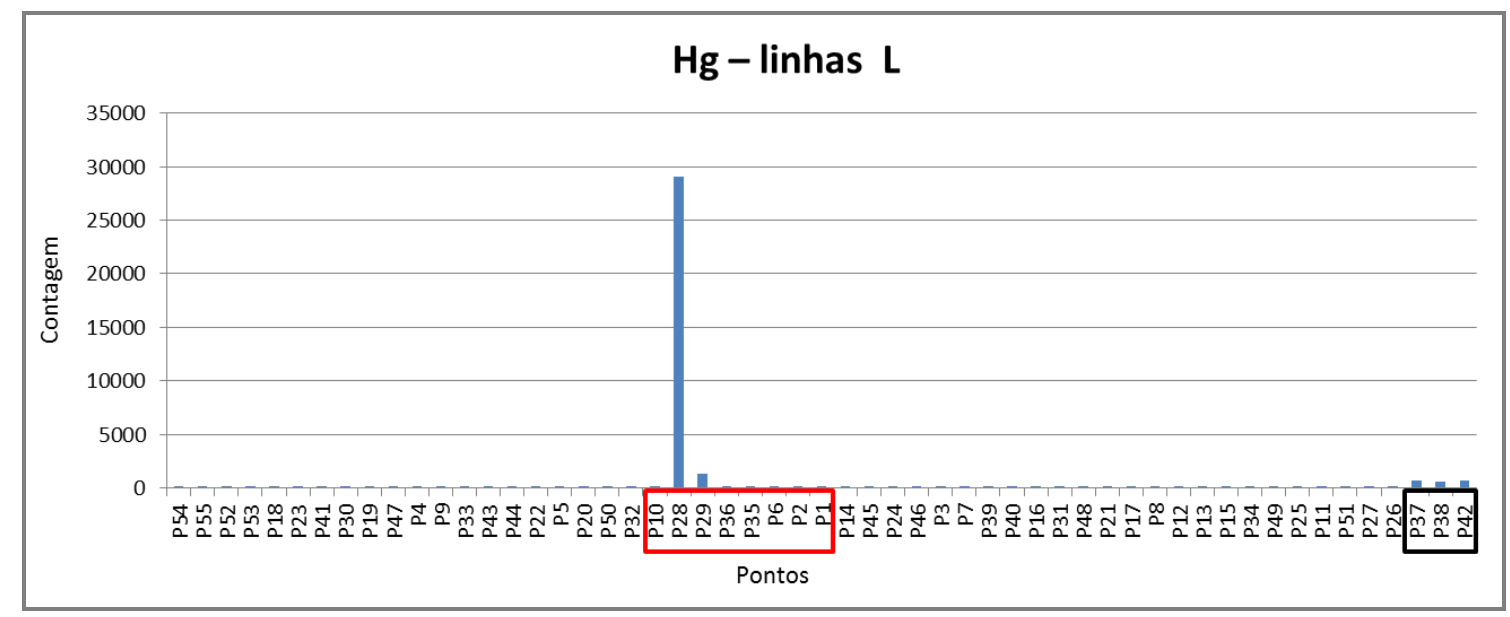

Figura 4.17- Gráfico de barras das áreas do pico de $\mathrm{Hg}$ identificado nos espectros de EDXRF para os diferentes pontos medidos na obra "O Japonês" de Anita Malfatti (1915/1916) do acervo do IEB-USP

Observando os pontos azuis e violetas nenhum elemento aparece com grande destaque, mas aqueles pontos que possuem maiores quantidades de ferro $(\mathrm{Fe})$, também apresentam uma pequena quantidade de potássio $(\mathrm{K})$, figura 4.18, isso indica a presença do azul da Prússia $\mathrm{Fe}_{4}\left[\mathrm{Fe}(\mathrm{CN})_{6}\right] 3$, que em sua outra forma ( $\mathrm{KFeFe}(\mathrm{CN}) 6$ ) contém o K (BUSER et al., 1977), no entanto não podemos descartar a utilização de azul ultramarino ou lapis lazuli $\left(\mathrm{Na}_{8-}\right.$ ${ }_{10} \mathrm{Al}_{6} \mathrm{Si}_{6} \mathrm{O}_{24} \mathrm{~S}_{2-4}$ ), que não são detectados facilmente pela técnica de EDXRF (baixa eficiência de detecção para os elementos leves) Os pigmentos originalmente violetas possuem $\mathrm{Cu}$ ou $\mathrm{Co}$ na sua constituição, elementos que não foram observados nesta obra. 


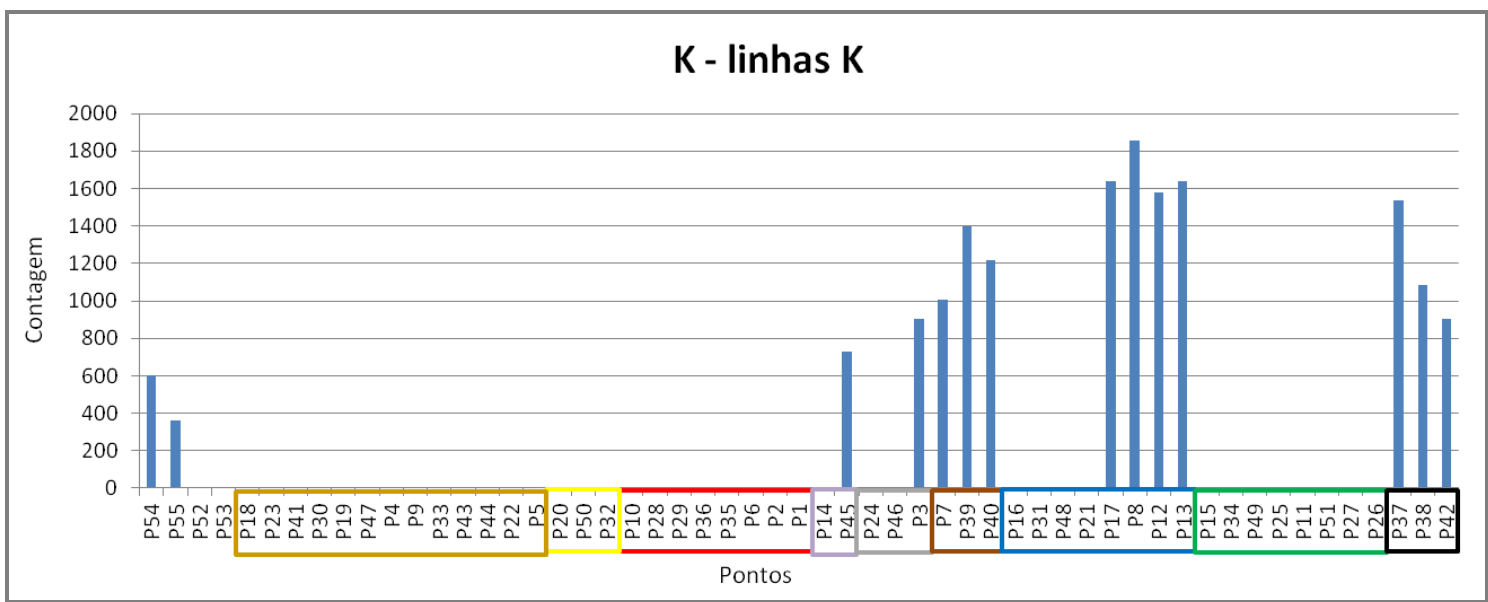

Figura 4.18 - Gráfico de barras das áreas do pico do K identificado nos espectros de EDXRF para evidenciar a correlação entre este elementos os diferentes pontos medidos na obra "O Japonês" de Anita Malfatti (1915/1916) do acervo do IEB-USP

O elemento $\mathrm{Zn}$ foi observado em diversos pontos da obra (figura 4.11), com diversas colorações. Já foi excluída a possibilidade deste pertencer à base ou ao pigmento branco utilizado, mas podemos observar que em todos os pontos que o $\mathrm{Zn}$ está presente, também temos a presença de Ba. Desta forma, deve-se trata do litopônio, que é constituído de sulfeto de zinco $30 \%$ e sulfato de bário $70 \%$, algumas vezes utilizados pelos fabricantes de tintas para obter variações de cor (MAYER, 2006).

As análises estatísticas que mostram as correlações entre os elementos presentes nas medidas EDXRF podem ser observadas na tabela 4.3 e na figura 4.19. Podemos verificar uma correlação positiva, porém não forte entre os elementos $\mathrm{Cr}$ e $\mathrm{Sr}(0,895)$ e entre o $\mathrm{Cr}$ e $\mathrm{Ba}(0,697)$, e com base na discussão anterior, indicando a presença do amarelo de cromo $\left(\mathrm{BaCrO}_{4}\right)$, do amarelo de estrôncio $\left(\mathrm{SrCrO}_{4}\right)$, ou ainda o amarelo de cromo e o verde de cromo tenham barita ( $\mathrm{Ba}$ e $\mathrm{Sr}$ ) na composição da sua tinta. $\mathrm{O}$ chumbo e o cálcio possuem correlação de 0,662, sendo mais uma indicação do fundo ser constituído de $\mathrm{Ca}$ e $\mathrm{Pb}$. (Ba, Sr e Zn). Na projeção estes grupos de elementos também se encontram próximos. Entre o Ba e o Zn também há uma correlação alta $(0,705)$, indicando a presença do litopônio. 
Tabela 4.3 - Matriz de correlação dos elementos presentes nos pontos analisados por EDXRF na obra "O Japonês" de Anita Malfatti (1915/1916) do acervo do IEB-USP

\begin{tabular}{l|r|r|r|r|r|r|r|r|r|r} 
variable & $\mathrm{Ca}-\mathrm{K}$ & $\mathrm{Ti}-\mathrm{K}$ & $\mathrm{Cr}-\mathrm{K}$ & $\mathrm{Fe}-\mathrm{K}$ & $\mathrm{Zn}-\mathrm{K}$ & $\mathrm{Sr}-\mathrm{K}$ & $\mathrm{Cd}-\mathrm{K}$ & $\mathrm{Ba}-\mathrm{L}$ & $\mathrm{Hg}-\mathrm{L}$ & $\mathrm{Pb}-\mathrm{L}$ \\
\hline $\mathrm{Ca}-\mathrm{K}$ & 1,000 & $-0,349$ & $-0,467$ & $-0,099$ & $-0,392$ & $-0,425$ & $-0,105$ & $-0,554$ & $-0,196$ & 0,662 \\
\hline $\mathrm{Ti}-\mathrm{K}$ & $-0,349$ & 1,000 & $-0,104$ & $-0,072$ & $-0,106$ & $-0,126$ & $-0,049$ & $-0,168$ & $-0,028$ & $-0,728$ \\
\hline $\mathrm{Cr}-\mathrm{K}$ & $-0,467$ & $-0,104$ & 1,000 & $-0,008$ & 0,184 & 0,895 & 0,272 & 0,697 & $-0,029$ & $-0,014$ \\
\hline $\mathrm{Fe}-\mathrm{K}$ & $-0,099$ & $-0,072$ & $-0,008$ & 1,000 & $-0,199$ & $-0,070$ & $-0,040$ & $-0,099$ & $-0,048$ & 0,083 \\
\hline $\mathrm{Zn}-\mathrm{K}$ & $-0,392$ & $-0,106$ & 0,184 & $-0,199$ & 1,000 & 0,385 & $-0,194$ & 0,705 & $-0,026$ & $-0,324$ \\
\hline $\mathrm{Sr}-\mathrm{K}$ & $-0,425$ & $-0,126$ & 0,895 & $-0,070$ & 0,385 & 1,000 & 0,298 & 0,812 & $-0,104$ & $-0,042$ \\
\hline $\mathrm{Cd}-\mathrm{K}$ & $-0,105$ & $-0,049$ & 0,272 & $-0,040$ & $-0,194$ & 0,298 & 1,000 & 0,116 & $-0,150$ & 0,144 \\
\hline $\mathrm{Ba}-\mathrm{L}$ & $-0,554$ & $-0,168$ & 0,697 & $-0,099$ & 0,705 & 0,812 & 0,116 & 1,000 & $-0,064$ & $-0,165$ \\
\hline $\mathrm{Hg}-\mathrm{L}$ & $-0,196$ & $-0,028$ & $-0,029$ & $-0,048$ & $-0,026$ & $-0,104$ & $-0,150$ & $-0,064$ & 1,000 & $-0,180$ \\
\hline $\mathrm{Pb}-\mathrm{L}$ & 0,662 & $-0,728$ & $-0,014$ & 0,083 & $-0,324$ & $-0,042$ & 0,144 & $-0,165$ & $-0,180$ & 1,000
\end{tabular}

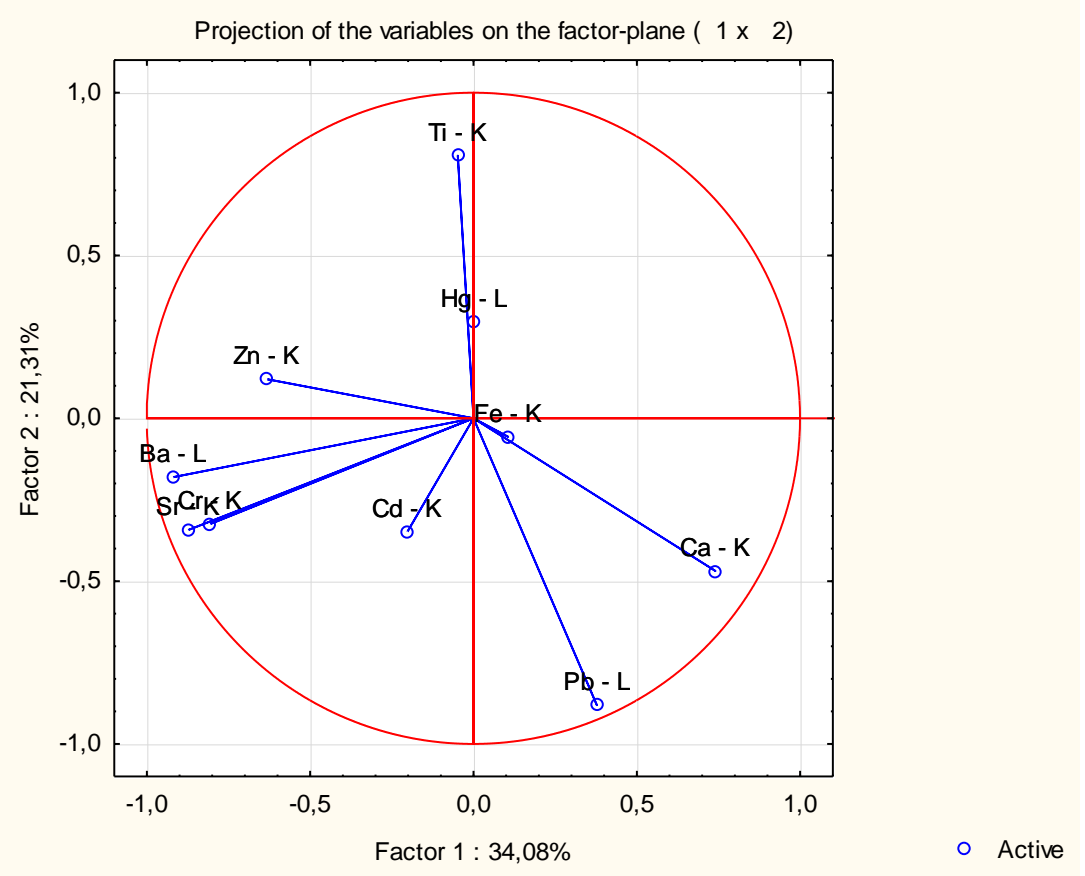

Figura 4.19 - Gráfico da correlação por PCA entre os elementos presentes nos espectros de EDXRF pontos medidos na obra "O Japonês" de Anita Malfatti do acervo do IEB-USP

Resumidamente, pode-se montar uma tabela com possíveis pigmentos presentes na obra "O Japonês" (tabela 4.4). 
Tabela 4.4: Possíveis pigmentos utilizados por Anita Malfatti na obra "O Japonês" de Anita Malfatti (1915/1916) do acervo do IEB-USP (JANSSENS, 2004; STUART, 2008;

VASCONCELOS et al., 1992; MAYER, 2006; LFNATEC, 2009)

\begin{tabular}{|c|c|c|c|c|}
\hline Cor & $\begin{array}{l}\text { Elementos } \\
\text { Presentes }\end{array}$ & $\begin{array}{l}\text { Composição } \\
\text { Química }\end{array}$ & $\begin{array}{l}\text { Nome do } \\
\text { Pigmento }\end{array}$ & $\begin{array}{c}\text { Empregado } \\
\text { desde }\end{array}$ \\
\hline \multirow{3}{*}{ Brancos } & $\mathrm{Pb}$ & $2 \mathrm{PbCO}_{3 .} \mathrm{Pb}(\mathrm{OH})_{2}$ & $\begin{array}{l}\text { Branco de } \\
\text { Chumbo }\end{array}$ & Antiguidade \\
\hline & $\mathrm{Zn}, \mathrm{Ba}$ & $\mathrm{ZnS}+\mathrm{BaSO}_{4}$ & Litopônio & Século 19 \\
\hline & $\mathrm{Ba}, \mathrm{Sr}$ & $\mathrm{BaSO}_{4}+\mathrm{SrSO}_{4}$ & Barita* & Mineral \\
\hline \multirow{3}{*}{ Amarelos } & $\mathrm{Cd}$ & $\begin{array}{c}\text { CdS ou } \\
\mathrm{CdS}+\mathrm{BaSO}_{4}\end{array}$ & $\begin{array}{l}\text { Amarelo de } \\
\text { Cádmio }\end{array}$ & $\begin{array}{l}\text { Mineral e } \\
\text { século } 19\end{array}$ \\
\hline & $\mathrm{Cr}, \mathrm{Sr}$ & $\mathrm{SrCrO}_{4}$ & $\begin{array}{l}\text { Amarelo de } \\
\text { Estrôncio }\end{array}$ & Século 19 \\
\hline & $\mathrm{Cr}, \mathrm{Ba}$ & $\mathrm{BaCrO}_{4}$ & $\begin{array}{c}\text { Amarelo de } \\
\text { Bário (amarelo } \\
\text { de limão) }\end{array}$ & Século 19 \\
\hline Vermelhos & $\mathrm{Hg}$ & $\mathrm{HgS}$ & Vermelhão & Século 13 \\
\hline Verdes & $\mathrm{Cr}$ & $\mathrm{Cr}_{2} \mathrm{O}_{3}$ & $\begin{array}{l}\text { Óxido de } \\
\text { Cromo ou } \\
\text { Veridian }\end{array}$ & Século 19 \\
\hline \multirow{2}{*}{ Pretos } & $\mathrm{Fe}$ & $\mathrm{Fe}_{3} \mathrm{O}_{4}$ & Preto de Ferro & Século 19 \\
\hline & $\mathrm{C}$ & $\mathrm{C}$ & $\begin{array}{l}\text { Preto de } \\
\text { Carbono }\end{array}$ & Antiguidade \\
\hline Marrons & $\mathrm{Fe}$ & $\mathrm{Fe}_{2} \mathrm{O}_{3}$ & $\begin{array}{c}\text { Óxido de Ferro, } \\
\text { Siena }\end{array}$ & Século 19 \\
\hline Azuis & \multicolumn{4}{|c|}{ Indeterminado } \\
\hline \multirow{2}{*}{ Base } & $\mathrm{Ca}$ & $\begin{array}{c}\mathrm{CaCO}_{3} \text { ou } \\
\mathrm{CaSO}_{4} 2 \mathrm{H}_{2} \mathrm{O}\end{array}$ & Cal ou Gesso & Mineral \\
\hline & $\mathrm{Pb}$ & $2 \mathrm{PbCO}_{3} \cdot \mathrm{Pb}(\mathrm{OH})_{2}$ & $\begin{array}{c}\text { Branco de } \\
\text { Chumbo }\end{array}$ & Antiguidade \\
\hline
\end{tabular}

\section{2. "A Estudante Russa"}

Na obra "A Estudante Russa", foi feito o imageamento com as técnicas: fotografia com luz visível, fotografia com luz rasante, fluorescência com luz UV e reflectografias IR. Na figura 4.20 é possível ver a imagem obtida por reflectografia $I R$, onde observamos que o quadro não possui pinturas 
subjacentes definidas, apenas algumas regiões de pentimentos, como no punho direito, e traços espalhados por toda a tela. Também podemos ver que a artista não se utilizou de um desenho prévio a grafite, mas não é possível afirmar se fez traços prévios com uma tinta à base de carbono, pois quando comparado com a imagem na luz visível (figura 3.3), há na imagem uma mistura de informação da presença de carbono tanto nas camadas subjacentes como no fundo. Aparentemente, o fundo não estava totalmente branco quando a tela foi pintada, pois há traços negros na diagonal espalhados pela tela.

Pela técnica de fluorescência com luz UV (figura 4.21), é possível observar nesta obra uma grossa camada de verniz espalhada por toda a sua superfície, dando o caráter esverdeado em quase toda a obra. Além disso, há em algumas áreas do quadro pontos violeta escuro, indicando que houve intervenções de restauro nestes locais. Essa grossa camada de verniz prejudica a visualização da fluorescência dos pigmentos presentes, pois o UV interage com o verniz, produzindo a fluorescência esverdeada. Por outro lado, o verniz protege a obra das características prejudiciais da luz UV, que está suscetível em outras condições.

Com a técnica por luz rasante, foram feitas imagens de várias regiões do quadro, que possibilitaram a visualização da ondulação do suporte, mostrando que a espessura da camada pictórica na tela é fina, pois não foi observada variação sensível de grande massa de tinta. $\mathrm{Na}$ imagem (figura 4.22), também é possível observar que em algumas regiões há uma deformação do suporte, aparentando ter havido uma pressão sobre ele em algum momento, informação importante para conservadores, pois podem ser potenciais áreas de risco no futuro, pela fragilidade da trama do suporte, devido a deformação nestas regiões.

Uma imagem em alta resolução da assinatura da artista foi obtida, a fim de gerar um banco de dados para posteriores estudos e comparações (Figura 4.23). 


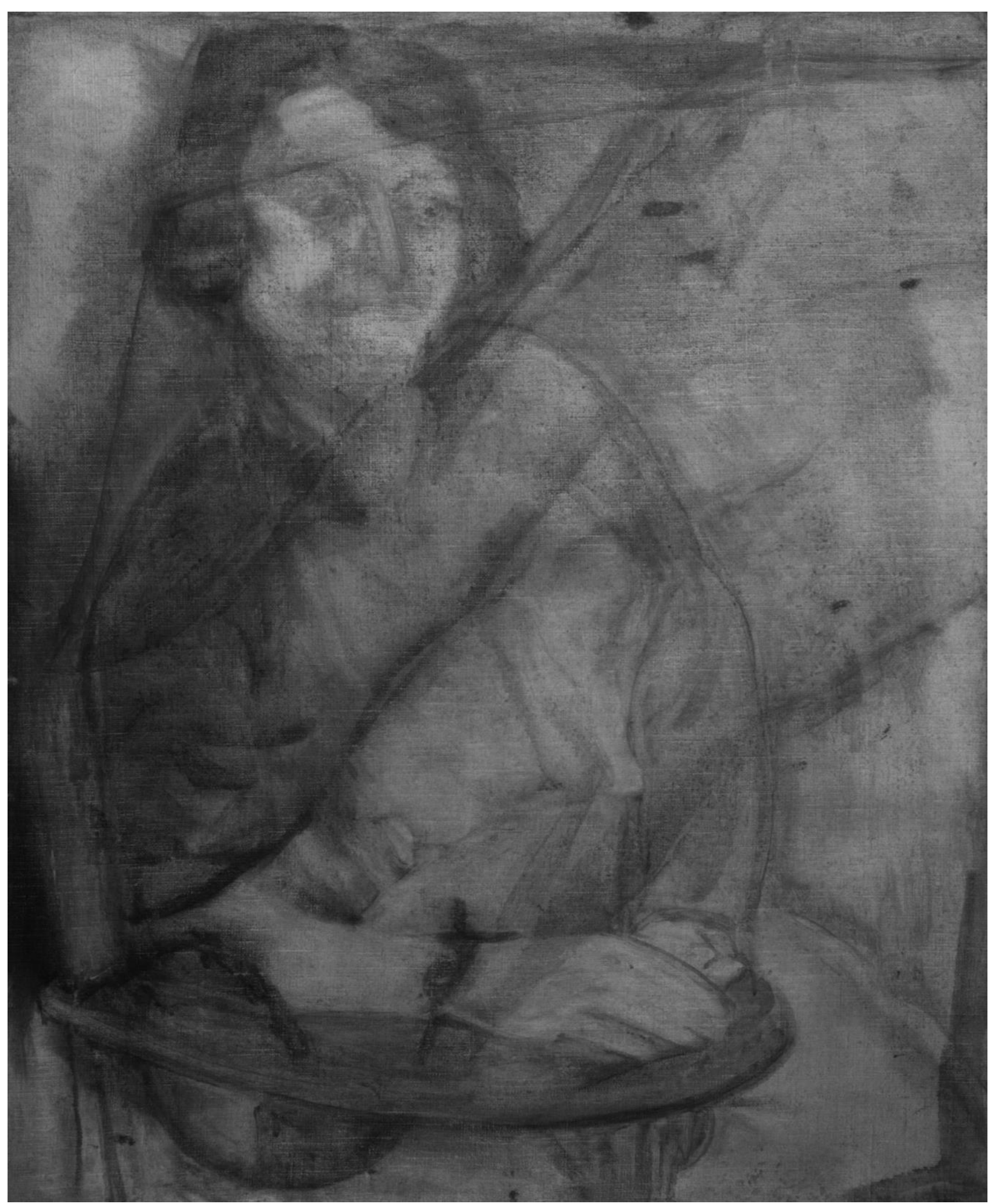

Figura 4.20 - Imagem de reflectografia por infravermelho da obra "A Estudante Russa" (1915) do acervo do IEB-USP 


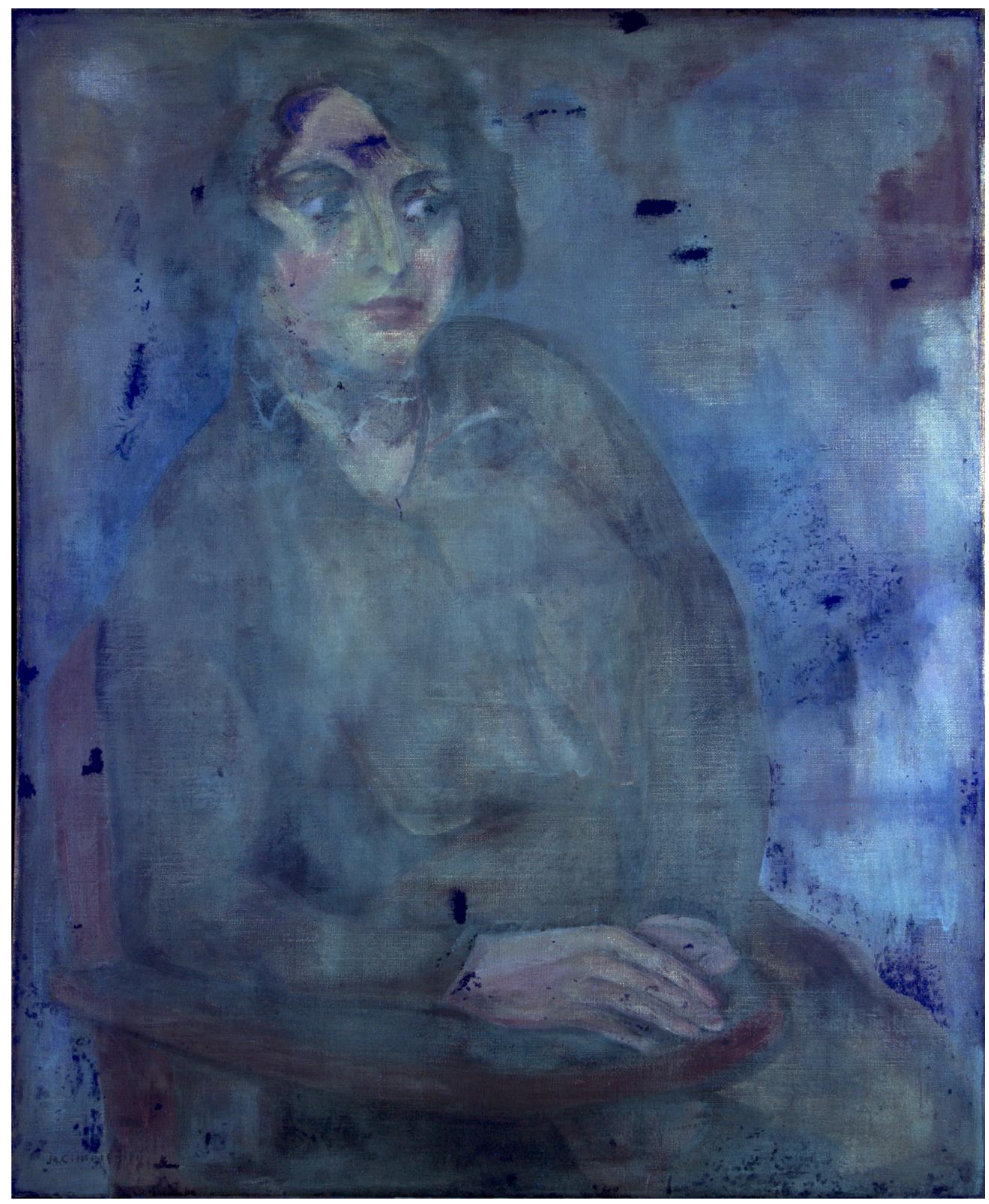

Figura 4.21 - Imagem de fluorescência de ultravioleta da obra "A Estudante Russa" (1915) do acervo do IEB-USP 


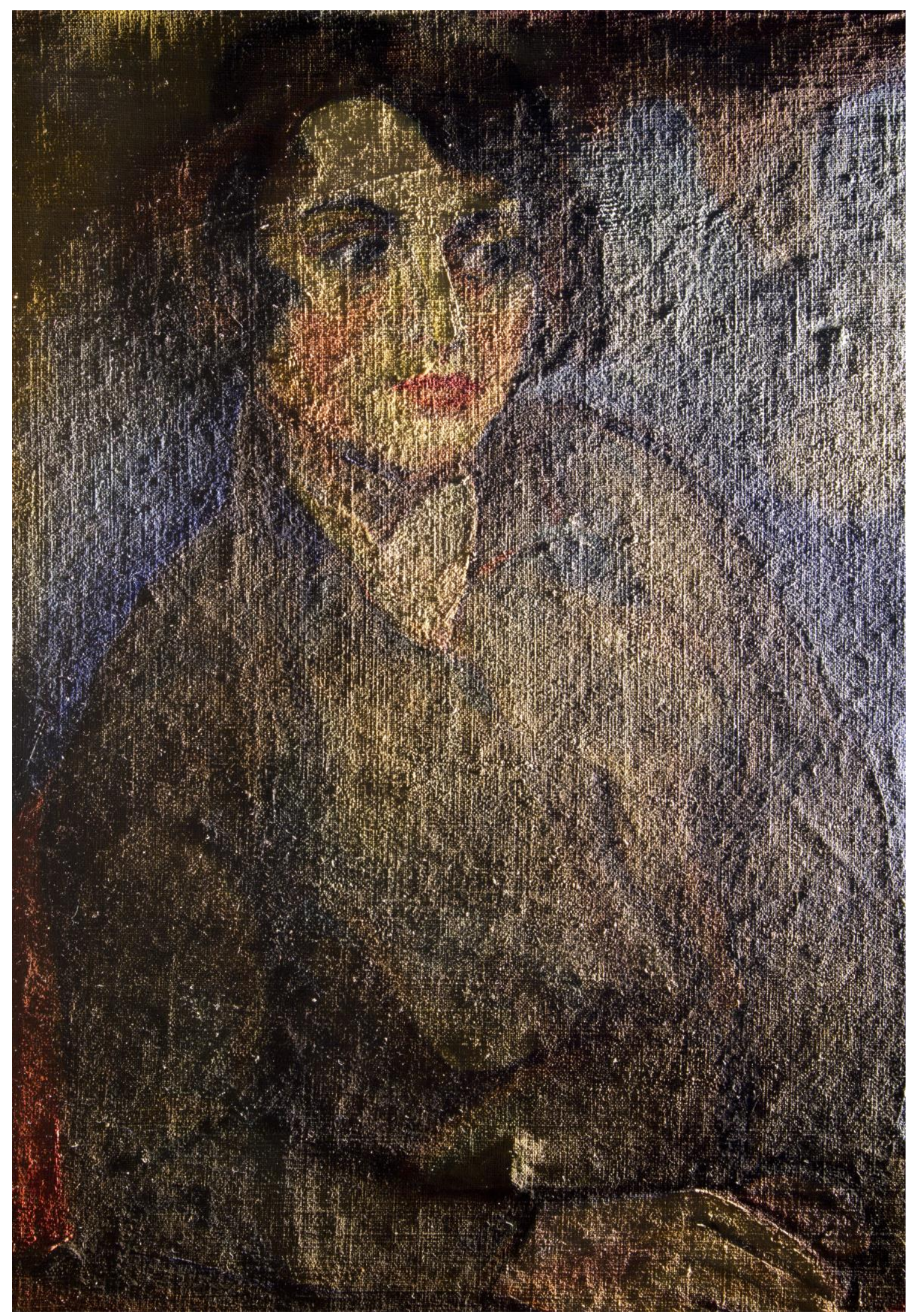

Figura 4.22 - Imagem com iluminação rasante de uma região da obra "A Estudante Russa" (1915) do acervo do IEB-USP 


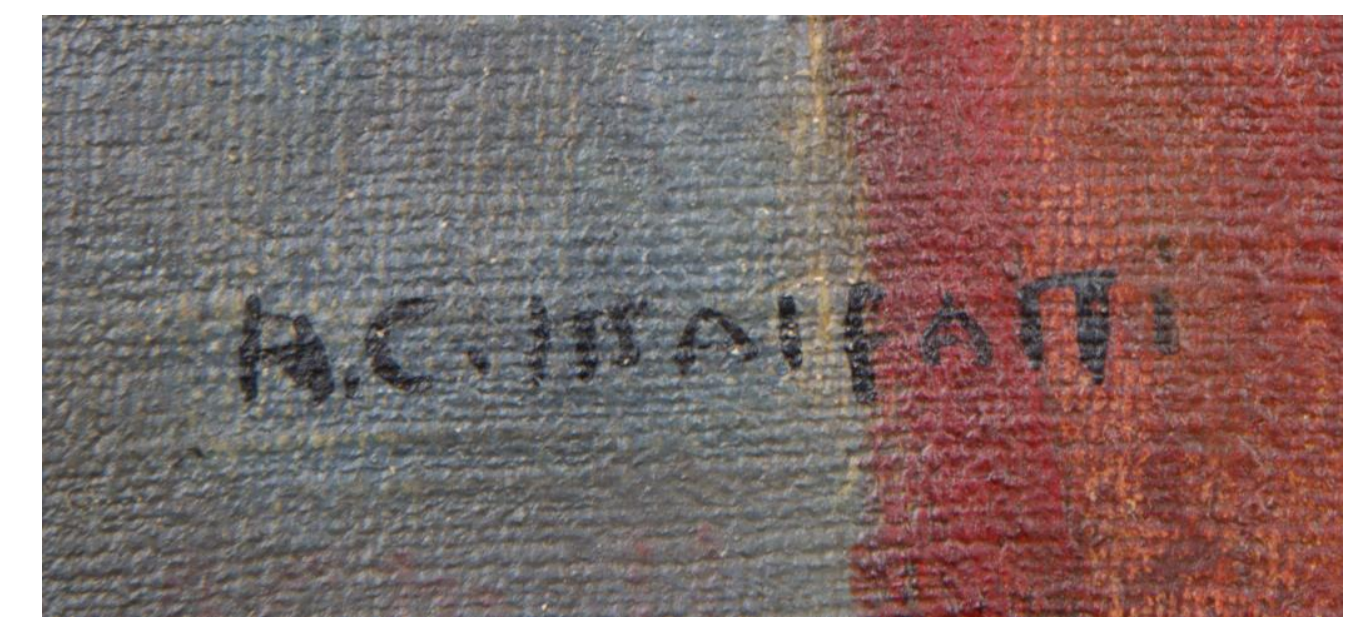

Figura 4.23 - Imagem da assinatura da obra "A Estudante Russa" (1915) do acervo do IEBUSP

Na obra "A Estudante Russa", como pode ser observado na figura 4.24, trinta e nove (39) pontos foram medidos. Na maioria desses pontos, foram feitas as medidas de cor com o espectrofotômetro e a determinação da média de cores pela fotografia com luz visível. Esta relação está listada na tabela 4.5 e os pontos estão na mesma ordem em que se apresentam nos gráficos de barras dos picos de cada elemento.

Dentre os pontos analisados, os pontos P37, P38 e P39 foram feitos na borda lateral da tela, sendo os dois primeiros pontos de regiões que aparentemente possuíam apenas a base de preparação, sem a camada pictórica, mas com colorações diferentes (escura e clara, respectivamente), e o ponto P39 foi obtido em uma região onde a trama do tecido estava visível e desgastada. Nestes pontos, os únicos elementos que foram observados foram o $\mathrm{Pb}$ e $\circ \mathrm{Ca}$ (figuras 4.25 e 4.26, respectivamente), em maior quantidade nos pontos P37 e P38. Estes dois elementos também foram encontrados em quase todos os pontos analisados, em se tratando do $\mathrm{Ca}$, e para todos os pontos analisados para o $\mathrm{Pb}$. Desta forma, como na tela "O Japonês", podemos afirmar que o fundo para pintura aplicado sobre a tela, que se torna o suporte da camada pictórica da obra, é constituída de branco de chumbo $\left(2 \mathrm{PbCO}_{3} \mathrm{~Pb}(\mathrm{OH})_{2}\right)$ e carbonato de cálcio $(\mathrm{CaO})$. Os elementos $\mathrm{Fe}$ e $\mathrm{Cd}$, também estão presentes nestes três pontos, mas não sabemos ao certo sua origem. 


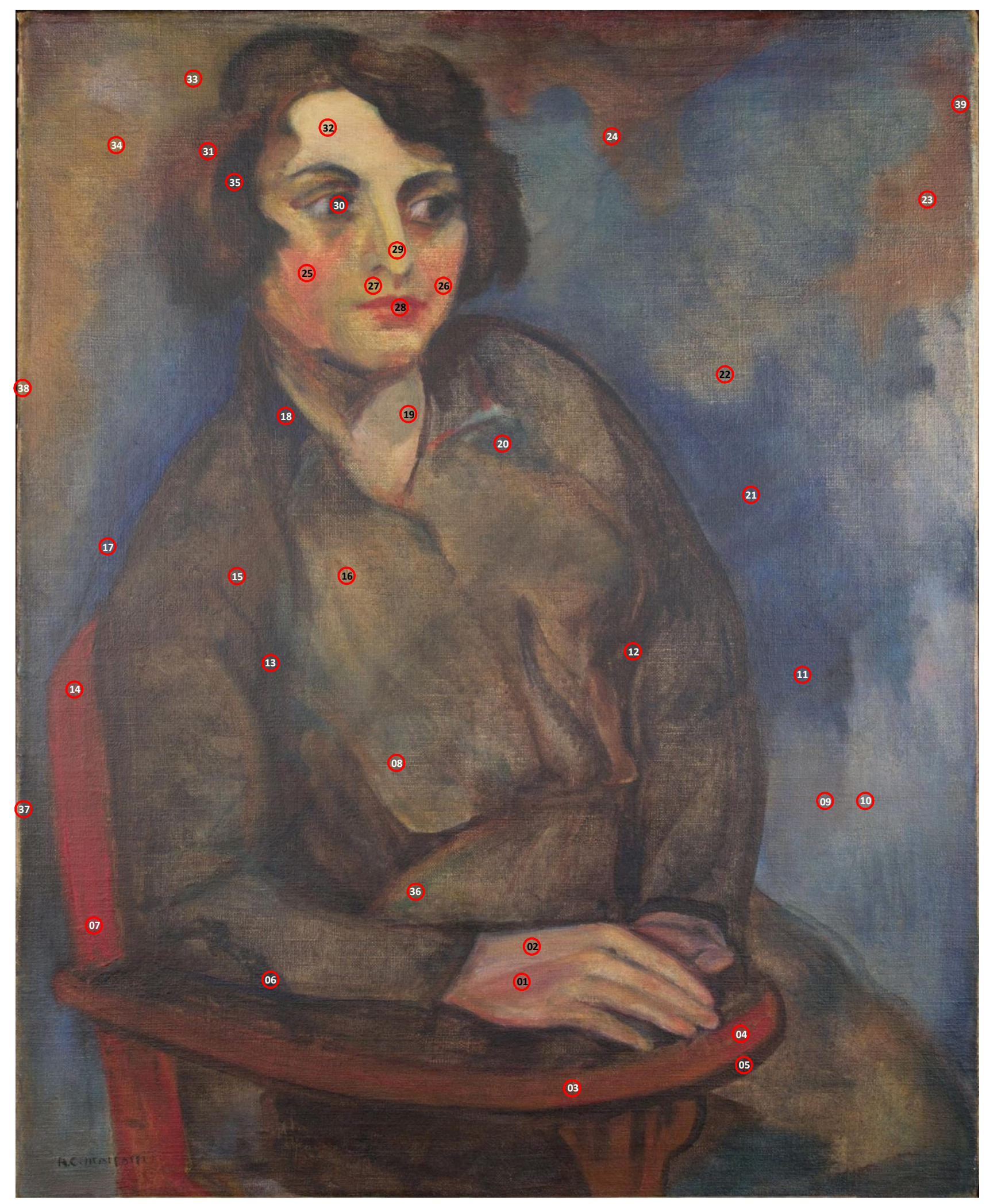

Figura 4.24 - Fotografia com os pontos de EDXRF medidos na obra "A estudante Russa" de Anita Malfatti (1915, óleo sobre tela, $76 \times 61 \mathrm{~cm})$ do acervo do IEB-USP 
Tabela 4.5 - Relação das cores obtidas por colorimetria (em coordenadas $L^{*} a^{*} b^{*}$ ) e fotografia digital (em coordenadas RGB) nos pontos analisados por EDXRF na obra "A Estudante Russa" de Anita Malfatti (1915/1916) do acervo do IEB-USP

\begin{tabular}{|c|c|c|c|c|c|c|}
\hline Ponto & P5 & P6 & P35 & P30 & P12 & P13 \\
\hline Fotografia & $56,41,40$ & $52,51,56$ & $58,57,62$ & $58,56,61$ & $68,62,66$ & $70,68,72$ \\
\hline (RGB) & & & & & & \\
\hline \multirow{2}{*}{$\begin{array}{c}\text { Colorimetria } \\
\left(L^{*}, a^{*}, b^{*}\right)\end{array}$} & & & & & & \\
\hline & - & $27,2,1$ & - & $26,-1,1$ & - & - \\
\hline Ponto & P18 & P9 & P10 & P15 & P24 & P23 \\
\hline \multirow{2}{*}{$\begin{array}{l}\text { Fotografia } \\
\text { (RGB) }\end{array}$} & $67,68,79$ & $110,108,115$ & $118,123,131$ & $86,78,77$ & $93,70,67$ & $123,93,81$ \\
\hline & & & & & & \\
\hline \multirow{2}{*}{$\begin{array}{c}\text { Colorimetria } \\
\left(L^{*}, a^{*}, b^{*}\right)\end{array}$} & & & & & & \\
\hline & $24,-1,-4$ & $38,-4,1$ & $41,-4,0$ & $28,2,3$ & - & $34,5,9$ \\
\hline Ponto & P33 & P34 & P19 & P2 & P25 & P26 \\
\hline \multirow{2}{*}{$\begin{array}{c}\text { Fotografia } \\
\text { (RGB) }\end{array}$} & $116,92,68$ & $141,106,75$ & $140,123,105$ & $153,114,98$ & $199,110,87$ & $189,116,88$ \\
\hline & & & & & & \\
\hline \multirow{2}{*}{$\begin{array}{c}\text { Colorimetria } \\
\left(L^{*}, a^{*}, b^{*}\right)\end{array}$} & & & & & & \\
\hline & - & $39,8,18$ & $44,1,13$ & $43,4,12$ & $44,22,20$ & - \\
\hline Ponto & P1 & P14 & P28 & P7 & P4 & P3 \\
\hline \multirow{2}{*}{$\begin{array}{l}\text { Fotografia } \\
\text { (RGB) }\end{array}$} & $148,93,89$ & $131,77,76$ & $151,70,67$ & $150,57,60$ & $123,54,50$ & $104,54,42$ \\
\hline & & & & & & \\
\hline \multirow{2}{*}{$\begin{array}{c}\text { Colorimetria } \\
\left(L^{*}, a^{*}, b^{*}\right)\end{array}$} & & & & & & \\
\hline & $40,13,8$ & - & $31,20,10$ & $31,24,11$ & $30,18,8$ & $29,9,6$ \\
\hline Ponto & P31 & P11 & P17 & P21 & P20 & P36 \\
\hline \multirow{2}{*}{$\begin{array}{l}\text { Fotografia } \\
\text { (RGB) }\end{array}$} & $101,66,62$ & $77,88,107$ & $81,89,108$ & $78,88,105$ & $78,84,89$ & $79,80,68$ \\
\hline & & & & & & \\
\hline \multirow{2}{*}{$\begin{array}{c}\text { Colorimetria } \\
\left(L^{*}, a^{*}, b^{*}\right)\end{array}$} & & & & & & \\
\hline & $30,9,6$ & $29,-5,-7$ & $28,-4,-9$ & - & $29,-3,-2$ & - \\
\hline Ponto & P8 & P22 & P16 & P27 & P29 & P32 \\
\hline \multirow{2}{*}{$\begin{array}{c}\text { Fotografia } \\
\text { (RGB) }\end{array}$} & $100,96,91$ & $117,11,106$ & $150,122,98$ & $176,140,91$ & $190,156,103$ & $200,164,127$ \\
\hline & & & & & & \\
\hline \multirow{2}{*}{$\begin{array}{c}\text { Colorimetria } \\
\left(L^{*}, a^{*}, b^{*}\right)\end{array}$} & & & & & & \\
\hline & $35,-2,6$ & - & - & $45,7,22$ & $52,3,26$ & $57,4,24$ \\
\hline
\end{tabular}

O elemento ferro está presente em todos os espectros de raios $\mathrm{X}$ (figura 4.27), mas as áreas dos picos das suas linhas $K \alpha$ são maiores em pontos de coloração preta, como no ponto $\mathrm{P} 5$, que é o contorno do descanso de braço da cadeira, e o ponto P35, que é uma mecha escura no cabelo, e marrom, como no ponto P23, que é um detalhe marrom no canto superior direito, mostrando a presença de pigmentos à base de óxidos de ferro. As áreas pretas se devem ao preto de ferro $\left(\mathrm{Fe}_{3} \mathrm{O}_{4}\right)$, os marrons ao óxido de ferro III $\left(\mathrm{Fe}_{2} \mathrm{O}_{3}\right)$. 


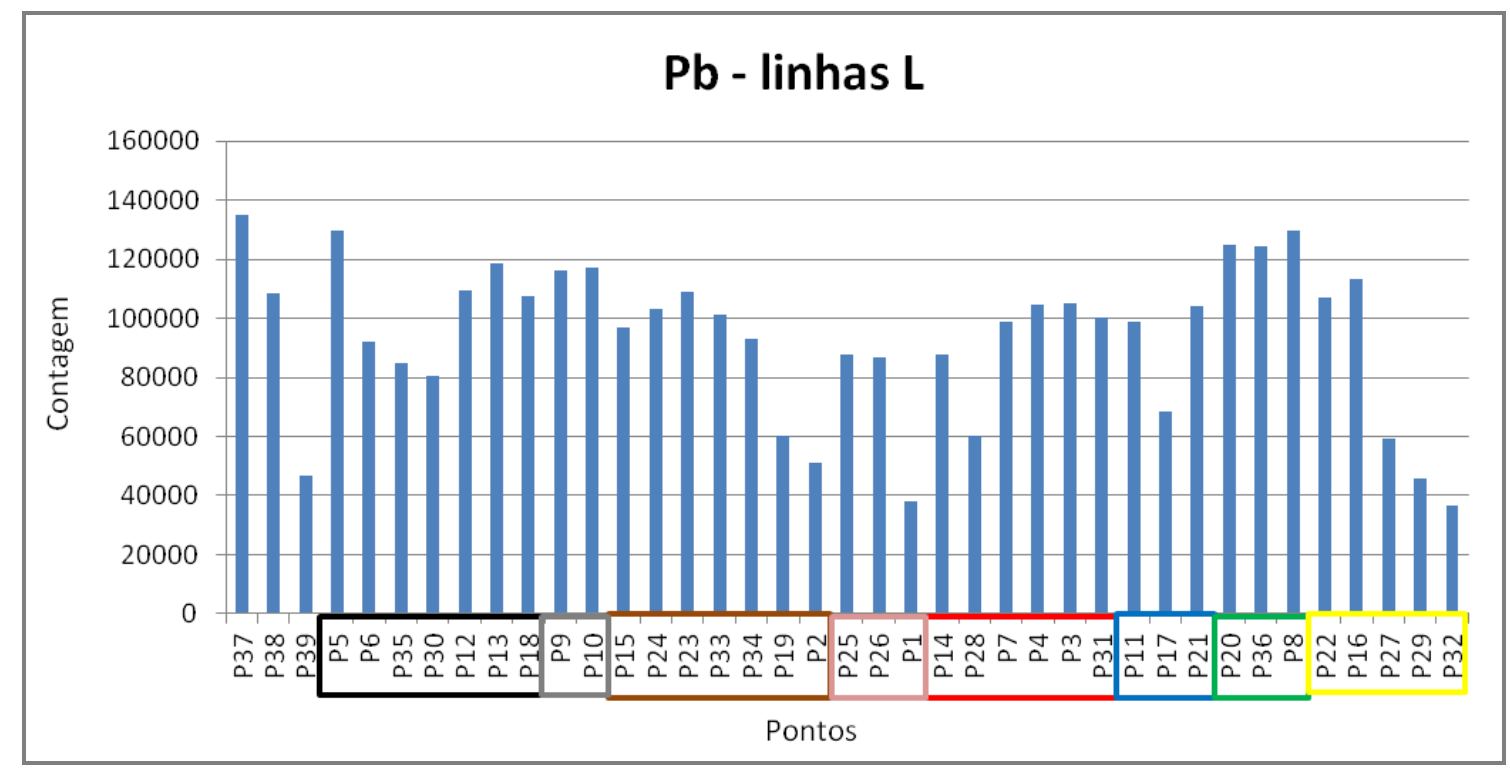

Figura 4.25 - Gráfico de barras das áreas do pico do Pb identificado nos espectros de EDXRF para os diferentes pontos medidos na obra "A Estudante Russa" de Anita Malfatti (1915) do acervo do IEB-USP

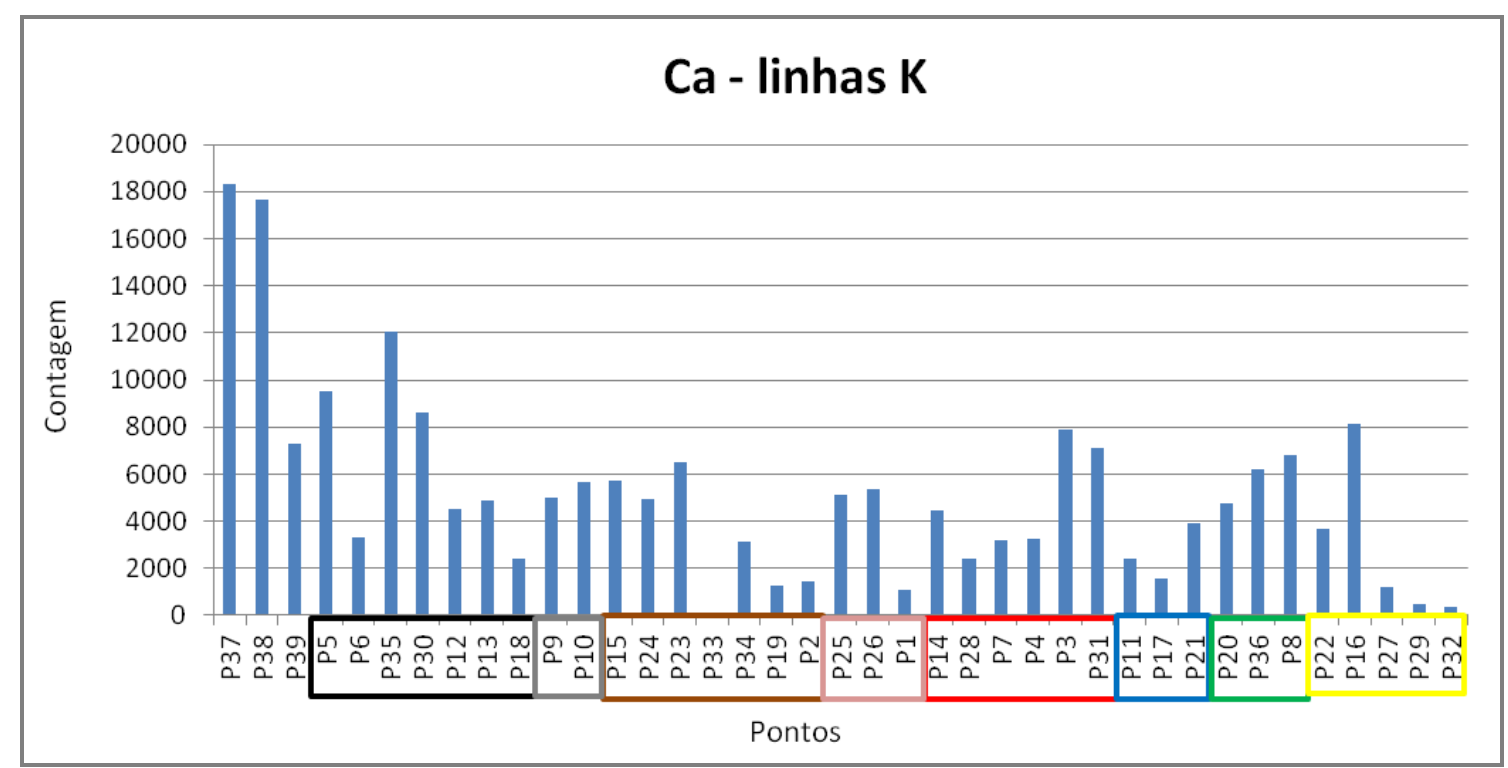

Figura 4.26 - Gráfico de barras das áreas do pico do Ca identificado nos espectros de EDXRF para os diferentes pontos medidos na obra "A Estudante Russa" de Anita Malfatti (1915) do acervo do IEB-USP 


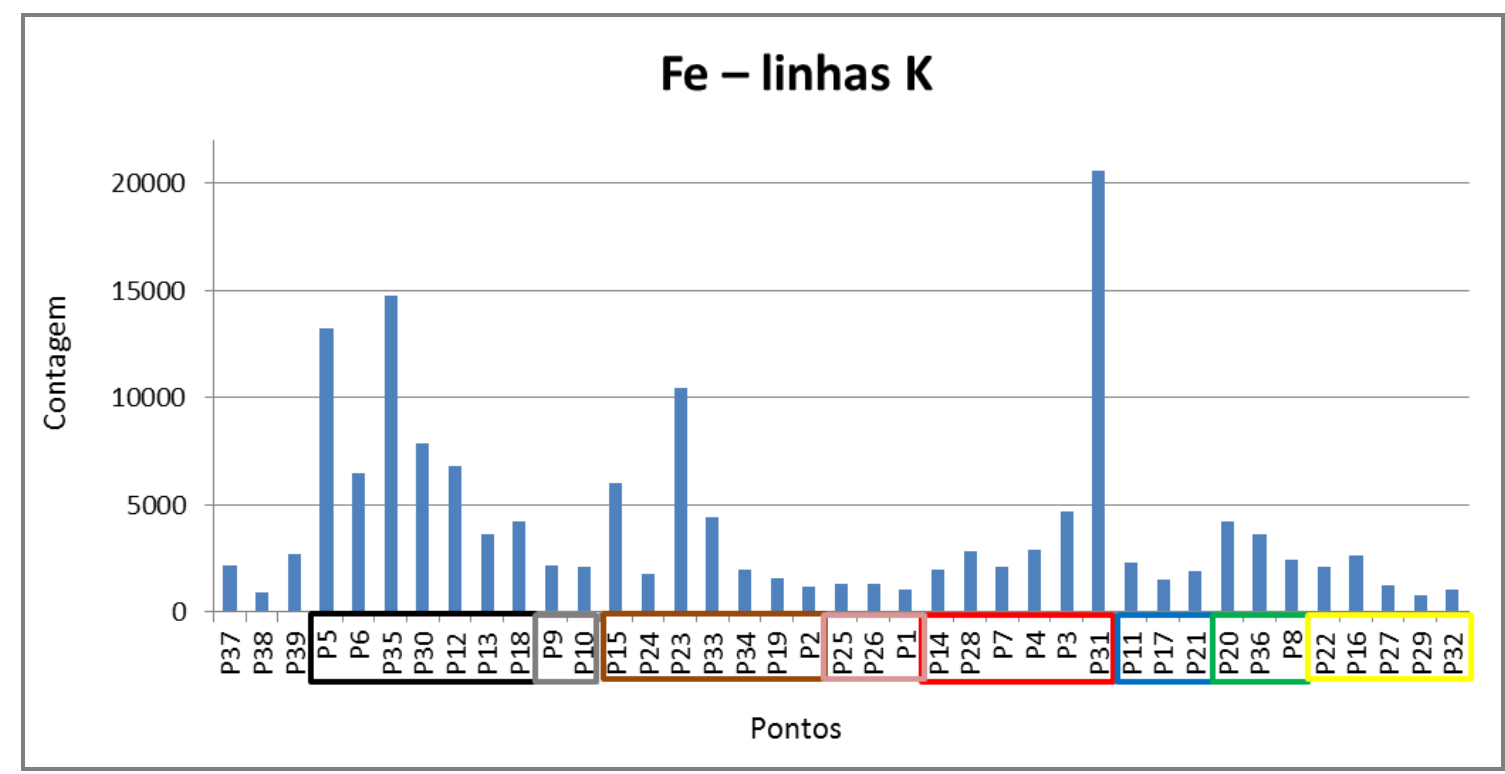

Figura 4.27 - Gráfico de barras das áreas do pico do Fe identificado nos espectros de EDXRF para os diferentes pontos medidos na obra "A Estudante Russa" de Anita Malfatti (1915) do acervo do IEB-USP

Quando observamos na figura 4.28 alguns pontos vermelhos (P03) ou escuros, como marrons e pretos (P05 e P15), encontramos o mercúrio presente, indicando a presença do vermelhão $(\mathrm{HgS})$, como pigmento predominante para a composição da cor da tinta, ou como parte dos compostos das tintas.

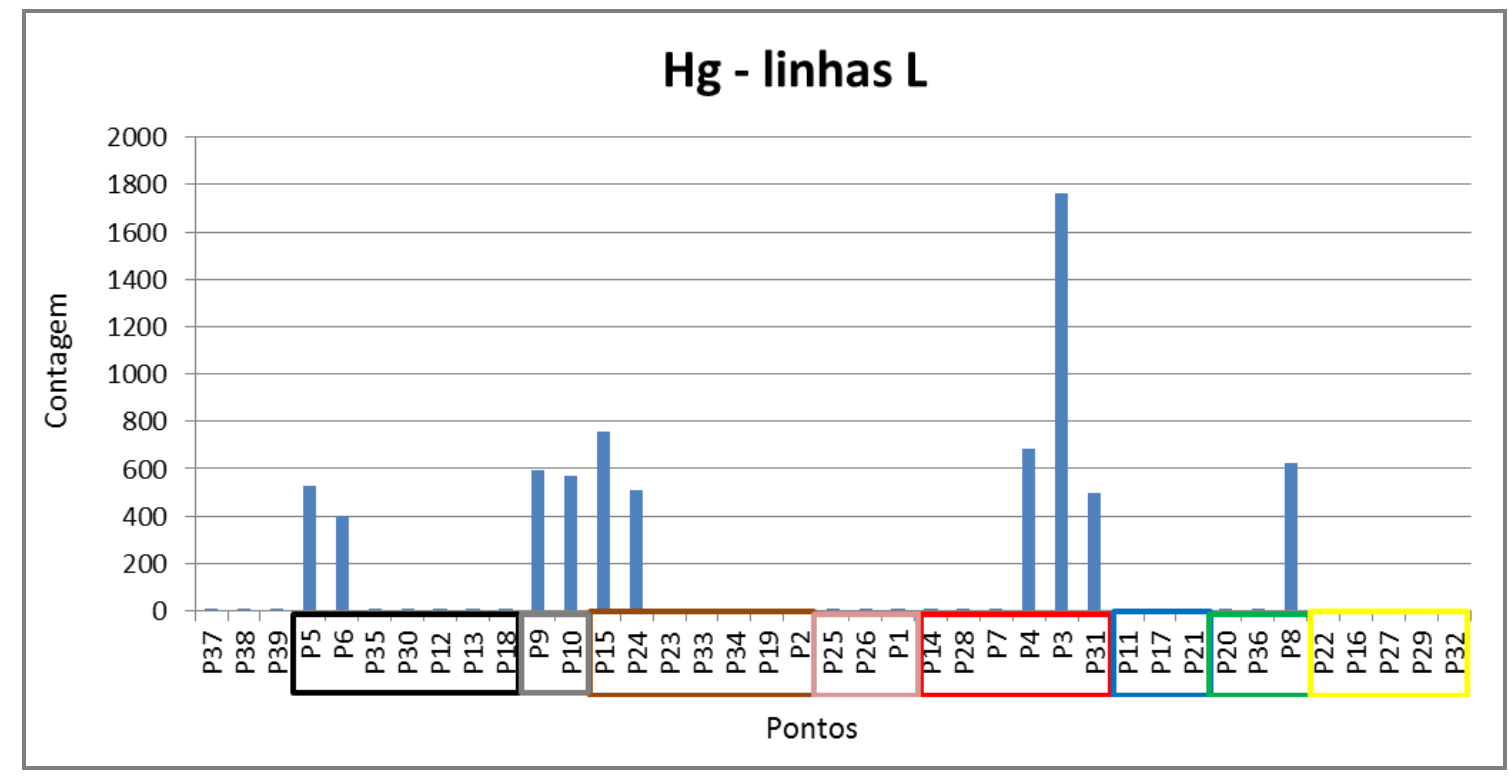

Figura 4.28 - Gráfico de barras das áreas do pico do Hg identificado nos espectros de EDXRF para os diferentes pontos medidos na obra "A Estudante Russa" de Anita Malfatti (1915) do acervo do IEB-USP

O cádmio $(\mathrm{Cd})$ está presente em muitas regiões amarelas, vermelhas e laranjas da obra (figura 4.29), inclusive em regiões com outras cores que não 
estas três, mas como já foi discutido, o Cd compõe pigmentos amarelos, laranjas e vermelhos, mas nos dois últimos, ele é acompanhado do selênio (Se) na composição, que não foi encontrado nesta obra. O ponto que mais tem Cd é um vermelho intenso (P04), na borda do braço da cadeira, mas não possível determinar sua origem.

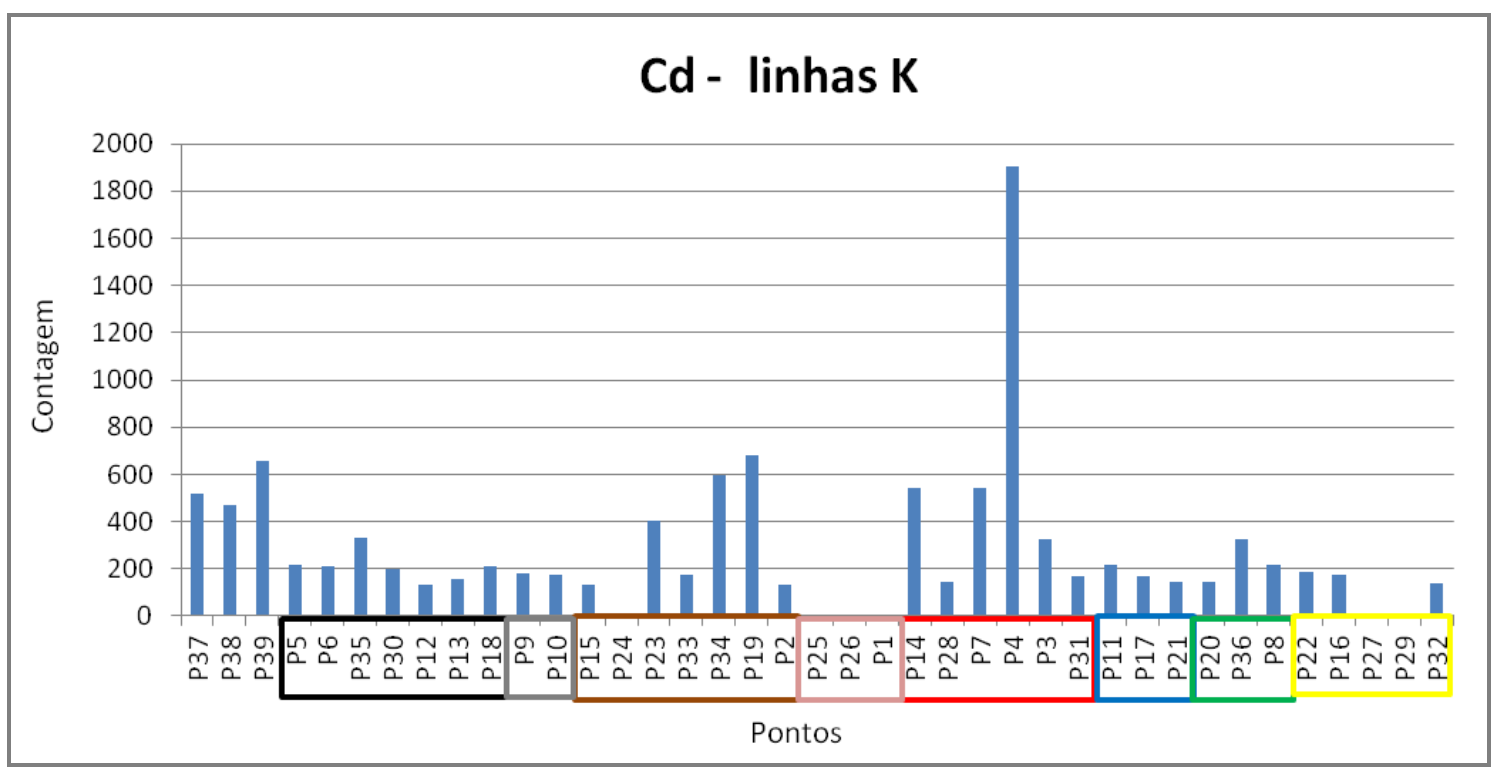

Figura 4.29 - Gráfico de barras das áreas do pico do Cd identificado nos espectros de EDXRF para os diferentes pontos medidos na obra "A Estudante Russa" de Anita Malfatti (1915) do acervo do IEB-USP

O cromo está presente na maioria dos pontos (figura 4.30), com maior área de contagens nas regiões de cores verdes (P36), beges (P33) e amarelos (P27). Desta forma, podemos afirmar que os verdes são provenientes do óxido de cromo $\left(\mathrm{Cr}_{2} \mathrm{O}_{3}\right.$ ). Nas regiões beges amareladas (pontos P02, P16, P19, P22, P27, P29, P32, P33, P34), também há a presença de Zn (figura 4.31) e Ba (figura 4.32), e em algumas o $\mathrm{Zr}$ (figura 4.33), podendo indicar a presença do amarelo de bário $\left(\mathrm{BaCrO}_{4}\right)$ ou o amarelo de estrôncio $\left(\mathrm{SrCrO}_{4}\right)$. O zinco poderia estar presente no branco de zinco que compõe a tinta. $O$ amarelo ainda poderia ser composto pelo amarelo de cromo, que possui $\mathrm{Pb}$ na sua composição. Para definir estas questões levamos em conta as correlações estatísticas dos elementos. 


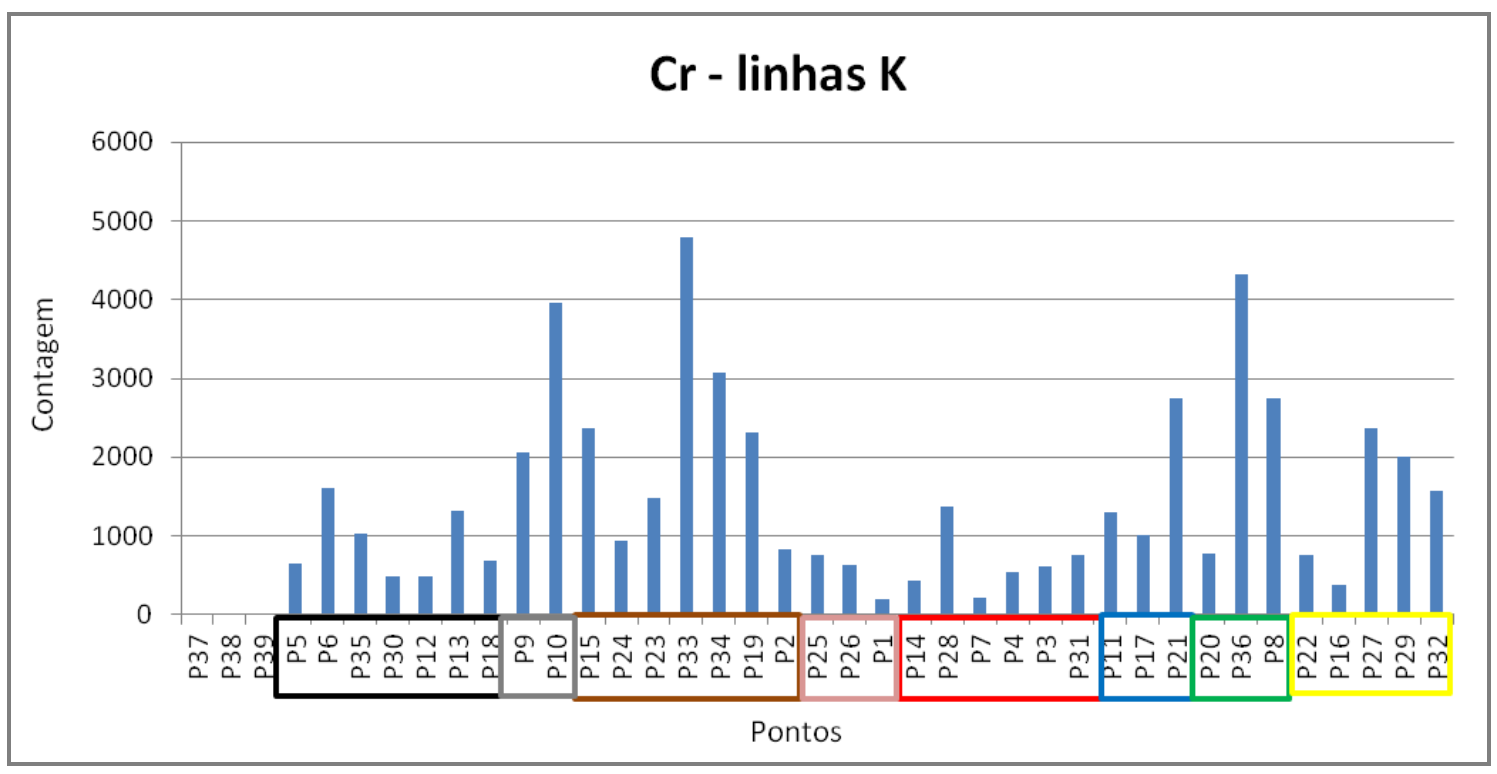

Figura 4.30 - Gráfico de barras das áreas do pico do Pb identificado nos espectros de EDXRF para os diferentes pontos medidos na obra "A Estudante Russa" de Anita Malfatti (1915) do acervo do IEB-USP

Mesmo em regiões de outras colorações, como o ponto P10, que tem uma cor azul acinzentada, está presente, e em destaque, o Cr. Mas ao observamos com atenção, este tom de azul, percebemos que há uma pigmentação bege abaixo dele.

O elemento zinco (figura 4.31) também está presente em todos os pontos do quadro, com exceção nos pontos da tela sem a camada pictórica (P37, P38, P39). Os P27, P29 e P32 são os pontos de carnação (no rosto da estudante), os pontos P19, P1 e P2 estão relacionados ao pescoço e mão da estudante e todos apresentam grande quantidade de $\mathrm{Zn}$, sugerindo que provavelmente a artista utilizou o branco de $\mathrm{Zn}$ para dar os efeitos na coloração da pele. 


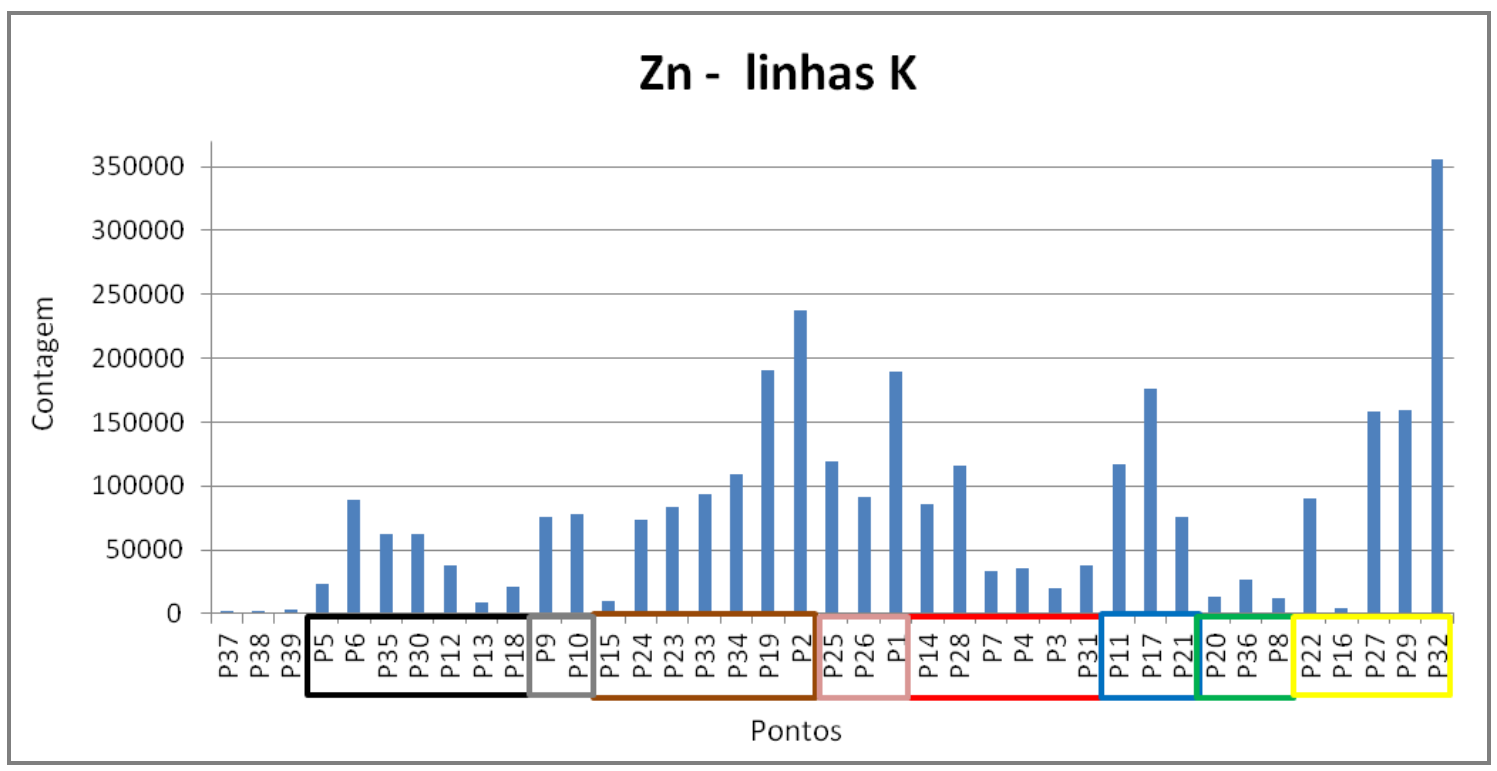

Figura 4.31 - Gráfico de barras das áreas do pico do Zn identificado nos espectros de EDXRF para os diferentes pontos medidos na obra "A Estudante Russa" de Anita Malfatti (1915) do acervo do IEB-USP

No gráfico de barras para o elemento Ba (figura 4.32), também temos a presença desse elemento em todos os pontos do quadro, com maior quantidade nos pontos vermelhos (principalmente os ponto P7 e P4). Este elemento não está relacionado diretamente a um pigmento vermelho, mas pode estar vinculado à tinta de determinado fabricante, que pode ter utilizado alguma carga com este elemento na sua constituição. O elemento Sr, pode possuir uma correlação com o Ba pois é um elemento traço da barita mineral. Desta forma, podemos sugerir que o Ba pode ser algum elemento de carga de tinta. O bário também pode estar associado ao branco de zinco presente na composição em algumas tintas utilizadas como elemento que dão opacidade, ou variam o tom final naquele matiz. 


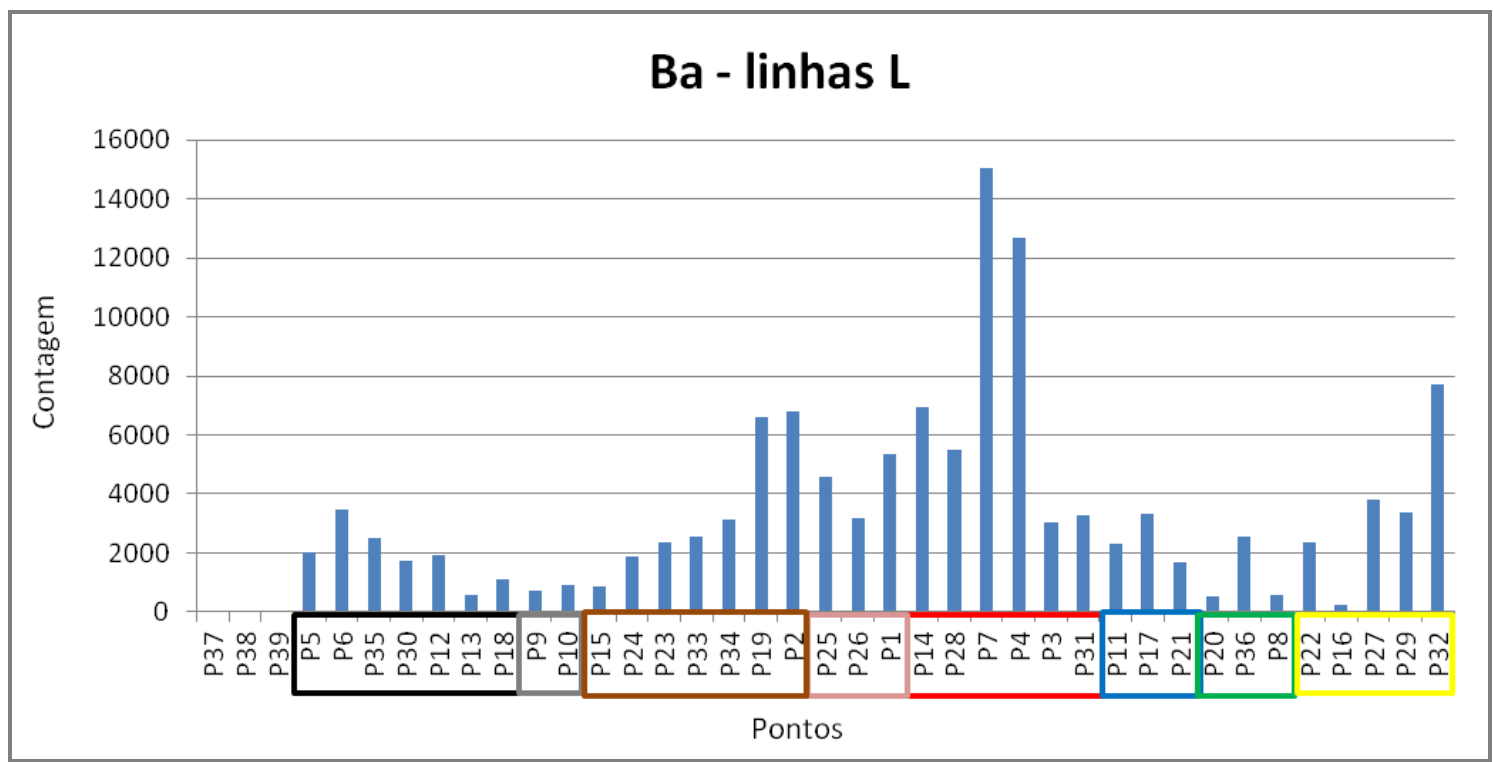

Figura 4.32 - Gráfico de barras das áreas dos picos do Ba identificados nos espectros de EDXRF para os diferentes pontos medidos na obra "A Estudante Russa" de Anita Malfatti (1915) do acervo do IEB-USP

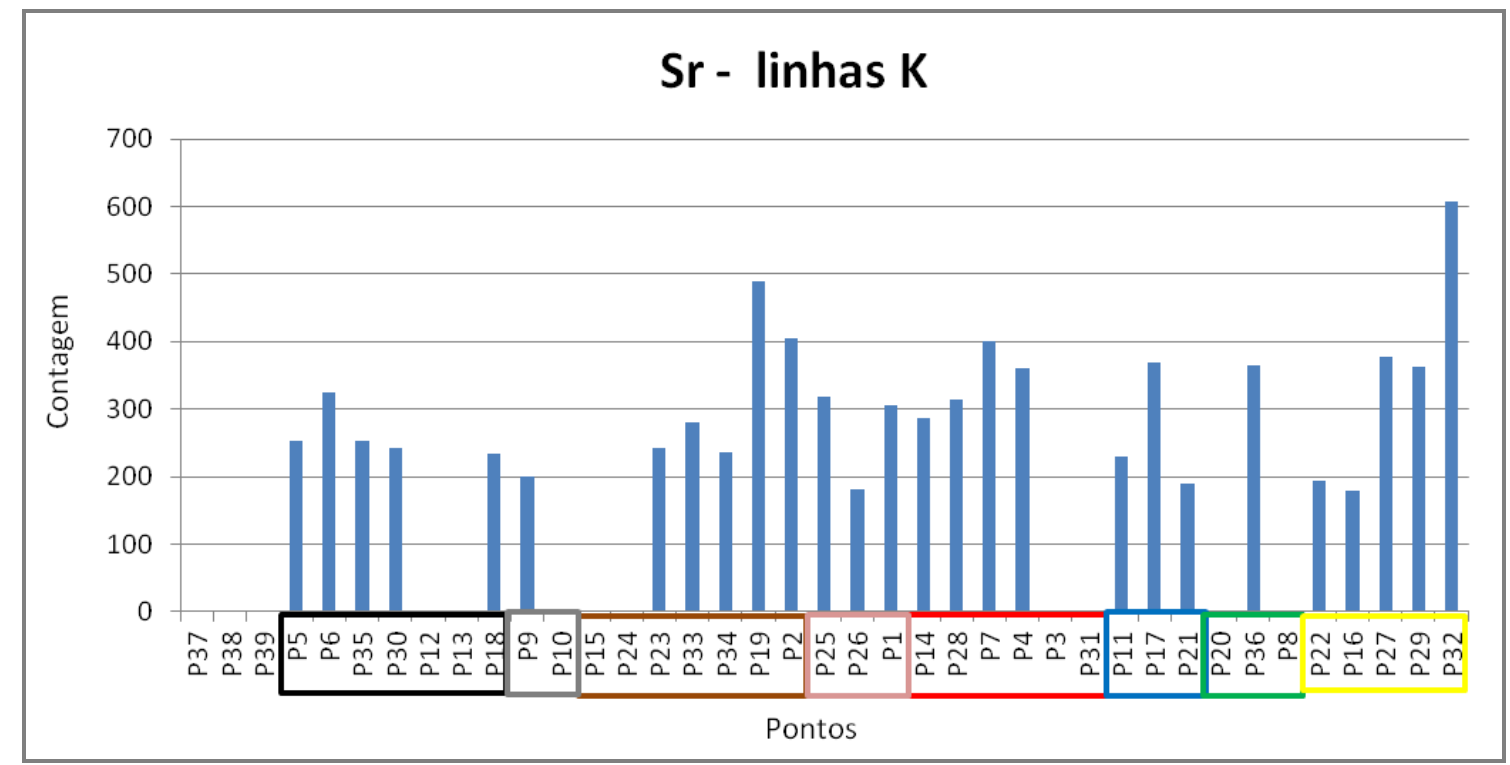

Figura 4.33 - Gráfico de barras das áreas dos picos do Sr identificados nos espectros de EDXRF para os diferentes pontos medidos na obra "A Estudante Russa" de Anita Malfatti (1915) do acervo do IEB-USP

Novamente, os pigmentos azuis analisados apresentam pouca quantidade de $\mathrm{Sr}, \mathrm{Ba}, \mathrm{Cr}, \mathrm{Zn}$ e $\mathrm{Fe}$ e não foi identificado elemento majoritario nestes pontos, o que pode indicar que o azul pode estar vinculado ao azul ultramar, ou lazurita, que possuem elementos leves em suas constituições. 
As correlações obtidas por análises estatísticas dos elementos presentes nas medidas EDXRF podem ser observadas na tabela 4.6 e na figura 4.34. Neste caso, temos um correlação positiva entre $\circ \mathrm{Ca}$ e $\circ \mathrm{Pb}$ $(0,500)$, indicando que estão presentes no fundo de preparação da tela. Ao mesmo tempo, o zinco possui correlação negativa com o $\mathrm{Pb}(-0,754)$, mostrando que os brancos de chumbo e de zinco não foram utilizados juntamente.

O cromo não tem correlação positiva com os elementos $\mathrm{Ba}(-0,147)$, e tem baixa correlação positiva com $\mathrm{Sr}(0,145)$ e $\mathrm{Pb}(0,111)$, mostrando que os amarelos que contêm cromo não foram utilizados. A alta correlação entre bário e estrôncio permanece $(0,654)$, reforçando a possível presença de barita.

Pela reflectografia de infravermelho obtida da obra (figura 4.20), foi possível verificar que o quadro possui pinturas e traços subjacentes, mas também se observou que há traços negros de pigmentos a base de carbono na superfície, como no traço preto do contorno do apoio de braço da cadeira retratada.

Desta forma, pode-se montar uma tabela com possíveis pigmentos presentes na obra "A Estudante Russa" (tabela 4.7).

Tabela 4.6 - Matriz de correlação dos elementos presentes nos pontos analisados por EDXRF na obra "A Estudante Russa" de Anita Malfatti (1915) do acervo do IEB-USP

\begin{tabular}{l|r|r|r|r|r|r|r|r|r|r} 
variable & $\mathrm{Ca}-\mathrm{K}$ & $\mathrm{Cr}-\mathrm{K}$ & $\mathrm{Fe}-\mathrm{K}$ & $\mathrm{Cu}-\mathrm{K}$ & $\mathrm{Zn}-\mathrm{K}$ & $\mathrm{Sr}-\mathrm{K}$ & $\mathrm{Cd}-\mathrm{K}$ & $\mathrm{Ba}-\mathrm{L}$ & $\mathrm{Hg}-\mathrm{L}$ & $\mathrm{Pb}-\mathrm{L}$ \\
\hline $\mathrm{Ca}-\mathrm{K}$ & 1,000 & $-0,347$ & 0,300 & $-0,031$ & $-0,603$ & $-0,557$ & 0,134 & $-0,432$ & 0,135 & 0,500 \\
\hline $\mathrm{Cr}-\mathrm{K}$ & $-0,347$ & 1,000 & $-0,101$ & $-0,089$ & 0,146 & 0,145 & $-0,138$ & $-0,147$ & 0,046 & 0,111 \\
\hline $\mathrm{Fe}-\mathrm{K}$ & 0,300 & $-0,101$ & 1,000 & 0,023 & $-0,310$ & $-0,216$ & $-0,023$ & $-0,149$ & 0,202 & 0,245 \\
\hline $\mathrm{Cu}-\mathrm{K}$ & $-0,031$ & $-0,089$ & 0,023 & 1,000 & $-0,021$ & $-0,175$ & $-0,160$ & $-0,164$ & $-0,032$ & 0,107 \\
\hline $\mathrm{Zn}-\mathrm{K}$ & $-0,603$ & 0,146 & $-0,310$ & $-0,021$ & 1,000 & 0,734 & $-0,221$ & 0,393 & $-0,288$ & $-0,754$ \\
\hline $\mathrm{Sr}-\mathrm{K}$ & $-0,557$ & 0,145 & $-0,216$ & $-0,175$ & 0,734 & 1,000 & 0,115 & 0,654 & $-0,366$ & $-0,570$ \\
\hline $\mathrm{Cd}-\mathrm{K}$ & 0,134 & $-0,138$ & $-0,023$ & $-0,160$ & $-0,221$ & 0,115 & 1,000 & 0,467 & 0,148 & 0,113 \\
\hline $\mathrm{Ba}-\mathrm{L}$ & $-0,432$ & $-0,147$ & $-0,149$ & $-0,164$ & 0,393 & 0,654 & 0,467 & 1,000 & $-0,036$ & $-0,373$ \\
\hline $\mathrm{Hg}-\mathrm{L}$ & 0,135 & 0,046 & 0,202 & $-0,032$ & $-0,288$ & $-0,366$ & 0,148 & $-0,036$ & 1,000 & 0,295 \\
\hline $\mathrm{Pb}-\mathrm{L}$ & 0,500 & 0,111 & 0,245 & 0,107 & $-0,754$ & $-0,570$ & 0,113 & $-0,373$ & 0,295 & 1,000
\end{tabular}




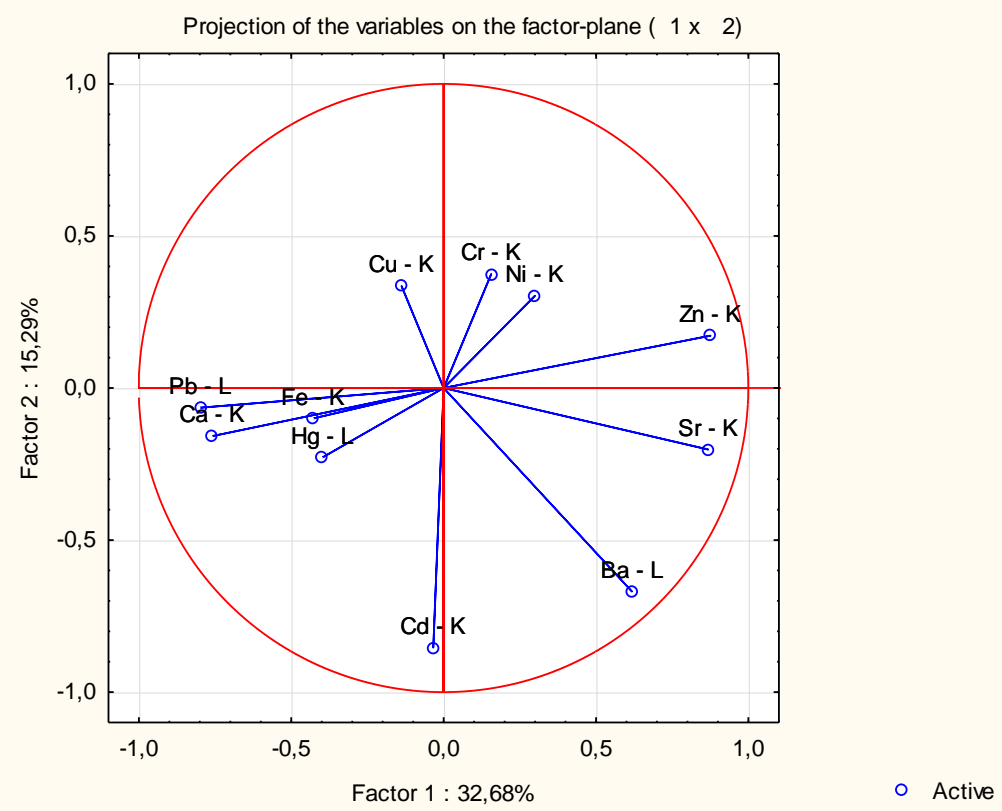

Figura 4.34 - Gráfico da correlação por PCA entre os elementos presentes nos espectros de EDXRF pontos medidos na obra "A Estudante Russa" de Anita Malfatti do acervo do IEB-USP

Tabela 4.7: Possíveis pigmentos utilizados por Anita Malfatti na obra "A Estudante Russa" de Anita Malfatti (1915) do acervo do IEB-USP (JANSSENS, 2004; STUART, 2008; VASCONCELOS et al., 1992; MAYER, 2006; LFNATEC, 2009)

\begin{tabular}{|c|c|c|c|c|}
\hline Cor & $\begin{array}{l}\text { Elementos } \\
\text { Presentes }\end{array}$ & $\begin{array}{c}\text { Composição } \\
\text { Química }\end{array}$ & $\begin{array}{l}\text { Nome do } \\
\text { Pigmento }\end{array}$ & $\begin{array}{c}\text { Empregado } \\
\text { desde }\end{array}$ \\
\hline \multirow{2}{*}{ Brancos } & $\mathrm{Zn}^{*}$ & $\mathrm{ZnO}$ & $\begin{array}{l}\text { Branco de } \\
\text { Zinco }\end{array}$ & Século 19 \\
\hline & $\mathrm{Ba}^{*}, \mathrm{Sr}^{*}$ & $\mathrm{BaSO} 4+\mathrm{SrSO} 4$ & Barita & Mineral \\
\hline Amarelos & \multicolumn{4}{|c|}{ Indeterminado } \\
\hline Vermelhos & $\mathrm{Hg}, \mathrm{S}$ & $\mathrm{HgS}$ & Vermelhão & Século 13 \\
\hline Verdes & $\mathrm{Cr}$ & $\mathrm{Cr}_{2} \mathrm{O}_{3}$ & $\begin{array}{l}\text { Óxido de } \\
\text { Cromo }\end{array}$ & Século 19 \\
\hline \multirow{2}{*}{ Pretos } & $\mathrm{Fe}$ & $\mathrm{Fe}_{3} \mathrm{O}_{4}$ & $\begin{array}{l}\text { Preto de } \\
\text { Ferro }\end{array}$ & Século 19 \\
\hline & C & C & $\begin{array}{l}\text { Preto de } \\
\text { Carbono }\end{array}$ & Antiguidade \\
\hline Marrons & $\mathrm{Fe}$ & $\mathrm{Fe}_{2} \mathrm{O}_{3}$ & $\begin{array}{c}\text { Óxido de } \\
\text { Ferro, Siena }\end{array}$ & Século 19 \\
\hline \multirow{2}{*}{ Base } & $\mathrm{Ca}$ & $\begin{array}{c}\mathrm{CaCO}_{3} \mathrm{Ou} \\
\mathrm{CaSO}_{4} 2 \mathrm{H}_{2} \mathrm{O}\end{array}$ & Cal ou Gesso & Mineral \\
\hline & $\mathrm{Pb}$ & 2PbCO3. $\mathrm{Pb}(\mathrm{OH})_{2}$ & $\begin{array}{c}\text { Branco de } \\
\text { Chumbo }\end{array}$ & Antiguidade \\
\hline
\end{tabular}

${ }^{*}$ Associado a outras cores 


\section{3. "Retrato de Mário de Andrade"}

Na obra "Retrato de Mário de Andrade" (figura 4.35), apenas foram realizadas as análises por fluorescência de raio-X por dispersão de energia (EDXRF), vinte e sete (27) pontos foram medidos, como pode ser observado na figura 4.36. Com a observação a olhos nus e auxiliados por especialistas em conservação e restauro, podemos ver que nesta obra a camada pictórica é muito fina, a ponto de observar a tela em algumas áreas, e que não há indicação de pentimento ou reutilização de tela sob a camada pictórica mais externa.

Nesta obra, apesar de estar na borda do quadro, o ponto P27 possui uma coloração branca azulada, que indica a presença de uma camada pictórica. Mas uma região em especial chama atenção, nos pontos P17 e principalmente no P25, que apesar de aparentarem ter uma coloração mais branca, levemente azulada, na imagem, estas são regiões com pouquíssima ou quase nenhuma camada pictórica. Quando observamos os gráficos de barras das áreas dos picos para cada elemento em cada ponto analisado, podemos ver que nos pontos $\mathrm{P} 17$ e P25 temos a presença dos elementos $\mathrm{Ca}, \mathrm{Ba}$ e $\mathrm{Sr}$, e $\mathrm{Pb}$ (figuras 4.36, 4.37, 4.38 e 4.39, respectivamente), em quantidade maior do que a média dos demais pontos, com exceção do $\mathrm{Pb}$, que apresentou menor área em comparação aos demais pontos brancos (com exceção do P5, que será discutido posteriormente). Desta forma, é possível afirmar, que na camada de preparação, pré-pintura, está presente o carbonato de cálcio $\left(\mathrm{CaCO}_{3}\right)$ ou sulfato de cálcio $\left(\mathrm{CaSO}_{4}{ }_{2} \mathrm{H}_{2} \mathrm{O}\right)$, que não podemos diferenciar, pois o pico do $\mathrm{S}$ está sobreposto ao pico do $\mathrm{Pb}-\mathrm{M}$, como visto anteriormente. Além disso, nestes dois pontos temos $\mathrm{OPb}$, que está presente em todos os pontos analisados, figura 4.39, indicando que foi usado branco de chumbo $\left(2 \mathrm{PbCO}_{3} \cdot \mathrm{Pb}(\mathrm{OH})_{2}\right)$ na camada de preparação, como nos quadros anteriores. Mas, diferentemente das outras obras, temos presente $\mathrm{Ba}$ e Sr nestes pontos, indicando que foi utilizada a barita na preparação do fundo branco. Não apenas nos pontos P17 e P25, mas em vários outros pontos e cores há uma correlação entre estes três elementos ( $\mathrm{Ca}, \mathrm{Ba}$ e $\mathrm{Sr}$ ), indicando que a artista também pode ter utilizado o branco de $\mathrm{Ba}\left(\mathrm{BaSO}_{4}\right)$ que é conhecido como branco permanente. 


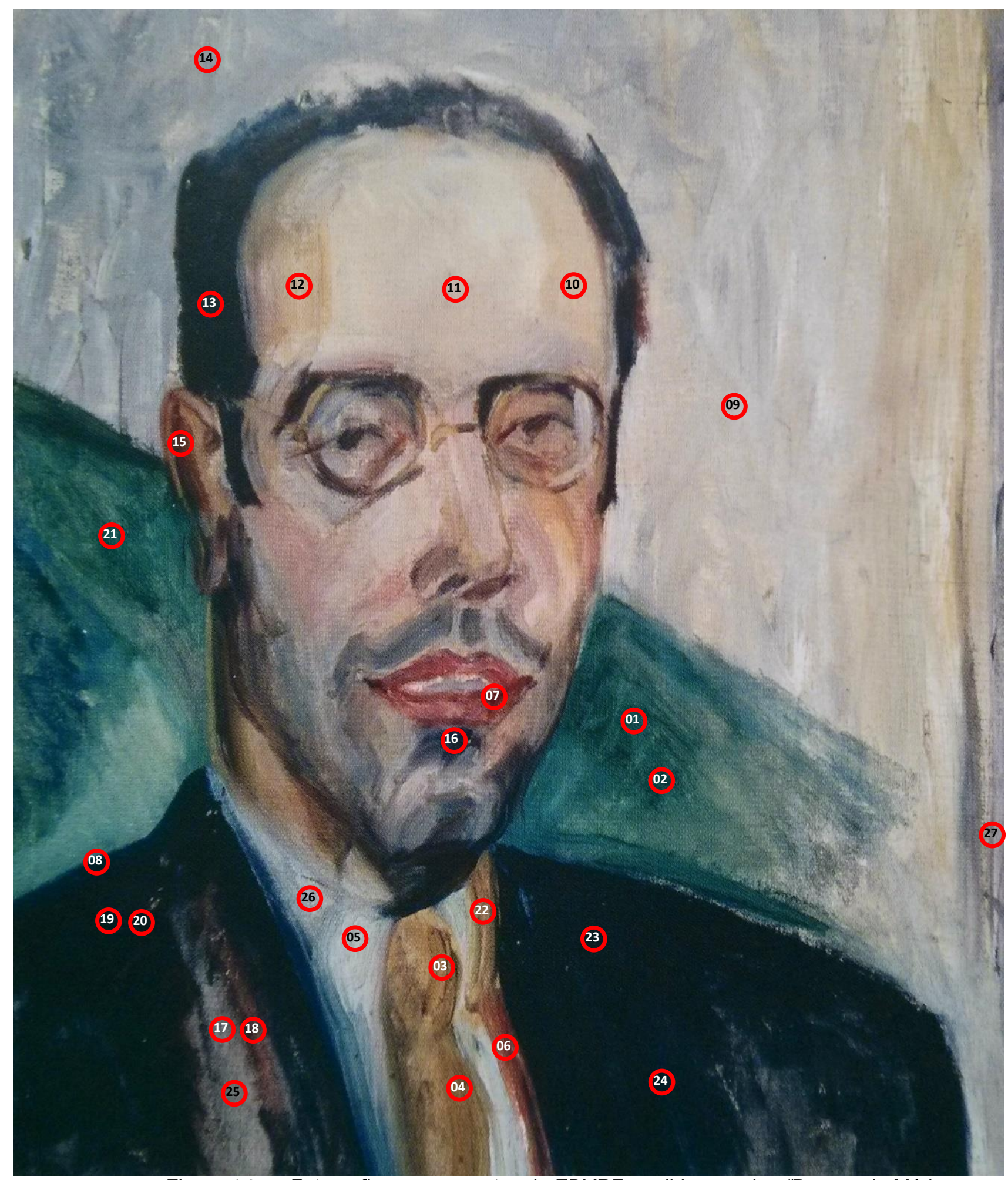

Figura 4.35 - Fotografia com os pontos de EDXRF medidos na obra "Retrato de Mário de Andrade" de Anita Malfatti (1923) do acervo do IEB-USP 


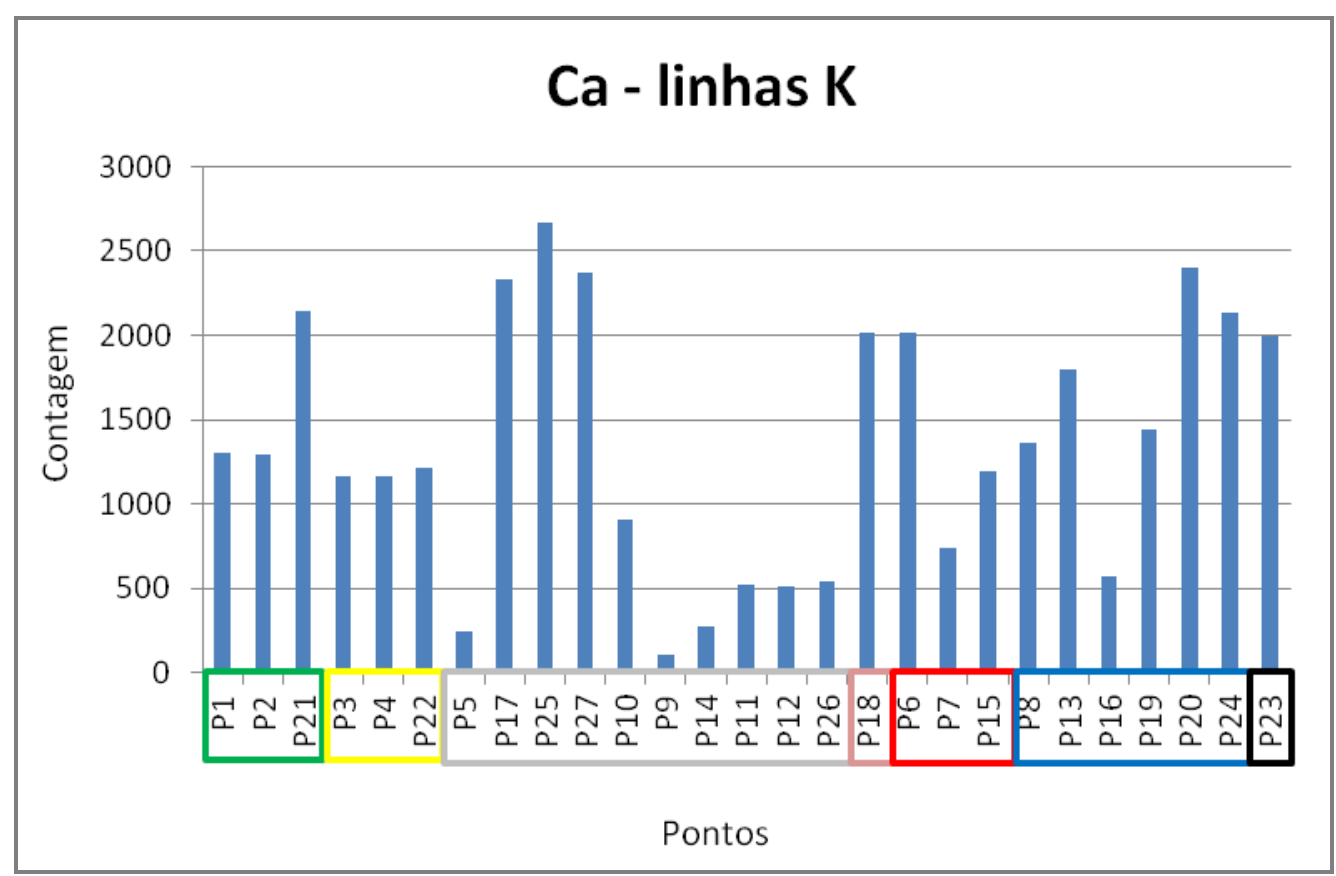

Figura 4.36 - Gráfico de barras das áreas dos picos do Ca identificados nos espectros de EDXRF para os diferentes pontos medidos na obra "Retrato de Mário de Andrade" de Anita Malfatti (1923) do acervo do IEB-USP

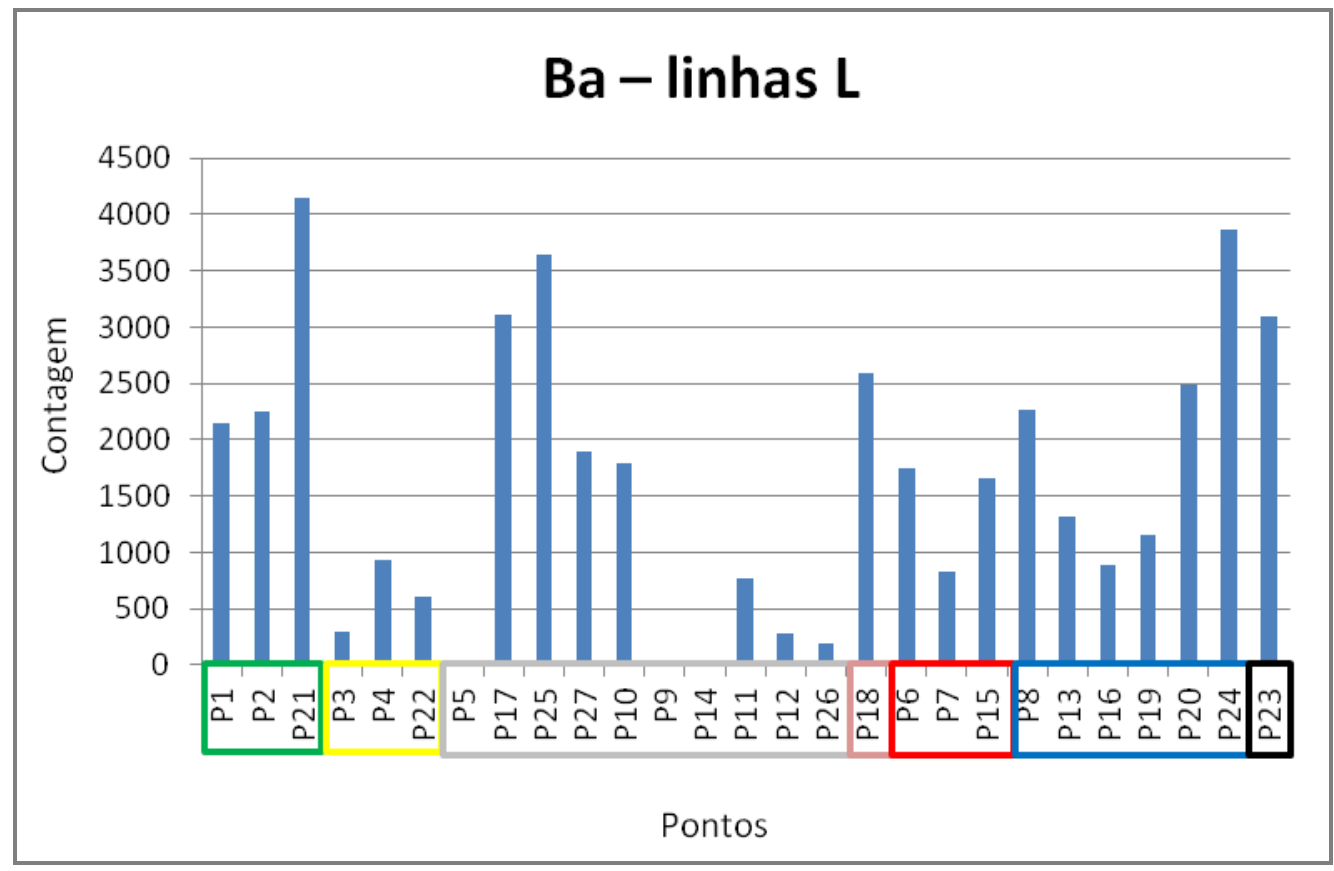

Figura 4.37 - Gráfico de barras das áreas dos picos do Ba identificados nos espectros de EDXRF para os diferentes pontos medidos na obra "Retrato de Mário de Andrade" de Anita Malfatti (1923) do acervo do IEB-USP 


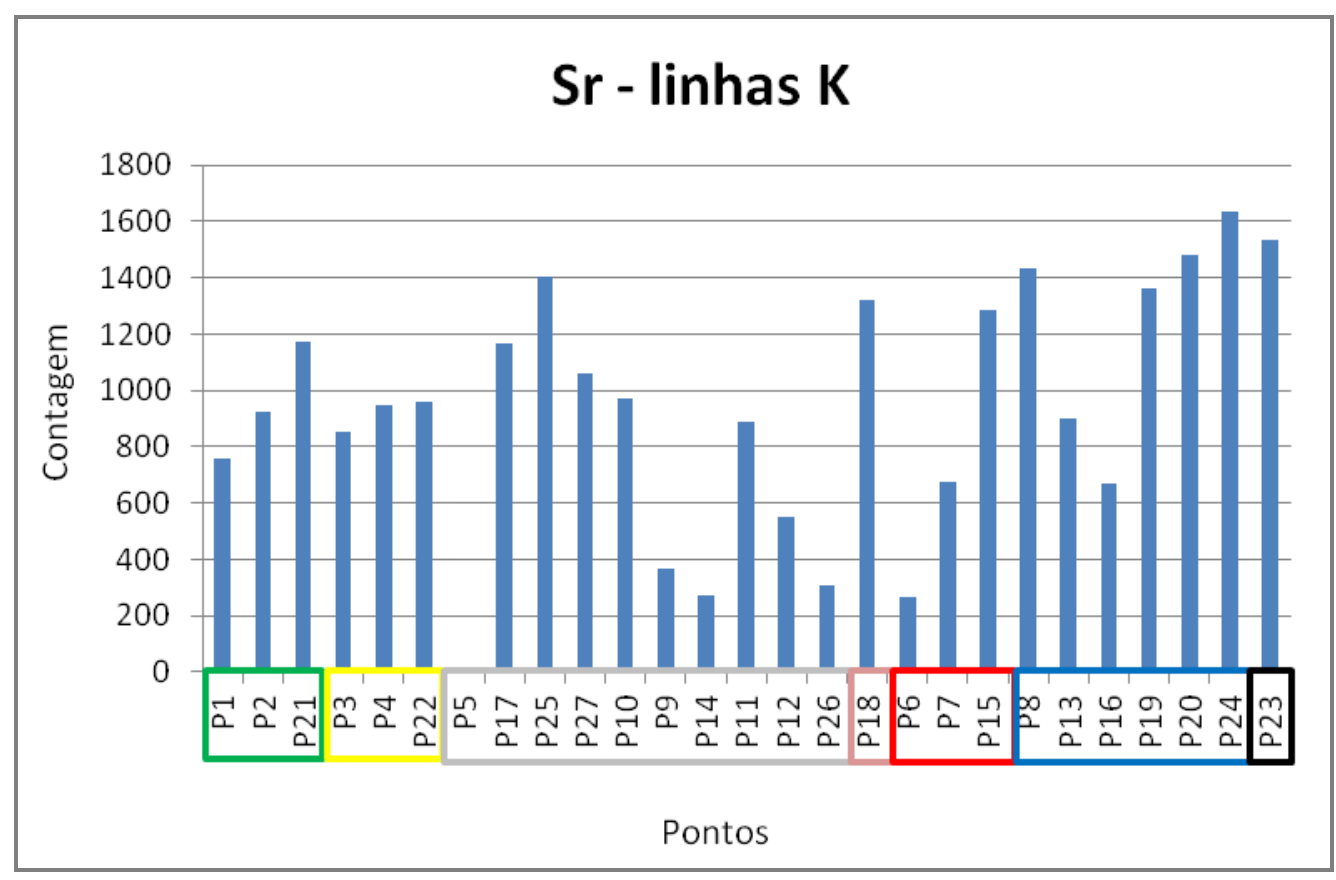

Figura 4.38 - Gráfico de barras das áreas dos picos do Sr identificados nos espectros de EDXRF para os diferentes pontos medidos na obra "Retrato de Mário de Andrade" de Anita Malfatti (1923) do acervo do IEB-USP

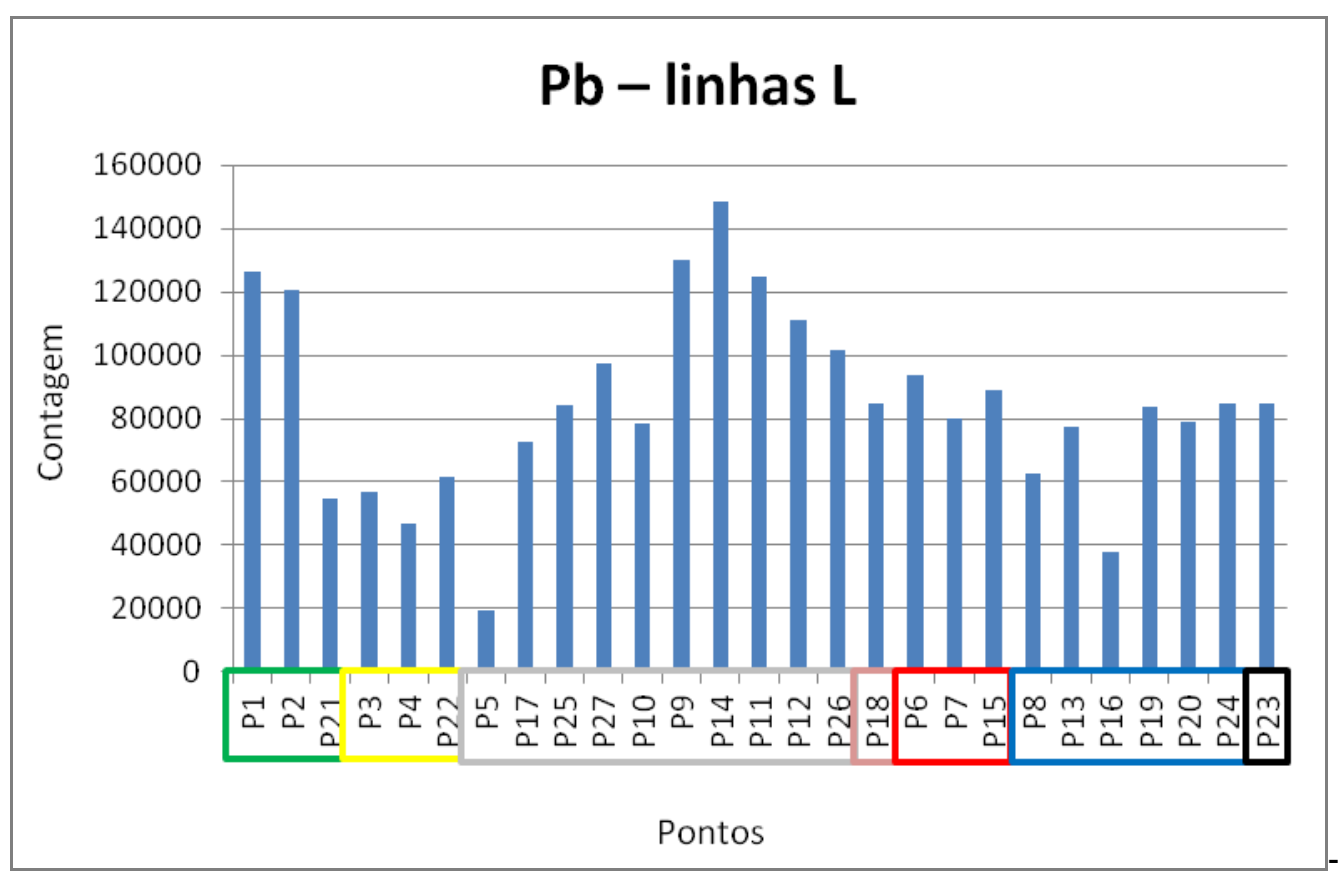

Figura 4.39 - Gráfico de barras das áreas dos picos do Pb identificados nos espectros de EDXRF para os diferentes pontos medidos na obra "Retrato de Mário de Andrade" de Anita Malfatti (1923) do acervo do IEB-USP

Outro ponto muito particular é o P06, pois apesar de possuir uma coloração vermelha alaranjada, possui muitos elementos químicos diferentes, indicando ser uma mistura dos pigmentos utilizados pela artista, podendo, além 
disso, ter sobreposição de pinceladas de diferentes tintas ou misturas. Temos, desta maneira, que considerar esta informação ao observarmos as demais discussões sobre esta obra.

O elemento $\mathrm{Fe}$, assim como o $\mathrm{Pb}$, está presente em todos os pontos medidos nesta obra, figura 4.40, podendo ser, desta forma, um elemento presente na camada de preparação, ou uma contaminação pela mistura das tintas da paleta da artista. Mas em alguns pontos como os azuis aparecem em maior destaque. Ao observarmos com atenção, vemos que muitas áreas, como nos pontos P19 e P20, possuem traços negros em sua composição. Ao mesmo tempo, um ponto predominantemente azul (P08), também tem Fe presente. Logo, podemos afirmar que está presente tanto o pigmento azul à base de ferro, azul da Prússia $\left(\mathrm{Fe}_{4}\left[\mathrm{Fe}(\mathrm{CN})_{6}\right] 3\right)$, quanto o negro à base de ferro, preto de ferro $\left(\mathrm{Fe}_{3} \mathrm{O}_{4}\right)$.

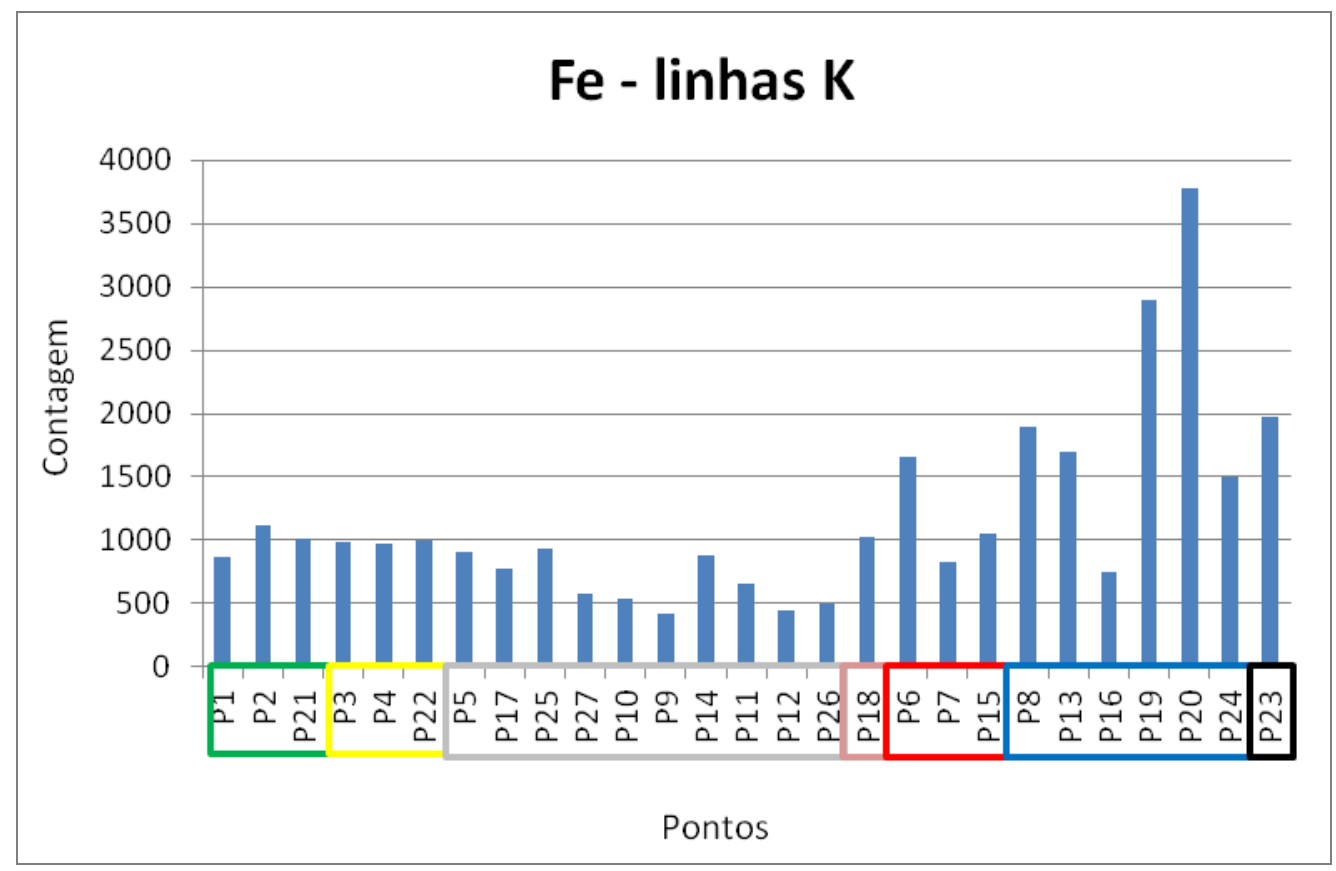

Figura 4.40 - Gráfico de barras das áreas dos picos do Fe identificados nos espectros de EDXRF para os diferentes pontos medidos na obra "Retrato de Mário de Andrade" de Anita Malfatti (1923) do acervo do IEB-USP

O cobalto também está presente em algumas regiões, como pode ser visto na figura 4.41, com maior intensidade nos pontos azuis, isso nos permite afirmar que o azul que compõe a obra é uma mistura do azul da Prússia e o azul de cobalto ( $\left.\mathrm{CoO} \cdot \mathrm{Al}_{2} \mathrm{O}_{3}\right)$. As demais áreas que possuem $\mathrm{Co}$, mas não são 
azuis, devem contê-lo por mistura de tintas, ou mais provavelmente, por sobreposição de camadas, pois não há pigmento verde de Co, e o pigmento amarelo não seria de Co, pois o ponto amarelo P03, que está em um traço amarelo sobre um fundo branco, possui quatro vezes menos Co do que o ponto P22, que é um traço amarelo provavelmente sobre um fundo azul.

O cromo também está presente nos pontos verdes, mas com uma intensidade muito maior do que nos demais pontos, como pode ser visto na figura 4.42. Isso nos possibilita afirmar que o pigmento verde utilizado possui cromo. O EDXRF não nos permite diferenciar quais dos pigmentos à base de Cr estão presentes, mas são um ou mais daqueles constituídos por óxido de cromo $\left(\mathrm{Cr}_{2} \mathrm{O}_{3}\right)$. Os pontos que não possuem verde na constituição, podem apresentá-lo por mistura (como no ponto P06) ou por sobreposição de pinceladas, que parece ser o caso do ponto P22. A presença de $\mathrm{Cr}$ nos pontos de azuis pode sugerir que a artista também misturou este elemento para dar tonalidade diferente a estes pontos.

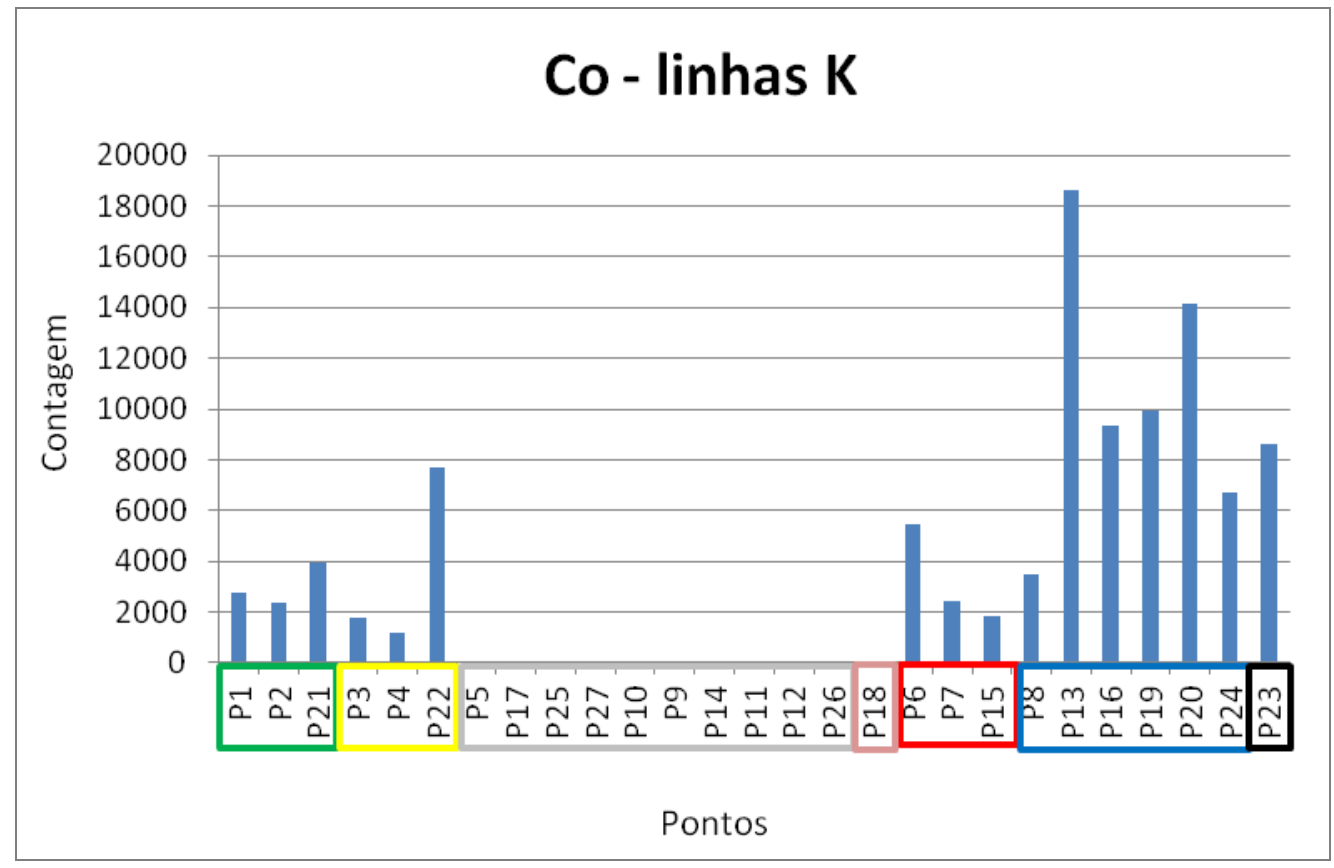

Figura 4.41 - Gráfico de barras das áreas dos picos do Co identificados nos espectros de EDXRF para os diferentes pontos medidos na obra "Retrato de Mário de Andrade" de Anita Malfatti (1923) do acervo do IEB-USP 


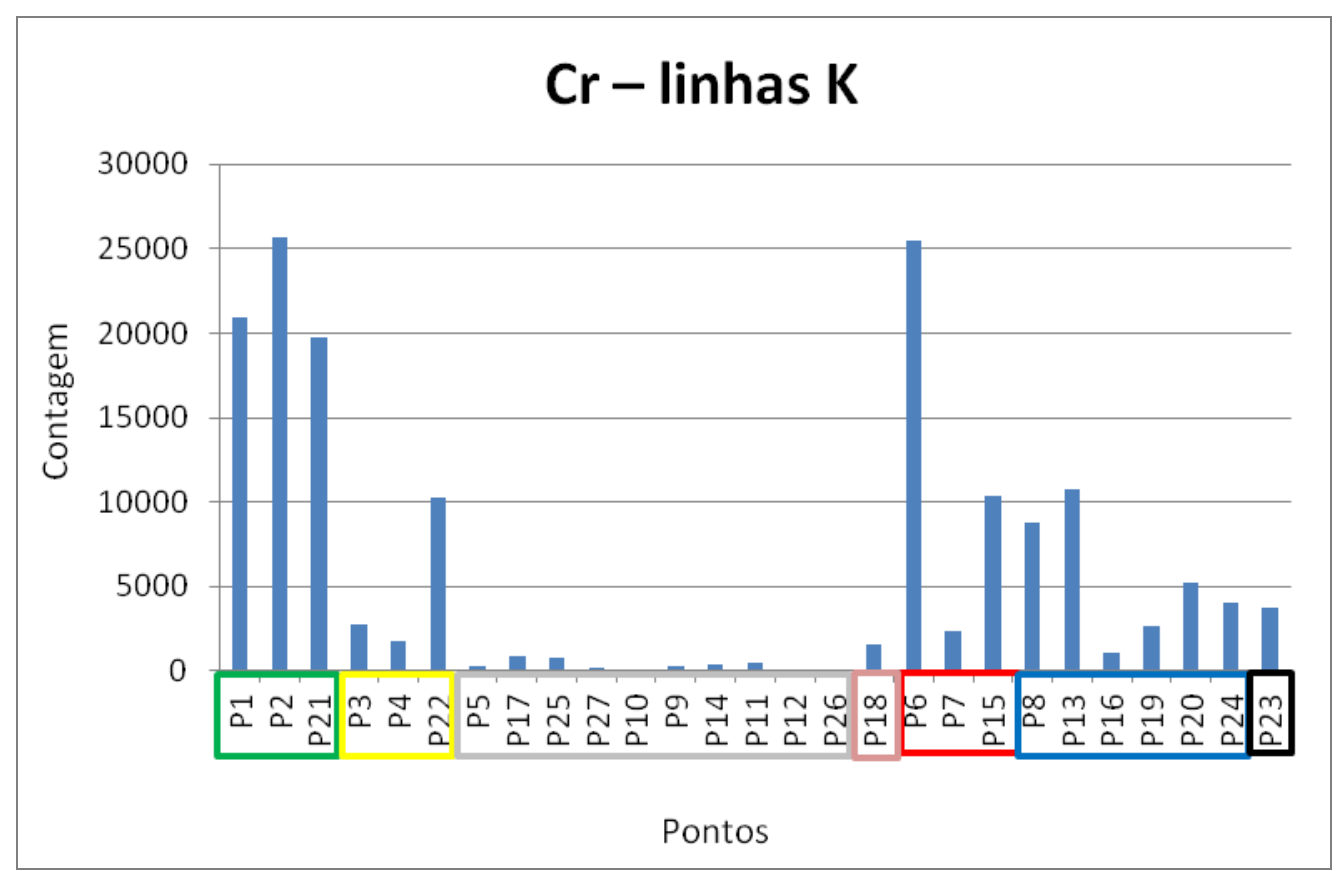

Figura 4.42 - Gráfico de barras das áreas dos picos do Fe identificados nos espectros de EDXRF para os diferentes pontos medidos na obra "Retrato de Mário de Andrade" de Anita Malfatti (1923) do acervo do IEB-USP

Assim como os pontos verdes, os pontos amarelos podem ser associados a outro elemento químico, a pigmentos que contenham $\mathrm{Cd}$, pois este elemento possui alta contagem nos pontos de cor amarela (figura 4.43). Os pigmentos à base de amarelos de cádmio podem vir na sua forma pura (CdS), ou associados associados com o sulfato de bário (BaSO 4$)$, com o óxido de zinco (ZnO), ou com o zinco (CdSZn) (MAYER, 2006; LFNATEC, 2009). Nos pontos amarelos, a contagem para o bário é baixa (figura 4.37), desta forma, podemos associar este bário a outra origem, que não o pigmento amarelo. Mas ao observarmos o gráfico do zinco, vemos que há grande presença deste elemento nos pontos amarelos (figura 4.44). Mas o Zn pode ter diversas origens, pois está presente em diversos pigmentos, podendo ser proveniente de uma mistura de tintas, ou devido à múltiplas camadas pictóricas, pois o Zn não varia na mesma proporção nos pontos amarelos, como o Cd.. 


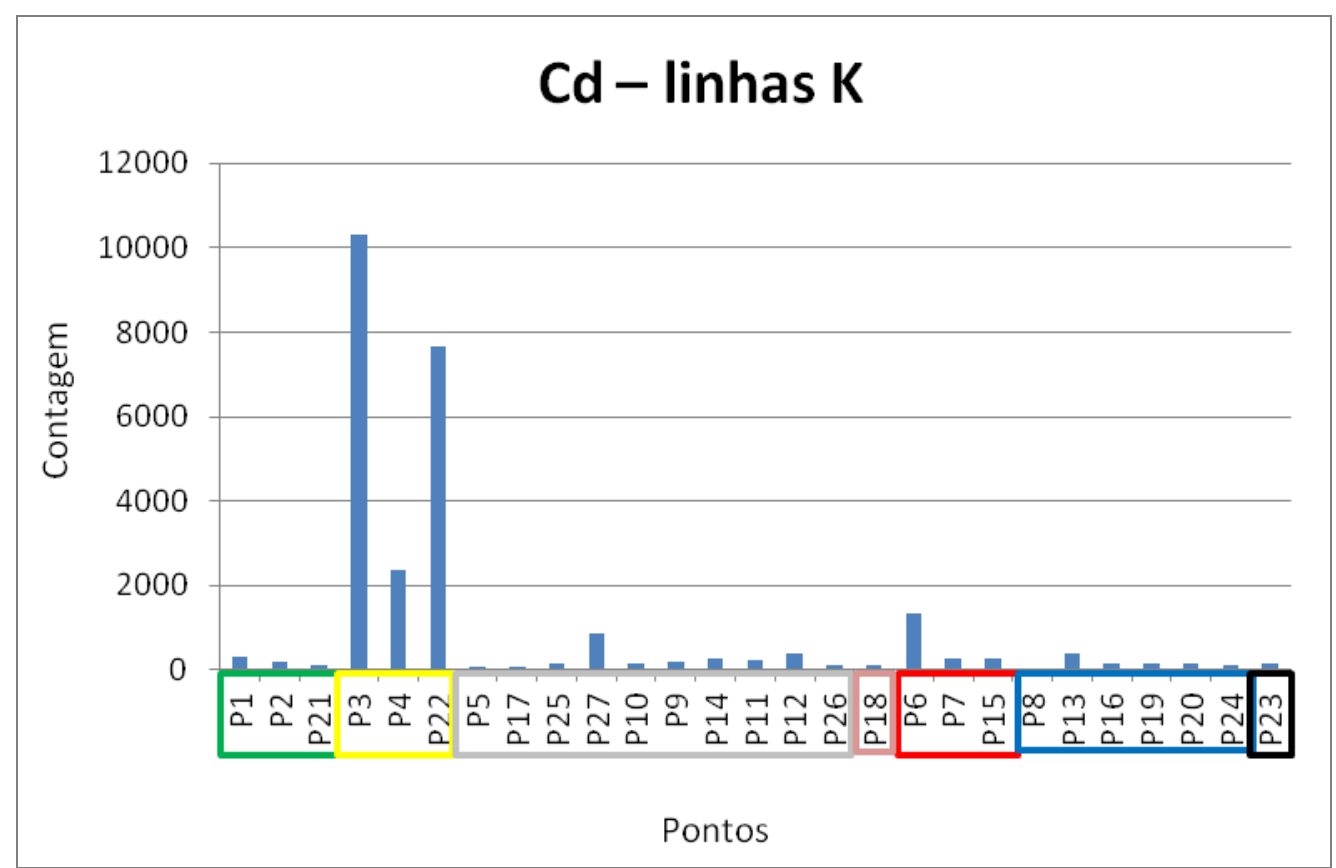

Figura 4.43 - Gráfico de barras das áreas dos picos do Cd identificados nos espectros de EDXRF para os diferentes pontos medidos na obra "Retrato de Mário de Andrade" de Anita Malfatti (1923) do acervo do IEB-USP

Ainda observando o zinco, para as áreas brancas, apenas o ponto P5 tem este elemento presente. Olhando nas imagens da obra, figura 4.35, podemos observar ainda que esta mesma região tem uma concentração maior de massa branca e mais clara do que o entorno e em comparação com outras regiões, como em torno da cabeça da personagem retratada. Isso nos permite afirmar que no ponto $\mathrm{P} 5$ temos a presença do branco de zinco $(\mathrm{ZnO})$, enquanto que nos demais pontos brancos, como pode ser observado no gráfico do $\mathrm{Pb}$ da figura 4.39, que foi utilizado o pigmento de branco de chumbo. Em algumas regiões com outra coloração que não branca, a presença do chumbo pode ser atribuída pela sobreposição de camadas, como é o caso dos pontos P1 e P2, que são em regiões verdes, mas que estão sobre um fundo branco. 


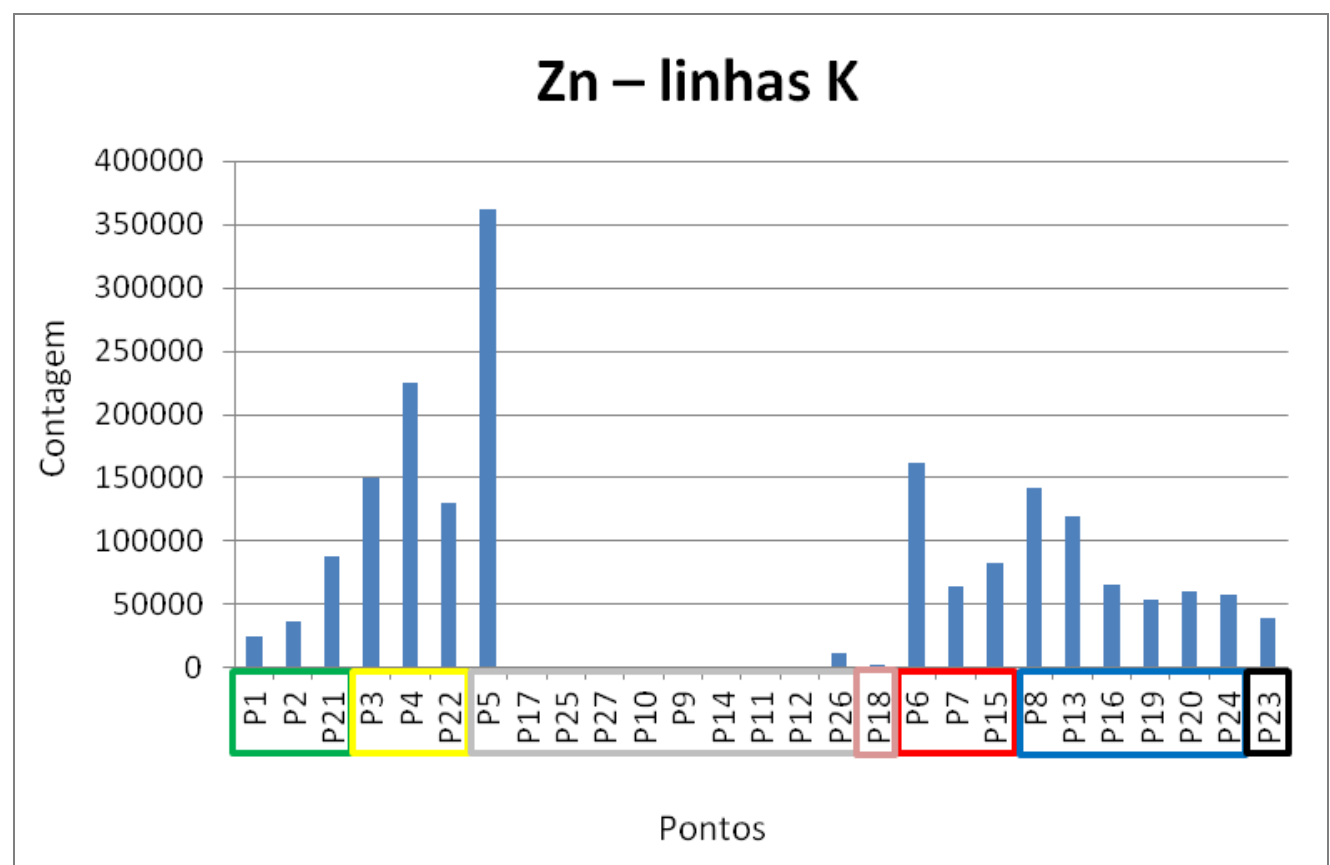

Figura 4.44 - Gráfico de barras das áreas dos picos do Zn identificados nos espectros de EDXRF para os diferentes pontos medidos na obra "Retrato de Mário de Andrade" de Anita Malfatti (1923) do acervo do IEB-USP

Em relação às regiões do quadro com tons em vermelho (P06, P07, P15 e talvez o P18), podemos ver na figura 4.45 que apenas os pontos P06 e P07 possuem o mercúrio. Assim, podemos afirmar que o pigmento vermelhão (HgS) foi usado nos lábios e na borda do paletó da figura retratada nesta pintura.

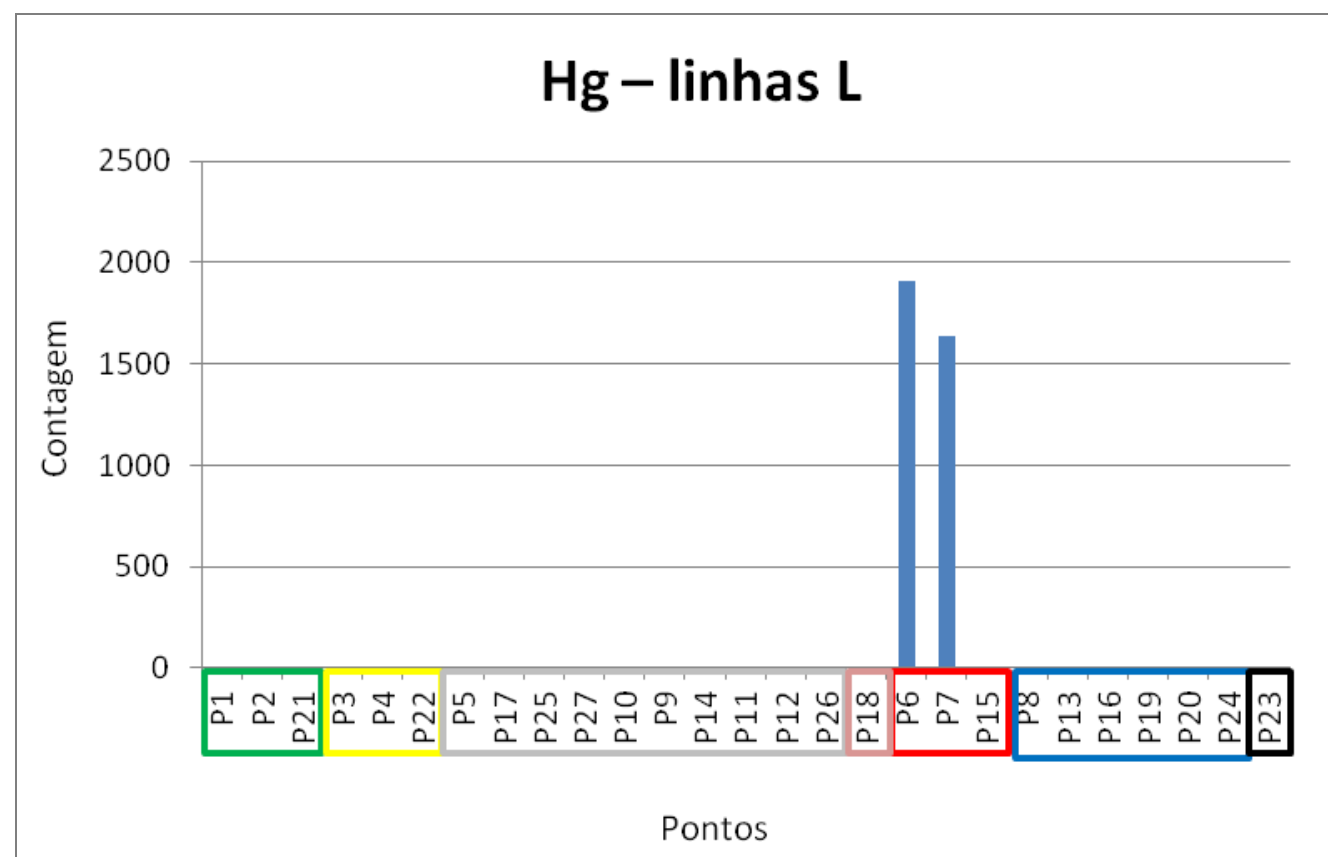

Figura 4.45 - Gráfico de barras das áreas dos picos do Hg identificados nos espectros de EDXRF para os diferentes pontos medidos na obra "Retrato de Mário de Andrade" de Anita Malfatti (1923) do acervo do IEB-USP 
Pela matriz de correlação (tabelas 4.8) e gráfico de correlação por PCA e (figura 4.46) podemos verificar uma correlação positiva entre os elementos $\mathrm{Ca}$ com o $\mathrm{Ba}(0,842)$ e Sr $(0,714)$, e entre $\mathrm{Ba}$ e Sr é 0,752 , tais valores indicam a presença destes elementos no fundo de preparação da tela.

Tabela 4.8 - Matriz de correlação dos elementos presentes nos pontos analisados por EDXRF na obra "Retrato de Mário de Andrade" de Anita Malfatti (1923) do acervo do IEB-USP

\begin{tabular}{|c|c|c|c|c|c|c|c|c|c|c|c|c|}
\hline variable & $\mathrm{Ca}-\mathrm{K}$ & $\mathrm{Cr}-\mathrm{K}$ & $\mathrm{Fe}-\mathrm{K}$ & $\mathrm{Co}-\mathrm{K}$ & $\mathrm{Cu}-\mathrm{K}$ & $\mathrm{Zn}-\mathrm{K}$ & $\mathrm{Sr}-\mathrm{K}$ & $\mathrm{Cd}-\mathrm{k}$ & $\mathrm{Ba}-\mathrm{L}$ & $\mathrm{Hg}-\mathrm{L}$ & $\mathrm{Pb}-\mathrm{L}$ & $V-K$ \\
\hline $\mathrm{Ca}-\mathrm{K}$ & 1,000 & 0,264 & 0,454 & 0,321 & $-0,204$ & $-0,139$ & 0,714 & $-0,049$ & 0,842 & 0,029 & $-0,163$ & $-0,269$ \\
\hline $\mathrm{Cr}-\mathrm{K}$ & 0,264 & 1,000 & 0,186 & 0,244 & $-0,121$ & 162 & 0,004 & 0,024 & 325 & 317 & 0,118 & $-0,205$ \\
\hline $\mathrm{Fe}-\mathrm{K}$ & 0,454 & 0,186 &, 000 & 0,718 & $-0,112$ & 153 & 0,495 & $-0,080$ & 296 & 040 & $-0,150$ & $-0,180$ \\
\hline $\mathrm{Co}-\mathrm{K}$ & 0,321 & 244 & 718 & 1,000 & 0,230 & 0,154 & 0,314 & 20 & 0,157 & 020 & , 241 & $-0,215$ \\
\hline $\mathrm{Cu}-\mathrm{K}$ & $-0,204$ & $-0,121$ & $-0,112$ & 0,230 & 1,000 & $-0,009$ & $-0,121$ & $-0,069$ & $-0,120$ & $-0,055$ & $-0,318$ & $-0,055$ \\
\hline$Z n-K$ & $-0,139$ & 0,162 & 0,153 & 0,154 & $-0,009$ & 1,000 & $-0,265$ & 0,308 & $-0,238$ & 0,158 & $-0,698$ & 0,269 \\
\hline $\mathrm{Sr}-\mathrm{K}$ & 0,714 & 0,004 & 0,495 & 0,314 & $-0,121$ & $-0,265$ & 1,000 & $-0,055$ & 0,752 & $-0,312$ & $-0,147$ & $-0,235$ \\
\hline $\mathrm{Cd}-\mathrm{k}$ & $-0,049$ & 0,024 & $-0,080$ & 0,020 & $-0,069$ & 0,308 & $-0,055$ & 1,000 & $-0,305$ & $-0,016$ & $-0,268$ & $-0,103$ \\
\hline$B a-L$ & 0,842 & 0,325 & 0,296 & 0,157 & $-0,120$ & $-0,238$ & 0,752 & $-0,305$ & 1,000 & $-0,070$ & $-0,105$ & $-0,132$ \\
\hline $\mathrm{Hg}-\mathrm{L}$ & 0,029 & 0,317 & 0,040 & 0,020 & $-0,055$ & 0,158 & $-0,312$ & $-0,016$ & $-0,070$ & 1,000 & 0,024 & $-0,079$ \\
\hline$P b-L$ & $-0,163$ & 0,118 & $-0,150$ & $-0,241$ & $-0,318$ & $-0,698$ & $-0,147$ & $-0,268$ & $-0,105$ & 0,024 & 1,000 & $-0,295$ \\
\hline I-K & $-0,269$ & 205 & $-0,180$ & $-0,215$ & $-0,055$ & 0,269 & $-0,235$ & $-0,103$ & $-0,132$ &, 079 & ,295 & 1,000 \\
\hline
\end{tabular}

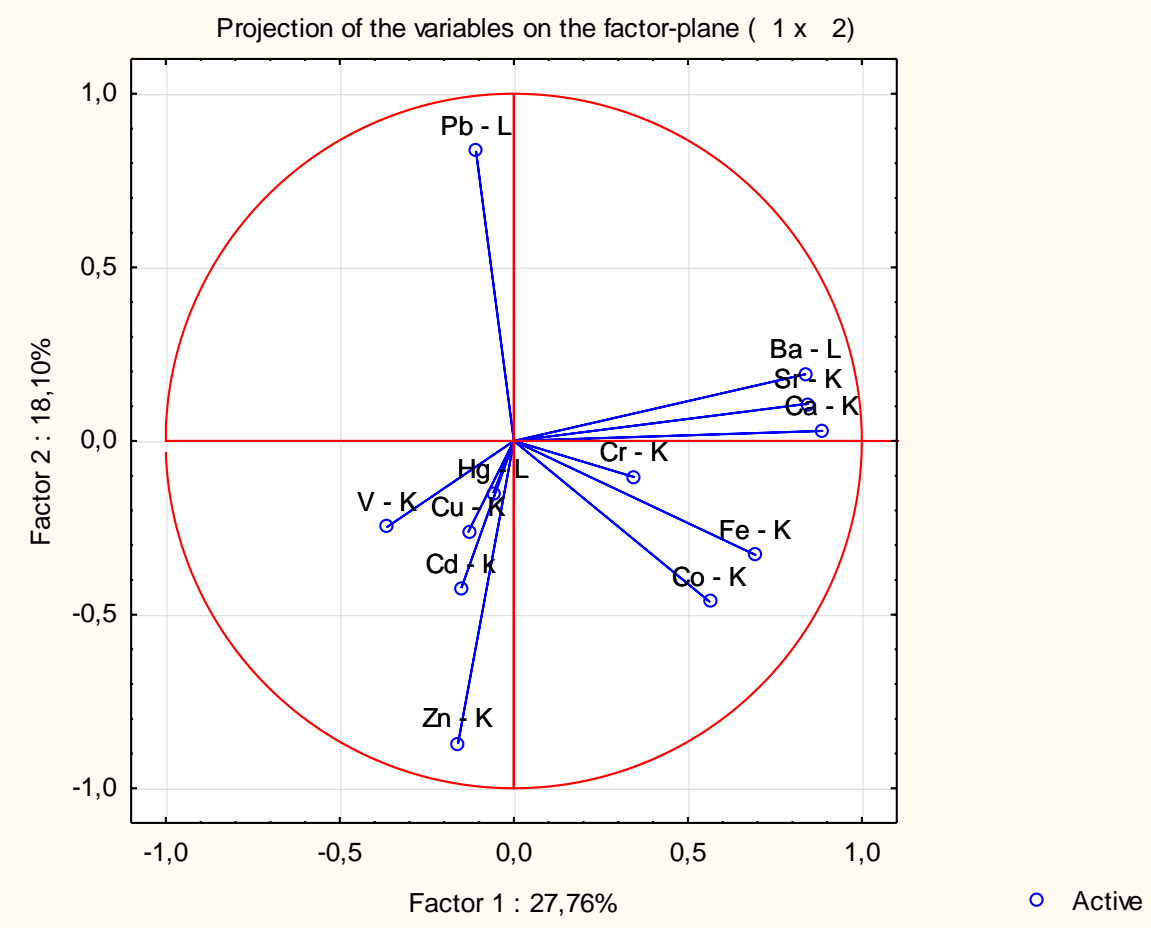

Figura 4.46 - Gráfico da correlação por PCA entre os elementos presentes nos espectros de EDXRF pontos medidos na obra "Retrato de Mário de Andrade" de Anita Malfatti do acervo do IEB-USP 
A correlação do $\mathrm{Ca}$ com o $\mathrm{Pb}$ é negativa $(-0,163)$, mas apesar disso, os pontos medidos na borda do quadro possuíam estes quatro elemento citados, mas nesta obra foi usado o branco de chumbo também na camada pictórica, o que mudaria a correlação entre $\mathrm{Ca}$ e $\mathrm{Pb}$, pois na superfície, onde pode ter muito chumbo mas pouco $\mathrm{Ca}$. A correlação entre o $\mathrm{Zn}$ e o $\mathrm{Pb}$ é $-0,698$, o que mostra a ausência do zinco quando o chumbo está presente. A correlação entre Fe e o Co é de 0,718, o que indicaria a composição de um azul a base de azul da Prússia e azul de cobalto. Desta forma, pode-se montar uma tabela com possíveis pigmentos presentes na obra "A Estudante Russa" (tabela 4.9).

Tabela 4.9: Possíveis pigmentos utilizados por Anita Malfatti na obra "Retrato de Mario de Andrade" de Anita Malfatti (1923) do acervo do IEB-USP (JANSSENS, 2004; STUART, 2008; VASCONCELOS et al., 1992; MAYER, 2006; LFNATEC, 2009)

\begin{tabular}{|c|c|c|c|c|}
\hline Cor & $\begin{array}{l}\text { Elementos } \\
\text { Presentes }\end{array}$ & $\begin{array}{c}\text { Composição } \\
\text { Química }\end{array}$ & $\begin{array}{l}\text { Nome do } \\
\text { Pigmento }\end{array}$ & $\begin{array}{c}\text { Empregado } \\
\text { desde }\end{array}$ \\
\hline \multirow{3}{*}{ Brancos } & $\mathrm{Zn}$ & $\mathrm{ZnO}$ & $\begin{array}{l}\text { Branco de } \\
\text { Zinco }\end{array}$ & Século 19 \\
\hline & $\mathrm{Pb}$ & $2 \mathrm{PbCO} 3 . \mathrm{Pb}(\mathrm{OH})_{2}$ & $\begin{array}{c}\text { Branco de } \\
\text { Chumbo }\end{array}$ & Antiguidade \\
\hline & $\mathrm{Ba}^{*}, \mathrm{Sr}^{*}$ & $\mathrm{BaSO} 4$ + SrSO4 & Barita & Mineral \\
\hline Amarelos & $\mathrm{Cd}$ & $\begin{array}{c}\text { CdS, CdSZn, ou } \\
\text { CdS + ZnO }\end{array}$ & \begin{tabular}{|c|} 
Amarelo de \\
Cádmio
\end{tabular} & Século 19 \\
\hline Vermelhos & $\mathrm{Hg}, \mathrm{S}$ & $\mathrm{HgS}$ & Vermelhão & Mineral \\
\hline Verdes & $\mathrm{Cr}$ & $\mathrm{Cr}_{2} \mathrm{O}_{3}$ & $\begin{array}{l}\text { Óxido de } \\
\text { Cromo }\end{array}$ & Século 19 \\
\hline \multirow{2}{*}{ Azuis } & Co & $\mathrm{CoO} \cdot \mathrm{Al}_{2} \mathrm{O}_{3}$ & $\begin{array}{l}\text { Azul de } \\
\text { Cobalto }\end{array}$ & Século 19 \\
\hline & $\mathrm{Fe}$ & $\mathrm{Fe}_{4}\left[\mathrm{Fe}(\mathrm{CN})_{6}\right]_{3}$ & $\begin{array}{l}\text { Azul da } \\
\text { Prússia }\end{array}$ & Século 18 \\
\hline Pretos & $\mathrm{Fe}$ & $\mathrm{Fe}_{3} \mathrm{O}_{4}$ & $\begin{array}{l}\text { Preto de } \\
\text { Ferro }\end{array}$ & Século 19 \\
\hline \multirow{4}{*}{ Base } & $\mathrm{Ca}$ & $\begin{array}{c}\mathrm{CaCO}_{3} \mathrm{Ou} \\
\mathrm{CaSO}_{4} 2 \mathrm{H}_{2} \mathrm{O}\end{array}$ & $\begin{array}{c}\text { Calcita ou } \\
\text { Gesso }\end{array}$ & Mineral \\
\hline & $\mathrm{Pb}$ & $2 \mathrm{PbCO}_{3} \mathrm{~Pb}(\mathrm{OH})_{2}$ & $\begin{array}{c}\text { Branco de } \\
\text { Chumbo }\end{array}$ & Antiguidade \\
\hline & $\mathrm{Ba}$ & $\mathrm{BaSO}_{4}$ & \multirow{2}{*}{ Barita } & \multirow{2}{*}{ Mineral } \\
\hline & $\mathrm{Sr}$ & $\mathrm{SrSO}_{4}$ & & \\
\hline
\end{tabular}

*Associado a outras cores 


\section{4. "Tropical"}

A investigação mais detalhada desta obra foi devido à observação a olho nu de figuras subjacentes (BATISTA, 2006; GREGGIO, 2013). A fotografia com luz visível realizada registra a paleta de cor da pintura, bem como o estado atual de conservação da obra e permitiu evidenciar melhor as alterações de cor e sombras existentes na obra. A figura 4.47 mostra uma imagem com luz visível da obra "Tropical".

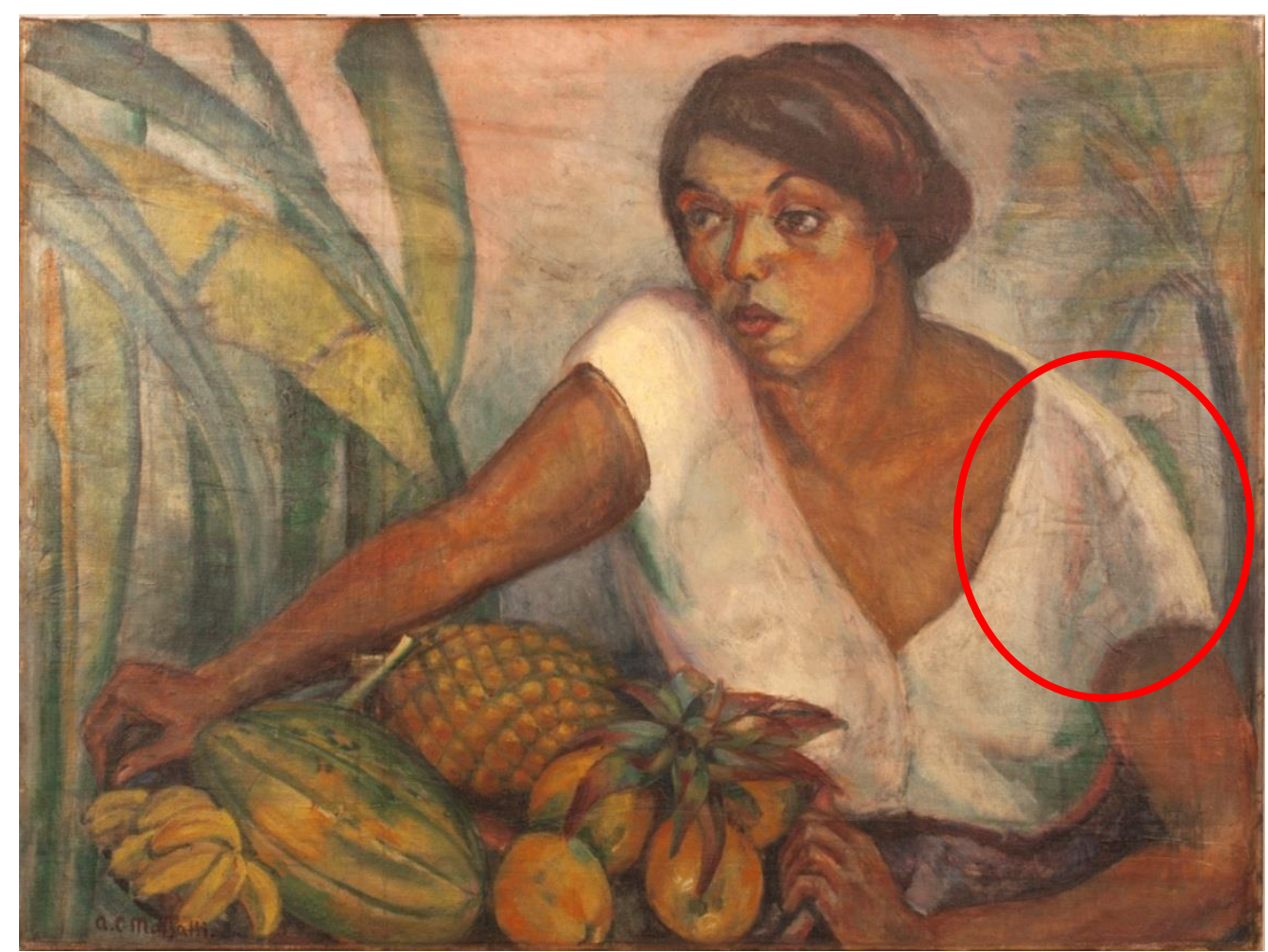

Figura 4.47 - Imagem de fotografia visível da obra "Tropical" de Anita Malfatti (1917, óleo sobre tela, $77 \times 102 \mathrm{~cm}$ ) do acervo da Pinacoteca do Estado de São Paulo. Foto: P.H.O.V. Campos e E. Kajiya

A análise da figura 4.47 evidencia sobre o ombro esquerdo da personagem feminina a presença de um aparente rosto, posicionado horizontalmente. Análises mais minuciosas desta obra foram realizadas na tentativa de identificação desta figura, bem como de outras informações em diferentes regiões da pintura. Outras técnicas de imagem (fluorescência com luz UV, fotografia com luz rasante e reflectografia de infravermelho) permitiram a comparação entre as diferentes técnicas e assim uma melhor observação da figura subjacente. 


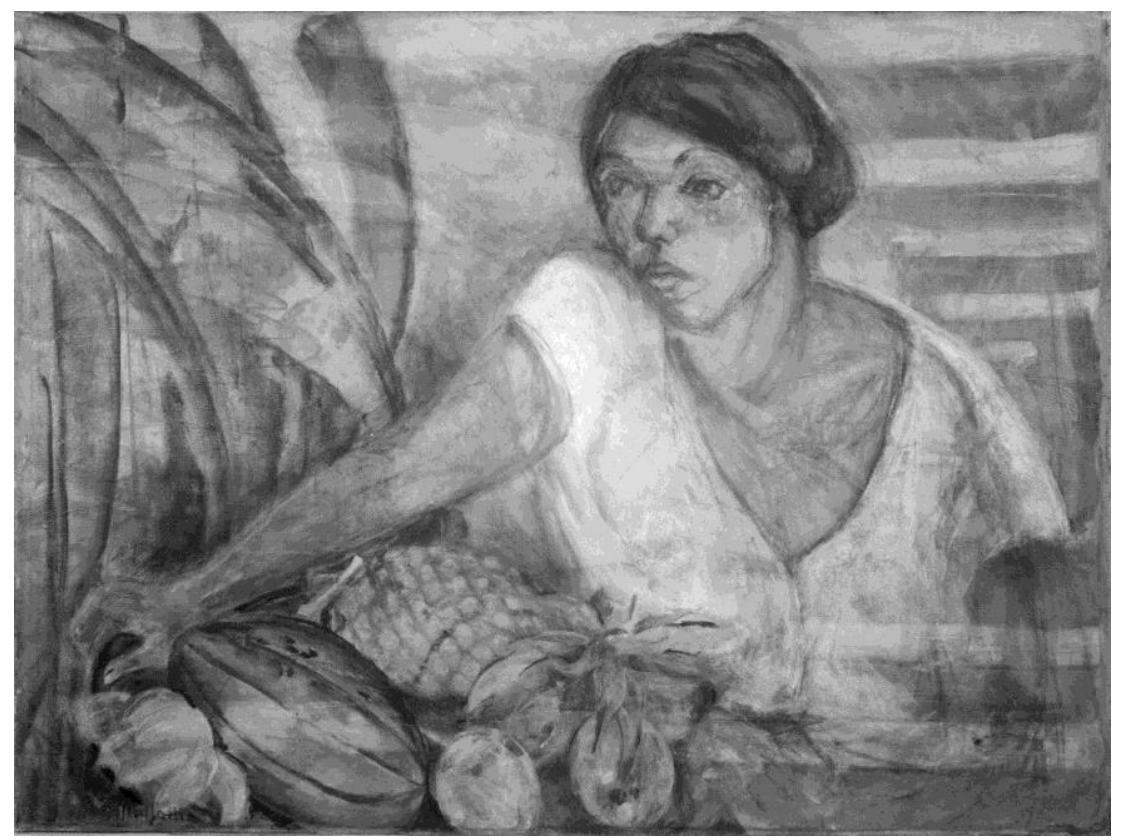

Figura 4.48 - Fotografia de Reflectografia de infravermelho da obra "Tropical" de Anita Malfatti do acervo da Pinacoteca do Estado de São Paulo. Foto: P.H.O. V. Campos e E. Kajiya

Nas análises realizadas a partir do uso da técnica de fotografia de reflectografia IR (figuras 4.48 e 4.49), foi possível observar com melhor resolução o rosto da figura subjacente já notado a olho nu, além da presença de faixas horizontais não vistas à luz visível (cenário atrás da figura). Há também detalhes de um braço humano subjacente e desenhos ondulatórios em sua base, possivelmente oriundos do estudo anterior da artista. De maneira geral, existem outros elementos de composição, diferentes da imagem observada com luz visível.

$\mathrm{Na}$ análise da fotografia com luz rasante, vista na figura 4.50, é possível observar as pinceladas empregadas pela artista, os empastamentos da tinta (locais onde aplicou camada diluída ou onde há uma concentração maior de tinta), que são importantes fatores para o estudo do seu estilo pessoal. Podemos também notar as deformações do suporte (tela), não observadas com luz visível, além da configuração da trama e urdidura do tecido. Comparando esta fotografia com a fotografia com luz visível, figura 4.47, é possível verificar a informação topográfica de relevo alto para o rosto e contorno do braço da imagem subjacente que não é observada só com luz visível. 


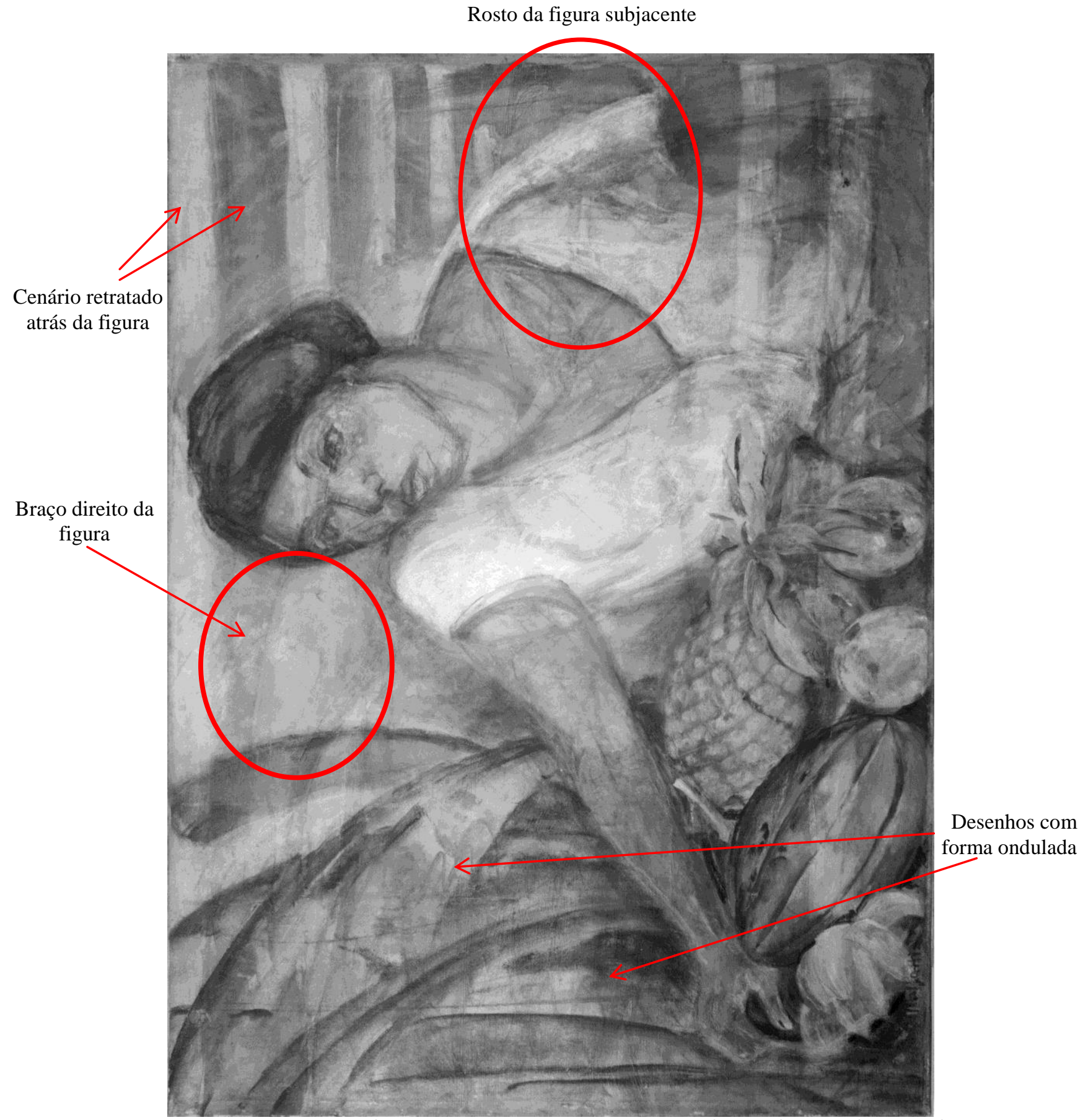

Figura 4.49-Destaques de figuras subjacentes observadas na fotografia de reflectografia de infravermelho da obra "Tropical" de Anita Malfatti do acervo da Pinacoteca do Estado de São Paulo. Foto: P.H.O.V. Campos e E. Kajiya 


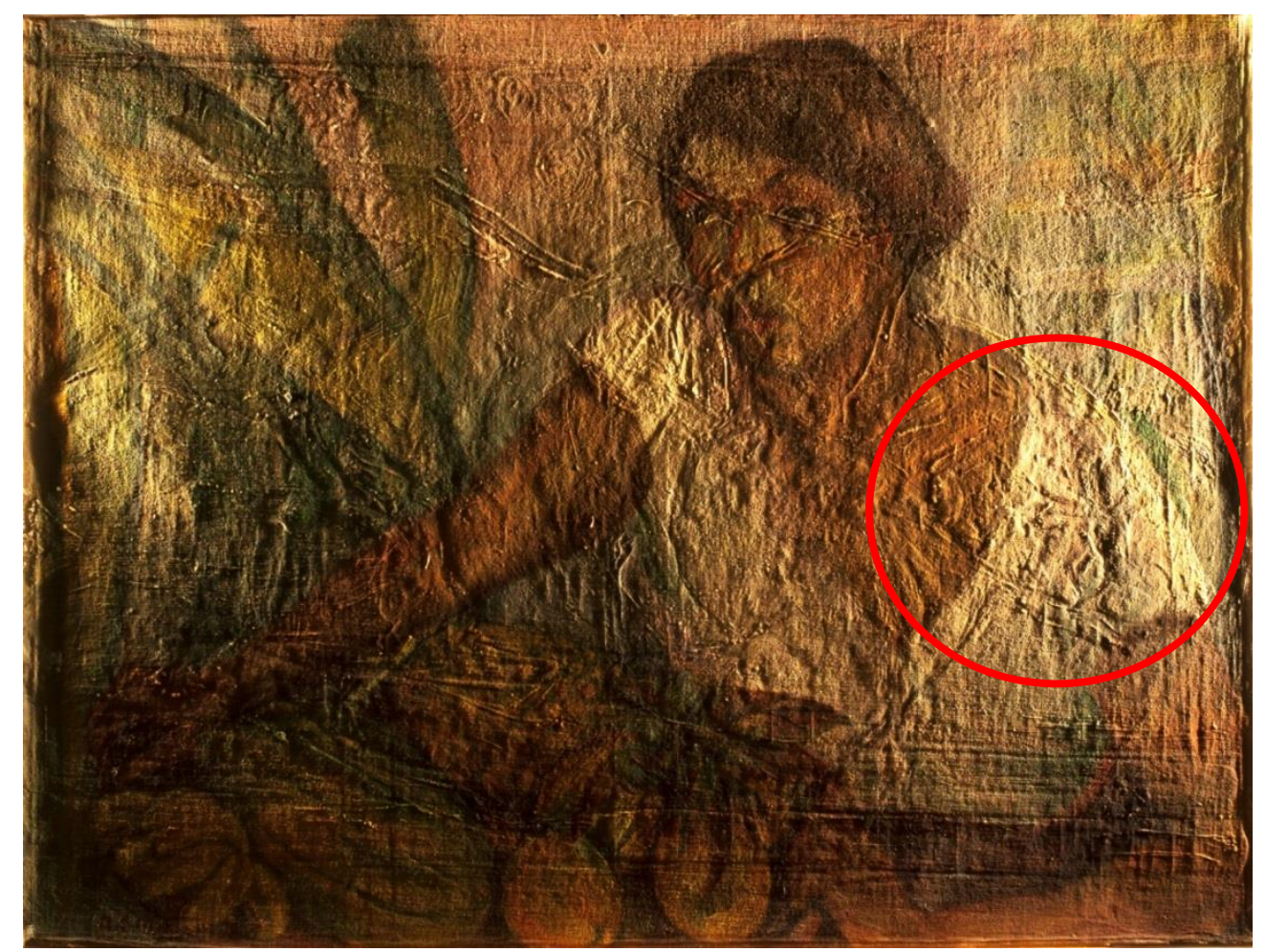

Figura 4.50 - Fotografia com luz rasante da obra "Tropical" de Anita Malfatti (1917, óleo sobre tela, $77 \times 102 \mathrm{~cm}$ ) do acervo da Pinacoteca do Estado de São Paulo. Foto: P.H.O.V. Campos e

E. Kajiya

Ao observarmos a imagem da fotografia com luz visível por fluorescência UV (figura 4.51), podemos notar a presença de forma uniforme do verniz em quase toda a obra, indicando uma aplicação mais recente deste material. Esta uniformidade aparece no tom esverdeado percebido em toda a obra e é característico das imagens por fluorescência UV para camadas de verniz. É possível ainda verificar pequenos pontos de intervenção de restauro recente, como observado nas regiões mais violetas da folhagem do abacaxi, entre as bananas e sobre o ombro direito desta figura (marcados com um círculo na figura 4.51).

Nesta obra, a camada de verniz presente na superfície pôde atenuar a possibilidade de observação de outros pontos de restauro e da fluorescência dos pigmentos presentes. Estas fluorescências são relatadas por diferentes autores, como Stuart (STUART, 2008), que apresenta as propriedades de fluorescência UV para uma série de pigmentos, e Tellechea (TELLECHEA, 1998), que descreve os pigmentos. Os sulfatos de cálcio podem se manifestar por um amarelo, alaranja, violeta lilás, rosa, azul, ou verde. Por sua vez, os 
sulfatos de bário, de zinco e de cádmio possuem alta fosforescência enquanto as resinas vegetais, como os vernizes, possuem várias fluorescências.



Figura 4.51 - Fotografia por luz visível da fluorescência ultravioleta da obra "Tropical" de Anita Malfatti (1917, óleo sobre tela, $77 \times 102 \mathrm{~cm}$ ) do acervo da Pinacoteca do Estado de São Paulo. As regiões circuladas representam áreas com intervenções de restauro recentes. Foto: P.H.O.V. Campos e E. Kajiya

Com as quatro técnicas de imageamento apresentadas, podemos fazer alguns recortes em regiões da obra em que há um interesse maior de estudo, observadas nas figuras 4.52 e 4.53. Destacam-se ainda exemplos significativos das técnicas de imageamento e suas especificidades. Enquanto as fotografias convencionais registram toda a paleta de cores presente no quadro e até uma possível diferenciação de cores de camadas subjacentes, como a aparente boca com tom mais avermelhado (região com círculo vermelho na figura 4.52), a reflectografia IR permiti observar imagens subjacentes com maior contraste, dependendo dos materiais utilizados na produção da obra e da espessura da camada pictórica, revelando rascunhos, estudos, "pentimentos" ou reaproveitamento de material. Já a fotografia por fluorescência UV mostra uma diferenciação de materiais presentes em camadas mais superficiais e dessa maneira traz pouca informação sobre as camadas inferiores. Com a fotografia com luz rasante vemos a informação da topografia presente na obra, que 
ocasionalmente pode nos revelar espessuras diferentes nas camadas de pintura, como na figura 4.52, que nos permite ver a figura subjacente a partir da diferença topográfica das camadas de tinta.

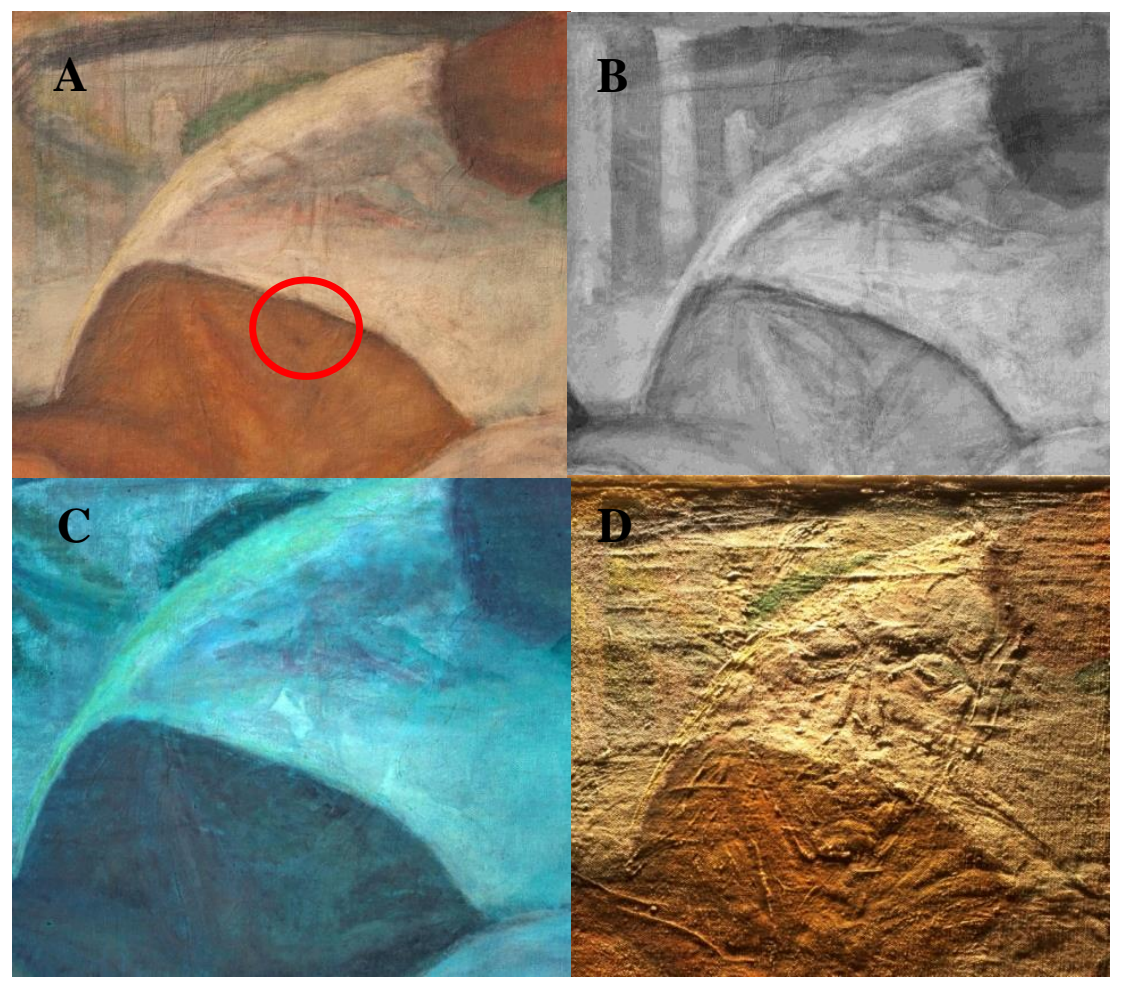

Figura 4.52 - Recortes das fotografias realizadas com as técnicas da região do rosto de uma figura subjacente da obra "Tropical" de Anita Malfatti (1917): A) luz visível; B) reflectografia de infravermelho; C) fotografia por fluorescência UV; D) fotografia com luz rasante. Fotos:

P.H.O.V. Campos e E. Kajiya

$\mathrm{Na}$ figura 4.53 é possível observar que o rosto da mulher retratada aparentemente poderia ter um "pentimento" na região do olho e nariz, pois a artista poderia ter mudado a posição, no seu processo de criação. Mas ao observarmos a imagem da reflectografia de IR, podemos observar que não há a informação de um esboço de um olho na região do nariz. Desta maneira, pode ter ocorrido uma perda de material, ou um material diferente foi aplicado na região entre olho esquerdo e o nariz. Ao observarmos o topo da cabeça na imagem de reflectografia IR, percebemos que existem sombras nesta região da cabeça podendo ser "pentimentos" realizados pela pintora. 


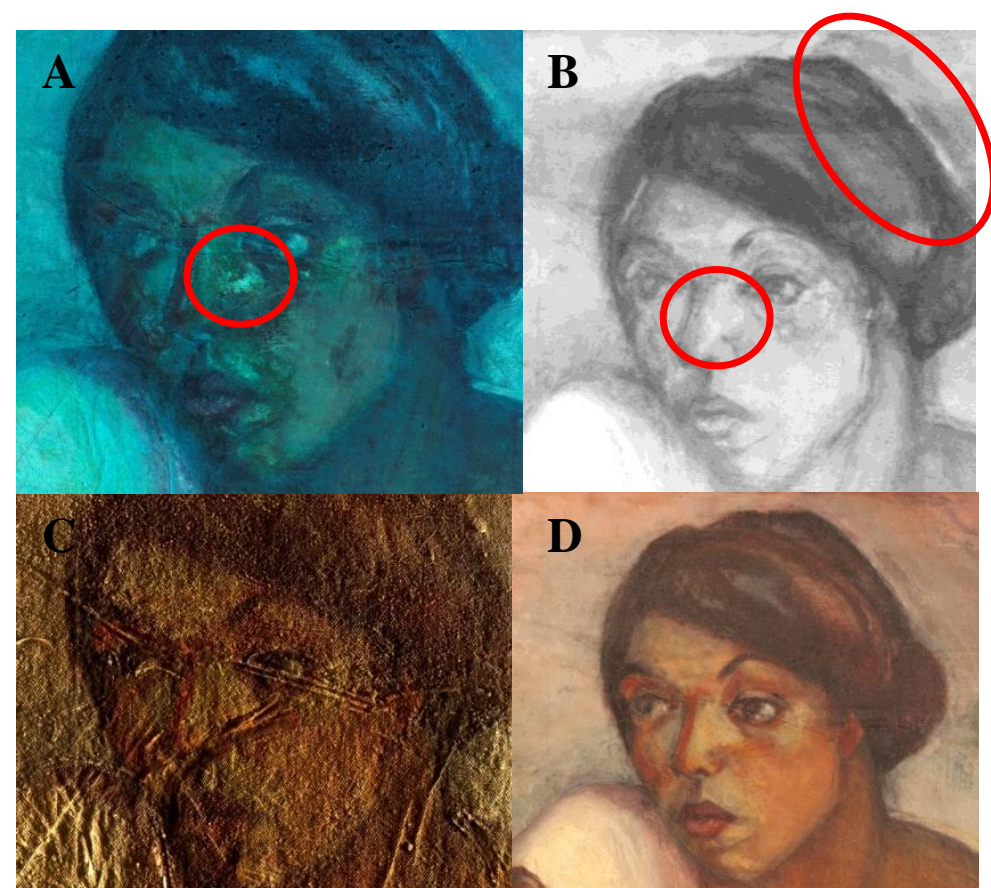

Figura 4.53 - Recortes das fotografias da região do rosto da figura principal da obra "Tropical" de Anita Malfatti (1917) realizadas com as técnicas de imageamento: A) fluorescência U; B) reflectografia de infravermelho; C) fotografia com luz rasante; D) fotografia com luz visível. P.H.O.V. Campos e E. Kajiya

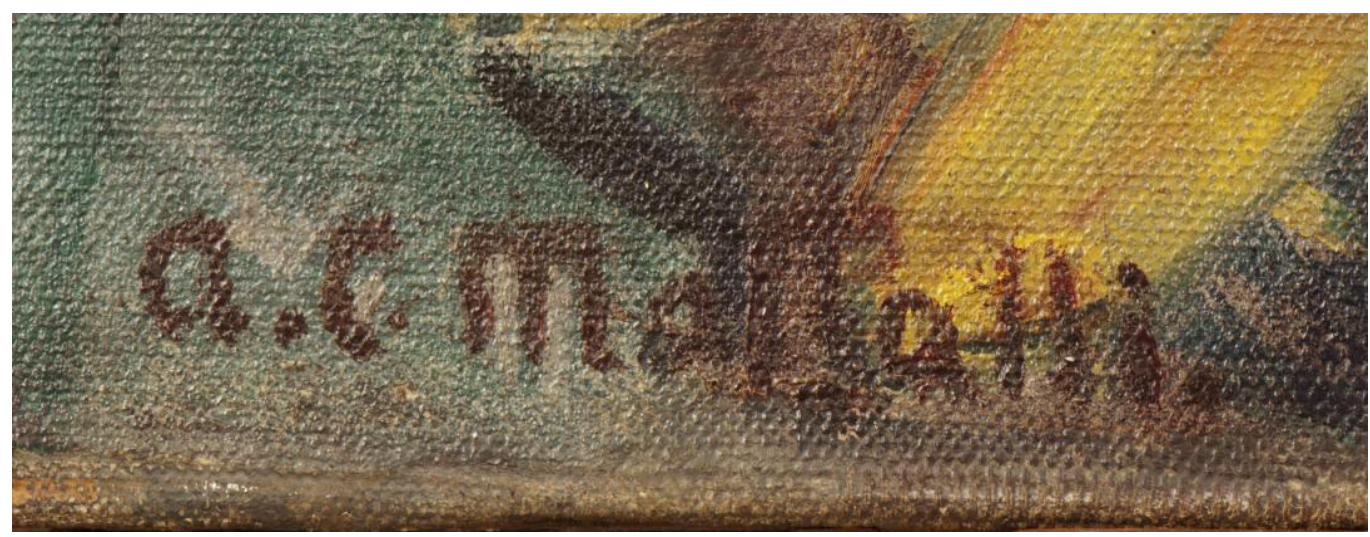

Figura 4.54 - Imagem da assinatura da artista Anita Malfatti da obra "Tropical" (1917) do acervo do IEB-USP

Foi registrada a assinatura da obra com fotografia digital de alta resolução (figura 4.54), com a finalidade de compor e contribuir para o banco de dados de assinaturas da artista.

Neste quadro da artista, foram medidos quarenta e sete (47) pontos com a técnica EDXRF, em diversas regiões, como pode ser visto na figura 4.55. $\mathrm{Na}$ tabela 4.10, estão dispostas as médias de cores de cada ponto, obtidas a partir da fotografia com luz visível. Esta relação está listada na mesma ordem em 
que se apresentam nos gráficos de barras dos picos de cada elemento. Diferentemente das obras anteriores, as obras "Tropical" e "O Homem Amarelo", que será discutida sua análise com EDXRF posteriormente, são obras que foram produzidas em telas reutilizadas, ou seja, as pinturas foram realizadas sobre pinturas, como foi mostrado no capítulo 3, pelas técnicas de imageamento, tanto com reflectografia por infravermelho, quanto para radiografia, no caso do "O Homem Amarelo".

Tabela 4.10 - Relação das médias de cores por fotografia digital (em coordenadas RGB) nos pontos analisados por EDXRF na obra "Tropical" de Anita Malfatti (1917) do acervo da Pinacoteca do Estado de São Paulo

\begin{tabular}{|c|c|c|c|c|c|c|}
\hline Ponto & P2 & P1 & P45 & P4 & P19 & P33 \\
\hline \multirow{2}{*}{$\begin{array}{c}\text { Fotografia } \\
\text { (RGB) }\end{array}$} & & & & & & \\
\hline & $84,78,70$ & $70,84,72$ & $77,87,81$ & $76,86,65$ & $78,92,82$ & $103,118,98$ \\
\hline Ponto & P46 & P18 & P47 & P3 & P36 & P6 \\
\hline \multirow{2}{*}{$\begin{array}{c}\text { Fotografia } \\
\text { (RGB) }\end{array}$} & & & & & & \\
\hline & $136,133,102$ & $170,154,105$ & $160,130,99$ & $157,128,74$ & $145,103,55$ & $146,84,44$ \\
\hline Ponto & P17 & P16 & P11 & P34 & P35 & P8 \\
\hline \multirow{2}{*}{$\begin{array}{c}\text { Fotografia } \\
\text { (RGB) }\end{array}$} & & & & & & \\
\hline & $122,81,74$ & $98,72,70$ & $102,71,67$ & $111,72,64$ & $119,76,65$ & $81,56,53$ \\
\hline Ponto & P22 & P12 & P13 & P20 & P21 & P7 \\
\hline \multirow{2}{*}{$\begin{array}{c}\text { Fotografia } \\
\text { (RGB) }\end{array}$} & & & & & & \\
\hline & $131,103,89$ & $96,70,58$ & $84,66,61$ & $94,83,76$ & $78,71,70$ & $81,56,53$ \\
\hline Ponto & P9 & P10 & P5 & P14 & P15 & P40 \\
\hline \multirow{2}{*}{$\begin{array}{c}\text { Fotografia } \\
\text { (RGB) }\end{array}$} & & & & & & \\
\hline & $68,61,68$ & $50,49,51$ & $54,51,48$ & $223,208,178$ & $222,208,178$ & $120,89,72$ \\
\hline Ponto & P41 & P42 & P43 & P44 & P23 & P24 \\
\hline \multirow{2}{*}{$\begin{array}{c}\text { Fotografia } \\
\text { (RGB) }\end{array}$} & & & & & & \\
\hline & $144,107,78$ & $138,109,78$ & $144,118,86$ & $109,85,70$ & $148,109,75$ & $134,102,78$ \\
\hline Ponto & P25 & P26 & P27 & P28 & P29 & P30 \\
\hline \multirow{2}{*}{$\begin{array}{c}\text { Fotografia } \\
\text { (RGB) }\end{array}$} & & & & & & \\
\hline & $127,95,72$ & $126,107,90$ & $182,167,149$ & $173,156,140$ & $159,132,122$ & $139,133,123$ \\
\hline Ponto & P31 & P32 & P37 & P38 & P39 & \\
\hline \multirow{2}{*}{$\begin{array}{c}\text { Fotografia } \\
\text { (RGB) }\end{array}$} & & & & & & \\
\hline & $155,146,135$ & $181,167,143$ & $193,164,145$ & $191,154,130$ & $186,158,141$ & \\
\hline
\end{tabular}

Diversos elementos estarão presentes nos pontos analisados, mas não necessariamente eles estão associados à cor de cada ponto medido. Assim como podemos observar no gráfico do ferro (figura 4.56), que é um elemento que compõe os pigmentos como vermelhos, marrons/laranjas, pretos e azuis, neste último no azul da Prússia (mas se o azul estiver presente é em baixa 
quantidade, pois os azuis na obra possuem pouco Fe). Entretanto, o ferro está muito presente em pontos de coloração bege, marrom (P20, P21, P40, P41) e negros (P05, P10), nos permitindo afirmar que os pigmentos utilizados para estas cores foram o preto de ferro $\left(\mathrm{Fe}_{3} \mathrm{O}_{4}\right)$ e o óxido de ferro III $\left(\mathrm{Fe}_{2} \mathrm{O}_{3}\right)$. 


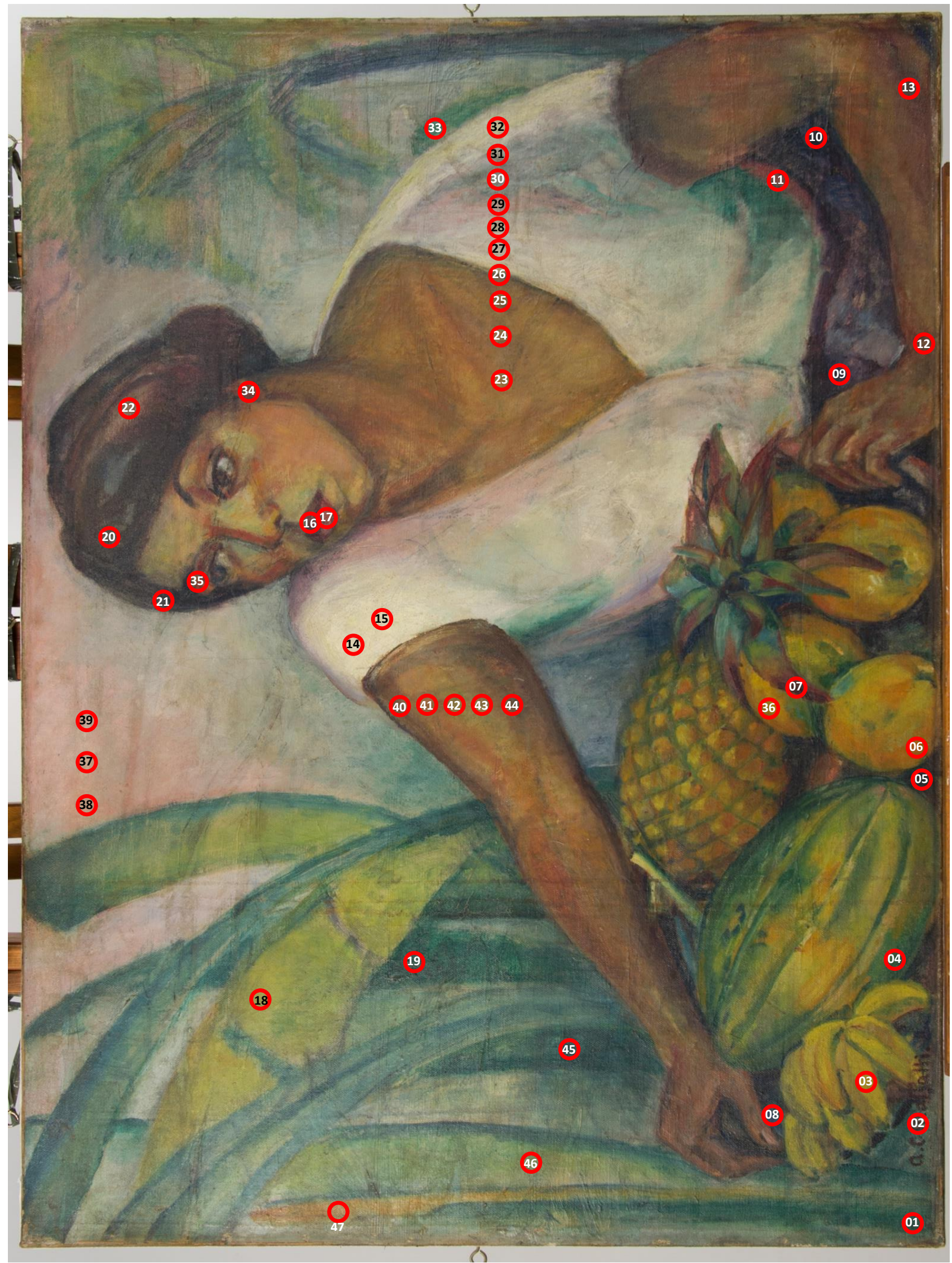

Figura 4.55 - Fotografia com os pontos de EDXRF medidos na obra "Tropical" de Anita Malfatti (1917, óleo sobre tela, $77 \times 102 \mathrm{~cm}$ ) do acervo da Pinacoteca do Estado de São Paulo 
Ainda em relação ao ferro, se observarmos o ponto P02, vemos que este tem uma quantidade muito elevada deste elemento, em comparação aos demais pontos. O ponto P02 é justamente um ponto medido na assinatura da artista, mostrando claramente que ali foi utilizado um material diferente. Alguns relatos históricos e a bibliografia mostram que a artista não tinha a prática de assinar todos os seus quadros, que por vezes o fazia para valorizar e aumentar o valor comercial da obra ou por solicitação da pessoa que comprava ou recebia de presente a obra (GREGGIO, 2007) Por vezes, a artista assinou duas vezes na mesma obra, pois a primeira assinatura havia sido feita com tinta escura sobre um fundo escuro, possuindo pouco contraste. (GREGGIO, 2007) Isto pode indicar que a assinatura tenha sido feita em um período distinto da produção da obra, pois é constituída de um material que contrasta com os pigmentos utilizados na composição da pintura.

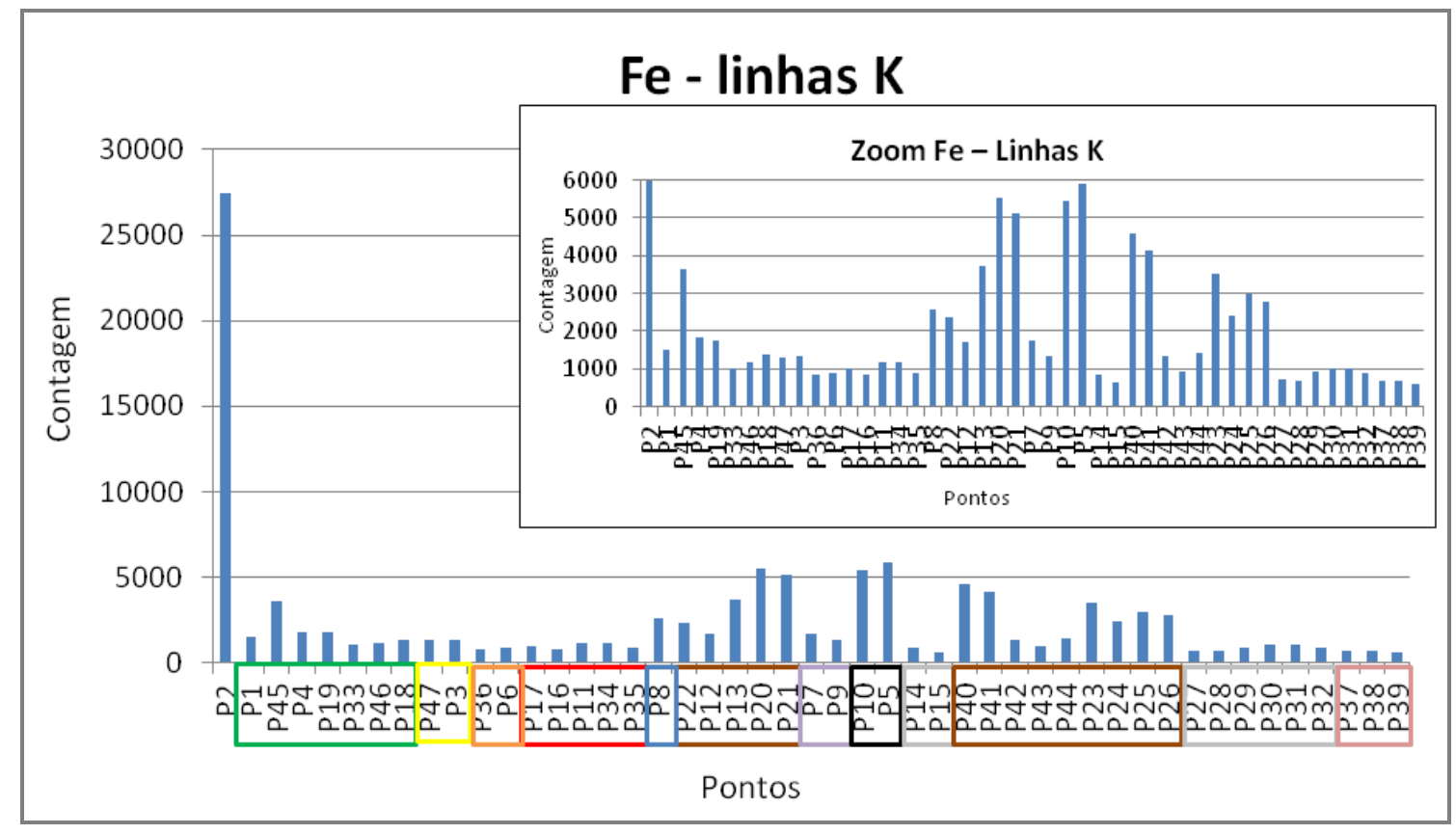

Figura 4.56 - Gráfico de barras das áreas do pico do Fe identificado nos espectros de EDXRF para os diferentes pontos medidos na obra "Tropical" de Anita Malfatti (1917) do acervo da Pinacoteca do Estado de São Paulo

A partir de uma observação geral dos elementos presentes nesta obra, vemos que em todos os pontos há a presença dos elementos cálcio, bário, estrôncio, chumbo, zinco, cádmio e ferro (figuras 4.57, 4.58, 4.59, 4.60, 4.61, 4.65 e 4.56, respectivamente). Infelizmente, neste quadro não houve a análise 
de uma região em que não há camada pictórica, onde houvesse apenas o fundo de preparação ou somente o suporte (tecido), para determinarmos os elementos que o compõem. Nas discussões das obras anteriores, vimos que a camada de preparação são formadas de cálcio (carbonato ou sulfato de cálcio) ("O Japonês", "A Estudante Russa"), barita (que contém Ba e Sr) ("O Retrato de Mário de Andrade") e branco de chumbo ( $\mathrm{Pb}$ ) ("O Japonês", "A Estudante Russa" e "O Retrato de Mário de Andrade).

Apenas a partir deste conhecimento prévio, pela presença destes elementos em todos os pontos, há um grande indicativo de que estes compunham a camada de preparação da tela. Mas ao mesmo tempo, é sabido que estes elementos também podem estar presentes na composição das tintas óleos comerciais (MAYER, 2006).

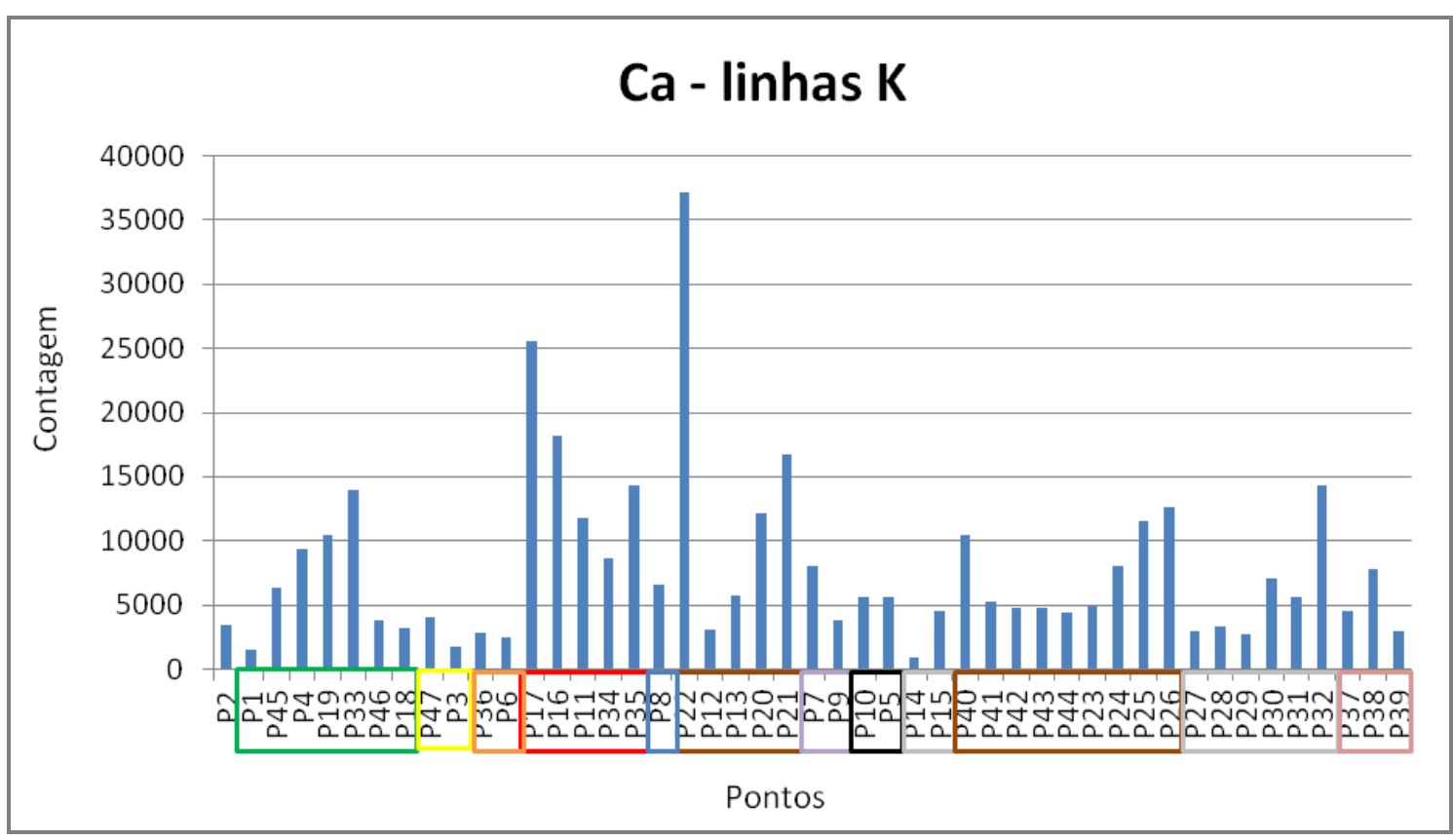

Figura 4.57 - Gráfico de barras das áreas do pico do Ca identificado nos espectros de EDXRF para os diferentes pontos medidos na obra "Tropical" de Anita Malfatti (1917) do acervo da Pinacoteca do Estado de São Paulo 


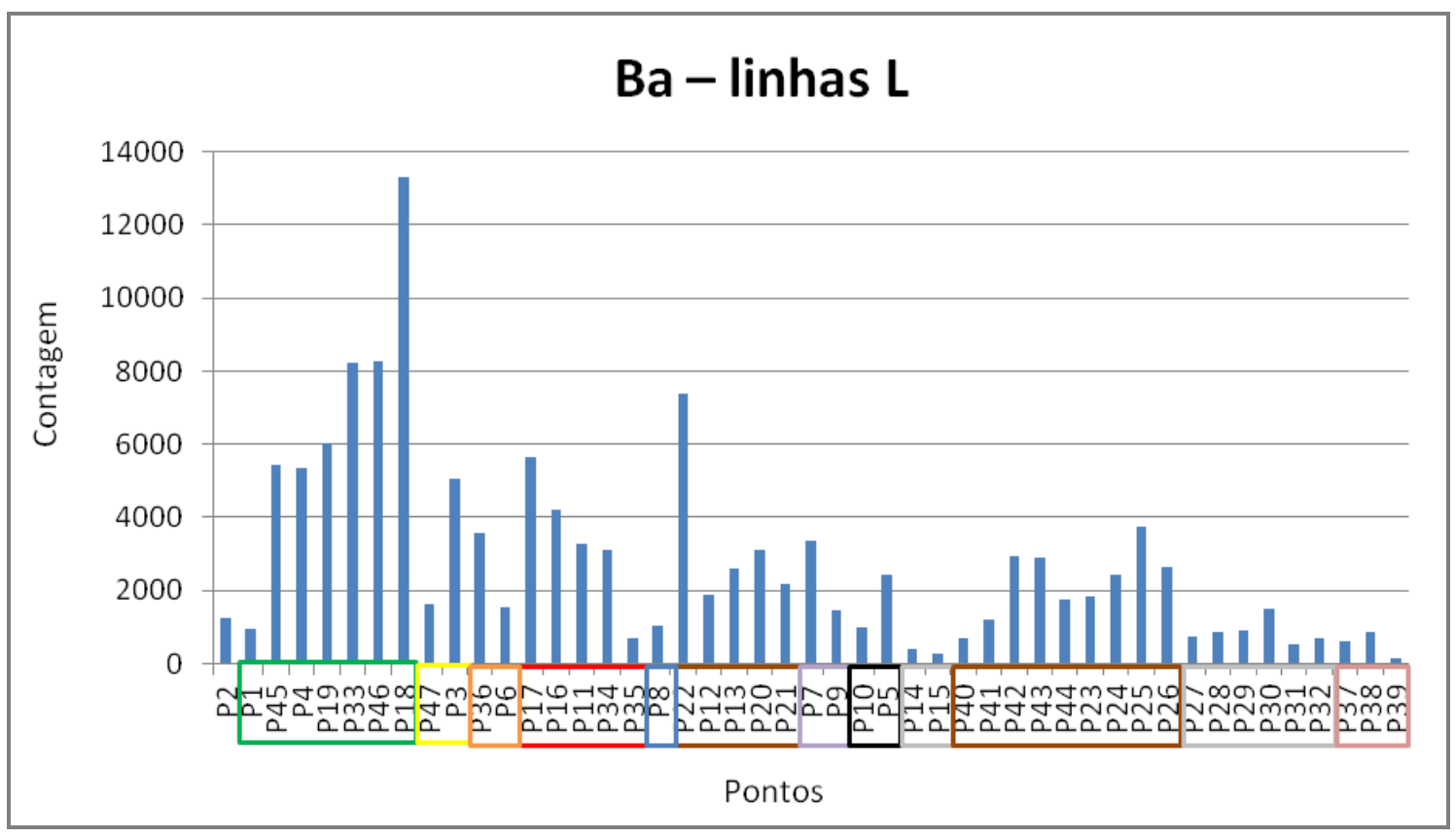

Figura 4.58 - Gráfico de barras das áreas do pico do Ba identificado nos espectros de EDXRF para os diferentes pontos medidos na obra "Tropical" de Anita Malfatti (1917) do acervo da Pinacoteca do Estado de São Paulo

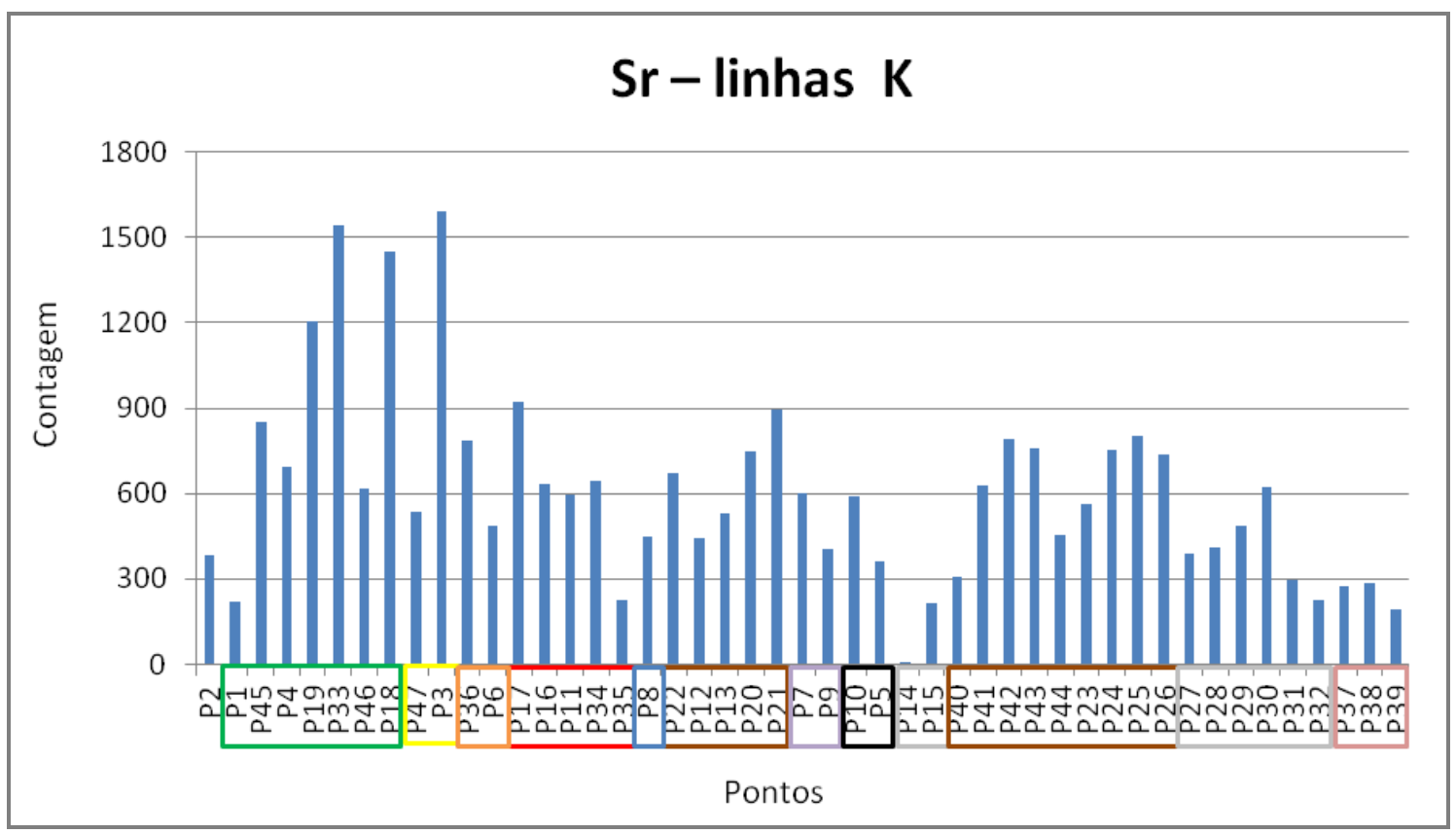

Figura 4.59 - Gráfico de barras das áreas do pico do Sr identificado nos espectros de EDXRF para os diferentes pontos medidos na obra "Tropical" de Anita Malfatti (1917) do acervo da Pinacoteca do Estado de São Paulo 


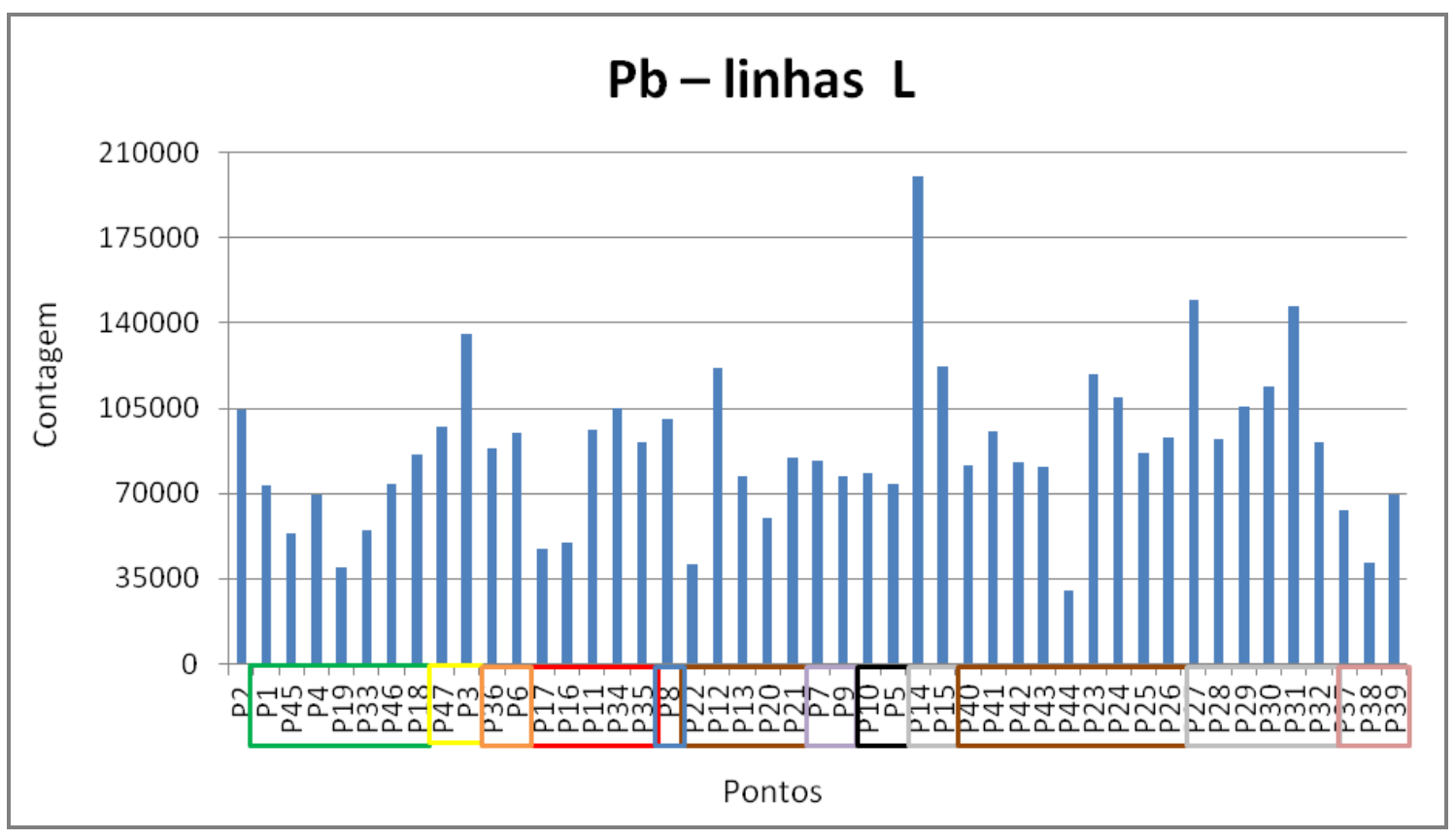

Figura 4.60 - Gráfico de barras das áreas do pico do Pb identificado nos espectros de EDXRF para os diferentes pontos medidos na obra "Tropical" de Anita Malfatti (1917) do acervo da Pinacoteca do Estado de São Paulo

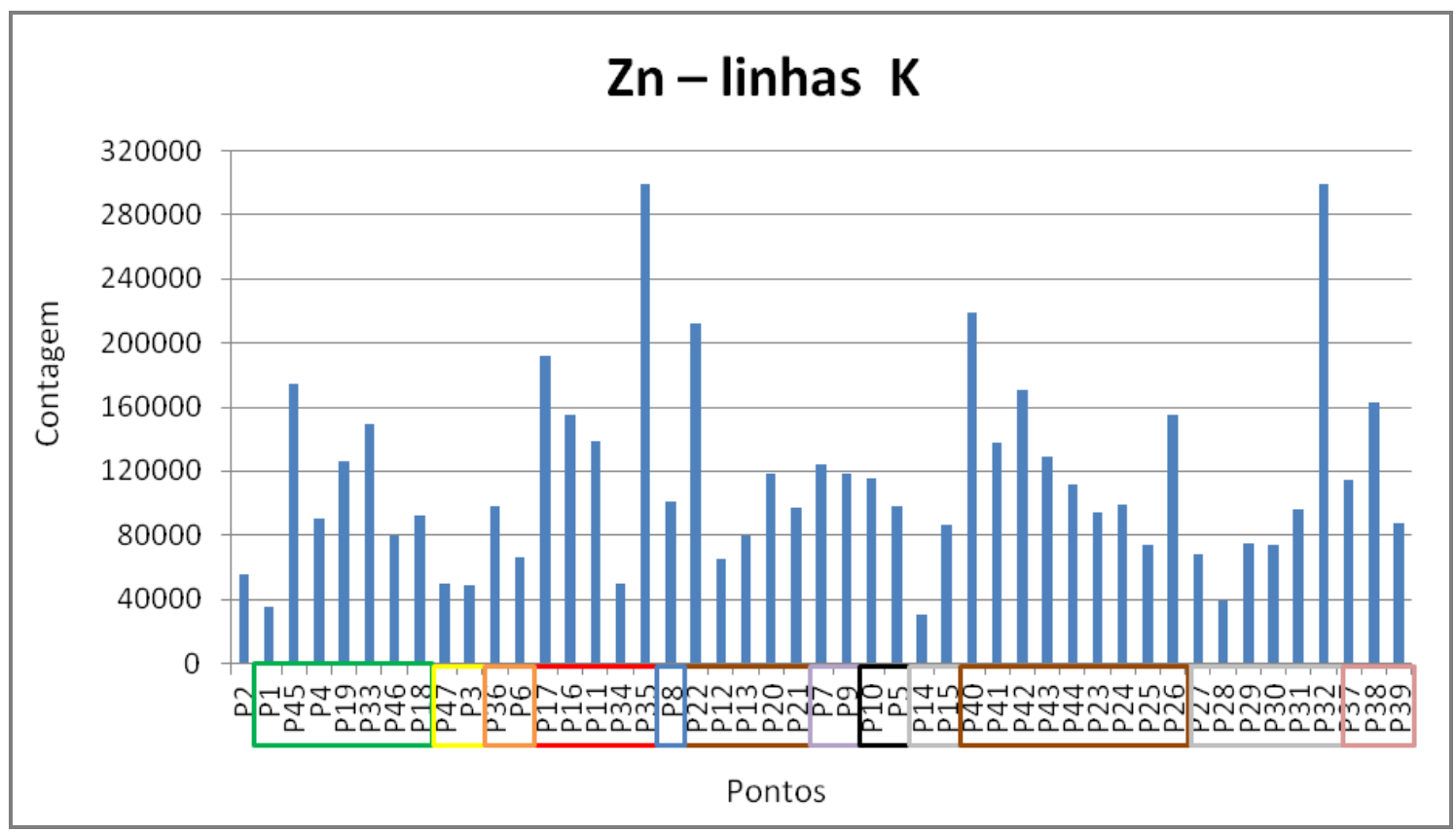

Figura 4.61 - Gráfico de barras das áreas do pico do Zn identificado nos espectros de EDXRF para os diferentes pontos medidos na obra "Tropical" de Anita Malfatti (1917) do acervo da Pinacoteca do Estado de São Paulo

Em relação ao zinco (figura 4.61), há uma variação muito grande da sua presença nos pontos deste quadro, estando em maior quantidade nos pontos P35 e P32, o primeiro é uma área vermelha próxima ao olho e o segundo uma região branca amarelada na manga da roupa, mas como havia sido observado, 
não pôde ser determinado o que se encontra nas subcamadas. Desta forma, fica indefinida a origem destes raios $\mathrm{X}$ característicos do $\mathrm{Zn}$, pois há uma alta contagem até nos pontos mais escuros. Em todos os pontos mais claros, temos a presença tanto do zinco, quanto do chumbo, figura 4.60, que tem uma contagem muito alta nos pontos P14 e P15, regiões brancas da roupa da personagem. Logo, podemos afirmar que nesta obra, estão presentes tanto 0 branco de zinco, quanto o branco de chumbo.

O cromo, assim como nas obras anteriores, está presente nos pontos de cor verde, demonstrando que nesta obra a artista utiliza o óxido de cromo ( $\left.\mathrm{Cr}_{2} \mathrm{O}_{3}\right)$, em uma das suas possíveis formas. Podemos também observar, que nos pontos medidos, os tons amarelos também têm registro do cromo. $\mathrm{Na}$ literatura temos pigmentos amarelos com cromo associados a diversos elementos. Pensando nos elementos 'observados nas medidas realizadas, temos pigmentos amarelos que possuem cromo, como o cromato de chumbo II (amarelo de cromo, $\mathrm{PbCrO}_{4}$ ou 2PbSO $4 . \mathrm{PbCrO}_{4}$ ), o amarelo de zinco ( $\mathrm{nnCrO}_{4}$ ), amarelo de bário $\left(\mathrm{BaCrO}_{4}\right)$ (STUART, 2008). Mas, pelas diversas origens possíveis destes mesmos elementos ( $\mathrm{Ba}, \mathrm{Sr}$ e $\mathrm{Zn}$ ), e pela proximidade destas áreas amarelas das áreas verde, que claramente possuem cromo, não foi possível determinar com precisão qual pigmento amarelo foi usado pela artista.

Com exceção do ponto marrom P21, nos demais pontos o nível de cromo é baixo. Isso nos faz acreditar que a pintura subjacente não tenha 0 cromo na sua constituição. 


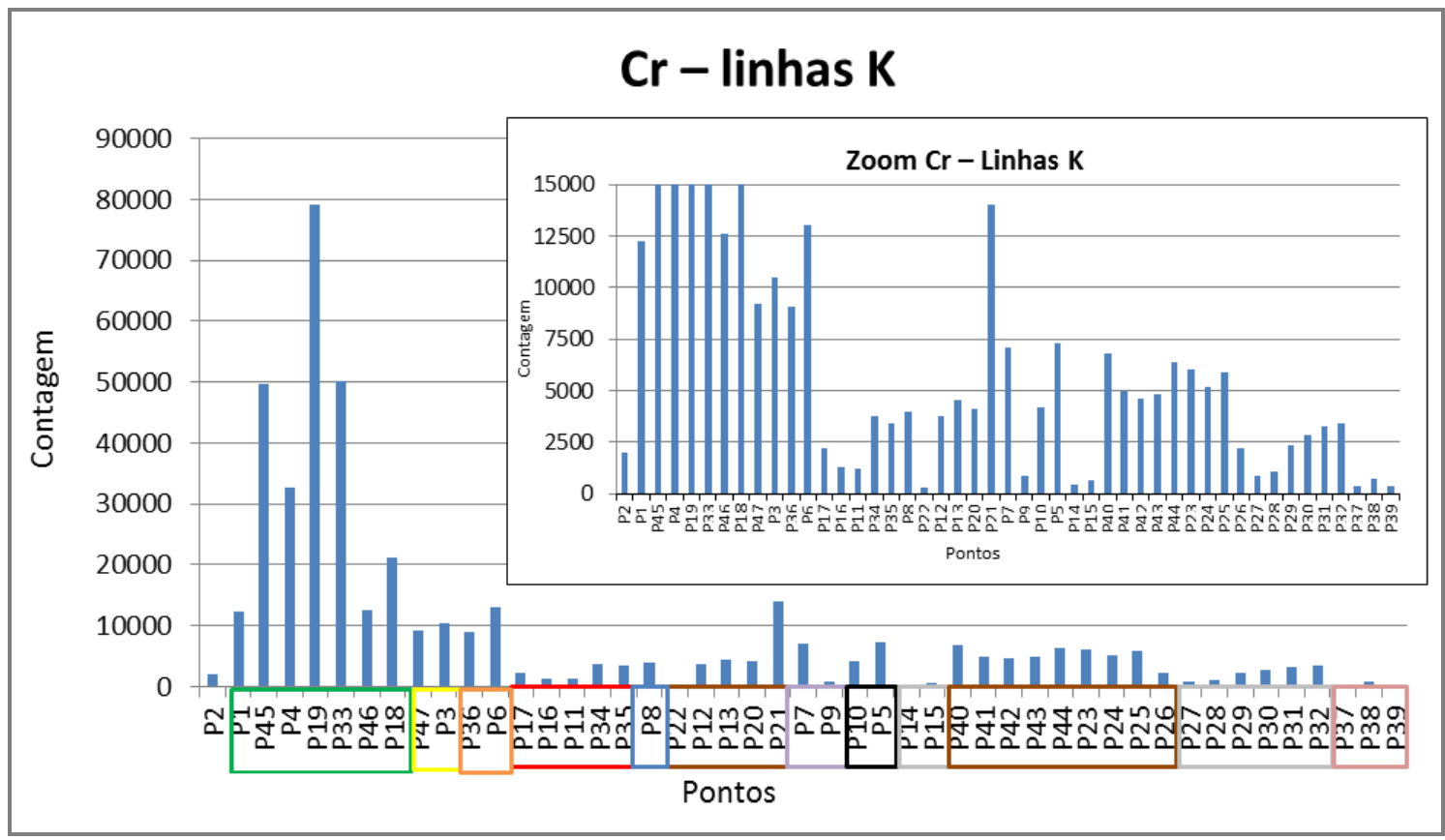

Figura 4.62 - Gráfico de barras das áreas do pico do Cr identificado nos espectros de EDXRF para os diferentes pontos medidos na obra "Tropical" de Anita Malfatti (1917) do acervo da Pinacoteca do Estado de São Paulo

Nesta obra, no entorno do braço esquerdo da mulher retratada, há regiões em que a artista utiliza um tom violeta para compor o espaço e colorir a folhagem da natureza morta representada. Nos pontos medidos nestes tons (P5, P7, P9 e P10), está presente o cobalto (figura 4.63), que também foi registrado na obra "Retrato de Mario de Andrade", mas diferentemente deste, não está relacionado com um pigmento azul. Além disso, nestes pontos, também há presença do arsênio (As), que não foi encontrado em nenhuma outra obra (figura 4.64). De acordo com Mayer (MAYER, 2006), alguns violetas de cobalto ( $\left.\mathrm{Co}_{3}\left(\mathrm{PO}_{4}\right)_{2}\right)$ também possuíam o As na composição do pigmento e eles eram manipulados com extremo cuidado, devido sua alta toxicidade. No gráfico de barras destes dois elementos também podemos observar uma grande correlação destes elementos nos pontos medidos. 


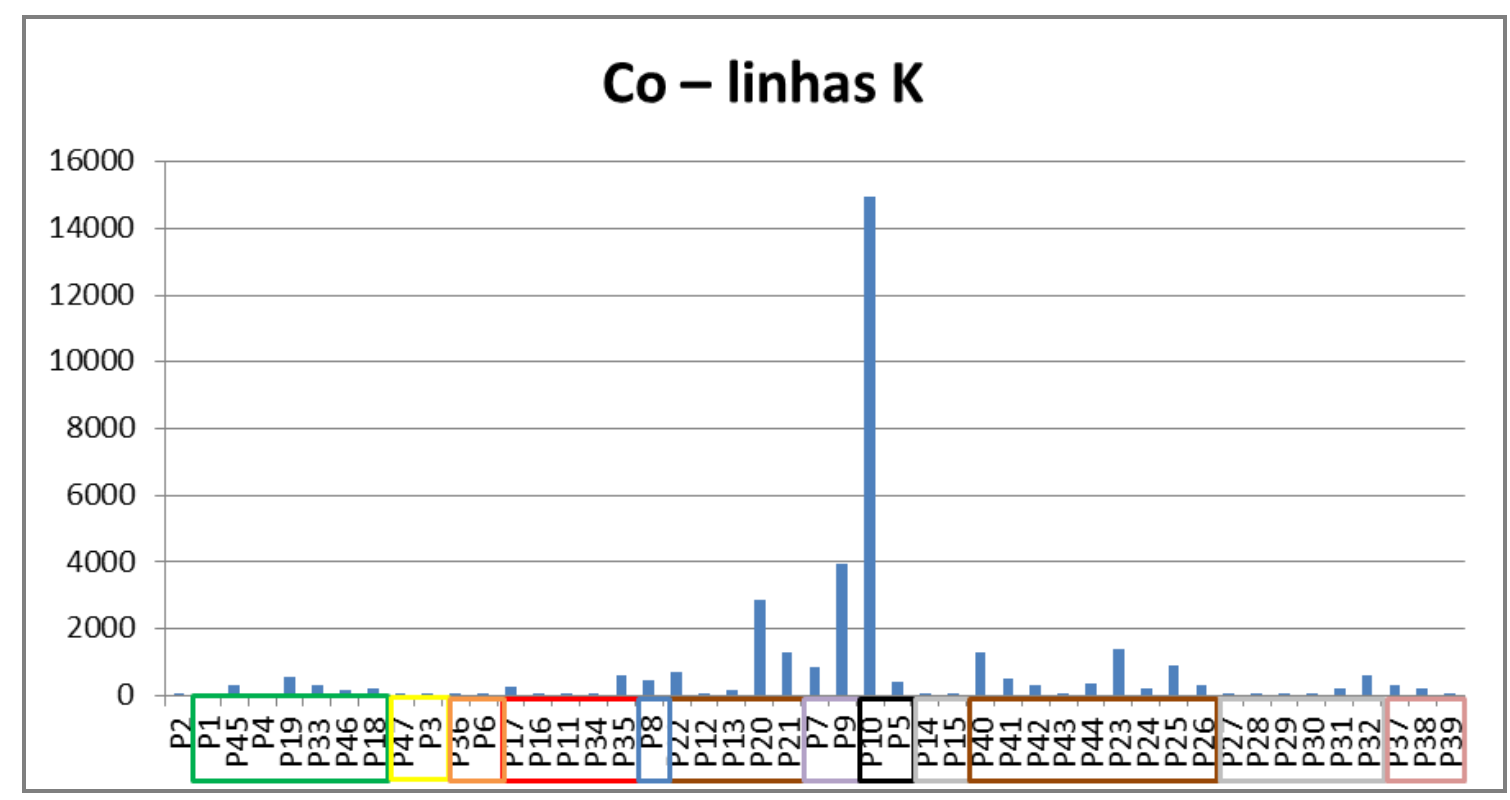

Figura 4.63 - Gráfico de barras das áreas do pico do Co identificado nos espectros de EDXRF para os diferentes pontos medidos na obra "Tropical" de Anita Malfatti (1917) do acervo da Pinacoteca do Estado de São Paulo.

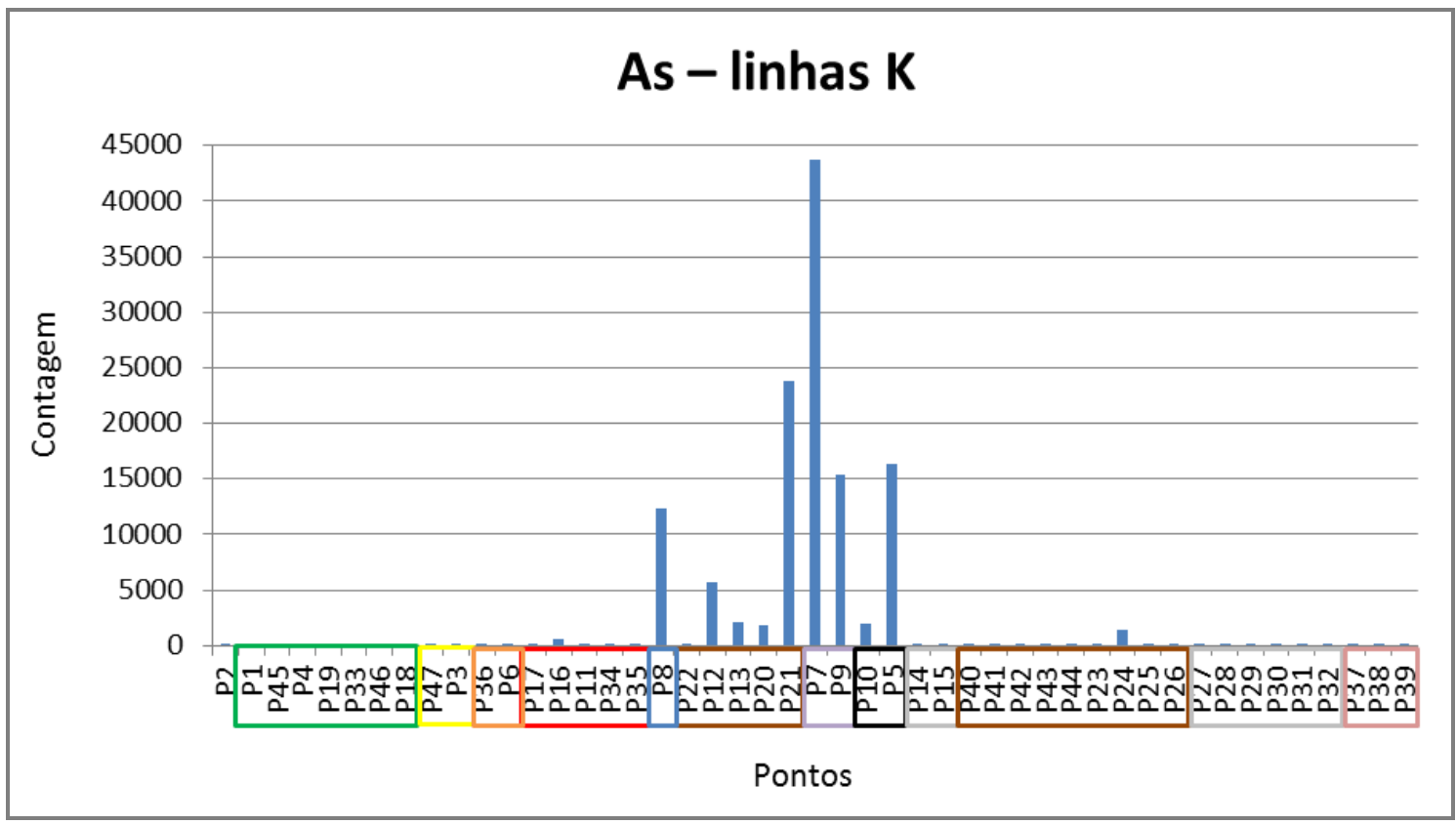

Figura 4.64 - Gráfico de barras das áreas do pico do As identificado nos espectros de EDXRF para os diferentes pontos medidos na obra "Tropical" de Anita Malfatti (1917) do acervo da Pinacoteca do Estado de São Paulo

A figura 4.65 mostra que o cádmio está presente em muito dos pontos analisados, mas sua presença é destacada no ponto P34, uma região vermelha na orelha da mulher retratada. Nenhum outro elemento teve destaque neste mesmo ponto. Diferentemente do esperado, o ponto P35, que possui a mesma tonalidade do ponto P34, não teve um destaque no registro do cádmio. Além 
disso, pela cor apresentada na figura, para ser um vermelho ou laranja de cádmio, $\mathrm{Cd}(\mathrm{S}, \mathrm{Se})$, necessariamente deveria estar presente o Se, que faz parte da composição destes pigmentos. Outras regiões também mostraram a presença o Cd, como pontos marrons (P23, P24, e P25), e pontos brancos (P27 e P29), mas não há pigmentos destas cores que contenham Cd. Torna-se assim inconclusiva a origem do $\mathrm{Cd}$ presente. Mas por não ter registro do Se, talvez o Cd venha de um pigmento amarelo de camadas subjacentes.

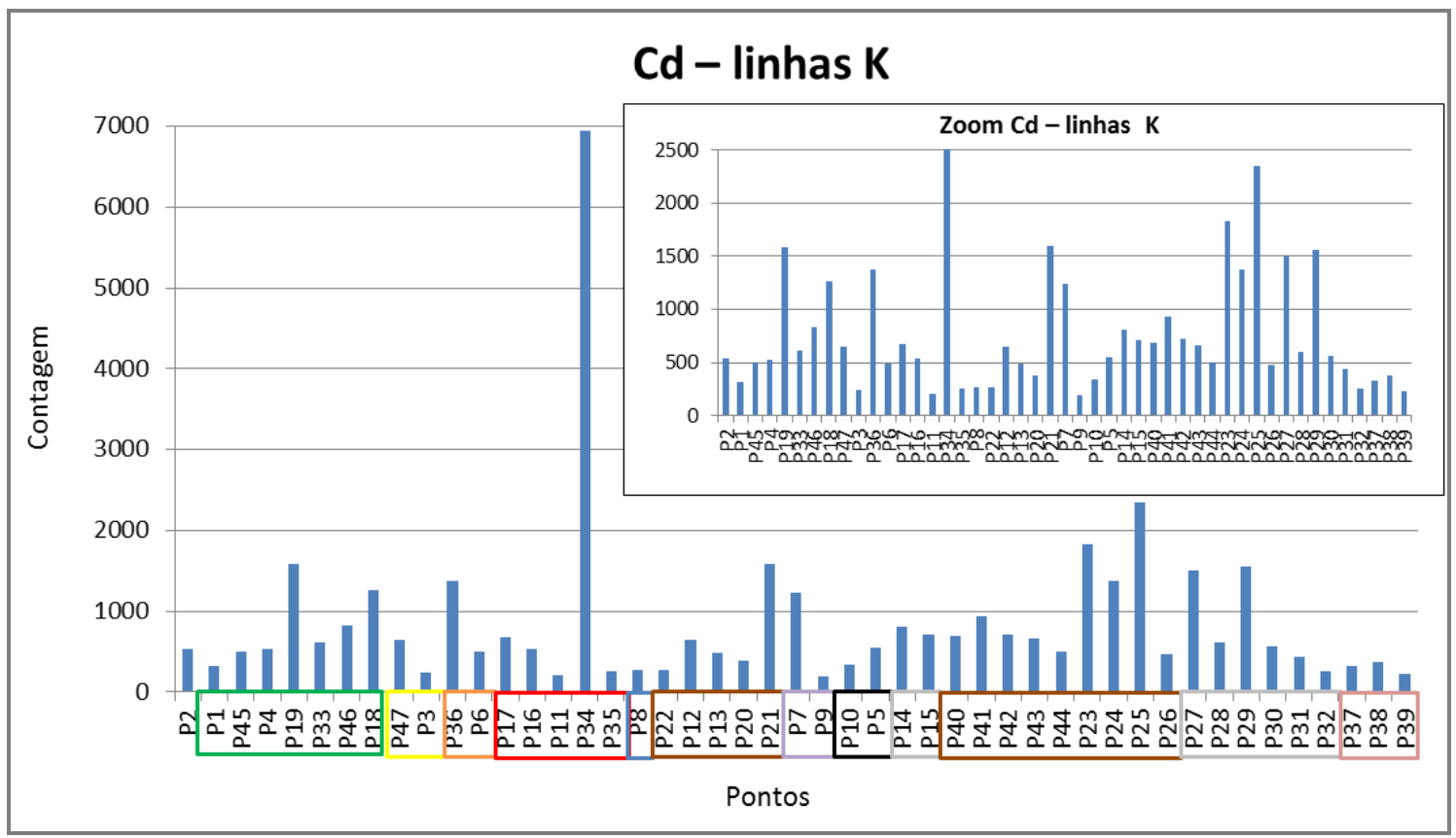

Figura 4.65 - Gráfico de barras das áreas do pico do Cd identificado nos espectros de EDXRF para os diferentes pontos medidos na obra "Tropical" de Anita Malfatti (1917) do acervo da Pinacoteca do Estado de São Paulo

Nas áreas de colorações laranja e vermelhas, como nos pontos P06 e P36, que são tons de laranja nas frutas, nos pontos P17 e P16, que são regiões dos lábios, ou ainda o ponto P35 que é uma área avermelhada próxima a sobrancelha da personagem, com exceção do ponto P34, nenhuma destas regiões tiveram destaque de um elemento que pudesse precisar a determinação de um pigmento. Nestas regiões, assim como nas demais, há a presença do chumbo, que não exclui a possibilidade do uso de pigmentos como o vermelho de chumbo ( $\mathrm{Pb3O} 4)$, o litargírio $(\mathrm{PbO})$, também vermelho, que é pouco usado em pinturas e mais comumente usado como material secante (MAYER, 2006), além dos inúmeros pigmentos orgânicos, não 
detectáveis por esta técnica. Logo, para estas cores, não foi possível determinar o pigmento utilizado.

Neste quadro, diferentemente das demais obras analisadas deste estudo, foi observada em alguns pontos a presença do cobre, ponto verde (P01) e em pontos violetas negros (P05, P07 e P10) como pode ser visto na figura 4.66. O cobre é associado a pigmentos verdes e azuis, com diversas composições químicas, (STUART, 2008). Mas como há uma diversidade de pigmentos que contêm $\mathrm{Cu}$, e pela não constância da presença deste elemento em pontos de mesma cor, não podemos definir a origem deste elemento.

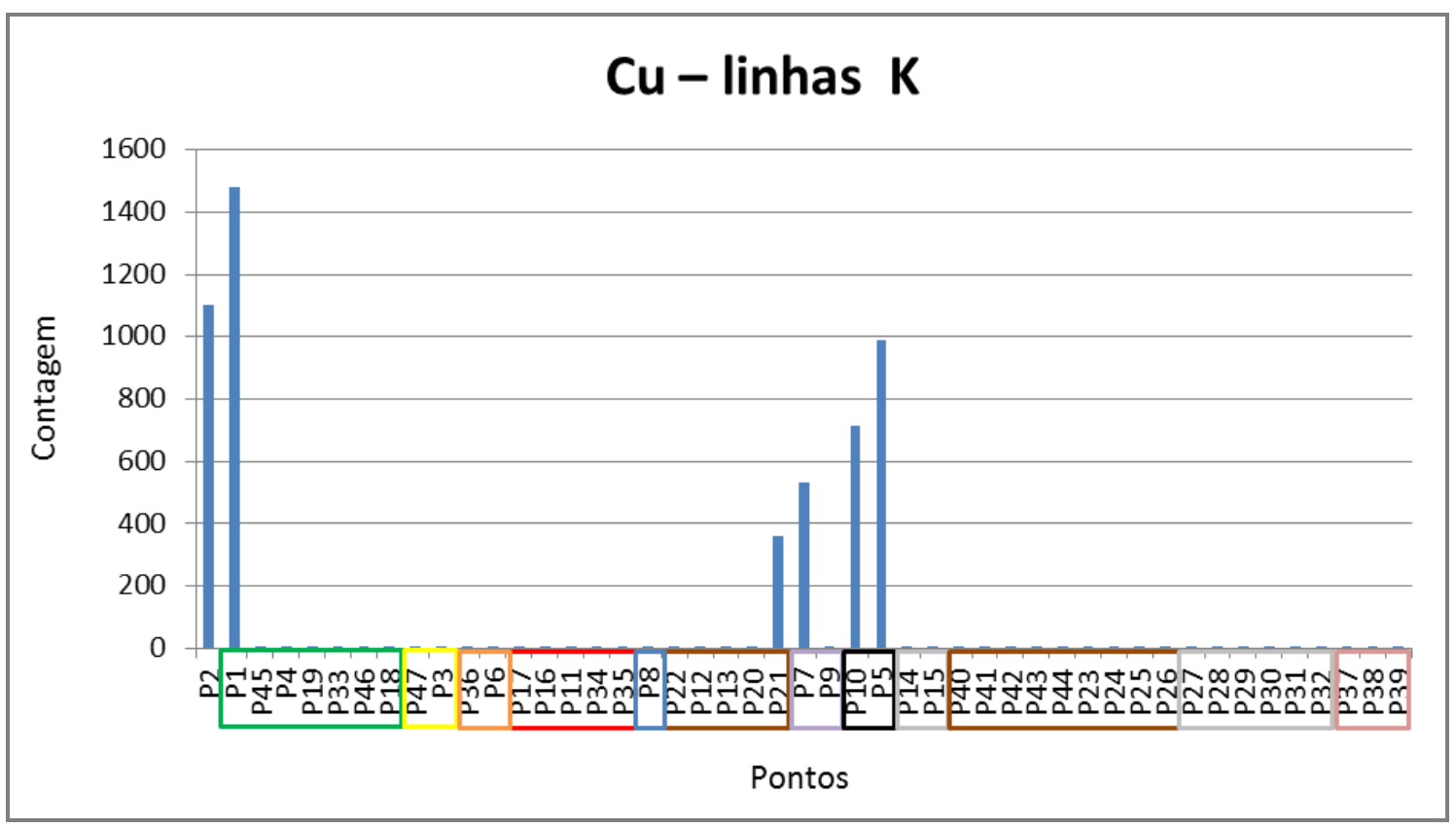

Figura 4.66 - Gráfico de barras das áreas do pico do Cu identificado nos espectros de EDXRF para os diferentes pontos medidos na obra "Tropical" de Anita Malfatti (1917) do acervo da Pinacoteca do Estado de São Paulo 
Tabela 4.11 - Matriz de correlação dos elementos presentes nos pontos analisados por EDXRF na obra "Tropical" (1917) de Anita Malfatti do acervo da Pinacoteca do Estado de são Paulo

\begin{tabular}{l|r|r|r|r|r|r|r|r|r|r|r} 
variable & $\mathrm{Ca}-\mathrm{K}$ & $\mathrm{Cr}-\mathrm{K}$ & $\mathrm{Fe}-\mathrm{K}$ & $\mathrm{Co}-\mathrm{K}$ & $\mathrm{Cu}-\mathrm{K}$ & $\mathrm{Zn}-\mathrm{K}$ & $\mathrm{As}-\mathrm{K}$ & $\mathrm{Sr}-\mathrm{K}$ & $\mathrm{Cd}-\mathrm{K}$ & $\mathrm{Ba}-\mathrm{L}$ & $\mathrm{Pb}-\mathrm{L}$ \\
\hline $\mathrm{Ca}-\mathrm{K}$ & 1,000 & 0,033 & $-0,040$ & 0,008 & $-0,152$ & 0,611 & 0,034 & 0,203 & $-0,021$ & 0,322 & $-0,444$ \\
\hline $\mathrm{Cr}-\mathrm{K}$ & 0,033 & 1,000 & $-0,040$ & $-0,057$ & $-0,035$ & 0,050 & $-0,047$ & 0,563 & 0,052 & 0,513 & $-0,341$ \\
\hline $\mathrm{Fe}-\mathrm{K}$ & $-0,040$ & $-0,040$ & 1,000 & 0,128 & 0,543 & $-0,111$ & 0,052 & $-0,056$ & $-0,047$ & $-0,089$ & 0,013 \\
\hline $\mathrm{Co}-\mathrm{K}$ & 0,008 & $-0,057$ & 0,128 & 1,000 & 0,248 & 0,079 & 0,102 & $-0,005$ & $-0,092$ & $-0,111$ & $-0,108$ \\
\hline $\mathrm{Cu}-\mathrm{K}$ & $-0,152$ & $-0,035$ & 0,543 & 0,248 & 1,000 & $-0,223$ & 0,307 & $-0,190$ & $-0,090$ & $-0,156$ & $-0,060$ \\
\hline $\mathrm{Zn}-\mathrm{K}$ & 0,611 & 0,050 & $-0,111$ & 0,079 & $-0,223$ & 1,000 & $-0,029$ & $-0,010$ & $-0,262$ & 0,078 & $-0,421$ \\
\hline $\mathrm{As}-\mathrm{K}$ & 0,034 & $-0,047$ & 0,052 & 0,102 & 0,307 & $-0,029$ & 1,000 & $-0,020$ & 0,021 & $-0,049$ & $-0,034$ \\
\hline $\mathrm{Sr}-\mathrm{K}$ & 0,203 & 0,563 & $-0,056$ & $-0,005$ & $-0,190$ & $-0,010$ & $-0,020$ & 1,000 & 0,145 & 0,778 & $-0,249$ \\
\hline $\mathrm{Cd}-\mathrm{K}$ & $-0,021$ & 0,052 & $-0,047$ & $-0,092$ & $-0,090$ & $-0,262$ & 0,021 & 0,145 & 1,000 & 0,097 & 0,156 \\
\hline $\mathrm{Ba}-\mathrm{L}$ & 0,322 & 0,513 & $-0,089$ & $-0,111$ & $-0,156$ & 0,078 & $-0,049$ & 0,778 & 0,097 & 1,000 & $-0,359$ \\
\hline $\mathrm{Pb}-\mathrm{L}$ & $-0,444$ & $-0,341$ & 0,013 & $-0,108$ & $-0,060$ & $-0,421$ & $-0,034$ & $-0,249$ & 0,156 & $-0,359$ & 1,000
\end{tabular}

Observando a matriz e o gráfico de correlação (figura 4.67 e tabela 4.11), podemos verificar uma correlação positiva entre os elementos $\mathrm{Ba}, \mathrm{Sr}$ e $\mathrm{Cr}$, sugerindo a presença de barita nos pigmento com cromo. Também há uma correlação positiva entre $\mathrm{Zn}$ e $\mathrm{Ca}$, como não foi possível medir o fundo de preparação da tela, esta correlação pode indicar que o Zn também esteja presente no fundo, pois o $\mathrm{Ca}$ é tipicamente usado para a imprimatura do suporte. Existe uma correlação entre o $\mathrm{Cu}$ e $\circ \mathrm{Fe}$, indicando a possível presença do $\mathrm{Cu}$ nos pigmentos marrons e negros. Novamente o chumbo e $\mathrm{o}$ zinco possuem correlação negativa $(-0,421)$, indicando que onde há um elemento diminui a presença do outro. Assim, a lista dos possíveis pigmentos presentes na obra "Tropical" está na tabela 4.12 


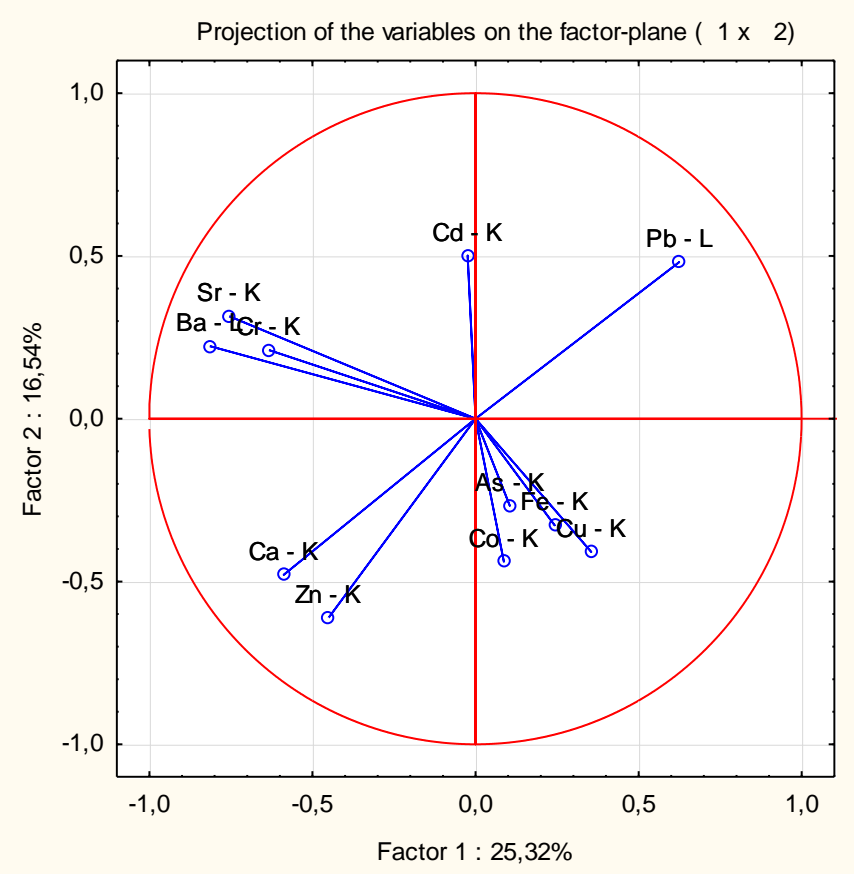

- Active

Figura 4.67 - Gráfico da correlação por PCA entre os elementos presentes nos espectros de EDXRF pontos medidos na obra "Tropical" de Anita Malfatti (1917) do acervo da Pinacoteca do Estado de São Paulo

Tabela 4.12 - Possíveis pigmentos utilizados por Anita Malfatti na obra "Tropical" de Anita Malfatti (1917) do acervo da Pinacoteca do Estado de São Paulo (JANSSENS, 2004; STUART, 2008; VASCONCELOS et al., 1992; MAYER, 2006; LFNATEC, 2009)

\begin{tabular}{|c|c|c|c|c|}
\hline Cor & $\begin{array}{l}\text { Elementos } \\
\text { Presentes }\end{array}$ & $\begin{array}{l}\text { Composição } \\
\text { Química }\end{array}$ & $\begin{array}{l}\text { Nome do } \\
\text { Pigmento }\end{array}$ & $\begin{array}{c}\text { Empregado } \\
\text { desde }\end{array}$ \\
\hline \multirow{2}{*}{ Brancos } & $\mathrm{Zn}$ & $\mathrm{ZnO}$ & $\begin{array}{c}\text { Branco de } \\
\text { Zinco }\end{array}$ & Século 19 \\
\hline & $\mathrm{Pb}$ & 2PbCO3.Pb(OH)2 & $\begin{array}{l}\text { Branco de } \\
\text { Chumbo }\end{array}$ & Antiguidade \\
\hline Amarelos & \multicolumn{4}{|c|}{ indeterminado } \\
\hline Laranjas/Vermelhos & \multicolumn{4}{|c|}{ indeterminado } \\
\hline Verdes & $\mathrm{Cr}$ & $\mathrm{Cr}_{2} \mathrm{O}_{3}$ & $\begin{array}{l}\text { Óxido de } \\
\text { Cromo }\end{array}$ & Século 19 \\
\hline Marrons & $\mathrm{Fe}$ & $\mathrm{Fe}_{2} \mathrm{O}_{3}$ & $\begin{array}{l}\text { Oxido de } \\
\text { Ferro; Siena }\end{array}$ & Século 19 \\
\hline Pretos & $\mathrm{Fe}$ & $\mathrm{Fe}_{3} \mathrm{O}_{4}$ & $\begin{array}{l}\text { Preto de } \\
\text { Ferro }\end{array}$ & Mineral \\
\hline Violeta & $\mathrm{Co}, \mathrm{As}^{*}$ & $\mathrm{Co} 3\left(\mathrm{PO}_{4}\right)_{2}$ & $\begin{array}{l}\text { Violeta de } \\
\text { Cobalto }\end{array}$ & Século 19 \\
\hline Base & \multicolumn{4}{|c|}{ indeterminado } \\
\hline
\end{tabular}




\section{5 "O Homem Amarelo"}

"O Homem Amarelo", destacado na figura 4.68, é uma obra muito relevante do movimento dos modernistas brasileiros. Entretanto, não havia sido realizado anteriormente nenhum estudo por imageamento desta obra. Dessa maneira, não existem registros sobre diferentes tonalidades presentes nas figuras subjacentes e indicações sobre o reaproveitamento da tela.

A fotografia de luz visível (figura 4.68) registra a paleta de cor da obra e detalhes que são visíveis a olho nu, como o caso do aparente olho perto da lapela direita do paletó e a aparente mão presente sobre o ombro esquerdo do personagem retratado. A busca da melhor identificação destes aparentes elementos identificados na imagem visível foi realizada através da imagem de reflectografia IR (figura 4.69), no entanto, não contribuiu muito para a visualização dos desenhos subjacentes, pois estes detalhes que são visíveis a olho nu não aparecem na imagem registrada, possivelmente devido à composição do material utilizado pela artista ou ao fato da camada superior ser espessa.

No entanto, com a fotografia de reflectografia IR, na figura 4.70 foi possível observar com mais detalhes a assinatura da artista na obra que era pouco nítida na fotografia com luz visível devido às cores utilizadas pela artista. 


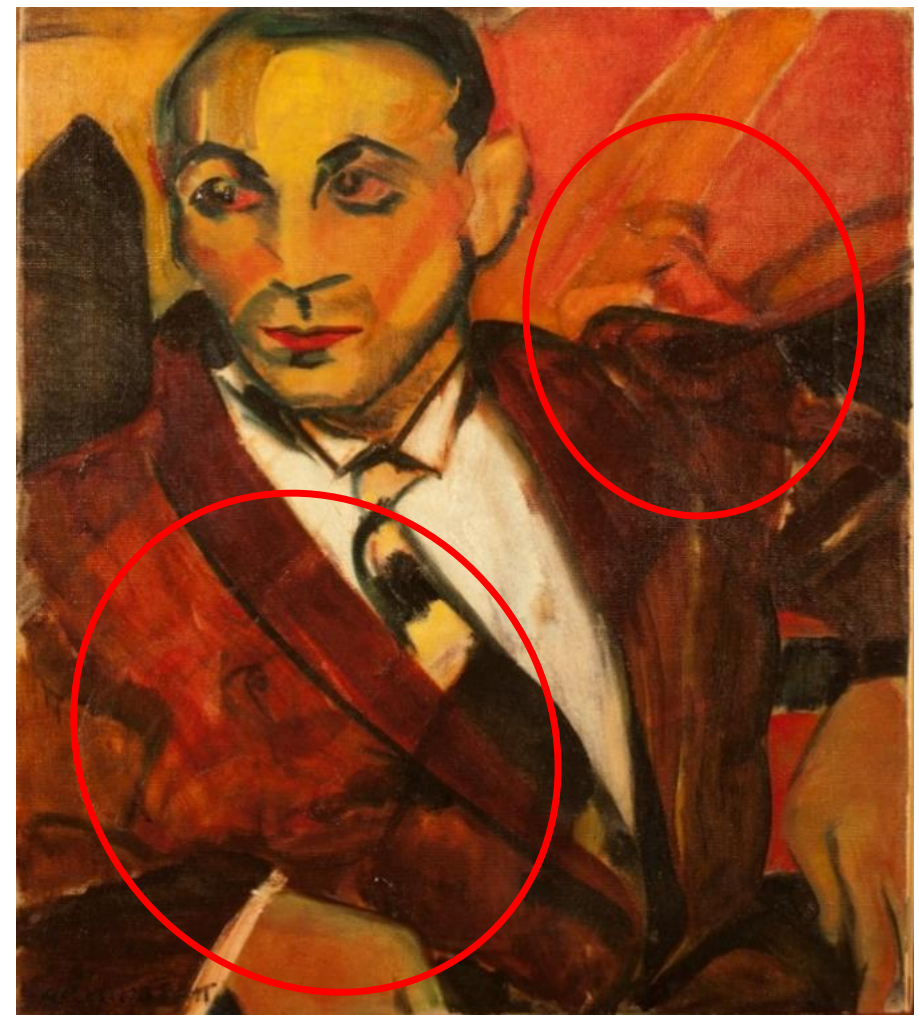

Figura 4.68 - Fotografia com luz visível da obra "O Homem Amarelo" de Anita Malfatti (1915/1916, óleo sobre tela, 61x51cm) do acervo do IEB-USP. Foto: P.H.O.V. Campos e E. Kajiya

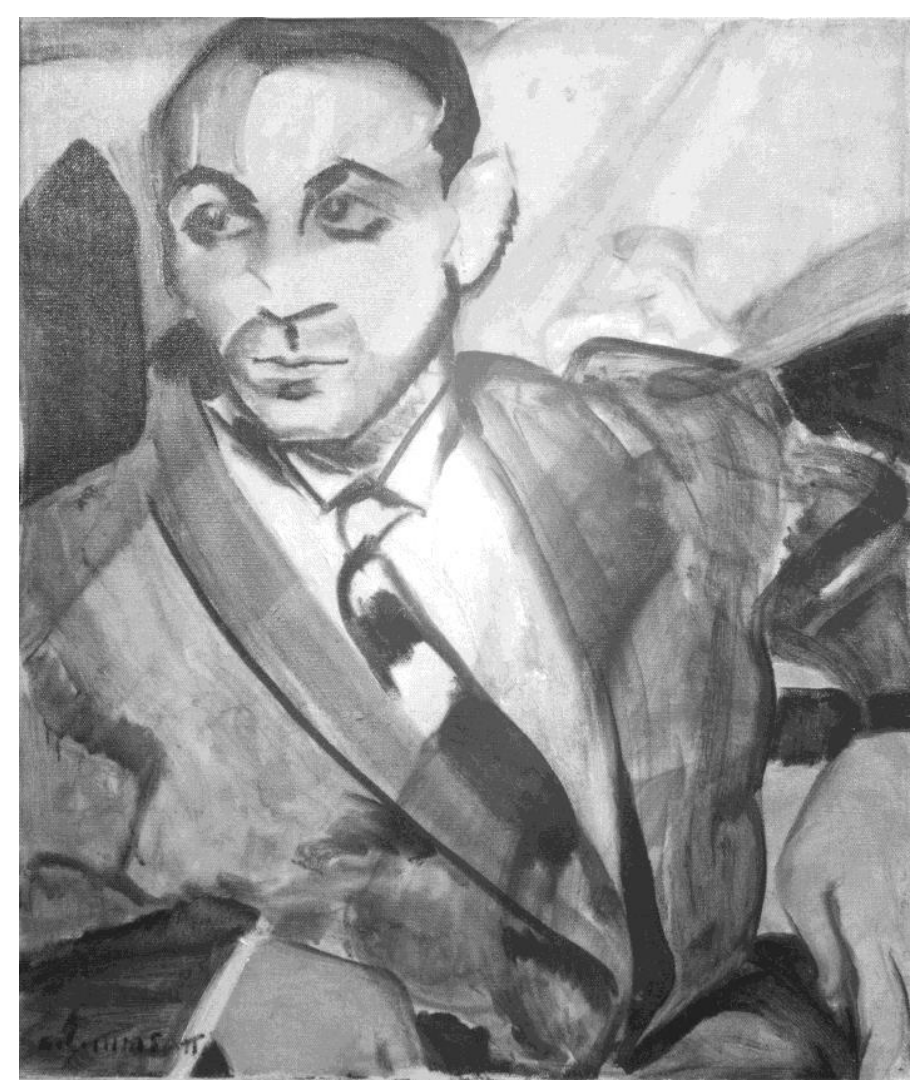

Figura 4.69 - Fotografia de reflectografia de infravermelho da obra "O Homem Amarelo" de Anita Malfatti (1915/1916, óleo sobre tela, $61 \times 51 \mathrm{~cm})$ do acervo do IEB-USP. Foto P.H.O.V. Campos e E. Kajiya 


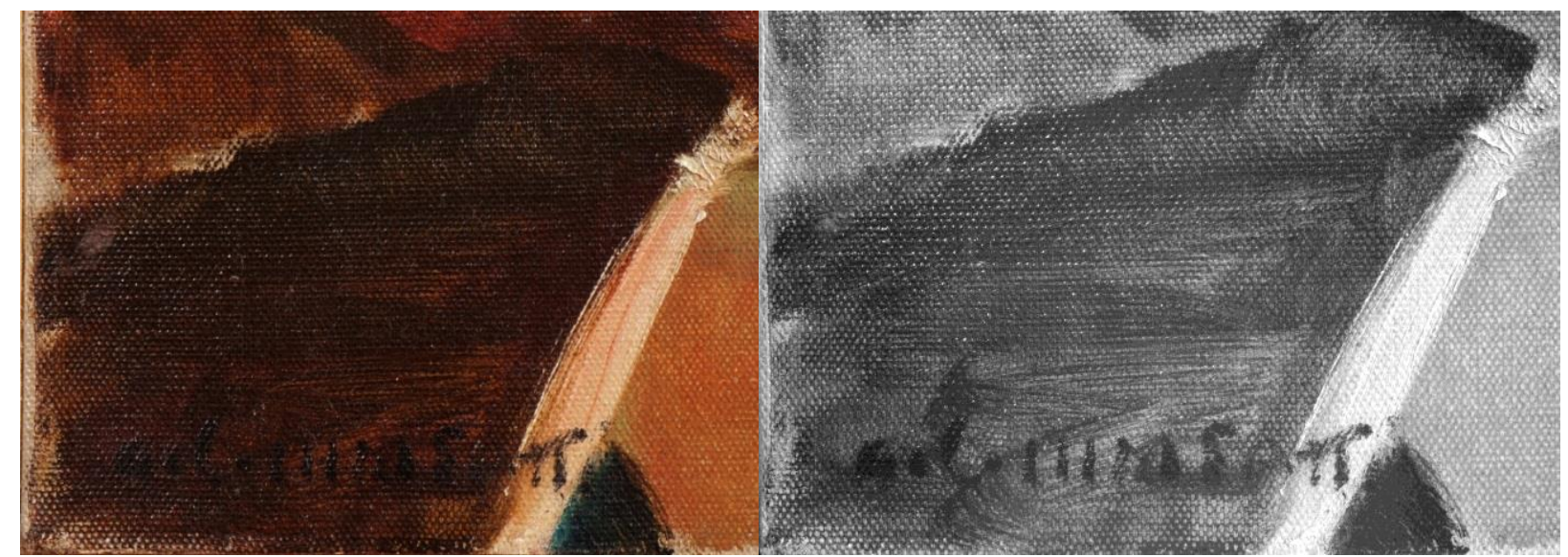

Figura 4.70 - Imagens da região da assinatura com fotografia com luz visível (esquerda) e reflectografia IR (direita) da obra "O Homem Amarelo" de Anita Malfatti do acervo do IEB-USP. Foto: P.H.O.V. Campos e E. Kajiya

Dada a dificuldade de identificação dos elementos (possível olho e mão) apontados na imagem visível na obra optou-se pela análise com radiografia digitalizada conforme figura 4.71. Nestas imagens radiográficas é possível observar com maior contraste os traços realizados pela artista (4.71) e as possíveis figuras subjacentes (figuras 4.71 a 4.73 ) e com mais nitidez uma cabeça no canto inferior esquerdo da tela. 


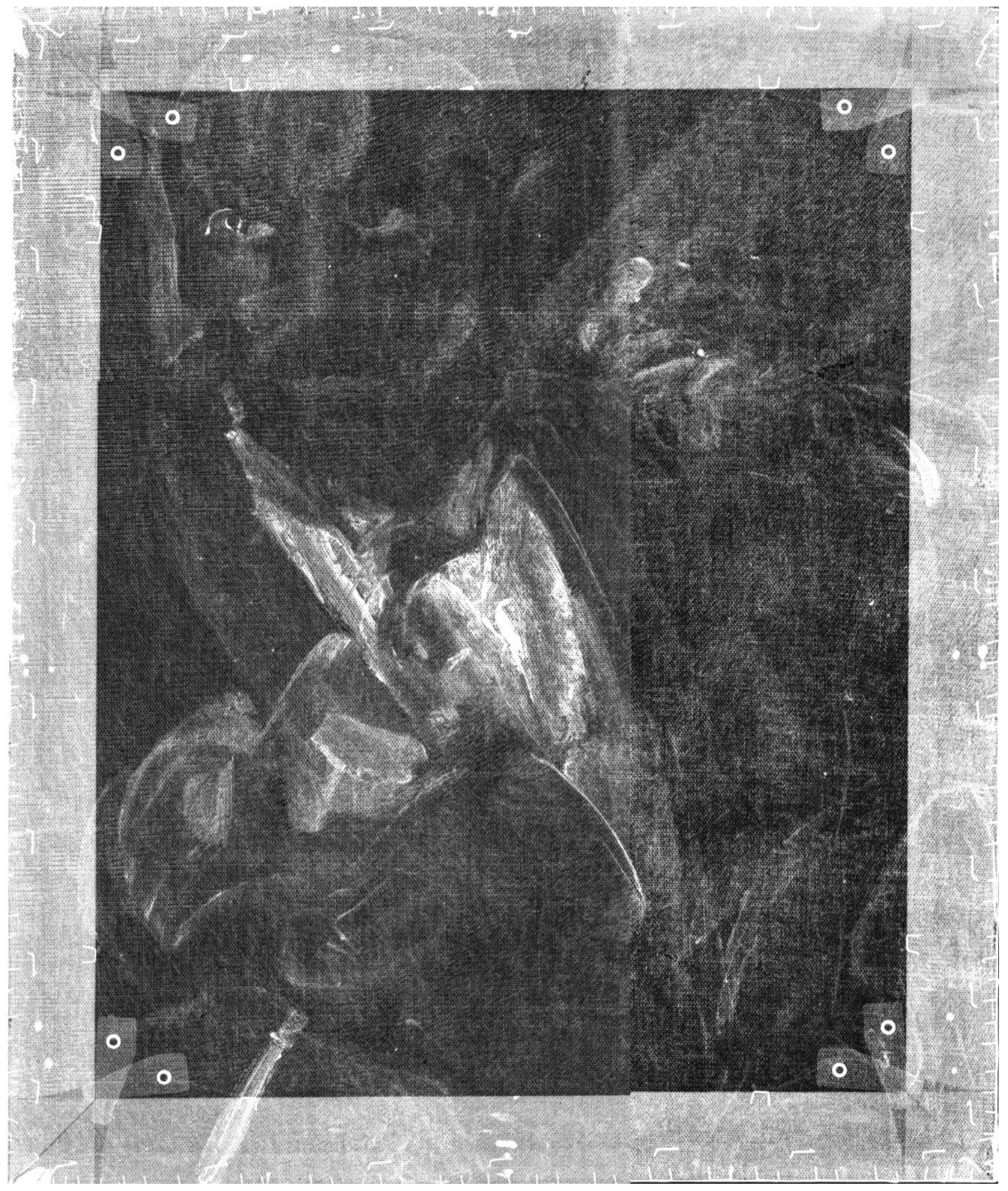

Figura 4.71 - Imagem de Radiografia digital da obra "O Homem Amarelo" de Anita Malfatti (1915/1916, óleo sobre tela, 61×51cm) do acervo do IEB-USP 


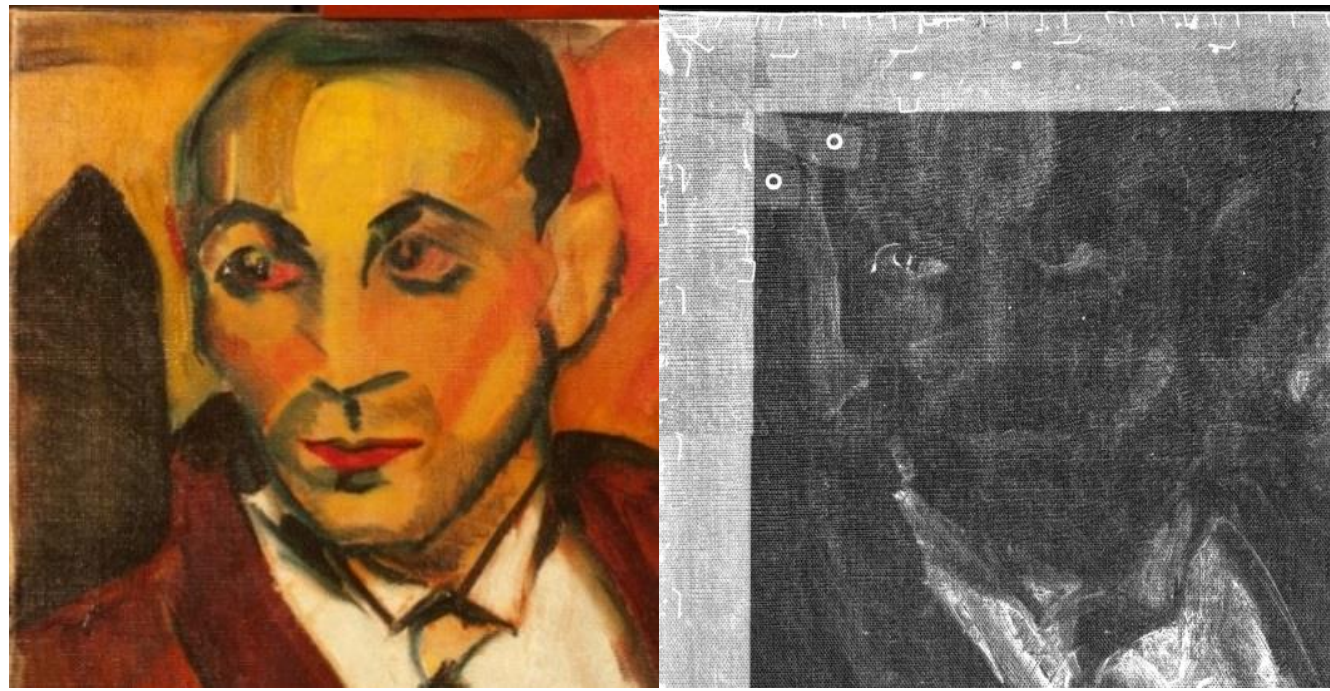

Figura 4.72 - Imagem visível e de Radiografia digital da parte superior esquerda da obra "O Homem Amarelo" de Anita Malfatti (1915/1916, óleo sobre tela, 61x51cm) do acervo do IEBUSP

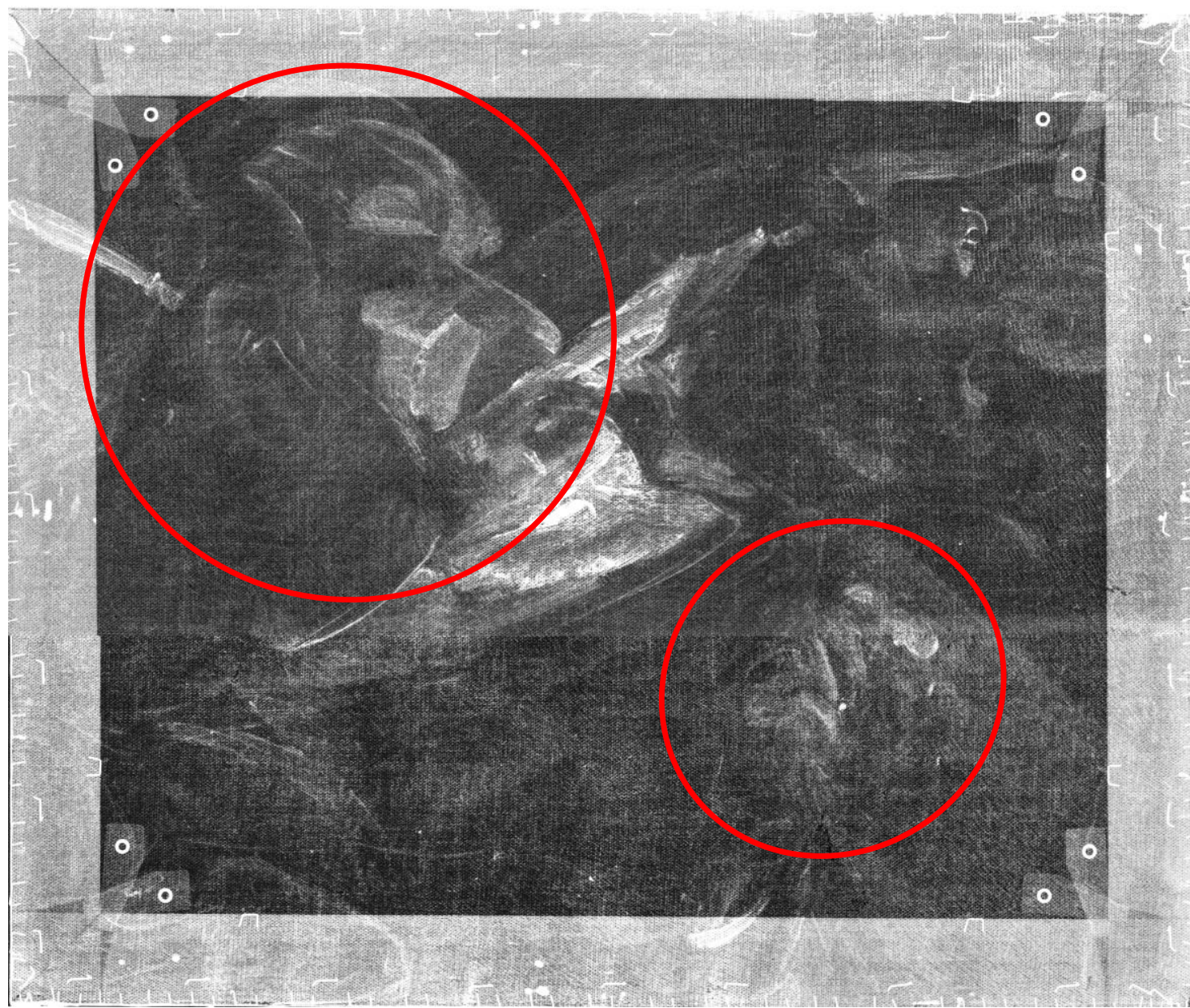

Figura 4.73 - Imagem girada de $90^{\circ}$ da Radiografia digital da obra "O Homem Amarelo" de Anita Malfatti (1915/1916, óleo sobre tela, 61×51cm) do acervo do IEB-USP 
Esta imagem de radiografia permite evidenciar o pentimento da artista e servirá como uma "impressão digital" desta obra, dificultando deste modo qualquer reprodução desta e de seus detalhes. A análise da imagem da radiografia também é capaz de evidenciar onde se encontram os pigmentos de maior densidade na pintura (particularmente pigmentos à base de branco de chumbo), pois nestas regiões houve maior absorção dos raios $X$ e menos sensibilização na imagem radiográfica.

As imagens de reflectografia IR e radiografia desta obra evidenciam que dependendo do material utilizado pelo artista, é possível que os desenhos subjacentes em algumas obras sejam melhor observados com a radiografia do que com a reflectografia IR. Entretanto, em outros casos, situações inversas podem ser percebidas.

As fotografias obtidas utilizando uma fonte de luz rasante ao quadro são apresentadas na figura 4.74. Observamos com esta técnica as marcas do chassi e ainda algumas regiões onde há uma camada mais espessa de tinta (destaque para o branco da camisa do personagem). A imagem também nos mostra áreas onde há deformações e afundamentos do suporte (tela) e marcas das pinceladas utilizadas. 


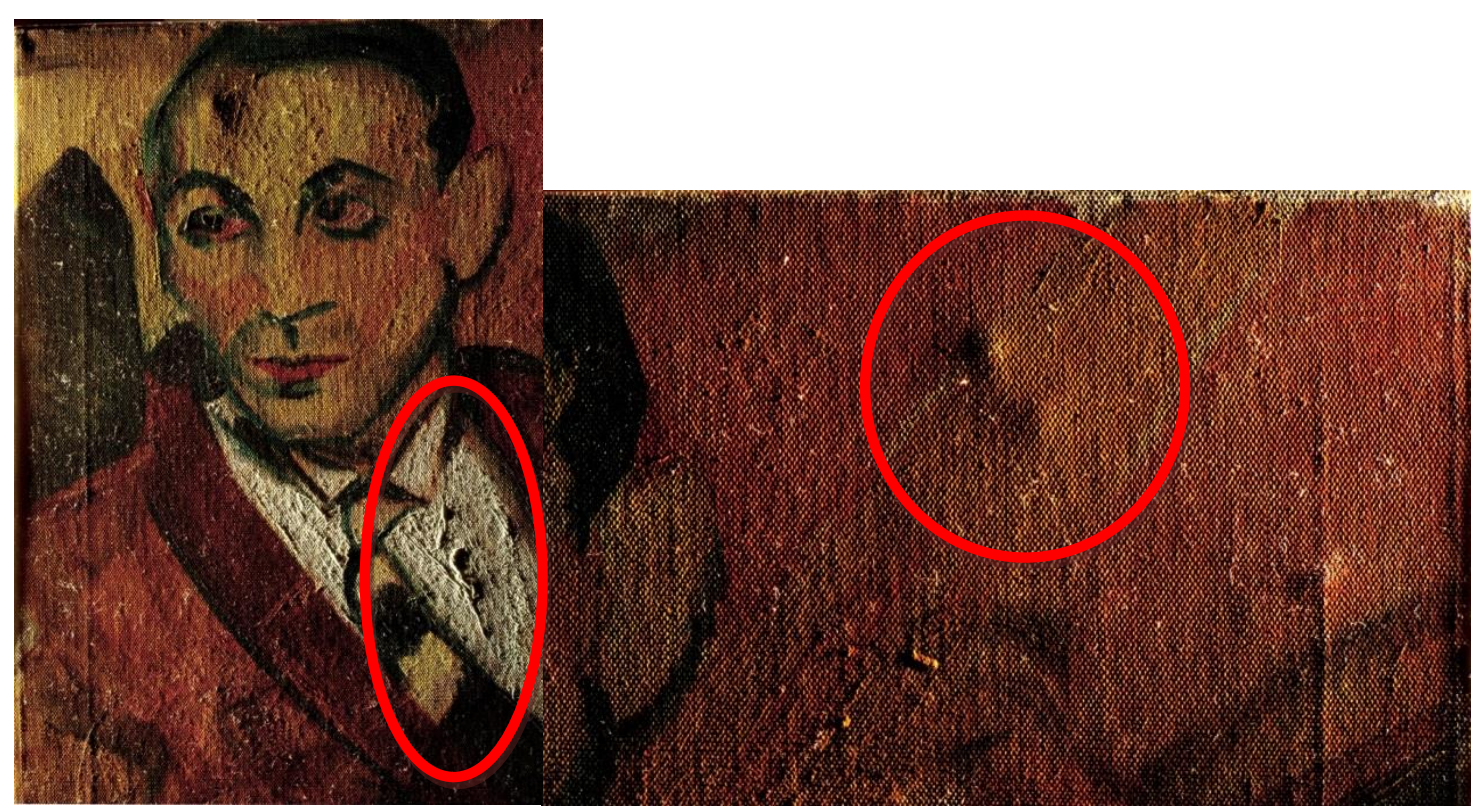

Figura 4.74 - Imagens obtidas com fotografia com luz rasante da obra "O Homem Amarelo" de Anita Malfatti do acervo do IEB-USP, lado esquerdo evidencia a camada espessa de tinta, Lado direito evidencia detalhes e pontos de deformação do suporte. Foto: P.H.O.V.

Campos e E. Kajiya

A fotografia por fluorescência UV (figura 4.75), quando comparada com a observação à luz visível, permite identificar a existência de uma gama diferente de cores que se manifestam, devido a fluorescência dos pigmentos presentes na obra. Além disso, é possível identificar as regiões onde houve intervenções de restauros recentes (identificados com círculos), como o ponto escuro na camisa branca, na parte inferior da gravata e na região vermelha à direita da cabeça, além de muitos outros pequenos pontos, criteriosos, minuciosos e localizados, indicando que houve uma preocupação em executar intervenções pontuais, preservando a originalidade da obra, e não a descaracterizando. Pela fotografia de UV é possível também observar que há uma camada espessa e não uniforme do verniz, que pode, deste modo, dificultar, mascarar ou impedir que seja vista a fluorescência dos pigmentos presentes na obra. Um recorte o rosto do Homem Amarelo é mostrado na figura 4.76, com as diversas técnicas de imageamento aplicada, tornando possivel comparar as diferenças de informações que cada técnica fornece. 


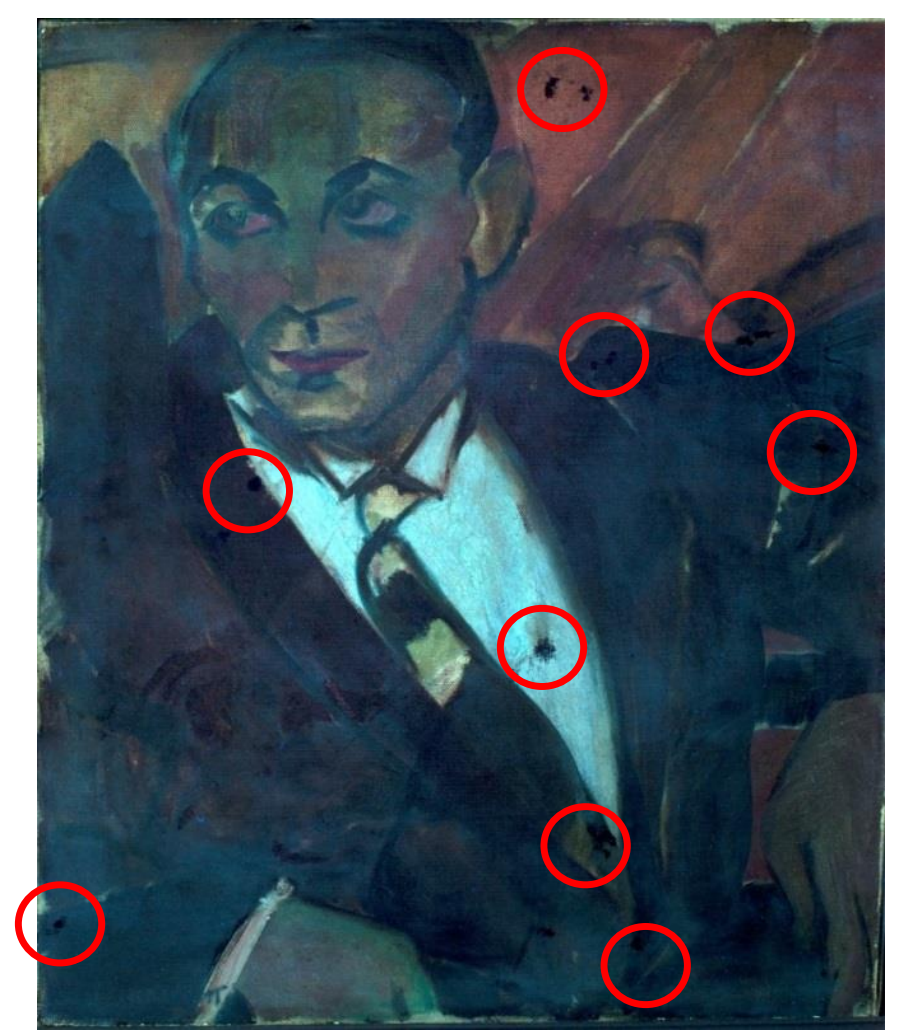

Figura 4.75 - Fotografia por fluorescência UV da obra "O Homem Amarelo" de Anita Malfatti (1915/1916, óleo sobre tela, 61x51cm) do acervo do IEB-USP. Foto: P.H.O.V. Campos e E. Kajiya

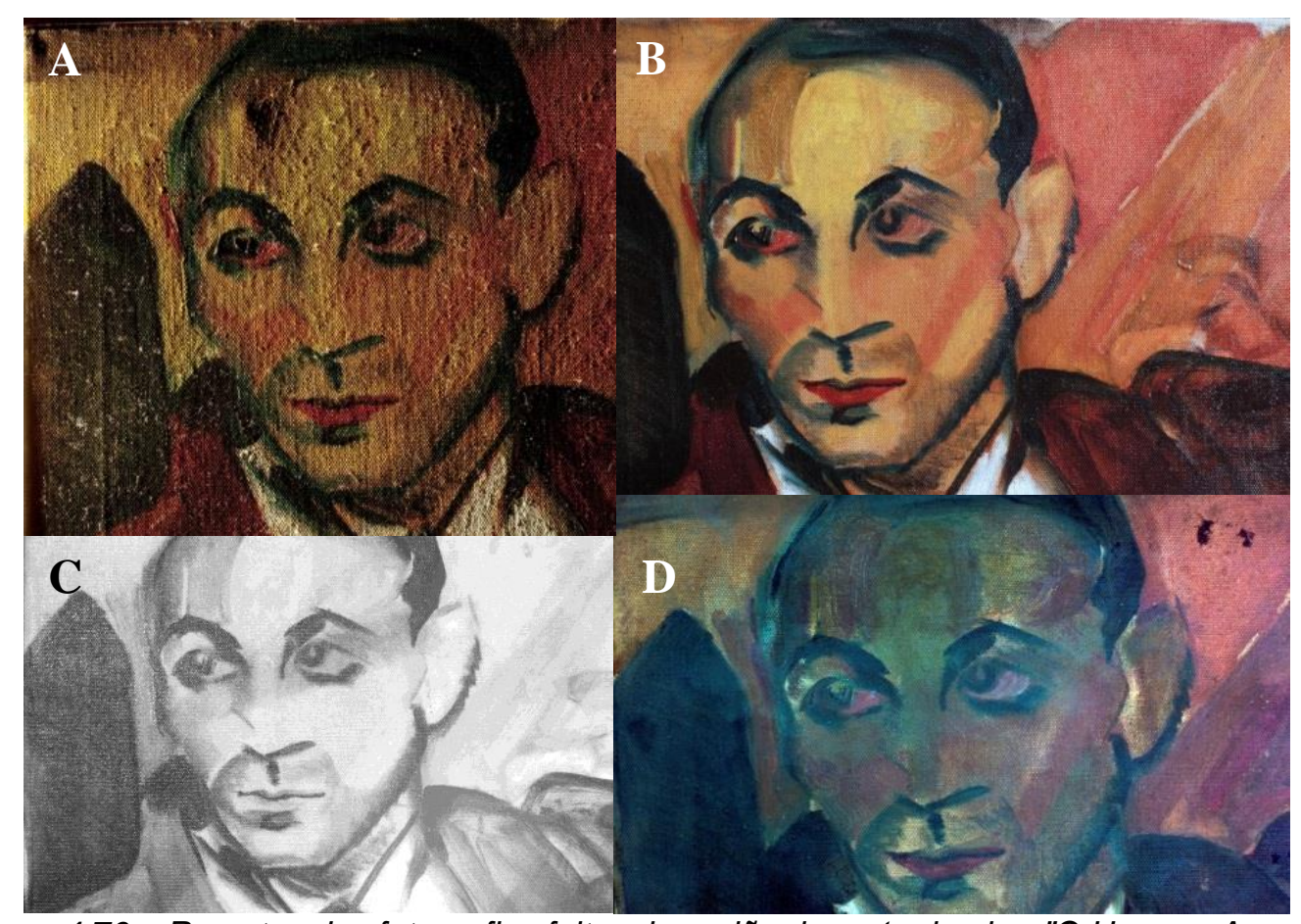

Figura 4.76 - Recortes das fotografias feitas da região do rosto da obra "O Homem Amarelo" de Anita Malfatti do acervo do IEB-USP com as técnicas de: A) fotografia de luz rasante; B) visível; C) reflectografia de infravermelho; D) fluorescência UV Foto: P.H.O.V. Campos e E. Kajiya 
Na obra "O Homem Amarelo", foram medidos quarenta e sete (47) pontos em diversas regiões do quadro, levando em conta a diversidade de cores e tons, como pode ser visto na figura 4.77. Na maioria desses pontos, foram feitas as medidas de cor com o espectrofotômetro e a determinação da média de cores pela fotografia com luz visível. Esta relação está listada na tabela 4.13 e os pontos estão na mesma ordem em que se apresentam nos gráficos de barras dos picos de cada elemento.

Assim como na obra "Tropical", "O Homem Amarelo" foi produzido em uma tela reutilizada, ou seja, as pinturas foram realizadas sobre outra pintura, como já foi mostrado pelas técnicas de imageamento, tanto com reflectografia por infravermelho, quanto para radiografia.

Nesta obra foram medidos três pontos na borda do quadro, em uma região onde há menos ou nenhuma camada pictórica, possibilitando que fosse analisada o fundo de preparação da tela. Ao observamos os pontos P39, P40 e $P 47$, vemos que todos possuem quase que exclusivamente os elementos chumbo e cálcio (figuras 4.78 e 4.79), a menos do ponto P39, que possui bário (figura 4.80) e o ponto P47, que possui $\mathrm{Sr}$ em pequena quantidade (figura 4.83).

O chumbo está presente em todos os pontos analisados, e o cálcio está presente na maioria deles também. Desta forma, podemos afirmar que a base de preparação desta obra é constituída de branco de chumbo $\left(2 \mathrm{PbCO}_{3} \mathrm{~Pb}(\mathrm{OH})_{2}\right)$ e carbonato de cálcio ou sulfato de cálcio $\left(\mathrm{CaCO}_{3} \mathrm{e}\right.$ $\mathrm{CaSO}_{4} .2 \mathrm{H}_{2} \mathrm{O}$, respectivamente). A presença do $\mathrm{Ba}$ e $\mathrm{Sr}$ podem ser pela pequena presença de outros pigmentos nestas regiões, pois estão apenas em um dos três pontos. 
Tabela 4.13 - Relação das cores obtidas por colorimetria (em coordenadas L*a*b*) e fotografia digital (em coordenadas RGB) nos pontos analisados por EDXRF na obra "O Homem Amarelo"

\begin{tabular}{|c|c|c|c|c|c|c|}
\hline Ponto & P8 & P9 & P7 & P10 & P36 & P17 \\
\hline \multirow{2}{*}{$\begin{array}{c}\text { Fotografia } \\
\text { (RGB) } \\
\end{array}$} & $201,216,188$ & $194,204,178$ & $176,164,124$ & $202,185,77$ & $206,179,64$ & $199,167,61$ \\
\hline & & & & & & \\
\hline \multirow{2}{*}{$\begin{array}{c}\text { Colorimetria } \\
\left(L^{*}, a^{*}, b^{*}\right)\end{array}$} & & & & & & \\
\hline & $73,-9,11$ & $71,-7,11$ & $53,2,16$ & $59,-1,32$ & - & $53,2,37$ \\
\hline Ponto & P33 & P26 & $\mathbf{P 2}$ & P1 & P35 & P19 \\
\hline \multirow{2}{*}{$\begin{array}{c}\text { Fotografia } \\
\text { (RGB) }\end{array}$} & $205,147,65$ & $166,105,48$ & $137,83,36$ & $137,63,34$ & $194,101,59$ & $185,76,54$ \\
\hline & & & & & & \\
\hline \multirow{2}{*}{$\begin{array}{c}\text { Colorimetria } \\
\left(L^{*}, a^{*}, b^{*}\right)\end{array}$} & & & & & & \\
\hline & - & $42,9,23$ & $43,5,23$ & $40,9,18$ & $45,13,26$ & $42,22,26$ \\
\hline Ponto & P41 & P37 & P38 & P18 & P23 & P20 \\
\hline \multirow{2}{*}{$\begin{array}{c}\text { Fotografia } \\
\text { (RGB) }\end{array}$} & $200,81,62$ & $208,75,77$ & $209,77,76$ & $209,75,76$ & $173,55,56$ & $180,51,62$ \\
\hline & & & & & & \\
\hline \multirow{2}{*}{$\begin{array}{c}\text { Colorimetria } \\
\left(L^{*}, a^{*}, b^{*}\right)\end{array}$} & & & & & & \\
\hline & - & - & - & $41,26,20$ & $37,19,16$ & $35,21,17$ \\
\hline Ponto & P27 & P3 & P16 & P14 & P31 & P29 \\
\hline \multirow{2}{*}{$\begin{array}{c}\text { Fotografia } \\
\text { (RGB) }\end{array}$} & $151,61,61$ & $137,5,38$ & $117,20,37$ & $146,51,35$ & $152,29,40$ & $159,34,45$ \\
\hline & & & & & & \\
\hline \multirow{2}{*}{$\begin{array}{c}\text { Colorimetria } \\
\left(L^{*}, a^{*}, b^{*}\right)\end{array}$} & & & & & & \\
\hline & $36,17,13$ & $34,18,13$ & $30,15,9$ & $41,14,21$ & - & $36,19,17$ \\
\hline Ponto & P34 & P24 & P42 & P43 & P6 & P28 \\
\hline \multirow{2}{*}{$\begin{array}{c}\text { Fotografia } \\
\text { (RGB) }\end{array}$} & $155,16,42$ & $102,42,39$ & $95,37,32$ & $94,36,32$ & $71,23,27$ & $69,22,27$ \\
\hline & & & & & & \\
\hline \multirow{2}{*}{$\begin{array}{c}\text { Colorimetria } \\
\left(L^{*}, a^{*}, b^{*}\right)\end{array}$} & & & & & & \\
\hline & - & $29,8,6$ & - & - & $28,9,6$ & $26,5,3$ \\
\hline Ponto & P15 & P30 & P5 & P4 & P46 & P32 \\
\hline \multirow{2}{*}{$\begin{array}{c}\text { Fotografia } \\
\text { (RGB) }\end{array}$} & $65,23,27$ & $53,21,22$ & $42,20,15$ & $27,21,16$ & $47,47,37$ & $68,61,43$ \\
\hline & & & & & & \\
\hline \multirow{2}{*}{$\begin{array}{c}\text { Colorimetria } \\
\left(L^{*}, a^{*}, b^{*}\right)\end{array}$} & & & & & & \\
\hline & $26,7,3$ & $26,5,3$ & $26,2,3$ & $27,-1,3$ & - & - \\
\hline Ponto & P12 & P22 & P11 & P25 & P21 & P45 \\
\hline \multirow{2}{*}{$\begin{array}{c}\text { Fotografia } \\
\text { (RGB) }\end{array}$} & $110,102,54$ & $101,44,42$ & $25,17,11$ & $54,46,43$ & $37,34,31$ & $20,27,15$ \\
\hline & & & & & & \\
\hline \multirow{2}{*}{$\begin{array}{c}\text { Colorimetria } \\
\left(L^{*}, a^{*}, b^{*}\right)\end{array}$} & & & & & & \\
\hline & $44,7,24$ & $34,10,13$ & $26,0,2$ & $25,-1,1$ & $26,-2,1$ & $23,0,0$ \\
\hline \multirow{3}{*}{$\begin{array}{c}\text { Ponto } \\
\begin{array}{c}\text { Fotografia } \\
\text { (RGB) }\end{array} \\
\end{array}$} & P44 & P13 & P39 ; P 4 & 10 ; P47 & & \\
\hline & $26,19,13$ & $25,19,14$ & - & - & & \\
\hline & & & & & & \\
\hline \multirow{2}{*}{$\begin{array}{c}\text { Colorimetria } \\
\left(L^{*}, a^{*}, b^{*}\right)\end{array}$} & & & & & & \\
\hline & - & - & - & - & & \\
\hline
\end{tabular}




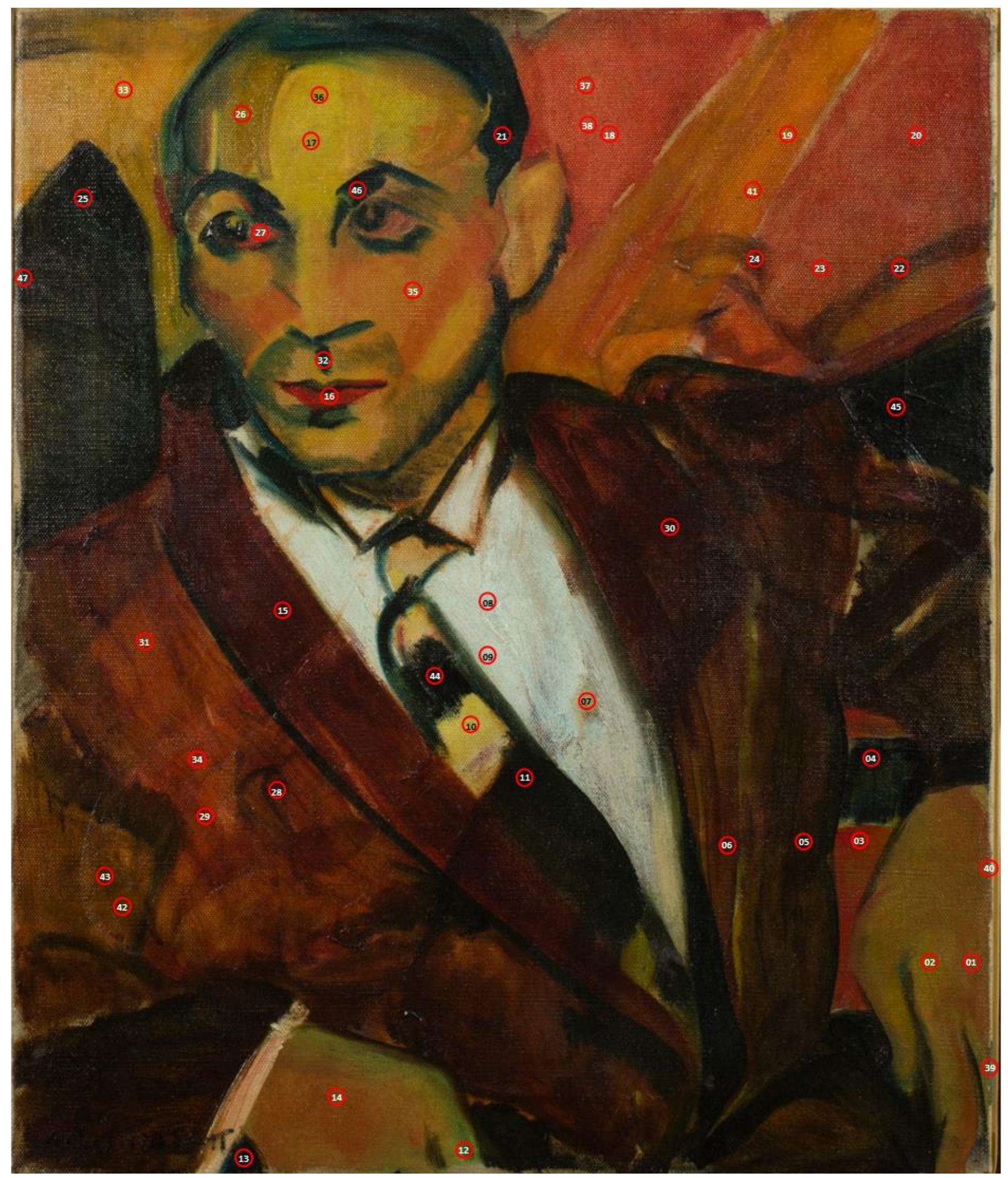

Figura 4.77 - Fotografia com os pontos de EDXRF medidos na obra "O Homem Amarelo" de Anita Malfatti (1915/1916, óleo sobre tela, 61x51cm) do acervo da Pinacoteca do Estado de São Paulo 


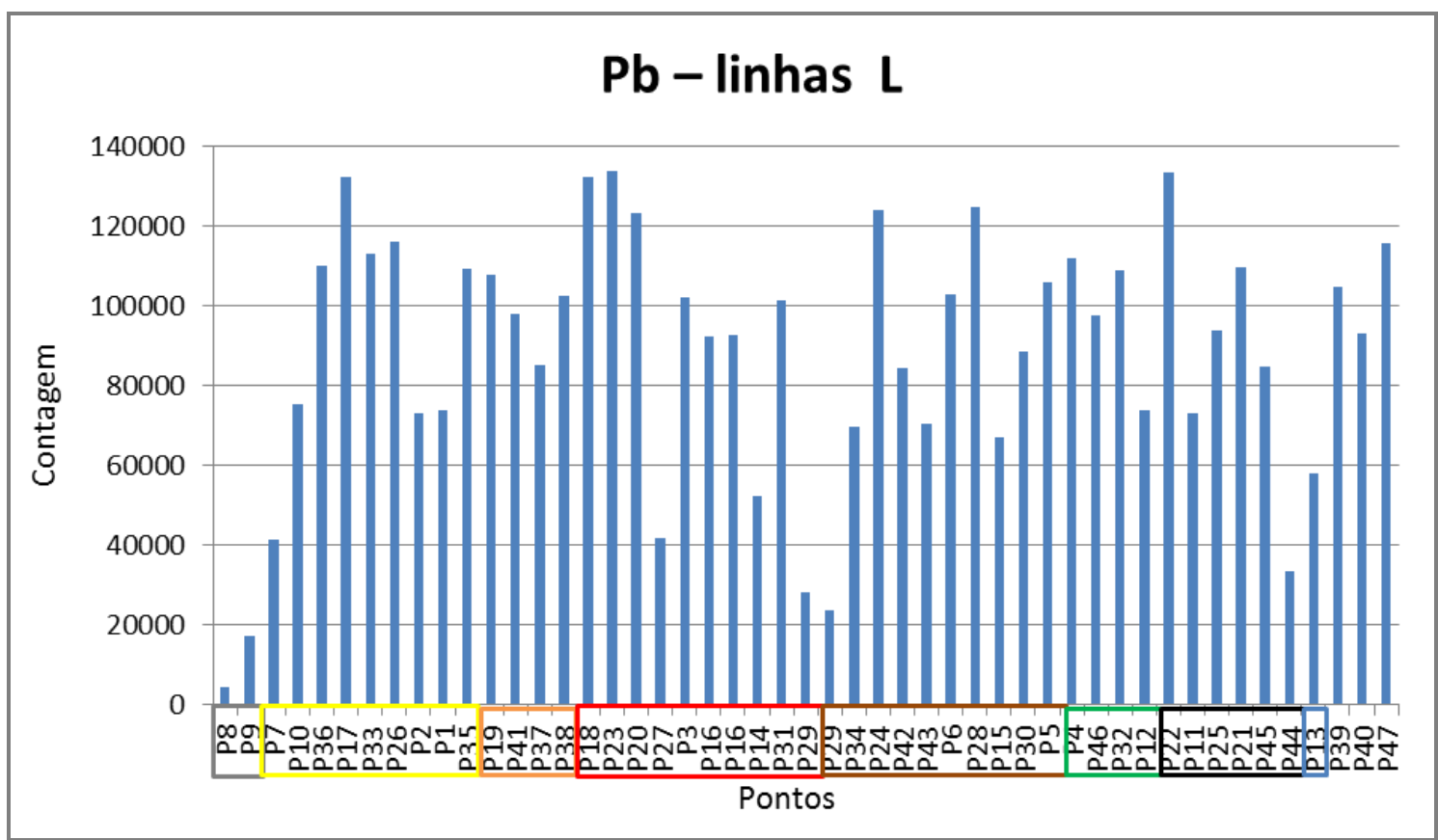

Figura 4.78 - Gráfico de barras das áreas do pico do Pb identificado nos espectros de EDXRF para os diferentes pontos medidos na obra "O Homem Amarelo" de Anita Malfatti (1915/1916) do acervo da Pinacoteca do Estado de São Paulo

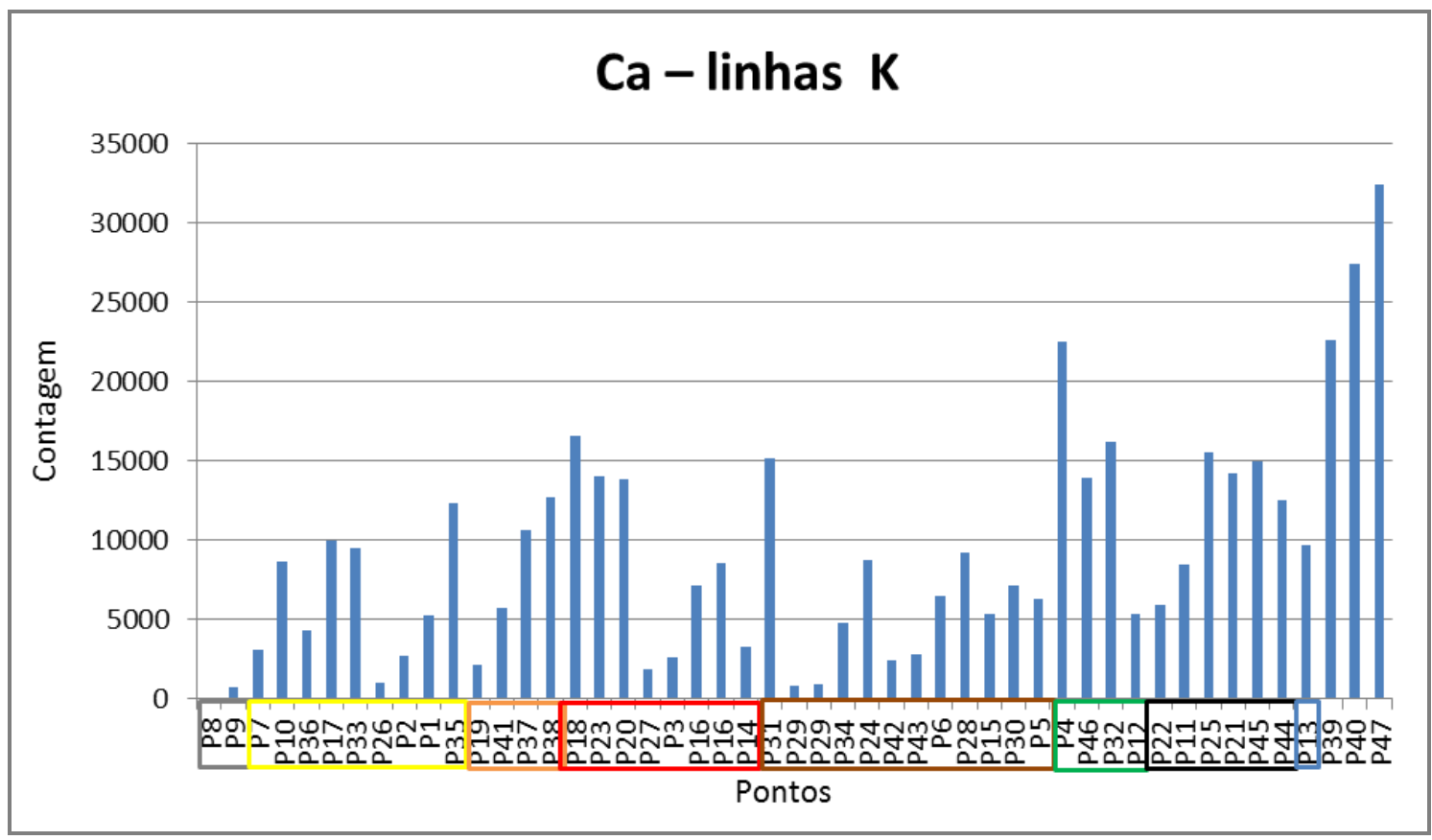

Figura 4.79 - Gráfico de barras das áreas do pico do Ca identificado nos espectros de EDXRF para os diferentes pontos medidos na obra "O Homem Amarelo" de Anita Malfatti (1915/1916) do acervo da Pinacoteca do Estado de São Paulo 


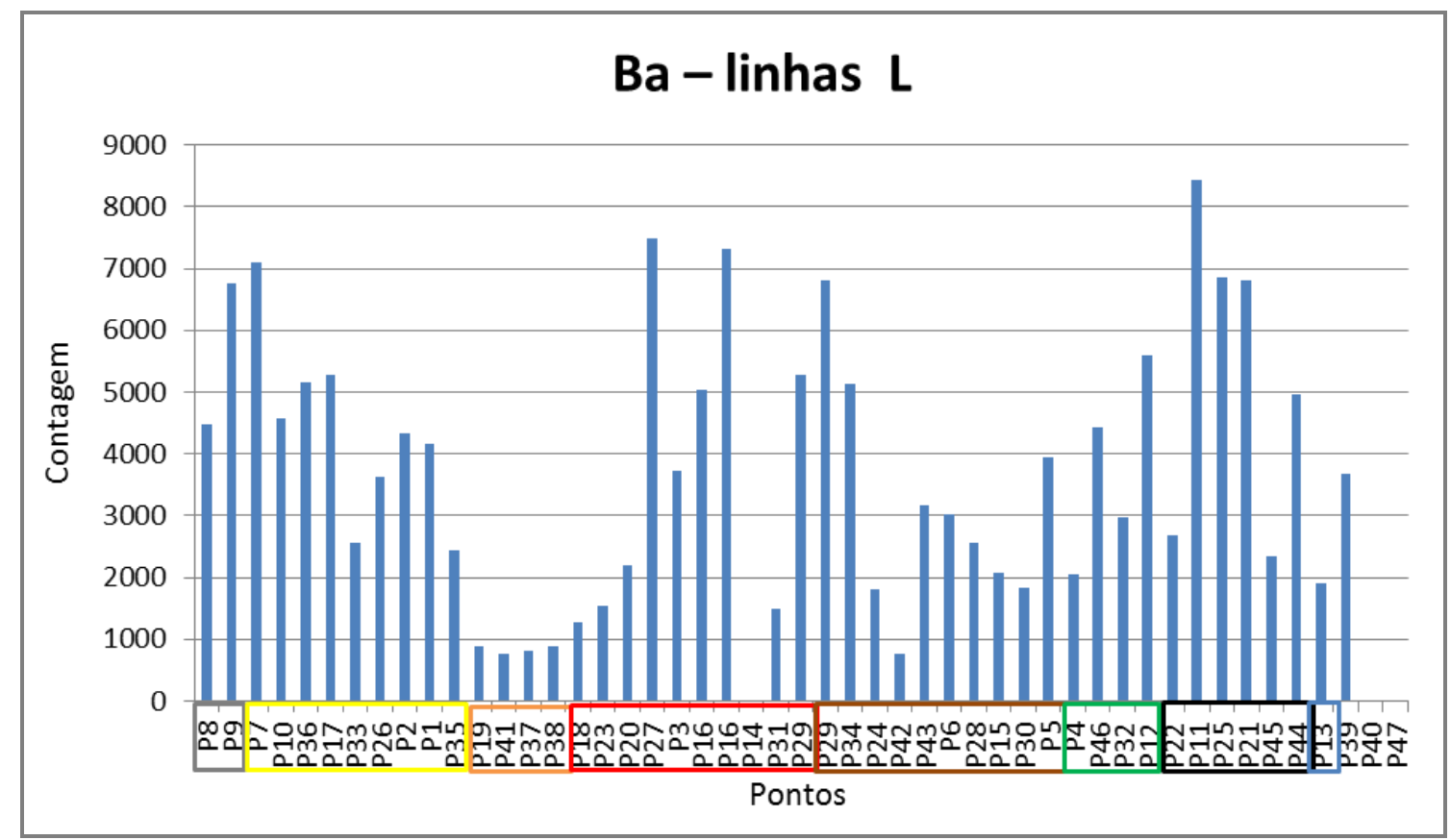

Figura 4.80 - Gráfico de barras das áreas do pico do Ba identificado nos espectros de EDXRF para os diferentes pontos medidos na obra "O Homem Amarelo" de Anita Malfatti (1915/1916) do acervo da Pinacoteca do Estado de São Paulo

Observando o zinco presente nesta obra, figura 4.81, podemos ver que nos pontos brancos P08 e P09 sua presença é destacada, assim como na região branca avermelhada do olho direito, P27. Além disso, o zinco está presente em outros pontos, como os marrons P29 e P34, próximos entre si. Isso é um indicação de que a artista tenha utilizado o branco de zinco na mistura com demais pigmentos, para compor as cores, ou as tintas utilizadas possuíam este pigmento na sua constituição, ou ainda, o branco de zinco esteja na pintura subjacente. 


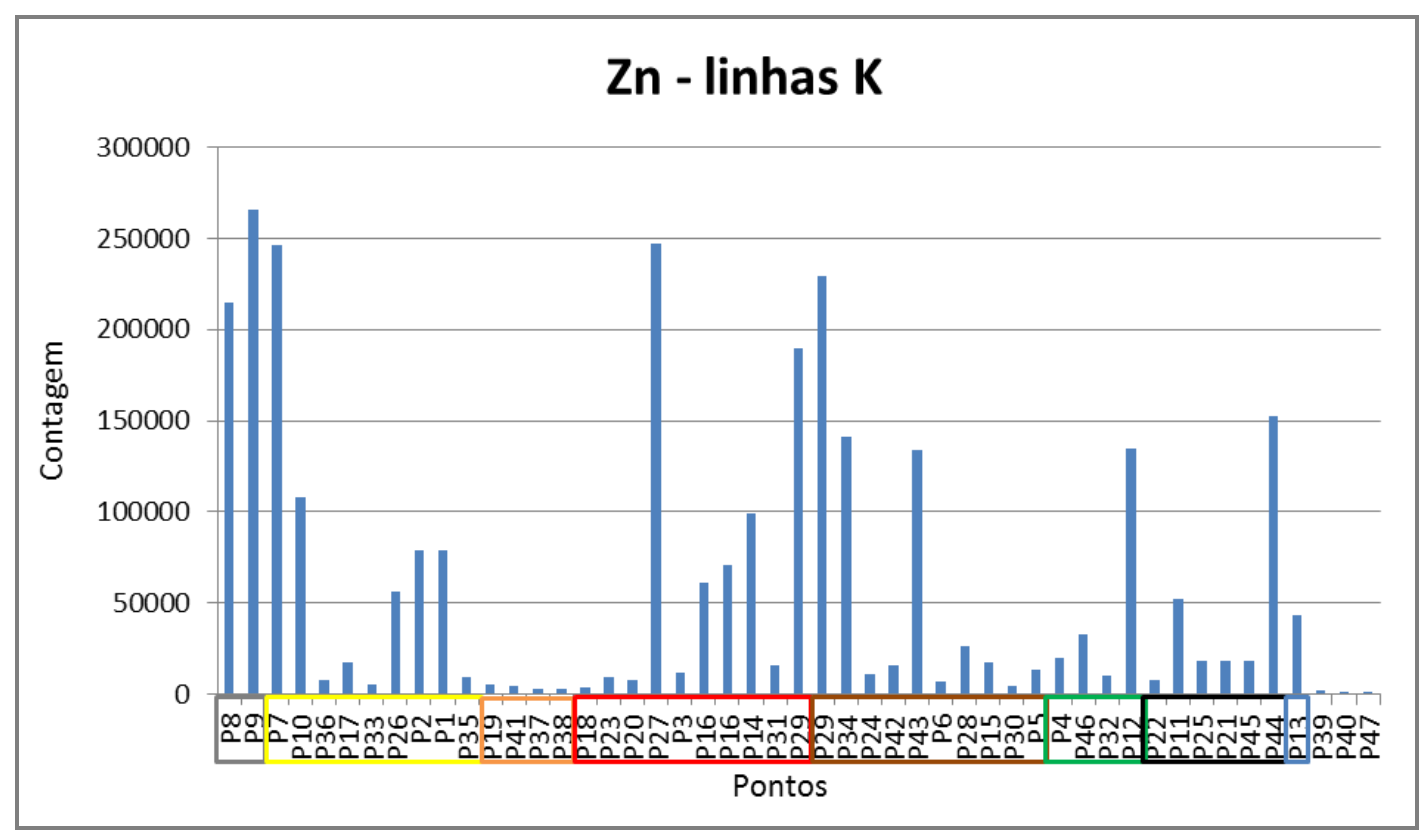

Figura 4.81 - Gráfico de barras das áreas do pico do Zn identificado nos espectros de EDXRF para os diferentes pontos medidos na obra "O Homem Amarelo" de Anita Malfatti (1915/1916) do acervo da Pinacoteca do Estado de São Paulo

Assim como o zinco, neste quadro o cromo está presente em muitos pontos, de diversas cores. Porém, este elemento tem destaque maior nos pontos amarelos, como pode ser visto na figura 4.82, Mas, nestas circunstâncias, onde temos a presença do $\mathrm{Pb}, \mathrm{Ba}$ e $\mathrm{Sr}$ nestes pontos (figuras $4.78,4.80,4.83)$ e em muitos outros do quadro, podem ter sua origem nos pigmentos: amarelo de cromo (2PbSO $\left.4 . \mathrm{PbCrO}_{4}\right)$, amarelo de estrôncio ( $\left.\mathrm{SrCrO}_{4}\right)$ e amarelo de bário (BaCrO4).

O cromo, como visto nas outras obras, também poderia estar associado às cores verdes. Entretanto, os pigmentos verdes utilizados nesta pinturas foram apenas em pequenos detalhes e estão muito próximos ou sobre áreas amarelas no quadro, logo, o cromo poderia ter sua origem nestes pigmentos amarelos. 


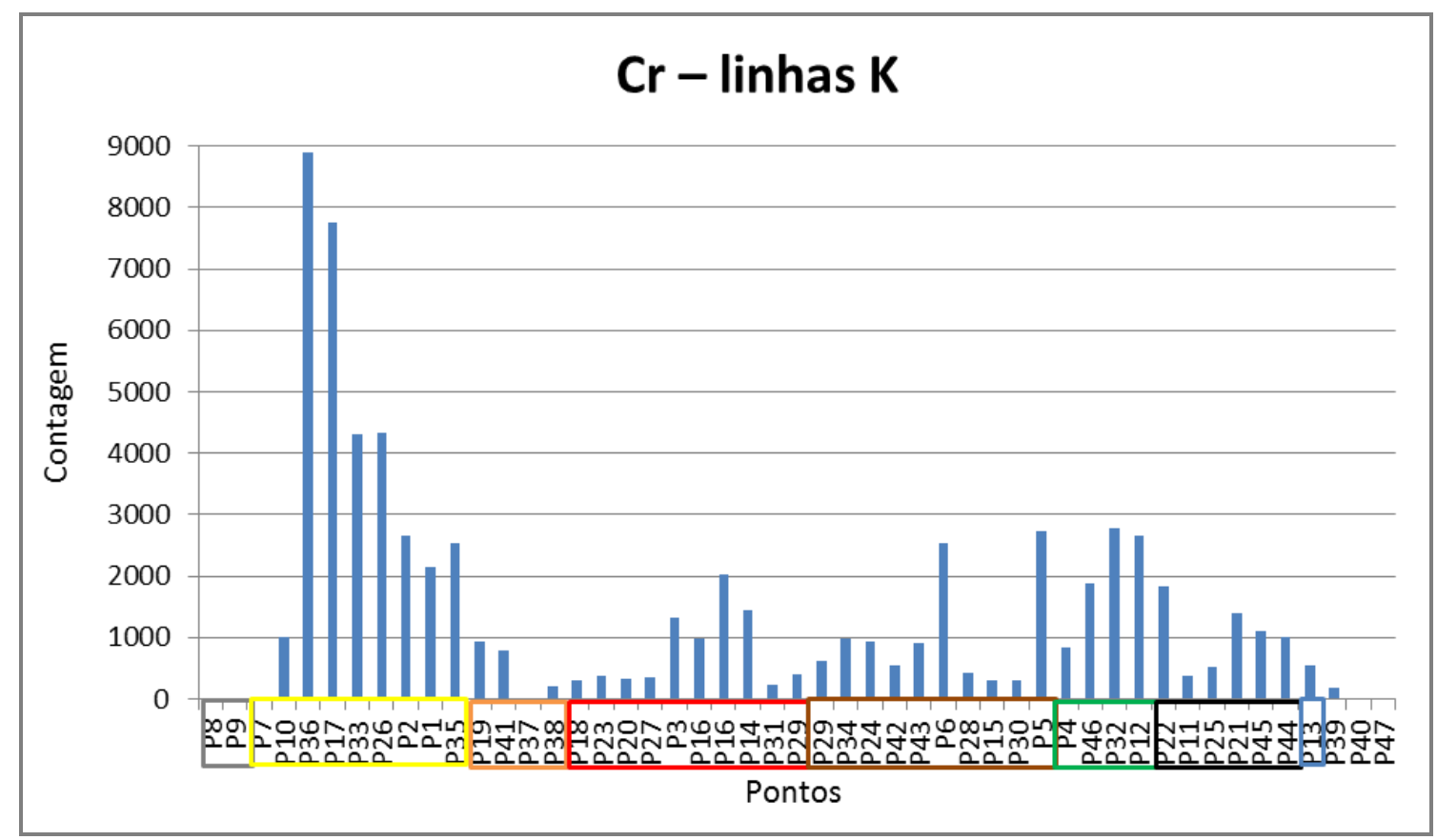

Figura 4.82 - Gráfico de barras das áreas do pico do Cr identificado nos espectros de EDXRF para os diferentes pontos medidos na obra "O Homem Amarelo" de Anita Malfatti (1915/1916) do acervo da Pinacoteca do Estado de São Paulo

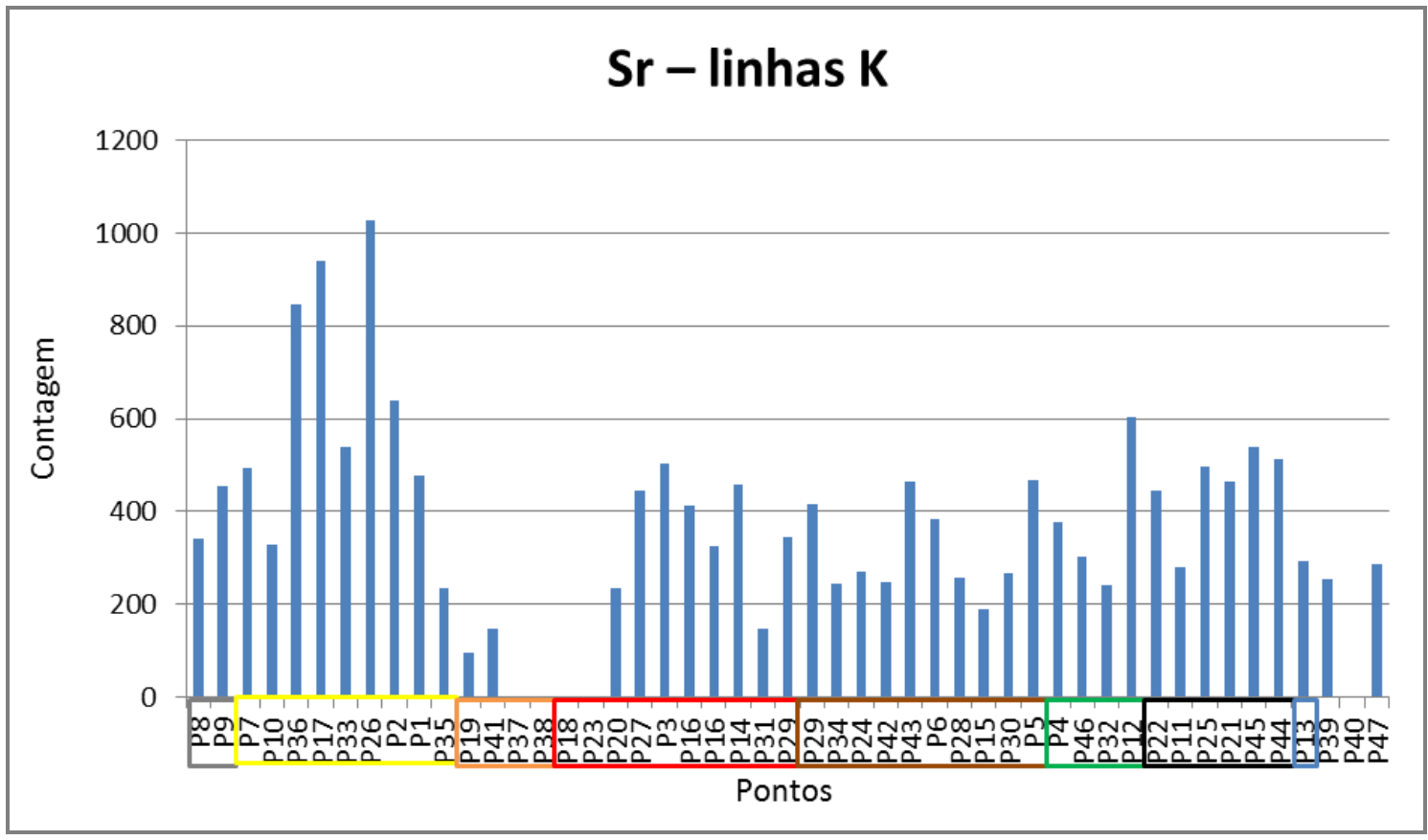

Figura 4.83 - Gráfico de barras das áreas do pico do Sr identificado nos espectros de EDXRF para os diferentes pontos medidos na obra "O Homem Amarelo" de Anita Malfatti (1915/1916) do acervo da Pinacoteca do Estado de São Paulo

Ao observarmos a figura 4.84, podemos ver que na obra "O Homem Amarelo" o ferro está presente nos pontos marrons e pretos. Esta presença nos permite afirmar, assim como nas demais obras, a presença dos pigmentos negros preto de ferro $\left(\mathrm{Fe}_{3} \mathrm{O}_{4}\right)$ e os marrons de óxido de ferro III $\left(\mathrm{Fe}_{2} \mathrm{O}_{3}\right)$. 


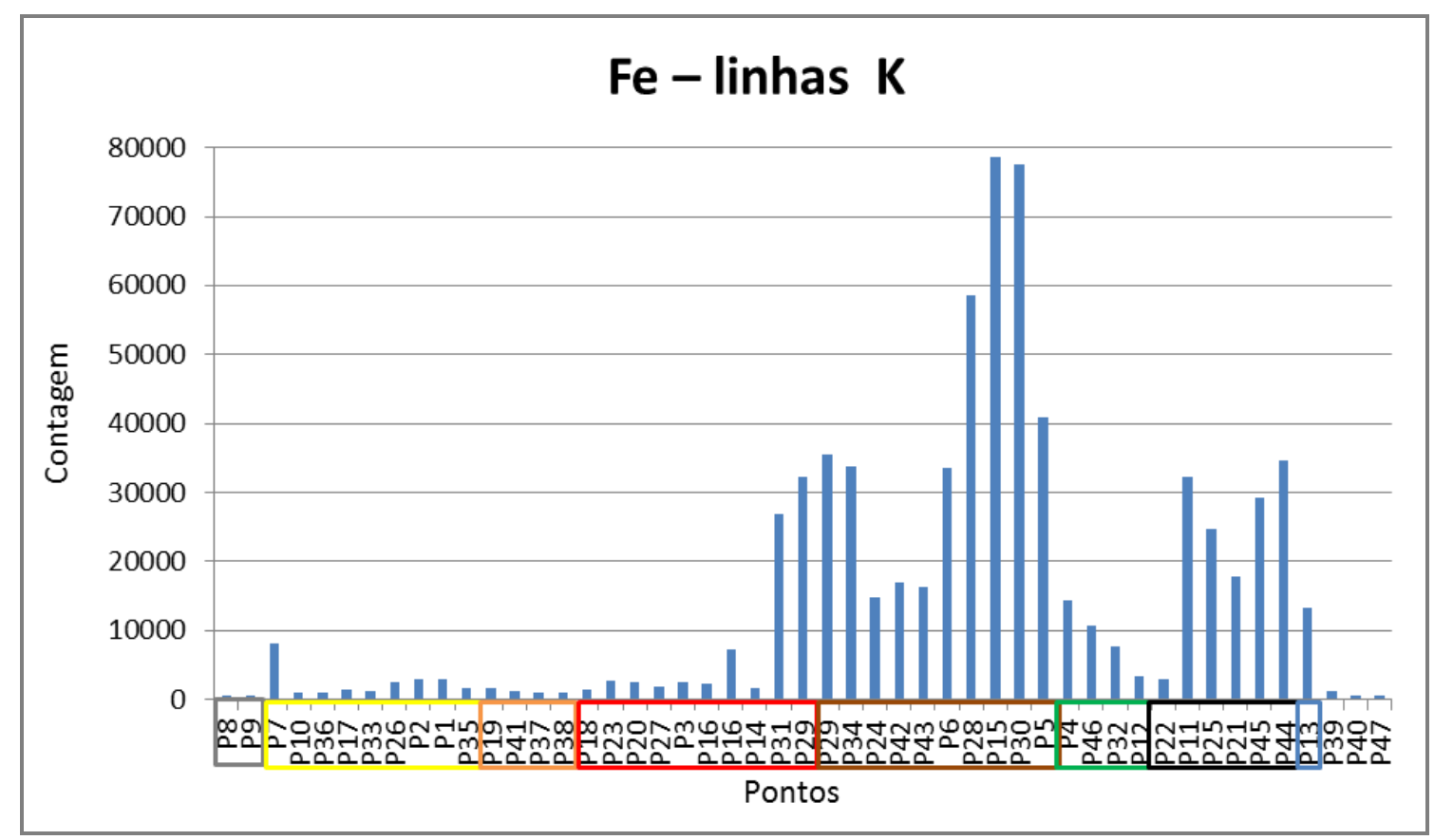

Figura 4.84 - Gráfico de barras das áreas do pico do Fe identificado nos espectros de EDXRF para os diferentes pontos medidos na obra "O Homem Amarelo" de Anita Malfatti (1915/1916) do acervo da Pinacoteca do Estado de São Paulo

O cádmio também está presente em diversos pontos com diversas cores (figura 4.85), mas tem um destaque maior em alguns pontos amarelos, laranjas, e marrons. Os pigmentos que possuem cádmio na sua formula também possuem o selênio em pigmentos para as cores vermelhas e laranjas. Desta maneira, apenas o amarelo de cádmio (CdS) pode estar presente nesta obra. Um pigmento que pode contribuir nas cores vermelhas, e compor as cores laranja, é o vermelhão (HgS), que estão presente na obra, como pode ser visto na figura 4.86 . 


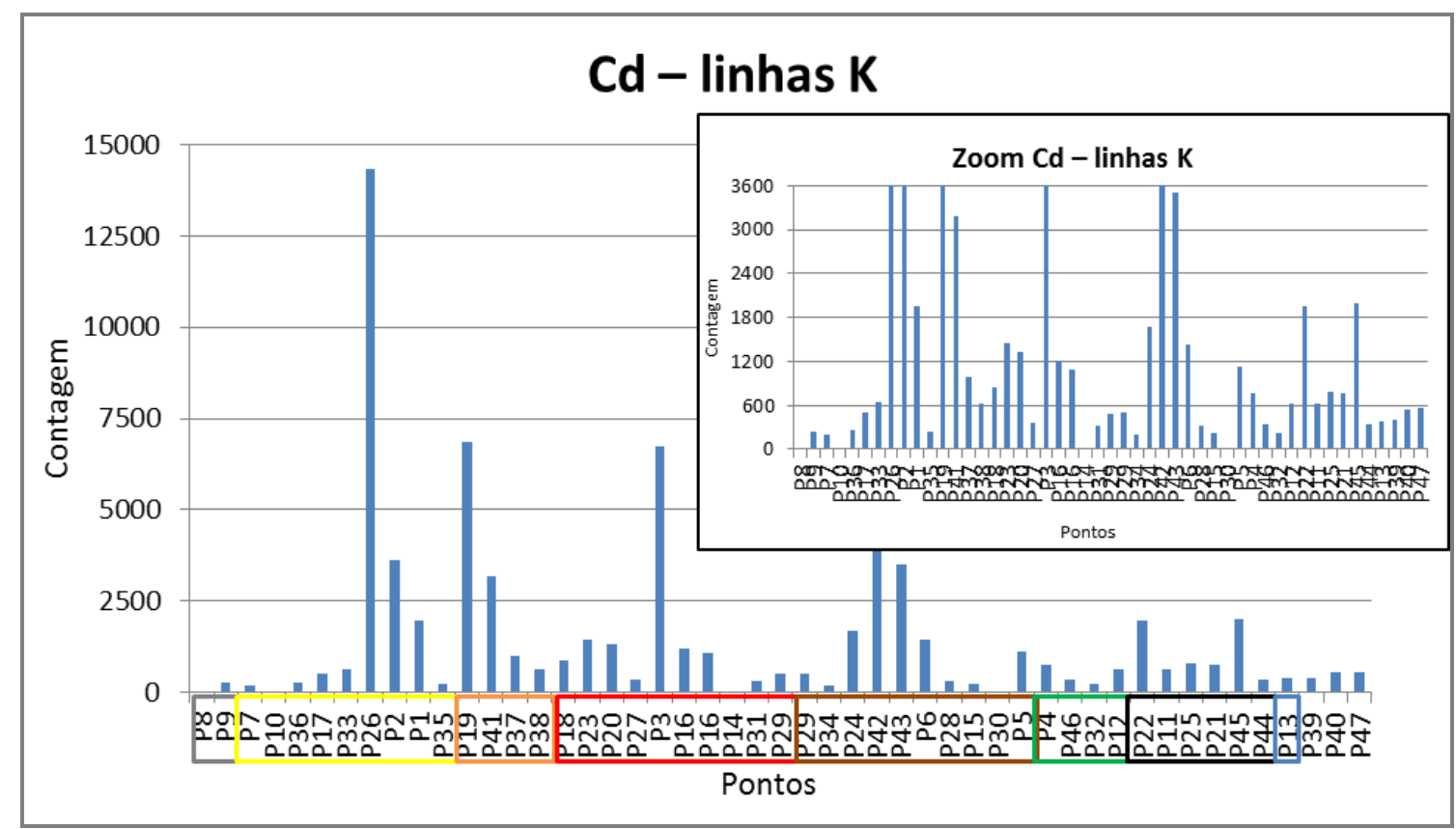

Figura 4.85 - Gráfico de barras das áreas do pico do Cd identificado nos espectros de EDXRF para os diferentes pontos medidos na obra "O Homem Amarelo" de Anita Malfatti (1915/1916) do acervo da Pinacoteca do Estado de São Paulo

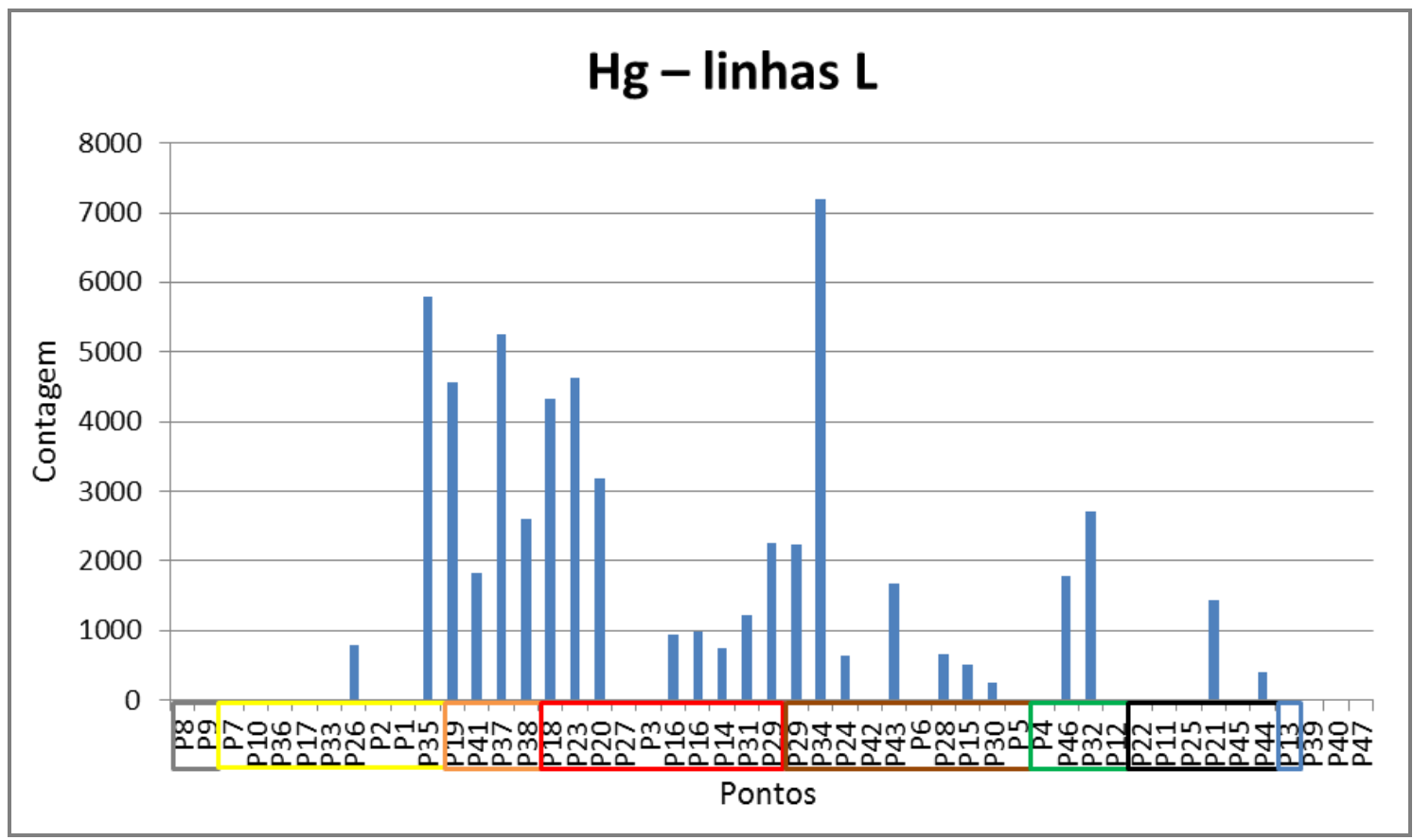

Figura 4.86 - Gráfico de barras das áreas do pico do Hg identificado nos espectros de EDXRF para os diferentes pontos medidos na obra "O Homem Amarelo" de Anita Malfatti (1915/1916) do acervo da Pinacoteca do Estado de São Paulo

O arsênio foi observado em apenas dois pontos (figura 4.87), ele está presente em alguns pigmentos vermelhos, laranjas e amarelos (As $\left.4 \mathrm{~S}_{4}\right)$. Nesta obra foi observado tal elemento nos pontos P15 e P30, que são dois pontos 
marrons de tons mais escuros. Desta forma, a artista pode ter usado nesta áreas um outro pigmento para mudar a cor final da tinta.

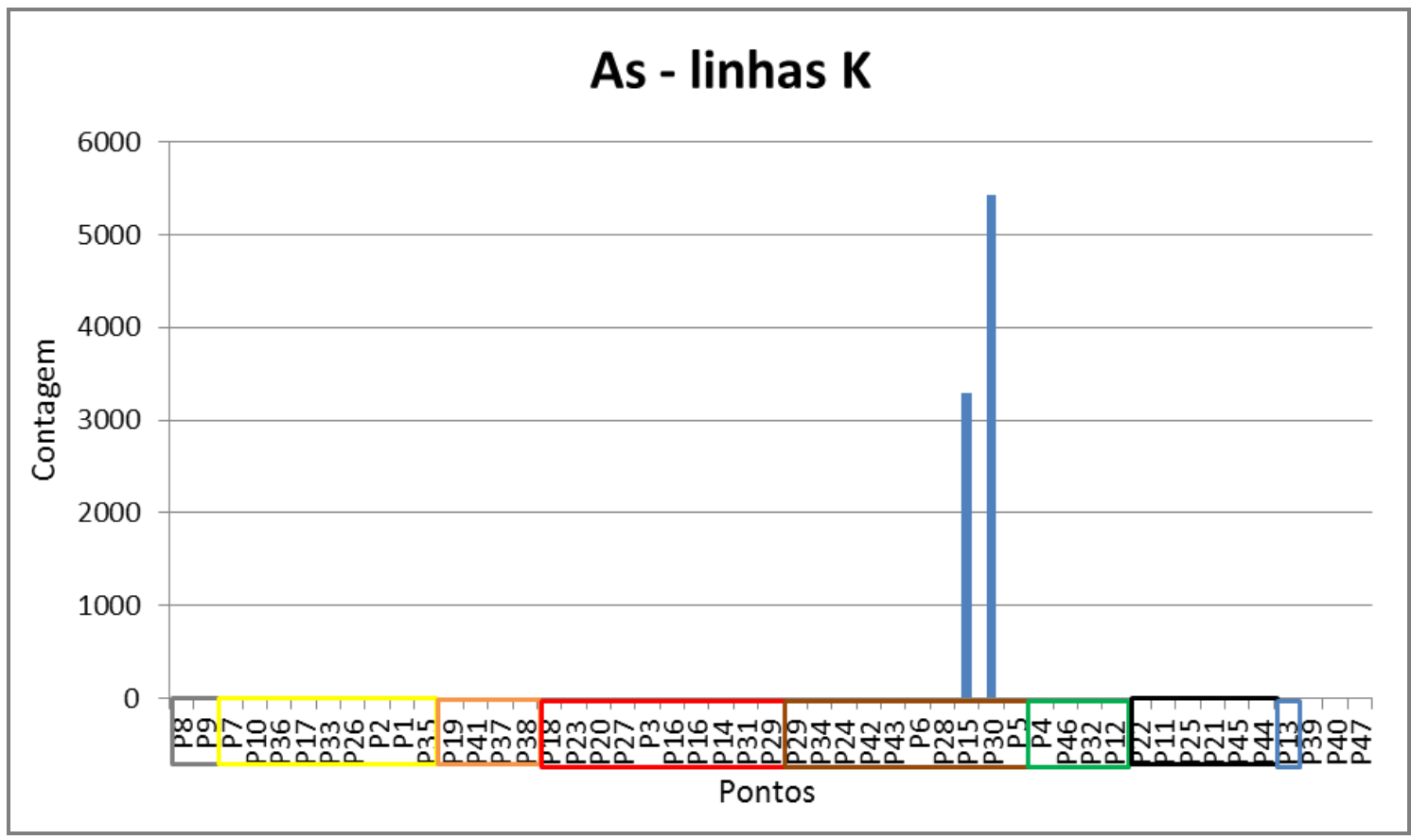

Figura 4.87 - Gráfico de barras das áreas do pico do As identificado nos espectros de EDXRF para os diferentes pontos medidos na obra "O Homem Amarelo" de Anita Malfatti (1915/1916) do acervo da Pinacoteca do Estado de São Paulo

Pela matriz (tabela 4.14) e gráfico de correlação (figura 4.88), podemos verificar que novamente o $\mathrm{Fe}$ e o As possuem uma correlação positiva $(0,666)$, que pode estar acompanhando os pigmentos marrons, mas o As está presente apenas em 2 pontos. Outra correlação positiva é entre o chumbo e 0 cálcio $(0,476)$, indicando novamente que o fundo possui estes elementos na composição. Entre os elementos $\mathrm{Cr}$ e $\mathrm{Sr}$ também há uma correlação positiva $(0,704)$, indicando a possível presença do amarelo de estrôncio $\left(\mathrm{SrCrO}_{4}\right)$.

Novamente encontramos uma correlação negativa $(-0,854)$ entre $\mathrm{Zn}$ e $\mathrm{Pb}$, mostrando que na maioria das vezes, quando se usa o zinco não se usa o chumbo. Desta forma, uma lista dos possíveis pigmentos presentes na obra encontra-se na tabela 4.15. 
Tabela 4.14 - Matriz de correlação dos elementos presentes nos pontos analisados por EDXRF na obra "O Homem Amarelo" de Anita Malfatti (1915/1916) do acervo da Pinacoteca do Estado de são Paulo

\begin{tabular}{l|r|r|r|r|r|r|r|r|r|r|r|r|} 
variable & $\mathrm{Ca}-\mathrm{K}$ & $\mathrm{Cr}-\mathrm{K}$ & $\mathrm{Fe}-\mathrm{K}$ & $\mathrm{Co}-\mathrm{K}$ & $\mathrm{Zn}-\mathrm{K}$ & $\mathrm{As}-\mathrm{K}$ & $\mathrm{Br}-\mathrm{K}$ & $\mathrm{Sr}-\mathrm{K}$ & $\mathrm{Cd}-\mathrm{K}$ & $\mathrm{Ba}-\mathrm{L}$ & $\mathrm{Hg}-\mathrm{L}$ & $\mathrm{Pb}-\mathrm{L}$ \\
\hline $\mathrm{Ca}-\mathrm{K}$ & 1,000 & $-0,172$ & $-0,112$ & $-0,001$ & $-0,524$ & $-0,076$ & $-0,153$ & $-0,359$ & $-0,301$ & $-0,363$ & 0,024 & 0,476 \\
\hline $\mathrm{Cr}-\mathrm{K}$ & $-0,172$ & 1,000 & $-0,204$ & $-0,068$ & $-0,203$ & $-0,124$ & 0,117 & 0,704 & 0,169 & 0,174 & $-0,156$ & 0,325 \\
\hline $\mathrm{Fe}-\mathrm{K}$ & $-0,112$ & $-0,204$ & 1,000 & $-0,087$ & $-0,026$ & 0,666 & $-0,125$ & $-0,089$ & $-0,194$ & 0,054 & $-0,084$ & $-0,141$ \\
\hline $\mathrm{Co}-\mathrm{K}$ & $-0,001$ & $-0,068$ & $-0,087$ & 1,000 & 0,054 & $-0,041$ & $-0,042$ & $-0,046$ & $-0,110$ & $-0,009$ & $-0,137$ & $-0,130$ \\
\hline $\mathrm{Zn}-\mathrm{K}$ & $-0,524$ & $-0,203$ & $-0,026$ & 0,054 & 1,000 & $-0,133$ & 0,051 & 0,245 & $-0,148$ & 0,599 & $-0,098$ & $-0,854$ \\
\hline $\mathrm{As}-\mathrm{K}$ & $-0,076$ & $-0,124$ & 0,666 & $-0,041$ & $-0,133$ & 1,000 & $-0,041$ & $-0,114$ & $-0,114$ & $-0,145$ & $-0,095$ & $-0,048$ \\
\hline $\mathrm{Br}-\mathrm{K}$ & $-0,153$ & 0,117 & $-0,125$ & $-0,042$ & 0,051 & $-0,041$ & 1,000 & 0,187 & 0,119 & 0,067 & $-0,138$ & $-0,094$ \\
\hline $\mathrm{Sr}-\mathrm{K}$ & $-0,359$ & 0,704 & $-0,089$ & $-0,046$ & 0,245 & $-0,114$ & 0,187 & 1,000 & 0,331 & 0,485 & $-0,498$ & $-0,087$ \\
\hline $\mathrm{Cd}-\mathrm{K}$ & $-0,301$ & 0,169 & $-0,194$ & $-0,110$ & $-0,148$ & $-0,114$ & 0,119 & 0,331 & 1,000 & $-0,135$ & 0,013 & 0,224 \\
\hline $\mathrm{Ba}-\mathrm{L}$ & $-0,363$ & 0,174 & 0,054 & $-0,009$ & 0,599 & $-0,145$ & 0,067 & 0,485 & $-0,135$ & 1,000 & $-0,222$ & $-0,424$ \\
\hline $\mathrm{Hg}-\mathrm{L}$ & 0,024 & $-0,156$ & $-0,084$ & $-0,137$ & $-0,098$ & $-0,095$ & $-0,138$ & $-0,498$ & 0,013 & $-0,222$ & 1,000 & 0,167 \\
\hline $\mathrm{Pb}-\mathrm{L}$ & 0,476 & 0,325 & $-0,141$ & $-0,130$ & $-0,854$ & $-0,048$ & $-0,094$ & $-0,087$ & 0,224 & $-0,424$ & 0,167 & 1,000
\end{tabular}

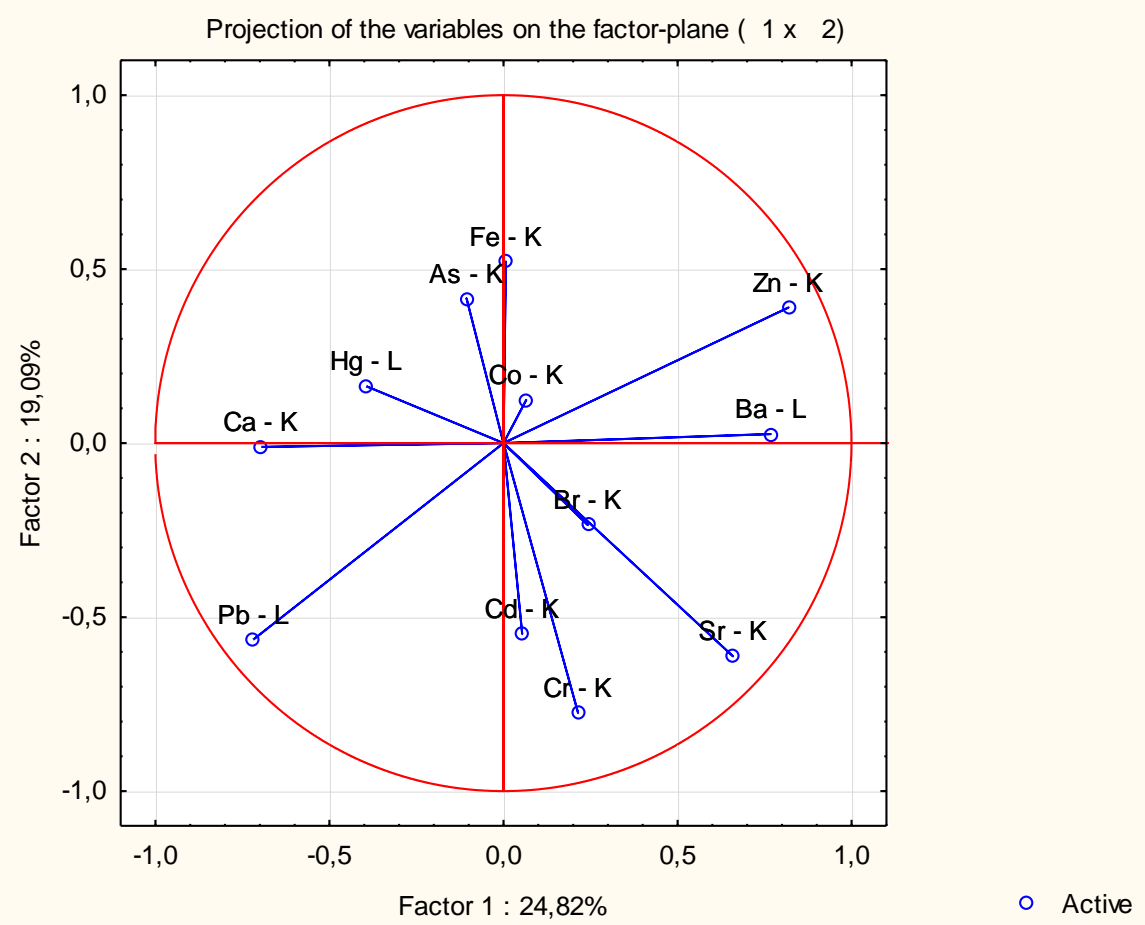

Figura 4.88 - Gráfico da correlação por PCA entre os elementos presentes nos espectros de EDXRF pontos medidos na obra "O Homem Amarelo" de Anita Malfatti (1915/1916) do acervo da Pinacoteca do Estado de São Paulo 
Tabela 4.15 - Possíveis pigmentos utilizados por Anita Malfatti na obra "O Homem Amarelo" de Anita Malfatti (1915/16, óleo sobre tela, 61×51 cm) do acervo do IEB-USP (JANSSENS, 2004; STUART, 2008; VASCONCELOS et al., 1992; MAYER, 2006; LFNATEC, 2009)

\begin{tabular}{|c|c|c|c|c|}
\hline Cor & $\begin{array}{l}\text { Elementos } \\
\text { Presentes }\end{array}$ & $\begin{array}{c}\text { Composição } \\
\text { Química }\end{array}$ & $\begin{array}{l}\text { Nome do } \\
\text { Pigmento }\end{array}$ & $\begin{array}{c}\text { Empregado } \\
\text { desde }\end{array}$ \\
\hline Brancos & $\mathrm{Zn}$ & $\mathrm{ZnO}$ & $\begin{array}{l}\text { Branco de } \\
\text { Zinco }\end{array}$ & Século 19 \\
\hline \multirow{2}{*}{ Amarelos } & $\mathrm{Cd}$ & CdS & $\begin{array}{l}\text { Amarelo de } \\
\text { Cádmio }\end{array}$ & Século 19 \\
\hline & $\mathrm{Cr}$ & $\mathrm{SrCrO}_{4}$ & $\begin{array}{c}\text { Amarelo de } \\
\text { Estrôncio }\end{array}$ & Século 19 \\
\hline \multirow{2}{*}{ Vermelhos } & $A s^{*}$ & \multicolumn{3}{|c|}{ Indeterminado } \\
\hline & $\mathrm{Hg}, \mathrm{S}$ & $\mathrm{HgS}$ & Vermelhão & Século 13 \\
\hline Verdes & \multicolumn{4}{|c|}{ Indeterminado } \\
\hline Pretos & $\mathrm{Fe}$ & $\mathrm{Fe}_{3} \mathrm{O}_{4}$ & $\begin{array}{l}\text { Preto de } \\
\text { Ferro }\end{array}$ & Século 19 \\
\hline Marrons & $\mathrm{Fe}$ & $\mathrm{Fe}_{2} \mathrm{O}_{3}$ & $\begin{array}{c}\text { Oxido de } \\
\text { Ferro; Siena }\end{array}$ & Século 19 \\
\hline \multirow{2}{*}{ Base } & $\mathrm{Ca}$ & $\begin{array}{c}\mathrm{CaCO}_{3} \mathrm{ou} \\
\mathrm{CaSO}_{4.2 \mathrm{H}_{2} \mathrm{O}}\end{array}$ & & Minério \\
\hline & $\mathrm{Pb}$ & $2 \mathrm{PbCO}_{3} \cdot \mathrm{Pb}(\mathrm{OH})_{2}$ & $\begin{array}{l}\text { Branco de } \\
\text { Chumbo }\end{array}$ & Antiguidade \\
\hline
\end{tabular}

*Este pode ter sua origem em um pigmento amarelo ou laranja

Desta forma, a Tabela 4.16 nos ajuda a sistematizar e correlacionar os elementos químicos aos pigmentos sugeridos para cada obra. Resumidamente estão listados nesta tabela os possíveis pigmentos encontrados nas obras da artista Anita Malfatti analisadas que são sugeridos por diferentes autores (JANSSENS, 2004; STUART, 2008; VASCONCELOS et al., 1992; MAYER, 2006; LFNATEC, 2009). 
Tabela 4.16 - Lista de pigmentos que podem estar presentes nas obras analisadas a partir dos elementos químicos encontrados nas analises por EDXRF, sendo as obras identificadas como "O Japonês" (J), "A Estudante Russa" (ER), "Retrato do Mário de Andrade" (RMA), "O Homem Amarelo" (HA) e "Tropical" (T). (JANSSENS, 2004; STUART, 2008; VASCONCELOS et al., 1992; MAYER, 2006; LFNATEC, 2009)

\begin{tabular}{|c|c|c|c|c|c|}
\hline Cor & \begin{tabular}{|l|} 
Elementos \\
Presentes
\end{tabular} & Composição Química & $\begin{array}{l}\text { Nome do } \\
\text { Pigmento }\end{array}$ & $\begin{array}{c}\text { Empregado } \\
\text { desde }\end{array}$ & Obras \\
\hline \multirow{4}{*}{ Brancos } & $\mathrm{Zn}$ & $\mathrm{ZnO}$ & $\begin{array}{c}\text { Branco de } \\
\text { Zinco }\end{array}$ & Século 19 & $\begin{array}{c}\text { J, ER }{ }^{1}, \mathrm{RMA}, \\
\text { HÁ, T }\end{array}$ \\
\hline & $\mathrm{Ba}, \mathrm{Sr}$ & $\mathrm{BaSO}_{4}+\mathrm{SrSO}_{4}$ & Barita & Mineral & $\mathrm{J}^{1}, \mathrm{ER}^{1}, \mathrm{RMA}^{1}$ \\
\hline & $\mathrm{Pb}$ & $2 \mathrm{PbCO}_{3} \mathrm{~Pb}(\mathrm{OH})_{2}$ & $\begin{array}{c}\text { Branco de } \\
\text { Chumbo }\end{array}$ & Antiguidade & J, RMA, T \\
\hline & $\mathrm{Zn}, \mathrm{Ba}$ & $\mathrm{ZnS}+\mathrm{BaSO}_{4}$ & Litopônio & Século 19 & $\mathrm{~J}$ \\
\hline \multirow{3}{*}{ Amarelos } & Cd & $\begin{array}{c}\text { CdS, ou } \\
\mathrm{CdS}+\mathrm{BaSO}_{4}\end{array}$ & $\begin{array}{l}\text { Amarelo de } \\
\text { Cádmio }\end{array}$ & Século 19 & $\mathrm{~J}^{2}, \mathrm{RMA}^{4}, \mathrm{HA}$ \\
\hline & $\mathrm{Cr}, \mathrm{Sr}$ & $\mathrm{SrCrO}_{4}$ & $\begin{array}{l}\text { Amarelo de } \\
\text { Estrôncio }\end{array}$ & Século 19 & $\mathrm{~J}, \mathrm{HA}$ \\
\hline & $\mathrm{Cr}, \mathrm{Ba}$ & $\mathrm{BaCrO}_{4}$ & $\begin{array}{c}\text { Amarelo de } \\
\text { Bário (amarelo } \\
\text { de limão) }\end{array}$ & Século 19 & $J$ \\
\hline \multirow{2}{*}{ Vermelhos } & $A s^{5}$ & $\mathrm{As}_{2} \mathrm{~S}_{3}$ & Realgar & Mineral & $\mathrm{HA}$ \\
\hline & $\mathrm{Hg}$ & $\mathrm{HgS}$ & Vermelhão & Século 13 & J, ER, RMA, HA \\
\hline Verdes & $\mathrm{Cr}$ & $\mathrm{Cr}_{2} \mathrm{O}_{3}$ & $\begin{array}{l}\text { Óxido de } \\
\text { Cromo }\end{array}$ & Século 19 & $\mathrm{~J}, \mathrm{ER}, \mathrm{RMA}, \mathrm{T}$ \\
\hline \multirow{2}{*}{ Azuis } & Co & $\mathrm{CoO} . \mathrm{Al}_{2} \mathrm{O}_{3}$ & Azul de Cobalto & Século 18 & RMA \\
\hline & $\mathrm{Fe}$ & $\mathrm{Fe}_{4}\left[\mathrm{Fe}(\mathrm{CN})_{6}\right]_{3}$ & Azul da Prússia & Século 18 & $J^{3}$ \\
\hline \multirow{2}{*}{ Pretos } & $\mathrm{Fe}$ & $\mathrm{Fe}_{3} \mathrm{O}_{4}$ & Preto de Ferro & Mineral & $\begin{array}{c}J, E R, \underset{T}{R M A}, H A, \\
T\end{array}$ \\
\hline & $\mathrm{C}$ & $\mathrm{C}$ & Preto de Osso & Antiguidade & $\mathrm{J}^{6}, \mathrm{ER}$ \\
\hline Marrons & $\mathrm{Fe}$ & $\mathrm{Fe}_{2} \mathrm{O}_{3}$ & $\begin{array}{c}\text { Óxido de Ferro; } \\
\text { Siena }\end{array}$ & Século 19 & $\begin{array}{c}\mathrm{J}, \mathrm{ER}, \mathrm{RMA}, \mathrm{HA}, \\
T\end{array}$ \\
\hline Violeta & Co & $\mathrm{Co}_{3}\left(\mathrm{PO}_{4}\right)_{2}$ & \begin{tabular}{c|} 
Violeta de \\
Cobalto \\
\end{tabular} & Século 19 & $\mathrm{~T}$ \\
\hline \multirow{4}{*}{ Base } & \multirow{2}{*}{$\mathrm{Ca}$} & $\mathrm{CaCO}_{3}$ & Calcita & Mineral & \multirow{2}{*}{ J, ER, RMA, HA } \\
\hline & & $\mathrm{CaSO}_{4} .2 \mathrm{H}_{2} \mathrm{O}$ & Gesso & Mineral & \\
\hline & $\mathrm{Pb}$ & $2 \mathrm{PbCO}_{3} \mathrm{~Pb}(\mathrm{OH})_{2}$ & $\begin{array}{c}\text { Branco de } \\
\text { Chumbo }\end{array}$ & Antiguidade & J, ER, RMA, HA \\
\hline & $\mathrm{Ba}, \mathrm{Sr}$ & $\mathrm{BaSO}_{4}+\mathrm{SrSO}_{4}$ & Barita & Mineral & RMA \\
\hline
\end{tabular}

${ }^{1} \mathrm{Na}$ composição de algumas tintas; ${ }^{2}$ Pode também conter BaSO4 na composição; ${ }^{3}$ Pode também ser a forma $\mathrm{KFeFe}(\mathrm{CN})_{6} ;{ }^{4}$ Pode conter o $\mathrm{Zn} ;{ }^{5}$ Pode ser amarelo e laranja também; ${ }^{6}$ Presença inferida pelas imagens de reflectografia no infravermelho 
Bases

Óxido de Cálcio ou Gesso

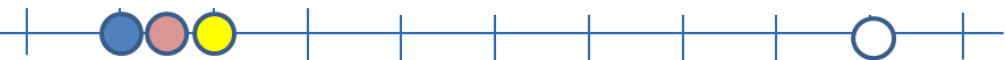

Branco de Chumbo

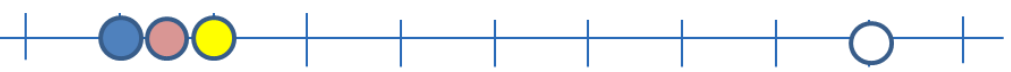

Barita

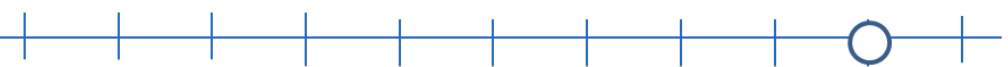

\section{Brancos}

Branco de Zinco

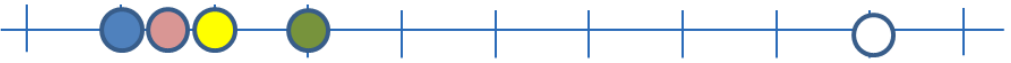

Branco de Chumbo

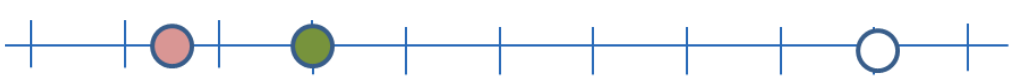

\section{Barita*}

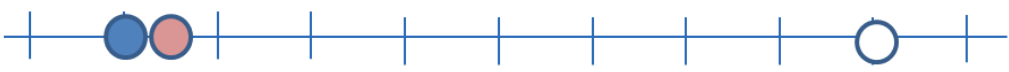

"O Homem Amarelo"

"Tropical"

"Retrato de Mário de Andrade"

Litopônio*

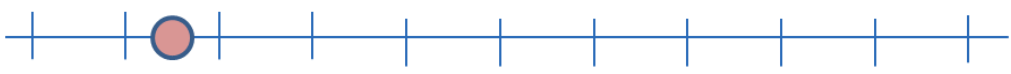

\section{Amarelos}

Amarelo de Cádmio

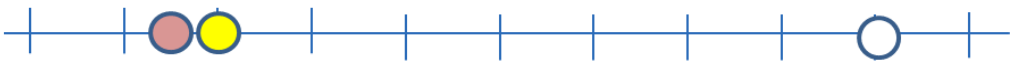

Amarelo de Estrôncio

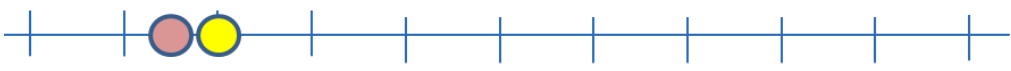

Amarelo de Bário

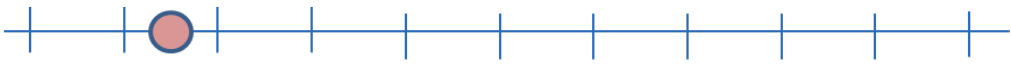

Figura 4.89: Esquema de distribuição temporal do uso dos pigmentos utilizados pela artista Anita Malfatti para obras aqui estudadas, na ordem de cima para baixo: Bases de preparação; pigmentos brancos; pigmentos amarelos 
$\underline{\text { Verdes }}$

Óxido de Cromo

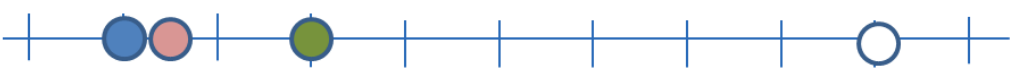

Azuis

Azul da Prússia

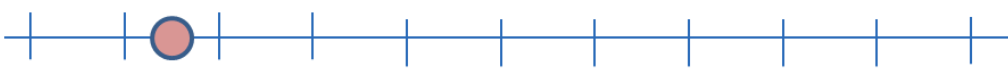

Azul de Cobalto

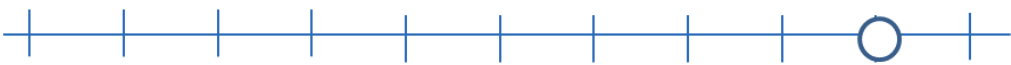

$\underline{\text { Violetas }}$

Violeta de Cobalto

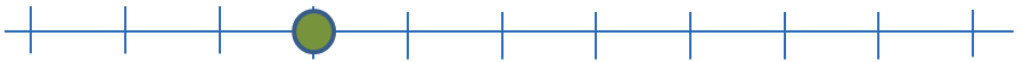

"A Estudante Russa"

"O Japonês"

"O Homem Amarelo"

"Tropical"

"Retrato de Mário de Andrade"

\section{Marrons}

Óxido de Ferro

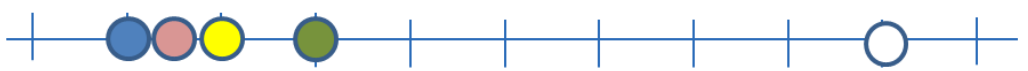

Pretos

Preto de Ferro

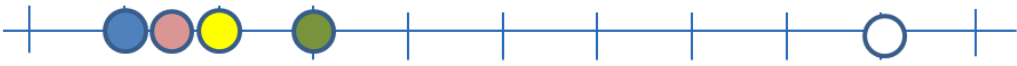

Preto de Carbono

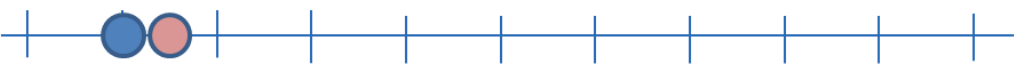

Figura 4.90: Esquema de distribuição temporal do uso dos pigmentos utilizados pela artista Anita Malfatti para obras aqui estudadas, na ordem de cima para baixo: pigmento verde; pigmentos azuis; pigmento violeta; pigmento marrom; pigmentos pretos 
As figuras 4.89 e 4.90 são esquemas gráficos da distribuição temporal dos resultados obtidos e listados na tabela 4.16, que ilustram o uso dos pigmentos pela artista nas cinco obras estudadas.

Pelos resultados, vemos que a barita foi utilizada em algumas obras tanto na composição do fundo da tela quanto associada aos pigmentos em algumas tintas utilizadas. A barita é um pó branco, mas sem poder corante, que pode ser usada como pigmento inerte em tintas para diminuir seu poder tintorial, principalmente associada a pigmentos orgânicos.

Pigmentos inertes são pigmentos brancos ou quase brancos que possuem baixos índices refrativos. São usados para conceder propriedades às tintas e pigmentos como volume, rigidez, reforço de película, aspereza, nivelamento da potência tintorial, etc. Em uma composição de cor por mistura os pigmentos precisam ter potência tintorial parecida, pois se um é muito mais forte que os demais, fica difícil realizar uma mistura adequada. Os pigmentos inertes também são usados como barateadores e adulterantes de tintas (MAYER, 2006)

A barita também pode ser usada como base de lacas. Isto é, uma base mineral inerte (inerte não no sentido químico, mas no sentido de não alterar muito a cor), onde são impregnados corantes orgânicos. A laca é um pigmento obtido pela precipitação ou fixação de um corante orgânico sintético ou natural sobre um pigmento inerte ou laca-base (barita, argila, silicato de alumínio, gipsita, etc).

Assim como a barita, o blanc fixe é composto por sulfato de bário, mas de origem artificial, sendo muito mais fino e volumoso que as baritas naturais, que possuem maior quantidade de estrôncio associado. O blanc fixe tem a mesma composição química, mas é completamente diferente em qualidade de pigmento e não é considerado adulterante, pois confere boas qualidades de resistência a ação do tempo. 
Observando a tabela 4.16 e as figura 4.89, vemos que a barita não foi associada às obras "O Homem Amarelo" e "Tropical", que possuem pentimentos visíveis a olhos nus. Logo, talvez não seja a baixa qualidade dos pigmentos utilizados, mas sim devido ao processo de envelhecimento da parcela orgânica que compões as tintas utilizadas.

Se a artista utilizou tintas com pigmentos orgânicos, como as lacas, há a possibilidade destes pigmentos terem sofrido uma exsudação, processo pelo qual as tintas a óleo perdem seu poder de recobrimento com o tempo, pela alteração do seu índice de refração que diminui com o tempo por causa da exsudação do óleo, permitindo a visualização de figuras subjacentes (MAYER, 2006). 


\section{CONCLUSÃO}

Dispõe-se atualmente de técnicas que permitem analisar diferentes materiais sem coletar amostras, sem precisar desmembrar o material, sem danificá-lo e sem tocá-lo, o que é de suma importância principalmente em análises dos materiais presentes nas obras, principalmente aquelas que possuem relevante valor histórico cultural. A grande e real vantagem de análises não destrutivas e com equipamentos portáteis é que a peça é analisada por inteiro, no próprio local, seja no acervo, ou na exposição, mantendo e preservando sua integridade. Há, portanto, um extenso caminho recém-aberto e promissor envolvendo estas novas tecnologias de análises e muito a ser feito, construído e superado em relação a estes estudos.

Umas das dificuldades encontradas nas nossas pesquisas realizadas foram as grossas camadas de verniz que cobriam as telas estudadas. Camadas estas usadas para proteger e preservar as obras, mas capazes de dificultar as análises, principalmente no caso de fotografias (luz visível e mais fortemente no caso da florescência de ultravioleta), pois produzem um reflexo muito intenso. Dificultaram também nas medidas de colorimetria, onde as cores encontradas pela técnica de espectrofotometria dos pontos analisados foram diferentes das cores obtidas nas imagens de fotografia. As cores observadas nestas medidas geralmente possuíam uma tonalidade mais escura, aparentando a presença de uma velatura sobre a cor, provavelmente devido à grossa camada de verniz. Desta forma, sugerimos que o melhor momento para a utilização de tais técnicas de imageamento para registro e análise deve ser realizada durante o processo de restauro, quando geralmente há uma remoção parcial do verniz facilitando a visualização e medida das cores mais fidedignamente.

Para as técnicas de imageamento com luz visível e ultravioleta, o carbono não é detectado, mas como existem informações que este pode ser utilizado por artistas para traçar desenhos, é muito importante utilizar técnicas que permitam esta identificação. Buscando algumas respostas sobre desenhos ou repinturas nas obras de Anita Malfatti, utilizou-se a reflectografia por 
infravermelho e radiografia para complementar as analises de imageamento. Através das imagens de reflectografia das obras foi possível registrar desenhos presentes nos quadros, o que indica que estes podem ser compostos por carbono. As imagens com luz tangencial também auxiliaram na determinação de imagens subjacentes e a radiografia digitalizada complementou 0 detalhamento da imagem escondida.

A técnica de EDXRF permitiu a caracterização dos elementos químicos presentes nas tintas analisadas das diferentes obras. Todos os pigmentos sugeridos que potencialmente estão presentes nas obras analisadas são apresentados. Não houve nenhum pigmento que discordasse dos materiais utilizados na época em que são datadas as obras analisadas. A presença de barita indica a utilização de algumas tintas que não são de alta qualidade (MAYER, 2006).

As técnicas de pintura não recomendam a reutilização de telas quando se pretende produzir uma obra com o intuito de que esta seja preservada por um longo tempo. Particularmente, os quadros da Anita, que possuem claramente uma figura subjacente, foram pintados em um contexto de prática como estudante de pintura, onde a questão da preservação da obra em longo prazo era menor. Com o passar do tempo, o índice de refração dos materiais pode se alterar, e uma camada fina de tinta que antes era suficiente para formar uma película opaca torna-se transparente e permite que se visualizem as subpinturas, ou os pentimentos, realizados pela artista. Normalmente este fenômeno de transparência acontece onde há pigmentos brancos ou cores reduzidas com bastante branco, ou em tintas óleos a base de pigmentos orgânicos (MAYER, 2006), o que parece ser o caso das obras da artista Anita Malfatti.

Nas obras analisadas, todas tinham em comum um fundo de preparação à base de branco de chumbo e carbonato de cálcio, ou sulfato de cálcio. Em comparação com os artistas do mesmo período, verificamos que o branco de chumbo era um recurso comum nas produções dos fundos (CAMPOS et al., 2013; CALZA et al., 2010). No entanto em alguns casos como a obra "Primeira Missa no Brasil" de Vitor Meireles (CALZA, 2007b), alguns pontos sugeriram a 
utilização do cálcio no seu fundo de preparação, semelhantemente ao que acontece nos quadro de Anita Malfatti.

As análises estatísticas realizadas foram excelentes ferramentas para corroborar a correlação existente entre alguns elementos químicos e deste modo ajudar a solucionar algumas dúvidas existentes. As análises auxiliaram na exclusão ou a indicação de alguns pigmentos presentes em determinadas obras e reforçaram a presença de outros. 


\section{REFERÊNCIAS}

ALMEIDA, P. M De Anita ao Museu. São Paulo: Perspectiva, 1976

AMPTEK, disponível em: <http://www.amptek.com>. Acessado em: ago. de 2014.

ANDRADE, M. de. Anita Malfatti, Jornal de Debates, São Paulo, 5 de out. 1921.

ANDRADE, M. Cartas a Anita Malfatti. Rio de Janeiro: Forense Universitária, 1989.

APPOLONI, C. R.; PARREIRA, P. S. Doze Anos de Atividade em Arte e Arqueometria no Laboratório de Física Nuclear Aplicada da Universidade Estadual de Londrina, Revista Brasileira de Arqueometria, Restauração e Conservação, v. 1, n. 6, pp. 301-304, 2007.

APPOLONI, C. R.; LOPES, F.; BRUNO, M. A. Analysis of the painting 'Moema' by PXRF, TXRF and Raman Spectroscopy. In: Karen Barbosa. (Org.). Moema restauração / restoration, p. 59-78. Comunique Editorial, São Paulo, 2013.

ASPEREN DE BOER, J. R. J. Infrared Reflectography: A Contribution to the Examination of Earlier European Paintings. Central Research Laboratory for Objects of Art and Science: Amsterdam, The Netherlands. 1970.

BALAS, C.; PAPADAKIS, V.; PAPADAKIS, N.; PAPADAKIS, A.; VAZGIOURAKI, E.; THEMELIS, G. A novel hyper-spectral imaging apparatus for the nondestructive analysis of objects of artistic and historic value. Journal of Cultural Heritage, v. 4, p. 330-337, 2003.

BARNES, P. L. Infrared Radiation in the Examination of Works of Art. 1994.

BATISTA, M. R.; LIMA, Y. S. Coleção Mário de Andrade: Artes Plásticas. Instituto de Estudos Brasileiros, Universidade de São Paulo, São Paulo, 1998.

BATISTA, M. R. Anita no tempo e no espaço: biografia e estudo da obra. São Paulo: Ed.34/EDUSP, 2006.

BERTIN, E. P. Principles and practice of X-ray spectrometry, 2 ed., New York: Plenum, 1975.

BUSER, H. J., SCHWARZENBACH, D., PETTER, W., LUDI, A.The Crystal Structure of Prussian Blue: Fe4[Fe(CN)6] $3^{*} \times \mathrm{H} 20$. Inorganic Chemistry, v.16, n. 11, pp. 2704-2710, 1977.

BUTCHER, K.; PONTING, M.; CHANDLER, G. A study of the chemical composition of Roman silver coinage, AD 196-197'. American Journal of Numismatics, v. 9, p. 17-36, 1997.

C2RMF - Centre de Recherche et de Restauration des Musées de France. Disponível em: <www.c2rmf.fr>. Acesso em: 2 junho 2013.

CABRAL, J. M. P. Exame Científico de Pinturas de Cavalete. Fundação Caloute Gulbenkian Publisher, Conferência, disponível em: <http://hdl.handle.net/123456789/214 >. Acesso em: jun. de 2013. 
CAHAN, D. Hermann Von Helmholtz and the Foundations of Nineteenth-century Science. University of California Press, 1993.

CALLIGARO, T.; DRAN, J.-C.; SALOMON, J. Ion beam microanalysis. In: JANSSENS, K.; GRICKEN, R. V. (Org.). Non-destructive microanalysis of cultural heritage materials, v. 42, Elsevier, cap. 5, p. 227-276, 2004

CALZA, C. F.; ANJOS, M.J.; LOPES, R.T.,"X-Ray Fluorescence analysis in pigments from sarcophagus cartonage of an Egyptian mummy". Activity Report Laboratório Nacional de Luz Síncrotron, v. 1, pp.1, 2004.

CALZA, C. F.; ANJOS, M.J.; MENDONÇA DE SOUZA S.M.F.; BRANCAGLION JR., A.; LOPES, R.T., "Pigments analysis in cartonages of an Egyptian mummy of the Roman Period using X-Ray Fluorescence Spectrometry". Journal of Biological Research, v. LXXX, pp. 136-138, 2005.

CALZA, C. F.; ANJOS, M.J.; BRANCAGLION JR., A.; MENDONÇA DE SOUZA S.M.F.; LIMA, T.A.; LOPES, R.T., "Fluorescência de Raios X aplicada à Arqueometria". Revista Brasileira de Arqueometria, Restauração e Conservação, v. 1, pp. 338-342, 2007a.

CALZA, C. F., Desenvolvimento de um Sistema Portátil de Fluorescência de Raios $X$ com Aplicações em Arqueometria, Tese (Doutorado) - COPPE, Universidade Federal do Rio de Janeiro, 2007b.

CALZA, C., PEDREIRA, A., LOPES, R.T. Analysis of paintings from the nineteenth century Brazilian painter Rodolfo Amoedo using EDXRF portable system. X-ray Spectrometry. 38, 327-332, 2009.

CALZA, C.; OLIVEIRA D. F.; ROCHA, H. S.; PEDREIRA, A.; LOPES, R. T. Analysis of the painting "Gioventu"' (Eliseu Visconti) using DXRF and computed radiography. Applied Radiation and Isotopes 68, pp. 861-865, 2010

CAMARgo, A. P. Anita Malfatti: A Festa da Cor. São Paulo: ed. Terceiro Nome, 2009.

CAMARGOS, Márcia. Semana de 22 entre vaias e aplausos. São Paulo: Boitempo Editorial, 2003.

CAMPOS, P.H.O.V.; KAJIYA, E.A.M.; RIZZUTTO, M.A.; NEIVA, A.C.; PINTO, H.P.F.; ALMEIDA, P.A.D. X-ray Fluorescence and Imaging Analyses of Paintings by the Brazilian Artist Oscar Pereira Da Silva. Radiation Physics and Chemistry, v. 95, pp. 362-367, 2013.

CESAREO, R. X-ray physics: Interaction with matter, production, detection. La Revista del Nuovo Cimento, Ed. Compositori, Bologna, Itália, 2000.

CHIARELLI, T. Um jeca nos vernissages: Monteiro Lobato e o desejo de uma arte nacional no Brasil. São Paulo: EDUSP, 1995.

CHIARELLI, T. Arte internacional brasileira. São Paulo: Lemos, p. 165-167, 1999.

CHIARELLI, T. Tropical, de Anita Malfatti: Reorientando uma velha questão. Estudos Novos, v. 80, pp. 163-172, 2008. 
CHIARELLI, T. De Anita à Academia: Para repensar a história da arte no Brasil, Novos Estudos, v. 88, pp.113-132, 2010.

CIE, Comission Internationale de L'éclairage. Industrial Colour-Difference Evaluation. Viena, Austria: CIE 116-1995, 1995.

CIE, Comission Internationale de L'éclairage. CIE Colorimetry - Part 4: $1976 L^{*} a^{*} b^{*}$ Colour Space, Disponível em: <http://cie.co.at/index.php?i ca id=485> (Acessado em: jun. 2015)

COMPTON A. H. A quantum theory of the scattering of $\mathrm{X}$-rays by light elements. Physical Review, v. 21, n. 5, p. 483-502, 1923.

CREAGH, D. C.; BRADLEY D. A. Radiation in Art and Archeometry.

Elsevier, Amsterdam, 2000.

CURADO, J. F. Estudo e Caracterização de cerâmicas indígenas brasileiras. Tese (Doutorado), São Paulo, Universidade de São Paulo, 2012.

DE ANDRADE, M. Fazendo História, Folha da Manhã, São Paulo, 24 de agosto de 1944.

DIN. DEUTSCHE INSTITUT für NORMUNG. DIN 6174. Farbmetrische Bestimmung von Farbabständen Bei Körperfarben nach der CIELAB-Formel. Berlim und Köln: Beuth Verlag, 1979.

EDWARDS, H. G. M.; MIDDLETON, P.; JORGE VILLAR, S.E. e FARIA, D.L.A., "Romano-British Wall Paintings II: Raman Spectroscopic Analysis of the Whitehall Farm Villa Site", Analytica Chim. Acta 484, pp. 211, 2003.

FAEPAH, Núcleo de Pesquisa de Física Aplicada ao Estudo do Patrimônio Artístico e Histórico, 2012, USP, São Paulo, disponível em: $<$ http://www.usp.br/faepah>. Acessado em: jun. de 2015.

FARIA D. L. A.; EDWARDS, H.G.M. Raman Spectroscopy: application for the nondestructive chemical analysis of Prehistoric Archaeological Pigments and Biomaterials. Asian Chemistry Letters, India, v. 5, p. 145, 2001.

FARIA, D .L. A.; AFONSO, M. C.; EDWARDS, H. G.M., "Espectroscopia Raman: uma nova luz no estudo de bens culturais", Revista do MAE 12, pp. 249, 2003.

FARIA, D. L. A.; EDWARDS, H. G. M.; AFONSO, M. C.; BRODY R.H. e MORAIS, J. L., "Raman spectroscopic analysis of a tembetá: a resin archaeological artefact in need of conservation", Spectrochim. Acta A 60 (7), 1505-1513, 2004.

FRANCISCO DE ASSIS, R. Diccionario technico e historico de pintura, esculptura, architectura e gravura. Lisboa, Imprensa nacional, 1875.

FREITAS, R. P. Aplicações De Técnicas Nucleares E Espectroscopia Molecular Em Arqueometria. Tese (Doutorado) - COPPER, Universidade Federal do Rio de Janeiro, Rio de Janeiro, 2014.

GRANDIS, L. D. Theory and Use of Color. New York, Ed. Harry N. Abrams, 1986. 
GREGGIO, L. P. Anita Malfatti - Tomei a Liberdade de Pintar a Meu Modo. São Paulo: ed. Magma Cultural, 2007.

GREGGIO, L. P., Anita Malfatti. Coleção Folha Grandes Pintores Brasileiros, v. 9. Folha de São Paulo, São Paulo, 2013.

HERNÁNDEZ, R. P. B.; NeIVA, A. C.; SALGUEIREDO, C. F.; MELO, H. G. Espectroscopia de impedância eletroquímica de pátinas artificiais produzidas sobre cobre e bronze quando expostas a soluções de cloreto de sódio de modo contínuo ou intermitente. III Simpósio de Técnicas Avançadas em Conservação de Bens Culturais. Recife : Agência de Estudos e Restauro do Patrimônio - AERPA, 2006.

HUBIN, A.; TERRYN, H. X-ray photoelectron and Auger electron spectroscopy. In: JANSSENS, K.; GRICKEN, R. V. (Org.). Non-destructive microanalysis of cultural heritage materials, v. 42, Cap. 6, p. 277-312. Elsevier, 2004.

HUNT, R. W. G. The Reproduction of Colour. v. 6, Ed. Wiley, England, 2004.

JANSSENS, K. X-ray based methods of analysis. In: JANSSENS, K.; GRICKEN, R. V. (Org.). Non-destructive microanalysis of cultural heritage materials, v. 42, Elsevier, Amsterdam, 2004, cap. 4, p. 129-226, 2004.

JENKINS, R.; GOULD, R.W.; GEDCKE, D. Quantitative X-Ray Spectrometry, Marcel Dekker, Inc. New York and Basel, 1981.

KAJIYA, E. A. M.; CAMPOS, P. H. O. V.; RIZZUTTO, M. A.; APPOLONI, C. R.; LOPES, F. Evaluation of the veracity of one work by the artist Di Cavalcanti through non-destructive techniques: XRF, imaging and brush stroke analysis. Radiation Physics and Chemistry, v. 95, pp. 373-377, 2013.

KONICA-MINOLTA, disponível em: <http://www.konicaminolta.eu>. Acessados em: set. de 2014.

KORTRIGHT, J. B.; THOMPSON, A. C. X-ray emission energies. In: THOMPSON, A. C.; ATTWOOD D. T.; GULLIKSON E. M.; HOWELLS M. R.; KORTRIGHT, J. B.; ROBINSON A. L.; UDERWOOD, J. H.; KIM, K. -J.; KIRZ J.; LINDAU, I.; PIANETTA, P.; WINICK, H.; WILLIAMS G.; SCOFIELD J. H.; VAUGHAN, D. X-Ray Data Booklet. Lawrence Berkeley National Laboratory, University of California, Berkeley, seção 1.2, 2001.

LAPAC - Rede de Laboratórios com Aplicações em Patrimônio Cultural no Brasil, disponível em: <http://www.dfn.if.usp.br/lapac/>. Acessados em: abr. de 2015.

LEÃO, A. C.; ARAÚJO A. de .A; SOUZA L. A. C. Implementação de Sistemas de Gerenciamento de Cores para Imagens Digitais. Ed. PUC-Minas, Poços de Caldas. Cap. 3, pp.61-96, 2005.

LEITE, F. N., Calibração de Dispositivos a Cores Utilizando uma Câmera Digital. Dissertação (Mestrado), Universidade de Brasília. Brasília, 2006. 
LFNATEC, Pigmentos; Propriedades Físicas, Químicas e o Período Histórico de Utilização. Publicação Técnica do Laboratório de Física nuclear Aplicada, v. 13, n.01, UEL, Londrina, 2009.

LOBATO, Monteiro. Paranoia ou mistificação? In: Ideias de Jeca Tatu, São Paulo: Monteiro Lobato \& Cia., 3ª edição,1922.

LONGAIR, M. Light and Colour. Colour: Art \& Science, Cambridge University Pree, Cambridge, 1995.

LUKICHEVA, K., "Artistic expertise and restoration", In: Conservation and Restoration of pictorial Art. IIC, Butterworth's, London, pp. 553-554, 1987.

MALFATTI, D. Minha Tia Anita Malfatti. São Paulo: ed. Terceiro Nome, 2009.

MAXWELL, J. C. A Dynamical Theory of the Electromagnetic Field .Philosophical Transactions of the Royal Society of London, v. 155, pp. 459-512, 1865.

MAYER, R. Manual do Artista. Martins ed., 2006.

MINGOTI, S. A. Análise de dados através de métodos de estatística multivariada, Editora UFMG, 2007.

MOENS, L.; BOHLEN, A. V.; VANDENABEELE, P. X-ray fluorescence. In: CILIBERTO, E.; SPOTO, G. (Ed.) Modern Analytical Methods in Art and Archaeology, v. 155, In: Chemical Analysis, p. 55-79. John Wiley \& Sons, 2000.

NASCIMENTO FILHO, V. F. Técnicas analíticas nucleares de fluorescência de raios $X$ por dispersão de energia (ED-XRF) e reflexão total (TXRF). Piracicaba: CENA-ESALQ/USP, 1999.

NATIONAL PHYSICAL LABORATORY. Tables of Physical \& Chemical Constants (16 ${ }^{\text {th }}$ edition 1995). 2.1.4 Hygrometry. Kaye \& Laby Online. Version 1.0, disponível em: <www.kayelaby.npl.co.uk>. 2005.

NAVE, C. R. Compton scattering data, Department of Physics and Astronomy, Georgia State University. Disponível em: <http://hyperphysics.phystr.gsu.edu/Hbase/quantum/compdat.htm|\#c1>. Acessado em: nov. de 2009.

NEIVA, A. C.; DRON, J. N.; MELO, H. G.; LIMA, S. C., "EDXRF Analysis of Alloys and Corrosion Products of Metallic Pre-Hispanic Pieces of the Museum of Ethnology and Archaeology of the University of Sao Paulo". In: TMS 2006 - 135th Annual Meeting \& Exhibition of The Minerals, Metals \& Materials Society, 2006, San Antonio, Texas. TMS 2006, Collected Proceedings: Structure, Extraction, Processing and Properties. Warrendale, PA, USA: The Minerals, Metals \& Materials Society. pp. 189-198, 2006.

NEIVA, A. C.; DRON, J. N.; LIMA, S. C., "EDXRF Analysis of Metallic Pre-Hispanic Pieces of The Museum of Ethnology and Archaeology of The University of Sao Paulo". In: 10 Simpósio LatinoAmericano sobre Métodos Físicos e Químicos em Arqueologia, Arte e Conservação de Patrimônio Cultural - LASMAC2007, 2007, São Paulo. 10 Simpósio LatinoAmericano sobre Métodos Físicos e Químicos em Arqueologia, Arte e Conservação de Patrimônio Cultural - LASMAC2007. São Paulo: Instituto de Física da USP, p. 296-306, 2007. 
NEIVA, A. C.; DRON, J. N., "Caracterização de bens culturais por espectroscopia de fluorescência de raios X”. Revista CPC, v. 6, pp. 188-197, 2008.

OLIVEIRA, D. F.; CALZA, C.; ROCHA, H. S.; NASCIMENTO, J. R.; LOPES, R. T. Application of Digital Radiography in the Analysis of Cultural Heritage. International Nuclear Atlantic Conference - INAC 2013, Recife, PE, Brazil, November pp. 24-29, 2013. Disponível em: http://www.iaea.org/inis/collection/NCLCollectionStore/ Public/45/086/45086050.pd $\mathrm{f}>$. Acessado em: abril de 2015.

OPUS, disponível em: <http://www.opusinstruments.com>. Acessado em: ago. de 2014.

PANTAZIS J. A.; HUBER A. C.; OKUN P.; SQUILLANTE M. R.; WAER P.; ENTINE G. New, high performance nuclear spectroscopy system using Si- PIN diodes and CdTe detectors, IEEE Transactions on Nuclear Science, v. 41, n. 4, 1994.

PESTANA, N. Exposição Malfatti. Revista do Brasil, São Paulo, n. 25, p.83, 1918.

PINNA, D.; GALEOTTI, M.; MAZZEO, R. Scientific Examination for the Investigation of Paintings: A handbook for conservator-restorers. Centro Di, Italy. 2009.

PINTO, S. M. C. A Controversa pintura de Anita Malfatti, Tese (Doutorado), Universidade de São Paulo, São Paulo 2007.

PLANCK, M. Entropie und Temperatur strahlender Wärme, Annalen der Physik. v. 306 (4): 719-737, 1900.

RASBAND W. ImageJ. Dispinivel em: www.imagej.nih.gov/ij. Acessado em: jul. de 2014.

REAL, W. A. Exploring New Applications for Infrared Reflectography. Bulletin of the Cleveland Museum of Art, Vol. 72, 1985.

RIZZUTTO, M.; TABACNIKS, M.; ADDED, N.; BARBOSA, M.; CURADO, J.; SANTOS JR, W.; LIMA, S.; MELO, H.; NEIVA, A. The external beam facility used to characterize corrosion products in metallic statuettes. Nuclear Instruments \& Methods in Physics Research. Section B. Beam Interactions with Materials and Atoms, v. 240, n. 240, p. 549-553, 2005.

RIZZUTTO, M. A.; ADDED, N.; TABACNIKS, M. H.; FALLA-SOTELO, F.; CURADO, J. F.; FRANCCI, C.; MARKARIAN, R. A.; QUINELATO, A.; YOUSSEF, F.; MORI, M.; YOUSSEF, M.. Teeth characterization using ion beam analysis. Journal of Radioanalytical and Nuclear Chemistry, v. 269, n.3, p. 683-687, 2006.

RIZZUTTO, M. A.; TABACNIKS, M. H.; ADDED, N.; BARBOSA, M. D. L.; CURADO, J. F.; PASCHOLATI, P. R.; NEVES, G.; LIMA, S. C.; MELO, H. G.; NEIVA, A. C. PIXE externo para análises de objetos de arte e arqueologia. Revista brasileira de arqueometria, restauração e conservação, v. 1, p. 309-312, 2007. 
RIZZUTTO, M. A. Técnicas Físicas Utilizadas no Estudo de Objetos de Arte, Arqueológicos e do Patrimônio Cultural. Tese (Livre Docência), Universidade de São Paulo, São Paulo, 2014.

RÖNTGEN, W. C. Über eine neue Art von Strahlen. Sitzungsberichte der Würzburger Physik.-medic. Gesellschaft, 1895.

ROSADO, A.; SOUZA, L. A. C.; FRONER G. Y., "História da Arte Técnica e Arqueometria: uma contribuição no processo de autenticação de obras de arte", $16^{\circ}$ Encontro Nacional da Associação Nacional de Pesquisadores de Artes Plásticas Dinâmicas Epistemológicas em Artes Visuais, Florianópolis, 2007.

ROSADO, A., História da Arte Técnica: um olhar contemporâneo sobre a práxis das Ciências Humanas e Naturais no estudo de pinturas sobre tela e madeira, Tese (Doutorado) - Escola de Belas Artes da Universidade Federal de Minas Gerais, Minas Gerais, 2011.

SAETTONE, E.; SEVIDANES MATTA, J.A.; ALVA, W.; CHUBACI, J.D.; FANTINI, M.C.A.; GALVÃO, R.M.O.; KIYOHARA, P.; TABACNIKS, M. H., "Plasma Cleaning and analysis of archaeological artifacts from Sipán", Journal of Physics D, Applied Physics 36, pp. 842-848, 2003.

SCORZELLI, R. B.; POUPEAU, G.; DORIGHEL, O.; -GURLET, L. B. Les Méthodes de caracterisation de l'obsidienne:datations par traces de fission et circulation de l'obsidienne dans I'Aire Septentrionale Andine préhispanique. Bulletin de la Société suisse des Américanistes, Suiça, v. 63, p. 97-110, 1999.

SCORZELLI, R. B.; POUPEAU, G.; DORIGHEL, O.; -GURLET, L. B. Obsidian archaeological artefacts provenance studies in the Western Mediterranean basin: an approach by Mössbauer spectroscopy and electron paramagnetic resonance. Comptes Rendus de L'Académie des Sciences, Earth And Planetary Science, v. 332(12), pp.769-776, 2001.

SCORZELLI, R. B.; GUERRA, M.; VIEIRA, R. Aplicação de Métodos Físicos na Conservação de Bens Culturais. Boletim da Sociedade Numismática Brasileira, São Paulo, v. 56, p. 78-92, 2005.

SÈVRE, R. Physique de la Couleur. Ed. Masson, Paris, 1996.

SILVA, R. A.; PETTER, C. O.; SCHNEIDER, I. A. H. Avaliação da Perda da Coloração Artificial de Ágatas, REM: R. Esc. Minas, Ouro Preto, v. 60(3), pp. 477482, 2007.

SOlÉ, V. A.; PAPILLON, E.; COTTE, M. ; WALTER, PH.; SUSINI, J. A multiplatform code for the analysis of energy-dispersive $X$-ray fluorescence spectra, Spectrochimica Acta Part B: Atomic Spectroscopy, v. 62, p. 63-68, 2007.

STUART, B. H. Analytical techniques in materials conservation, John Wiley \& Sons, England, 2008.

TAMENY R. Retratos de Mário de Andrade: catálogo da iconografia dedicada ao escritor. VI EHA - Encontro de História da Arte, Universidade Estadual de Campinas - UNICAMP, 2010. 
TELLECHEA, D. I. Pintura en restauro. v. 3, Instituto Domingo Tellechea, 1998.

TRUSSELL, J. H.; ELI, S.; VRHEL, M. Color Image Processing. IEEE Signal Processig Magazine. v. 14, pp.14-22, 2005.

VARELLA, C. A. A. Análise de componentes Principais, Universidade Federal Rural do Rio de Janeiro, 2008.

VASCONCELOS, A. C.; PEREIRA, A. F.; SCHARF C. P.; MEDEIROS, G. F.; COUTINHO, I. F.; DE OLIVEIRA, J. A. C.; OLIVEIRA, L. C.; DRUMOND. M. C. P.; MAIA, M. C.; SOUSA JUNIOR, M. A.; SWENSON, M. F. M.; TAGLIAPIETRA, R.; WILHELM, V. R. B.; BERRARA, V. R. G. Pigmentos. Trabalhos de Conclusão de Curso. CECOR-UFMG, Belo Horizonte, 1992.

VICINI, L. Análise multivariada, da teoria à prática, monografia, Universidade Federal de Santa Maria, 2005.

WEINER, C. Improved Acquisition Technique of Underdrawings in Oil-Paintings Using IR-Reflectography. Center for Imaging Science at the Rochester Institute of Technology, 1998.

WHITEHEAD Institute, Color Management, disponível em: $<$ http://jura.wi.mit.edu/bio/graphics/photoshop/colman.php $>$ Acessado em: jun. 2015)

WinQXAS - Quantitative X-ray Analysis System for MS Windows operating system, version 1.40, copyright (C) 2002 International Atomic Energy Agency.

WRIGHT, W. D. The Measurement of Colour, The MacMillan Company, New York, 1958.

YOUNG, T. Bakerian Lecture: On the Theory of Light and Colours. Phil. Trans. $R$. Soc. Lond. 92, pp.12-48, 1802 
Tabela A.1 - Energia dos fótons, em eV, das principais linhas de emissão das camadas $K, L$ e $M$ (KORTRIGHT; THOMPSON, 2001).

\begin{tabular}{|c|c|c|c|c|c|c|c|c|c|}
\hline Elemento & $K_{\alpha 1}$ & $K_{\alpha 2}$ & $K_{\beta 1}$ & $L_{\alpha 1}$ & $L_{\alpha 2}$ & $L_{\beta 1}$ & $L_{\beta 2}$ & $L_{\gamma 1}$ & $M_{\alpha 1}$ \\
\hline $3 \mathrm{Li}$ & 54,3 & & & & & & & & \\
\hline $4 \mathrm{Be}$ & 108,5 & & & & & & & & \\
\hline 5 B & 183,3 & & & & & & & & \\
\hline $6 \mathrm{C}$ & 277 & & & & & & & & \\
\hline $7 \mathrm{~N}$ & 392,4 & & & & & & & & \\
\hline 80 & 524,9 & & & & & & & & \\
\hline $9 \mathrm{~F}$ & 676,8 & & & & & & & & \\
\hline $10 \mathrm{Ne}$ & 848,6 & 848,6 & & & & & & & \\
\hline $11 \mathrm{Na}$ & 1040,98 & 1040,98 & 1071,1 & & & & & & \\
\hline $12 \mathrm{Mg}$ & 1253,60 & 1253,60 & 1302,2 & & & & & & \\
\hline $13 \mathrm{Al}$ & 1486,70 & 1486,27 & 1557,45 & & & & & & \\
\hline $14 \mathrm{Si}$ & 1739,98 & 1739,38 & 1835,94 & & & & & & \\
\hline $15 P$ & 2013,7 & 2012,7 & 2139,1 & & & & & & \\
\hline $16 s$ & 2307,84 & 2306,64 & 2464,04 & & & & & & \\
\hline $17 \mathrm{Cl}$ & 2622,39 & 2620,78 & 2815,6 & & & & & & \\
\hline $18 \mathrm{Ar}$ & 2957,70 & 2955,63 & 3190,5 & & & & & & \\
\hline $19 \mathrm{~K}$ & 3313,80 & 3311,10 & 3589,6 & & & & & & \\
\hline $20 \mathrm{Ca}$ & 3691,68 & 3688,09 & 4012,7 & 341,3 & 341,3 & 344,9 & & & \\
\hline $21 \mathrm{Sc}$ & 4090,6 & 4086,1 & 4460,5 & 395,4 & 395,4 & 399,6 & & & \\
\hline $22 \mathrm{Ti}$ & 4510,84 & 4504,86 & 4931,81 & 452,2 & 452,2 & 458,4 & & & \\
\hline $23 \mathrm{~V}$ & 4952,20 & 4944,64 & 5427,29 & 511,3 & 511,3 & 519,2 & & & \\
\hline $24 \mathrm{Cr}$ & 5414,72 & 5405,509 & 5946,71 & 572,8 & 572,8 & 582,8 & & & \\
\hline $25 \mathrm{Mn}$ & 5898,75 & 5887,65 & 6490,45 & 637,4 & 637,4 & 648,8 & & & \\
\hline $26 \mathrm{Fe}$ & 6403,84 & 6390,84 & 7057,98 & 705,0 & 705,0 & 718,5 & & & \\
\hline 27 Co & 6930,32 & 6915,30 & 7649,43 & 776,2 & 776,2 & 791,4 & & & \\
\hline $28 \mathrm{Ni}$ & 7478,15 & 7460,89 & 8264,66 & 851,5 & 851,5 & 868,8 & & & \\
\hline $29 \mathrm{Cu}$ & 8047,78 & 8027,83 & 8905,29 & 929,7 & 929,7 & 949,8 & & & \\
\hline $30 \mathrm{Zn}$ & 8638,86 & 8615,78 & 9572,0 & 1011,7 & 1011,7 & 1034,7 & & & \\
\hline $31 \mathrm{Ga}$ & 9251,74 & 9224,82 & 10264,2 & 1097,92 & 1097,92 & 1124,8 & & & \\
\hline $32 \mathrm{Ge}$ & 9886,42 & 9855,32 & 10982,1 & 1188,00 & 1188,00 & 1218,5 & & & \\
\hline
\end{tabular}




\begin{tabular}{|c|c|c|c|c|c|c|c|c|c|}
\hline Elemento & $K_{\alpha 1}$ & $K_{\alpha 2}$ & $K_{\beta 1}$ & $L_{\alpha 1}$ & $L_{\alpha 2}$ & $L_{\beta 1}$ & $L_{\beta 2}$ & $L_{\gamma 1}$ & $M_{\alpha 1}$ \\
\hline 33 As & 10543,72 & 10507,99 & 11726,2 & 1282,0 & 1282,0 & 1317,0 & & & \\
\hline $34 \mathrm{Se}$ & 11222,4 & 11181,4 & 12495,9 & 1379,10 & 1379,10 & 1419,23 & & & \\
\hline $35 \mathrm{Br}$ & 11924,2 & 11877,6 & 13291,4 & 1480,43 & 1480,43 & 1525,90 & & & \\
\hline $36 \mathrm{Kr}$ & 12649 & 12598 & 14112 & 1586,0 & 1586,0 & 1636,6 & & & \\
\hline $37 \mathrm{Rb}$ & 13395,3 & 13335,8 & 14961,3 & 1694,13 & 1692,56 & 1752,17 & & & \\
\hline $38 \mathrm{Sr}$ & 14165 & 14097,9 & 15835,7 & 1806,56 & 1804,74 & 1871,72 & & & \\
\hline $39 \mathrm{Y}$ & 14958,4 & 14882,9 & 16737,8 & 1922,56 & 1920,47 & 1995,84 & & & \\
\hline $40 \mathrm{Zr}$ & 15775,1 & 15690,9 & 17667,8 & 2042,36 & 2039,9 & 2124,4 & 2219,4 & 2302,7 & \\
\hline $41 \mathrm{Nb}$ & 16615,1 & 16521,0 & 18622,5 & 2165,89 & 2163,0 & 2257,40 & 2367,0 & 2461,8 & \\
\hline 42 Mo & 17479,34 & 17374,3 & 19608,3 & 2293,16 & 2289,85 & 2394,81 & 2518,3 & 2623,5 & \\
\hline $43 \mathrm{Tc}$ & 18367,1 & 18250,8 & 20619 & 2424 & 2420 & 2538 & 2674 & 2792 & \\
\hline $44 \mathrm{Ru}$ & 19279,2 & 19150,4 & 21656,8 & 2558,55 & 2554,31 & 2683,23 & 2836,0 & 2964,5 & \\
\hline $45 R h$ & 20216,1 & 20073,7 & 22723,6 & 2696,74 & 2692,05 & 2834,41 & 3001,3 & 3143,8 & \\
\hline $46 \mathrm{Pd}$ & 21177,1 & 21020,1 & 23818,7 & 2838,61 & 2833,29 & 2990,22 & 3171,79 & 3328,7 & \\
\hline $47 \mathrm{Ag}$ & 22162,92 & 21990,3 & 24942,4 & 2984,31 & 2978,21 & 3150,94 & 3347,81 & 3519,59 & \\
\hline $48 \mathrm{Cd}$ & 23173,6 & 22984,1 & 26095,5 & 3133,73 & 3126,91 & 3316,57 & 3528,12 & 3716,86 & \\
\hline 49 In & 24209,7 & 24002,0 & 27275,9 & 3286,94 & 3279,29 & 3487,21 & 3713,81 & 3920,81 & \\
\hline $50 \mathrm{Sn}$ & 25271,3 & 25044,0 & 28486,0 & 3443,98 & 3435,42 & 3662,80 & 3904,86 & 4131,12 & \\
\hline $51 \mathrm{Sb}$ & 26359,1 & 26110,8 & 29725,6 & 3604,72 & 3595,32 & 3843,57 & 4100,78 & 4347,79 & \\
\hline $52 \mathrm{Te}$ & 27472,3 & 27201,7 & 30995,7 & 3769,33 & 3758,80 & 4029,58 & 4301,7 & 4570,9 & \\
\hline 531 & 28612,0 & 28317,2 & 32294,7 & 3937,65 & 3926,04 & 4220,72 & 4507,5 & 4800,9 & \\
\hline $54 X e$ & 29779 & 29458 & 33624 & 4109,9 & - & - & - & - & \\
\hline $55 \mathrm{Cs}$ & 30972,8 & 30625,1 & 34986,9 & 4286,5 & 4272,2 & 4619,8 & 4935,9 & 5280,4 & \\
\hline $56 \mathrm{Ba}$ & 32193,6 & 31817,1 & 36378,2 & 4466,26 & 4450,90 & 4827,53 & 5156,5 & 5531,1 & \\
\hline $57 \mathrm{La}$ & 33441,8 & 33034,1 & 37801,0 & 4650,97 & 4634,23 & 5042,1 & 5383,5 & 5788,5 & 833 \\
\hline $58 \mathrm{Ce}$ & 34719,7 & 34278,9 & 39257,3 & 4840,2 & 4823,0 & 5262,2 & 5613,4 & 6052 & 883 \\
\hline $59 \mathrm{Pr}$ & 36026,3 & 35550,2 & 40748,2 & 5033,7 & 5013,5 & 5488,9 & 5850 & 6322,1 & 929 \\
\hline $60 \mathrm{Nd}$ & 37361,0 & 36847,4 & 42271,3 & 5230,4 & 5207,7 & 5721,6 & 6089,4 & 6602,1 & 978 \\
\hline $61 \mathrm{Pm}$ & 38724,7 & 38171,2 & 43826 & 5432,5 & 5407,8 & 5961 & 6339 & 6892 & - \\
\hline $62 \mathrm{Sm}$ & 40118,1 & 39522,4 & 45413 & 5636,1 & 5609,0 & 6205,1 & 6586 & 7178 & 1081 \\
\hline $63 \mathrm{Eu}$ & 41542,2 & 40901,9 & 47037,9 & 5845,7 & 5816,6 & 6456,4 & 6843,2 & 7480,3 & 1131 \\
\hline $64 \mathrm{Gd}$ & 42996,2 & 42308,9 & 48697 & 6057,2 & 6025,0 & 6713,2 & 7102,8 & 7785,8 & 1185 \\
\hline $65 \mathrm{~Tb}$ & 44481,6 & 43744,1 & 50382 & 6272,8 & 6238,0 & 6978 & 7366,7 & 8102 & 1240 \\
\hline 66 Dy & 45998,4 & 45207,8 & 52119 & 6495,2 & 6457,7 & 7247,7 & 7635,7 & 8418,8 & 1293 \\
\hline $67 \mathrm{Ho}$ & 47546,7 & 46699,7 & 53877 & 6719,8 & 6679,5 & 7525,3 & 7911 & 8747 & 1348 \\
\hline
\end{tabular}




\begin{tabular}{|c|c|c|c|c|c|c|c|c|c|}
\hline Elemento & $K_{\alpha 1}$ & $K_{\alpha 2}$ & $K_{\beta 1}$ & $L_{\alpha 1}$ & $L_{\alpha 2}$ & $L_{\beta 1}$ & $L_{\beta 2}$ & $L_{\gamma 1}$ & $M_{\alpha 1}$ \\
\hline $68 \mathrm{Er}$ & 49127,7 & 48221,1 & 55681 & 948,7 & 6905,0 & 7810,9 & 8189,0 & 9089 & 1406 \\
\hline $69 \mathrm{Tm}$ & 50741,6 & 49772,6 & 57517 & 7179,9 & 7133,1 & 8101 & 8468 & 9426 & 1462 \\
\hline $70 \mathrm{Yb}$ & 52388,9 & 51354,0 & 59370 & 7415,6 & 7367,3 & 8401,8 & 8758,8 & 9780,1 & 1521,4 \\
\hline $71 \mathrm{Lu}$ & 54069,8 & 52965,0 & 61283 & 7655,5 & 7604,9 & 8709,0 & 9048,9 & 10143,4 & 1581,3 \\
\hline $72 \mathrm{Hf}$ & 55790,2 & 54611,4 & 63234 & 7899,0 & 7844,6 & 9022,7 & 9347,3 & 10515,8 & 1644,6 \\
\hline $73 \mathrm{Ta}$ & 57532 & 56277 & 65223 & 8146,1 & 8087,9 & 9343,1 & 9651,8 & 10895,2 & 1710 \\
\hline 74 W & 59318,24 & 57981,7 & 67244,3 & 8397,6 & 8335,2 & 9672,35 & 9961,5 & 11285,9 & 1775,4 \\
\hline $75 \mathrm{Re}$ & 61140,3 & 59717,9 & 69310 & 8652,5 & 8586,2 & 10010,0 & 10275,2 & 11685,4 & 1842,5 \\
\hline 76 Os & 63000,5 & 61486,7 & 71413 & 8911,7 & 8841,0 & 10355,3 & 10598,5 & 12095,3 & 1910,2 \\
\hline $77 \mathrm{Ir}$ & 64895,6 & 63286,7 & 73560,8 & 9175,1 & 9099,5 & 10708,3 & 10920,3 & 12512,6 & 1979,9 \\
\hline $78 \mathrm{Pt}$ & 66832 & 65112 & 75748 & 9442,3 & 9361,8 & 11070,7 & 11250,5 & 12942,0 & 2050,5 \\
\hline $79 \mathrm{Au}$ & 68803,7 & 66989,5 & 77984 & 9713,3 & 9628,0 & 11442,3 & 11584,7 & 13381,7 & 2122,9 \\
\hline $80 \mathrm{Hg}$ & 70819 & 895 & 80253 & 9988,8 & 9897,6 & 11822,6 & 11924,1 & 13830,1 & 2195,3 \\
\hline $81 \mathrm{TI}$ & 72871,5 & 70831,9 & 82576 & 10268,5 & 10172,8 & 12213,3 & 12271,5 & 14291,5 & 2270,6 \\
\hline $82 \mathrm{~Pb}$ & 74969,4 & 72804,2 & 84936 & 10551,5 & 10449,5 & 12613,7 & 12622,6 & 14764,4 & 2345,5 \\
\hline $83 \mathrm{Bi}$ & 77107,9 & 7481 & טדם & 10 & 107 & 13023,5 & 12979,9 & 15247,7 & 2422,6 \\
\hline 84 Po & 79290 & 76862 & 89800 & 11130,8 & 11015,8 & 13447 & 13340,4 & 15744 & - \\
\hline $85 \mathrm{At}$ & 81520 & 78950 & 92300 & 11426,8 & 11304,8 & 13876 & - & 16251 & - \\
\hline $86 \mathrm{Rn}$ & 83780 & STE & 94870 & 7,0 & ,9 & אוד דו & - & 16770 & - \\
\hline $87 \mathrm{Fr}$ & 86100 & 83230 & 97470 & 12031,3 & 0 & 14770 & 14450 & 17303 & - \\
\hline $88 \mathrm{Ra}$ & 88470 & 85430 & 100130 & 12339,7 & 12196,2 & 15235,8 & 14841,4 & 17849 & - \\
\hline $89 \mathrm{Ac}$ & 90884 & 87670 & 102850 & 12652,0 & 12500,8 & 15713 & - & 18408 & - \\
\hline $90 \mathrm{Th}$ & 93350 & 0 & 105609 & 12968,7 & 9,6 & 16202,2 & 15623,7 & 18982,5 & 2996,1 \\
\hline $91 \mathrm{~Pa}$ & 95868 & 92287 & 108427 & 13290,7 & 13122,2 & 16702 & 16024 & 19568 & 3082,3 \\
\hline $92 \mathrm{U}$ & 98439 & 9466 & 111 & 1361 & ,8 &, 0 & 16 & 7,1 & 3170,8 \\
\hline $93 \mathrm{~Np}$ & - & - & - & 13944,1 & 13759,7 & 17750,2 & 16840,0 & 20784,8 & - \\
\hline $94 \mathrm{Pu}$ & - & - & - & 14278,6 & 14084,2 & 18293,7 & 17255,3 & 21417,3 & - \\
\hline $95 \mathrm{Am}$ & - & - & - & 14617,2 & 14411,9 & 18852,0 & 17676,5 & 22065,2 & - \\
\hline
\end{tabular}

